\title{
WestVirginiaUniversity
}

THE RESEARCH REPOSITORY @ WVU

Graduate Theses, Dissertations, and Problem Reports

1999

\section{Surface -enhanced Raman spectroscopic studies of organonitriles on copper colloids}

\author{
Candace Mikki Coyle \\ West Virginia University
}

Follow this and additional works at: https://researchrepository.wvu.edu/etd

\section{Recommended Citation}

Coyle, Candace Mikki, "Surface -enhanced Raman spectroscopic studies of organonitriles on copper colloids" (1999). Graduate Theses, Dissertations, and Problem Reports. 1052.

https://researchrepository.wvu.edu/etd/1052

This Dissertation is protected by copyright and/or related rights. It has been brought to you by the The Research Repository @ WVU with permission from the rights-holder(s). You are free to use this Dissertation in any way that is permitted by the copyright and related rights legislation that applies to your use. For other uses you must obtain permission from the rights-holder(s) directly, unless additional rights are indicated by a Creative Commons license in the record and/ or on the work itself. This Dissertation has been accepted for inclusion in WVU Graduate Theses, Dissertations, and Problem Reports collection by an authorized administrator of The Research Repository @ WVU.

For more information, please contact researchrepository@mail.wvu.edu. 


\title{
Surface-Enhanced Raman Spectroscopic Studies of Organonitriles on Copper Colloids
}

\author{
Candace Mikki Coyle \\ Dissertation Submitted to the College of Arts and Sciences \\ at West Virginia University \\ In Partial Fulfillment of the Requirements \\ for the Degree of \\ Doctor of Philosophy \\ in \\ Chemistry
}

Paul W. Jagodzinski, Ph.D., Chair

Kay M. Brummond, Ph.D.

Boyd F. Edwards, Ph.D.

Harry O. Finklea, Ph.D.

Reuben H. Simoyi, Ph.D.

Department of Chemistry

Morgantown, West Virginia

1999

Keywords: Copper Colloids, Borohydride Reduction of Nitriles, SERS 


\section{ABSTRACT \\ Surface-Enhanced Raman Spectroscopic Studies of Organonitriles on Copper Colloids}

\section{Candace Mikki Coyle}

Dramatic differences are observed between the surface-enhanced Raman spectra (SERS) of organonitriles mixed with copper colloids, the Raman of the free parent molecules, and the SERS for adsorption on a gold colloid. Specifically, $v(\mathrm{C} \equiv \mathrm{N})$ is missing in the SER spectra involving the copper colloid. The data are adequately explained by a transition metal assisted borohydride reduction of the cyano group to an amino group. SER spectra of the reduction products of the organonitriles in the presence of copper colloids are identical within experimental error. The $v(\mathrm{C} \equiv \mathrm{N})$ signal was observed when a gold colloid was prepared by borohydride reduction, thereby indicating the metal selectivity of the reaction. Adsorption on silver colloids exhibit a complete disappearance of the nitrile stretching normal mode. The absence of the nitrile stretching signal is not due to a metal-assisted reduction of the nitrile group to an amino group. The observation of no nitrile stretching band for the silver colloids indicates that the silver metal is distinct from the copper and gold. SERS data collected for the isomeric forms of cyanopyridine (4-CP, 3-CP and 2-CP) mixed with the copper and gold colloids supports the theory that the degree of surface enhancement is lowered by the loss of molecular symmetry. Addition of selected sodium salts were used to determine the role of aggregation and co-adsorption in surface enhancement. Our SERS data demonstrate that the increase in surface enhancement is primarily influenced by the chemical interaction between the adsorbate and the metal surface. Although the molecular symmetry of the adsorbate, as well as the affects of aggregation, affect the degree of enhancement observed, the chemical adsorption onto the metal dominates the enhancement mechanism. 


\section{ACKNOWLEDGMENTS}

There are a number of people, who, in one way or another, contributed to the completion of this dissertation. First and foremost among these is my research advisor, Dr. Paul 'Texas Carbon' Jagodzinksi. He provided the inspiration for the research by the dedication and enthusiasm for which he has always exhibited toward science. I must admit to learning far more from his training than from anyone else before. One of his greatest strengths is his ability to recognize a student's area of interest and allow them to pursue these interests.

My research committee must be thanked for their advice and criticism of the course of studies undertaken. The members of our research group, both past and present, have always been supportive and helping whenever called upon. A large debt of gratitude goes to my friends and peers for their never ending supply of antics and humor.

Part of this dissertation was achieved while serving a practicum at Iowa State University and Ames National Laboratory under the guidance of Dr. Therese M. Cotton and Dr. George Chumanov. To them, I thank them sincerely for their discussions and insight and for teaching me that every result is an answer and that you should always have an idea of what it may or may not mean, no matter what the outcome.

Finally, I acknowledge the support provided by my parents, Mr. and Mrs. Alvin M. Coyle, and my brothers Allan and Richie. Through them I've learned the meaning of hard work, integrity and where my home will always be. Their continual love, support and encouragement through all of my endeavors is deeply appreciated. 
This dissertation is dedicated to the memory of Dr. Therese M. Cotton. 
TABLE OF CONTENTS

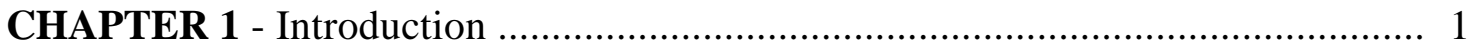

CHAPTER 2 - 4-Cyanopyridine Adsorbed on Copper Colloids

2.1 - Introduction .................................................................. 10

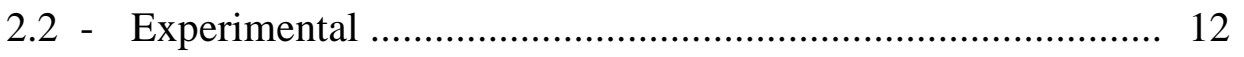

2.3 - Results and Discussion ..................................................... 16

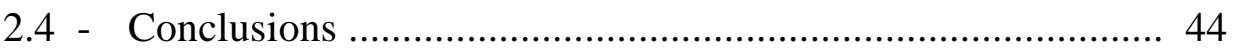

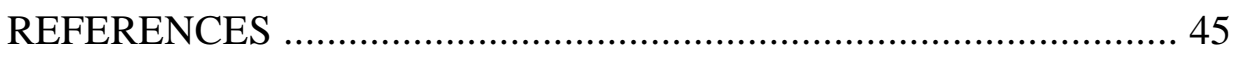

CHAPTER 3 - Isomeric Effects of 4-, 3-, and 2-Cyanopyridine Adsorbed on Copper

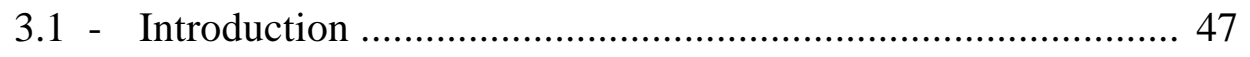

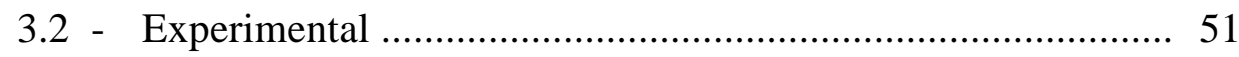

3.3 - Results and Discussion ..................................................... 52

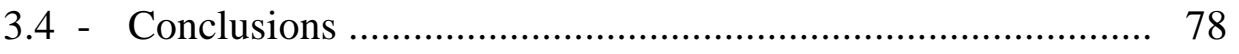

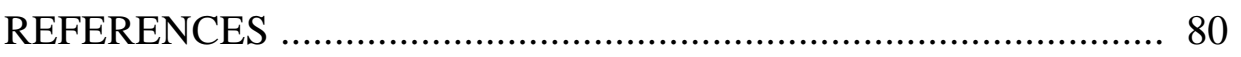

CHAPTER 4 - Reduction of Other Nitrile Adsorbates on Copper Colloids

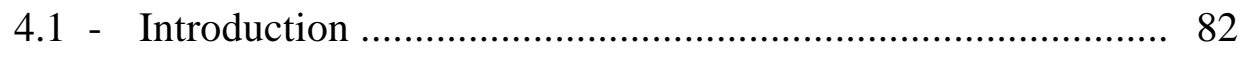

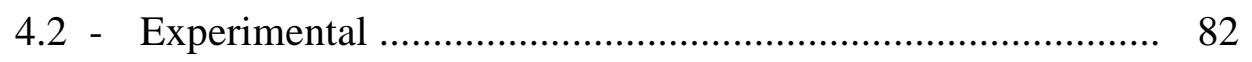

4.3 - Results and Discussion ………………………………....... 84

4.4 - Conclusions ................................................................... 110

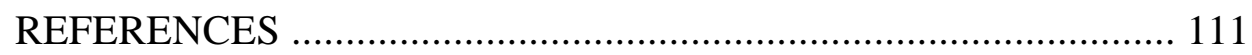


CHAPTER 5 - Effects of Colloid Aggregation on the Surface Enhanced Raman Effect

5.1 - Introduction ......................................................... 113

5.2 - Experimental .............................................................. 114

5.3 - Results and Discussion ............................................... 115

5.4 - Conclusions ............................................................... 130

REFERENCES ................................................................... 131

CHAPTER 6 - Cyanopyridines Adsorbed onto Silver Colloids

6.1 - Introduction ................................................................ 132

6.2 - Experimental ............................................................. 133

6.3 - Results and Discussion ................................................. 133

6.4 - Conclusions .............................................................. 160

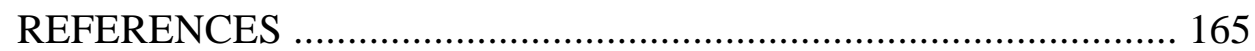

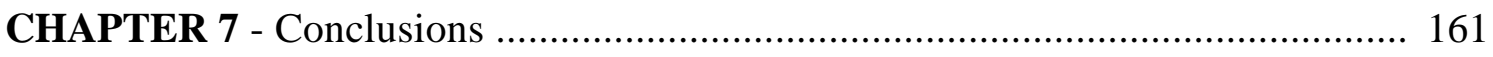

VITA 


\section{LIST OF FIGURES:}

Figure 1-1: $\quad$ Orientation of cyanopyridines (4-CP, 3-CP and 2-CP) adsorbed onto a metallic surface.

Figure 1-2: $\quad$ Possible orientations of 4-cyanopyridine upon adsorption to the surface of a metallic surface.

Figure 2-1: Molecular structures for 4-cyanopyridine (4-CP), 4-cyanopyridine- ${ }^{15} \mathrm{~N}$ $\left(4-\mathrm{CP}_{-}{ }^{15} \mathrm{~N}\right)$ and 4-aminomethylpyridine (4-AMP).

Figure 2-2: $\quad$ Raman spectra of 4-cyanopyridine (4-CP) and isotopically labeled 4cyanopyridine- $-{ }^{15} \mathrm{~N}\left(4-\mathrm{CP}-{ }^{15} \mathrm{~N}\right)$ in aqueous solution.

Figure 2-3: $\quad$ SERS of 4-cyanopyridine (4-CP) and isotopically labeled 4-cyanopyridine-

${ }^{15} \mathrm{~N}\left(4-\mathrm{CP}-{ }^{15} \mathrm{~N}\right)$ adsorbed onto copper $(/ \mathrm{Cu})$ colloids.

Figure 2-4: Raman spectra of 4-cyanopyridine (4-CP) and SERS of 4-CP adsorbed onto copper $(/ \mathrm{Cu})$ and gold $(/ \mathrm{Au})$ colloids.

Figure 2-5: $\quad$ SERS of 4-cyanopyridine (4-CP) and isotopically labeled 4-cyanopyridine${ }^{15} \mathrm{~N}\left(4-\mathrm{CP}-{ }^{15} \mathrm{~N}\right)$ adsorbed onto gold (/Au) colloids.

Figure 2-6: Raman spectra of 4-aminomethylpyridine (4-AMP) and SERS of 4-AMP and 4-CP adsorbed onto copper (/Cu) colloids.

Figure 2-7: $\quad$ SERS of 4-cyanopyridine (4-CP) adsorbed onto copper colloids prepared under aerobic $(/ \mathrm{Cu})$ and deoxygenated $(/ \mathrm{Cu}(\mathrm{d}))$ conditions.

Figure 2-8: $\quad$ SERS of 4-cyanopyridine (4-CP) adsorbed onto copper colloids prepared from $\mathrm{Cu}^{+1}(/ \mathrm{Cu}(\mathrm{I}))$ and $\mathrm{Cu}^{+2}(/ \mathrm{Cu}(\mathrm{II}))$ reduction. 
Figure 2-9: $\quad$ SERS of 4-cyanopyridine (4-CP) adsorbed onto a gold colloid (/Au), a gold colloid with $\mathrm{CuSO}_{4}$ added $\left(/ \mathrm{Au} / \mathrm{CuSO}_{4}\right)$, and a gold colloid with $\mathrm{CuSO}_{4}$ and borohydride added $\left(/ \mathrm{Au} / \mathrm{CuSO}_{4} / \mathrm{BH}_{4}{ }^{-}\right)$.

Figure 2-10: SERS of 4-cyanopyridine (4-CP) adsorbed onto a gold colloid (/Au) and after the addition of a copper colloid (/Au/Cu).

Figure 2-11: SERS of 4-aminomethylpyridine (4-AMP) adsorbed on gold (Au/) and copper $(/ \mathrm{Cu})$ colloids.

Figure 2-12: $\quad$ SERS of 4-cyanopyridine (4-CP) adsorbed onto a copper colloid (/Cu) and after the addition of a gold colloid (/Cu/Au).

Figure 2-13: Raman spectra of 4-cyanopyridine (4-CP) in aqueous solutions: (a) $0.2 \mathrm{M}$, (b) $0.1 \mathrm{M}$, (c) $6.56 \times 10^{-2} \mathrm{M}$, (d) $0.01 \mathrm{M}$, (e) $1 \times 10^{-3} \mathrm{M}$, (f) $1 \times 10^{-4} \mathrm{M}$, and (g) $1 \times 10^{-6} \mathrm{M}$.

Figure 2-14: SERS of 4-cyanopyridine (4-CP) adsorbed onto copper colloids as various concentrations: (a) $0.2 \mathrm{M}(600 \mu \mathrm{L})$, (b) $0.2 \mathrm{M}(300 \mu \mathrm{L})$, (c) $0.1 \mathrm{M}$ $(300 \mu \mathrm{L}),(\mathrm{d}) 6.56 \times 10^{-2} \mathrm{M}(300 \mu \mathrm{L}),(\mathrm{e}) 0.01 \mathrm{M}(300 \mu \mathrm{L}),(\mathrm{f}) 1 \times 10^{-3} \mathrm{M}$ $(300 \mu \mathrm{L}),(\mathrm{g}) 1 \times 10^{-4} \mathrm{M}(300 \mu \mathrm{L})$, and (h) $1 \times 10^{-6} \mathrm{M}(300 \mu \mathrm{L})$.

Figure 2-15: SERS of 4-cyanopyridine (4-CP) adsorbed onto gold colloids as various concentrations: (a) $0.2 \mathrm{M}(600 \mu \mathrm{L})$, (b) $0.2 \mathrm{M}(300 \mu \mathrm{L})$, (c) $0.1 \mathrm{M}$ $(300 \mu \mathrm{L}),(\mathrm{d}) 6.56 \times 10^{-2} \mathrm{M}(300 \mu \mathrm{L}),(\mathrm{e}) 0.01 \mathrm{M}(300 \mu \mathrm{L}),(\mathrm{f}) 1 \times 10^{-3} \mathrm{M}$ $(300 \mu \mathrm{L}),(\mathrm{g}) 1 \times 10^{-4} \mathrm{M}(300 \mu \mathrm{L})$, and (h) $1 \times 10^{-6} \mathrm{M}(300 \mu \mathrm{L})$. 
Figure 3-1: Molecular structures for the isomeric forms of cyanopyridine (4-CP, 3-CP, and 2-CP) and the isomeric forms of aminomethylpyridine (4-AMP, 3-AMP, and 2-AMP).

Figure 3-2: $\quad$ SERS of cyanopyridines (4-, 3-, and 2-CP) adsorbed onto copper colloids $(/ \mathrm{Cu})$.

Figure 3-3: Raman spectra of neat 3-aminomethylpyridine (3-AMP) and SERS of 3-AMP and 3-CP adsorbed onto copper colloids (/Cu).

Figure 3-4: Raman spectra of neat 2-aminomethylpyridine (2-AMP) and SERS of 2-AMP and 2-CP adsorbed onto copper colloids $(/ \mathrm{Cu})$.

Figure 3-5: $\quad$ SERS of 3-cyanopyridine (3-CP) adsorbed onto copper colloids prepared under aerobic $(/ \mathrm{Cu})$ and deoxygenated $(/ \mathrm{Cu}(\mathrm{d}))$ conditions.

Figure 3-6: $\quad$ SERS of 2-cyanopyridine (2-CP) adsorbed onto copper colloids prepared under aerobic $(/ \mathrm{Cu})$ and deoxygenated $(/ \mathrm{Cu}(\mathrm{d}))$ conditions.

Figure 3-7: $\quad$ SERS of 3-cyanopyridine (3-CP) adsorbed onto copper colloids prepared from $\mathrm{Cu}^{+1}(/ \mathrm{Cu}(\mathrm{I}))$ and $\mathrm{Cu}^{+2}(/ \mathrm{Cu}(\mathrm{II}))$ reduction.

Figure 3-8: $\quad$ SERS of 2-cyanopyridine (2-CP) adsorbed onto copper colloids prepared from $\mathrm{Cu}^{+1}(/ \mathrm{Cu}(\mathrm{I}))$ and $\mathrm{Cu}^{+2}(/ \mathrm{Cu}(\mathrm{II}))$ reduction.

Figure 3-9: $\quad$ Raman spectra of 3-cyanopyridine (3-CP) and SERS of 3-CP adsorbed onto copper $(/ \mathrm{Cu})$ and gold $(/ \mathrm{Au})$ colloids.

Figure 3-10: Raman spectra of 2-cyanopyridine (2-CP) and SERS of 2-CP adsorbed onto copper $(/ \mathrm{Cu})$ and gold $(/ \mathrm{Au})$ colloids. 
Figure 4-1: $\quad$ Molecular structures for benzonitrile (BN), benzylamine (BA), 1,4-dicyanobenzene (1,4-DCB), xylylenediamine (XY), acetonitrile (AN), ethylamine (EA), hexanenitrile (HN) and hexylamine (HA).

Figure 4-2: $\quad$ Raman spectra of neat benzonitrile (BN) and SERS of BN adsorbed onto copper $(/ \mathrm{Cu})$ and gold $(/ \mathrm{Au})$ colloids.

Figure 4-3: Raman spectra of neat benzylamine (BA) and SERS of BA and BN adsorbed onto copper (/Cu) colloids.

Figure 4-4: $\quad$ Raman spectra of 1,4-dicyanobenzene (1,4-DCB) in aqueous (2.0 M) and SERS of 1,4-DCB adsorbed onto copper (/Cu) and gold (/Au) colloids.

Figure 4-5: $\quad$ Raman spectra of xylylenediamine (XY) in aqueous (2.0 M) and SERS of $\mathrm{XY}$ and 1,4-DCB adsorbed onto copper (/Cu) colloids.

Figure 4-6: Raman spectra of neat acetonitrile (AN) and SERS of AN adsorbed onto copper $(/ \mathrm{Cu})$ and gold $(/ \mathrm{Au})$ colloids.

Figure 4-7: Raman spectra of neat ethylamine (EA) and SERS of EA and AN adsorbed onto copper $(/ \mathrm{Cu})$ colloids.

Figure 4-8: Raman spectra of neat hexanenitrile (HN) and SERS of HN adsorbed onto copper $(/ \mathrm{Cu})$ and gold (/Au) colloids.

Figure 4-9: Raman spectra of neat hexylamine (HA) and SERS of HA and HN adsorbed onto copper $(/ \mathrm{Cu})$ colloids. 
Figure 5-1: (a) SERS of 4-cyanopyridine (4-CP) adsorbed onto a copper colloid (/Cu), (b) SERS of 4-CP/Cu after the addition of $\mathrm{Na}_{2} \mathrm{SO}_{4}$, (c) SERS of 4-CP/Cu after the addition of $\mathrm{NaCl}$, and (d) SERS of 4-CP/Cu after the addition of $\mathrm{Na}_{2} \mathrm{~S}$.

Figure 5-2: (a) SERS of 3-cyanopyridine (3-CP) adsorbed onto a copper colloid (/Cu), (b) SERS of 3-CP/Cu after the addition of $\mathrm{Na}_{2} \mathrm{SO}_{4}$, (c) SERS of 3-CP/Cu after the addition of $\mathrm{NaCl}$, and (d) SERS of 3-CP/Cu after the addition of $\mathrm{Na}_{2} \mathrm{~S}$.

Figure 5-3: (a) SERS of 2-cyanopyridine (2-CP) adsorbed onto a copper colloid (/Cu), (b) SERS of 2-CP/Cu after the addition of $\mathrm{Na}_{2} \mathrm{SO}_{4}$, (c) SERS of 2-CP/Cu after the addition of $\mathrm{NaCl}$, and (d) SERS of 2-CP/Cu after the addition of $\mathrm{Na}_{2} \mathrm{~S}$.

Figure 5-4: (a) SERS of 4-cyanopyridine (4-CP) adsorbed onto a copper colloid (/Cu (I)) prepared by borohydride reduction of $\mathrm{Cu}^{+1}$, (b) SERS of 4$\mathrm{CP} / \mathrm{Cu}$ (I) after the addition of $\mathrm{Na}_{2} \mathrm{SO}_{4}$, and (c) SERS of 4-CP/Cu (I) after the addition of $\mathrm{NaCl}$.

Figure 5-5: (a) SERS of 4-cyanopyridine (4-CP) adsorbed onto a gold colloid (/Au), (b) SERS of 4-CP/Au after the addition of $\mathrm{Na}_{2} \mathrm{SO}_{4}$, (c) SERS of 4-CP/Au after the addition of $\mathrm{NaCl}$, and (d) SERS of 4-CP/Au after the addition of $\mathrm{Na}_{2} \mathrm{~S}$. 
Figure 5-6: (a) SERS of 3-cyanopyridine (3-CP) adsorbed onto a gold colloid (/Au), (b) SERS of 3-CP/Au after the addition of $\mathrm{Na}_{2} \mathrm{SO}_{4}$, (c) SERS of 3-CP/Au after the addition of $\mathrm{NaCl}$, and (d) SERS of 3-CP/Au after the addition of $\mathrm{Na}_{2} \mathrm{~S}$.

Figure 5-7: (a) SERS of 2-cyanopyridine (2-CP) adsorbed onto a gold colloid (/Au), (b) SERS of 2-CP/Au after the addition of $\mathrm{Na}_{2} \mathrm{SO}_{4}$, (c) SERS of 2-CP/Au after the addition of $\mathrm{NaCl}$, and (d) SERS of 2-CP/Au after the addition of $\mathrm{Na}_{2} \mathrm{~S}$.

Figure 5-8: $\quad$ SERS of 4-cyanopyridine (4-CP) adsorbed onto a gold (/Au) colloid with the addition of various concentrations of $\mathrm{NaCl}$ : (a) 4-CP/Au with no $\mathrm{NaCl}$, (b) 4-CP/Au with $0.05 \mathrm{M} \mathrm{NaCl}$, (c) 4-CP/Au with $0.1 \mathrm{M} \mathrm{NaCl}$, (d) 4-CP/Au with $0.5 \mathrm{M} \mathrm{NaCl}$, (e) 4-CP/Au with $0.75 \mathrm{M} \mathrm{NaCl}$, (f) 4-CP/Au with $1.0 \mathrm{M} \mathrm{NaCl}$, and (g) 4-CP/Au with $3.0 \mathrm{M} \mathrm{NaCl}$.

Figure 5-9: Dependence of relative integrated intensities of the $1605 \mathrm{~cm}^{-1}$ line as a function of concentration of $\mathrm{NaCl}$ and $\mathrm{Na}_{2} \mathrm{SO}_{4}$ in a sample of 4-CP/Au.

Figure 5-10 SERS of 4-cyanopyridine (4-CP) adsorbed onto a gold colloid (/Au) with the addition of various concentrations of $\mathrm{Na}_{2} \mathrm{SO}_{4}$ : (a) 4-CP/Au with no $\mathrm{Na}_{2} \mathrm{SO}_{4}$, (b) 4-CP/Au with $0.05 \mathrm{M} \mathrm{Na}_{2} \mathrm{SO}_{4}$, (c) 4-CP/Au with $0.1 \mathrm{M}$ $\mathrm{Na}_{2} \mathrm{SO}_{4}$, (d) 4-CP/Au with $0.5 \mathrm{M} \mathrm{Na}_{2} \mathrm{SO}_{4}$, (e) 4-CP/Au with $1.0 \mathrm{M}$ $\mathrm{Na}_{2} \mathrm{SO}_{4}$, and (f) 4-CP/Au with $3.0 \mathrm{M} \mathrm{Na}_{2} \mathrm{SO}_{4}$. 
Figure 6-1: $\quad$ Raman spectra of 4-cyanopyridine (4-CP) and SERS of 4-CP adsorbed onto silver colloids prepared by citrate reduction $\left(/ \mathrm{Ag}_{\text {cit }}\right)$ and borohydride reduction $\left(/ \mathrm{Ag}_{\mathrm{BH} 4^{-}}\right)$.

Figure 6-2: $\quad$ Raman spectra of 3-cyanopyridine (3-CP) and SERS of 3-CP adsorbed onto silver colloids prepared by citrate reduction $\left(/ \mathrm{Ag}_{\text {cit }}\right)$ and borohydride reduction $\left(/ \mathrm{Ag}_{\mathrm{BH}^{-}}\right)$.

Figure 6-3: Raman spectra of 2-cyanopyridine (2-CP) and SERS of 2-CP adsorbed onto silver colloids prepared by citrate reduction $\left(/ \mathrm{Ag}_{\mathrm{cit}}\right)$ and borohydride reduction $\left(/ \mathrm{Ag}_{\mathrm{BH}^{-}}\right)$.

Figure 6-4: $\quad$ SER scattering by trisodium citrate (CIT) in aqueous solution (2.0 M) and adsorbed on colloidal silver surfaces (/Ag).

Figure 6-5: $\quad$ SERS of cyanopyridines (4-, 3-, and 2-CP) adsorbed onto silver (/Ag $\left.\mathrm{BH}_{4}^{-}\right)$ colloids prepared by borohydride reduction.

Figure 6-6: $\quad$ SERS of cyanopyridines (4-, 3-, and 2-CP) adsorbed onto silver $\left(/ \mathrm{Ag}_{\mathrm{cit}}\right)$ colloids prepared by citrate reduction.

Figure 6-7: $\quad$ SERS of aminomethylpyridines (4- and 2-AMP) adsorbed onto silver $\left(/ \mathrm{Ag}_{\mathrm{BH}_{4}}\right)$ colloids prepared by borohydride reduction.

Figure 6-8: $\quad$ SERS of aminomethylpyridines (4-, 3-, and 2-AMP) adsorbed onto silver $\left(/ \mathrm{Ag}_{\mathrm{cit}}\right)$ colloids prepared by citrate reduction.

Figure 6-9: $\quad$ SERS of 4-cyanopyridine (4-CP) adsorbed onto silver $\left(/ \mathrm{Ag}_{\text {cit }}\right)$, copper (/Cu), and gold (/Au) colloids. 
Figure 6-10: SERS of 3-cyanopyridine (3-CP) adsorbed onto silver (/Ag $\left.{ }_{\text {cit }}\right)$, copper (/Cu), and gold (/Au) colloids.

Figure 6-11: SERS of 2-cyanopyridine (2-CP) adsorbed onto silver $\left(/ \mathrm{Ag}_{\text {cit }}\right)$, copper (/Cu), and gold (/Au) colloids. 


\section{LIST OF TABLES}

Table 2-1: $\quad$ Raman Frequencies $\left(\mathrm{cm}^{-1}\right)$ of 4-Cyanopyridine (4-CP) and 4-

Cyanopyridine- ${ }^{15} \mathrm{~N}\left(4-\mathrm{CP}_{-}{ }^{-15} \mathrm{~N}\right)$ in Aqueous Solution $(2.0 \mathrm{M})$ and Adsorbed onto Copper $(/ \mathrm{Cu})$ and Gold $(/ \mathrm{Au})$ Colloids.

Table 2-2: $\quad$ Raman Frequencies $\left(\mathrm{cm}^{-1}\right)$ of Neat 4-Aminomethylpyridine (4-AMP) and Adsorbed on Copper (/Cu) Colloids and 4-Cyanopyridine (4-CP) Adsorbed onto Copper Colloids.

Table 2-3: $\quad$ Raman Frequencies $\left(\mathrm{cm}^{-1}\right)$ of 4-Cyanopyridine (4-CP) Adsorbed onto Copper (/Cu) Colloids Prepared From $\mathrm{Cu}^{+2}\left(/ \mathrm{Cu}^{\circ}(\mathrm{ll})\right), \mathrm{Cu}^{+1}\left(/ \mathrm{Cu}^{\circ}(\mathrm{l})\right)$, and Under Deoxygenated Conditions (/Cu (d)).

Table 2.4: Raman Frequencies $\left(\mathrm{cm}^{-1}\right)$ of 4-Cyanopyridine (4-CP) Adsorbed onto Copper $(/ \mathrm{Cu})$ Colloids at Various Concentrations.

Table 3-1: $\quad$ Raman Frequencies $\left(\mathrm{cm}^{-1}\right)$ of 3-Cyanopyridine (3-CP) in Aqueous Solution $(2.0 \mathrm{M})$ and Adsorbed on Copper (/Cu) and Gold (/Au) Colloids.

Table 3-2: $\quad$ Raman Frequencies $\left(\mathrm{cm}^{-1}\right)$ of 2-Cyanopyridine (2-CP) in Aqueous Solution $(2.0 \mathrm{M})$ and Adsorbed on Copper (/Cu) and Gold (/Au) Colloids.

Table 3-3: $\quad$ Raman Frequencies $\left(\mathrm{cm}^{-1}\right)$ of Neat 3-Aminomethylpyridine (3-AMP) and Adsorbed on Copper (/Cu) Colloids and 3-Cyanopyridine (3-CP) in Aqueous Solution (2.0 M) and Adsorbed onto Copper Colloids.

Table 3-4: $\quad$ Raman Frequencies $\left(\mathrm{cm}^{-1}\right)$ of Neat 2-Aminomethylpyridine (2-AMP) and Adsorbed on Copper (/Cu) Colloids and 2-Cyanopyridine (2-CP) in aqueous Solution (2.0 M) and Adsorbed onto Copper Colloids. 
Table 3-5: Raman Frequencies $\left(\mathrm{cm}^{-1}\right)$ of 3-Cyanopyridine (3-CP) Adsorbed onto Copper (/Cu) Colloids Prepared From $\mathrm{Cu}^{+2}\left(/ \mathrm{Cu}^{\circ}(11)\right), \mathrm{Cu}^{+1}\left(/ \mathrm{Cu}^{\circ}(1)\right)$, and Under Deoxygenated Conditions (/Cu (d)).

Table 3-6: Raman Frequencies $\left(\mathrm{cm}^{-1}\right)$ of 2-Cyanopyridine (2-CP) Adsorbed onto Copper (/Cu) Colloids Prepared From $\mathrm{Cu}^{+2}\left(/ \mathrm{Cu}^{\circ}(11)\right), \mathrm{Cu}^{+1}\left(/ \mathrm{Cu}^{\circ}(1)\right)$, and Under Deoxygenated Conditions (/Cu (d)).

Table 3-7: $\quad$ Raman Frequencies $\left(\mathrm{cm}^{-1}\right)$ of Cyanopyridines (4-, 3-, and 2-CP) and Aminomethylpyridines (4-, 3-, and 2-AMP) Adsorbed onto Copper (/Cu) Colloids.

Table 4-1: $\quad$ Raman Frequencies $\left(\mathrm{cm}^{-1}\right)$ of Neat Benzonitrile $(\mathrm{BN})$ and Neat Benzylamine (BA) and Adsorbed onto Copper (/Cu) and Gold (/Au) Colloids.

Table 4-2: $\quad$ Raman Frequencies $\left(\mathrm{cm}^{-1}\right)$ of 1,4-Dicyanobenzene (1,4-DCB) in aqueous (2.0 M) and Xylylenediamine (XY) (2.0 M) and Adsorbed onto Copper (/Cu) and Gold (/Au) Colloids.

Table 4-3: $\quad$ Raman Frequencies $\left(\mathrm{cm}^{-1}\right)$ of Neat Acetonitrile (AN) and Neat Ethylamine (EA) and Adsorbed onto Copper (/Cu) and Gold (/Au) Colloids.

Table 4-4: $\quad$ Raman Frequencies $\left(\mathrm{cm}^{-1}\right)$ of Neat Hexanenitrile $(\mathrm{HN})$ and Neat Hexylamine (HA) and Adsorbed onto Copper (/Cu) and Gold (/Au) Colloids. 
Table 6-1: $\quad$ Raman Frequencies $\left(\mathrm{cm}^{-1}\right)$ of 4-Cyanopyridine (4-CP) and Adsorbed onto Silver Colloids Prepared by Borohydride Reduction (/ $\left.\mathrm{Ag}^{\circ}{ }_{\mathrm{BH} 4^{-}}\right)$, Citrate Reduction $\left(/ \mathrm{Ag}^{\circ}{ }_{\text {cit }}\right)$, and on a Silver Electrode $\left(/ \mathrm{Ag}_{\text {elec }}\right)$.

Table 6-2: $\quad$ Raman Frequencies $\left(\mathrm{cm}^{-1}\right)$ of 3-Cyanopyridine (3-CP) and Adsorbed onto Silver Colloids Prepared by Borohydride Reduction (/ $\left.\mathrm{Ag}^{\circ}{ }_{\mathrm{BH} 4^{-}}\right)$, Citrate Reduction $\left(/ \mathrm{Ag}^{\circ}{ }_{\text {cit }}\right)$, and on a Silver Electrode $\left(/ \mathrm{Ag}_{\text {elec }}\right)$.

Table 6-3: $\quad$ Raman Frequencies $\left(\mathrm{cm}^{-1}\right)$ of 2-Cyanopyridine (2-CP) and Adsorbed onto Silver Colloids Prepared by Borohydride Reduction $\left(/ \mathrm{Ag}^{\circ} \mathrm{BH}^{-}\right)$, Citrate Reduction $\left(/ \mathrm{Ag}^{\circ}{ }{ }\right)$, and on a Silver Electrode $\left(/ \mathrm{Ag}_{\text {elec }}\right)$.

Table 6-4: $\quad$ Raman Frequencies $\left(\mathrm{cm}^{-1}\right)$ of Trisodium Citrate (CIT) in Aqueous Solution (2.0 M) and Adsorbed onto Silver Colloids.

Table 6-5: $\quad$ Raman Frequencies $\left(\mathrm{cm}^{-1}\right)$ of Cyanopyridines (4-, 3-, and 2-CP) Adsorbed onto Silver Colloids Prepared by Borohydride Reduction $\left(/ \mathrm{Ag}^{\circ} \mathrm{BH}^{-}\right)$and Citrate Reduction $\left(/ \mathrm{Ag}^{\circ}{ }_{\text {cit }}\right)$.

Table 6-6: $\quad$ Raman Frequencies $\left(\mathrm{cm}^{-1}\right)$ of Aminomethylpyridines (4-, 3-, and 2-AMP) Adsorbed onto Silver Colloids Prepared by Borohydride Reduction $\left(/ \mathrm{Ag}^{\circ}{ }_{\mathrm{BH} 4^{-}}\right)$and Citrate Reduction $\left(/ \mathrm{Ag}^{\circ}{ }_{\text {cit }}\right)$. 


\section{CHAPTER 1}

\section{Introduction}

Surface-enhanced Raman spectroscopy (SERS) links the structural information of vibrational spectroscopy with the sensitivity and surface specificity of the enhancement mechanism. ${ }^{1,2}$ The vibrational information contained in the Raman spectra provide the molecular signature required to characterize adsorbate/surface interactions. This technique is applicable to surfaces of free-electron metals, although methods have been developed to overcome this limitation. ${ }^{1}$

Since the discovery of SERS ${ }^{3,4}$, numerous methods have been suggested for the preparation of active sites. ${ }^{5}$ Both metal colloids and roughened metal electrodes are

commonly used as substrates. $^{3-5}$ Other methods including chemical etching, laser ablation, and mechanical polishing have been used to prepare surfaces for SERS..$^{6-8}$ In almost all cases, careful control of the experimental conditions is important for obtaining reproducible and reliable data.

The electrochemical method of inducing roughness has become the most common preparation of active surfaces for SERS. ${ }^{3,4}$ However, intensities of the SERS scattering of molecules adsorbed on an electrochemically roughened metal surfaces undergo a potentialinduced irreversible decay. ${ }^{9}$ These irreversible changes are most pronounced at very negative electrode potentials and have been ascribed to the disappearance of the so-called "active sites", which are incorporated into the bulk metal after desorption of their ligand. ${ }^{9}$ While 
control of the surface morphology on electrodes is nearly impossible to achieve, colloidal particles with nearly spherical shapes can easily be prepared. ${ }^{10}$ Studies of Raman scattering by colloidal dispersions may serve as a guide to understand the SER effect at the surface of an isolated particle which has been suggested to be due to the same phenomenon as at a roughened macroscopic surface. ${ }^{11}$

Colloidal metals have been used in SERS experiments because adsorbed molecules exhibit strong enhancement and colloids are relatively easy to prepare by chemical reduction methods. ${ }^{12-16}$ Additionally, studies indicate that strong molecular mechanisms exist in colloidal systems. The advantages of colloids over electrodes are: (1) ease of formation and manipulation; (2) possibility of continuous renewal of sample by flowing through the light beam; (3) ability to control and vary particle size and shape; (4) more easily defined surface area; and (5) more tractable morphology for theoretical analysis. ${ }^{11}$

SER scattering from molecules on silver and gold electrodes and colloids have been extensively studied; however, copper colloids have received less attention due to their inherent instability. ${ }^{1,13,14,17,18}$ Given the potential applications of copper as an inexpensive sensor material or catalyst, it is important that the surface reactivity be explored. A few reports have appeared indicating that there is an effort to develop and study copper colloids. ${ }^{15,19-23}$ Therefore, we are investigating the adsorption of organonitriles on copper colloids. These molecules are important because they provide insight into the selectivity of adsorption sites of metal surfaces as well as the underlying reasons for the SER effect.

Prior studies by Van Duyne ${ }^{17,24}$ showed that there was a decrease in intensity of $v(\mathrm{C} \equiv \mathrm{N})$ as the nitrile was moved from the 4- to the 3- to the 2-positions for 4- 
cyanopyridine (4-CP), 3-cyanopyridine (3-CP), and 2-cyanopyridine (2-CP) on silver electrodes. This was interpreted as an enhancement controlled by the interaction of the nitrile moiety with the metal surface as determined by its position on the pyridine ring (see Figure 1-1). That is, greater interaction between the nitrile group and the surface leads to lower intensity for $v(C \equiv N)$. It was assumed that adsorption was occurring primarily through the lone pair electrons of the nitrogen in the aromatic ring as had been previously reported..$^{3,14}$

In another series of studies, it was determined that the intensity of $v(C \equiv N)$ was proportional to the applied potential as well as surface concentration when 4-CP was adsorbed onto copper and silver electrodes..$^{25,26,27}$ As the concentration of the adsorbate at the surface was decreased, the molecules were reported to lie flat-on relative to the electrode surface and $v(C \equiv N)$ was found at $2140 \mathrm{~cm}^{-1}$ (see Figure 1-2). At higher concentrations the molecules lie end-on and give rise to $\mathrm{v}(\mathrm{C} \equiv \mathrm{N})$ at $2238 \mathrm{~cm}^{-1}$. Both orientations give rise to $v(C \equiv N)$ values lower than that of the parent molecule $\left(2246 \mathrm{~cm}^{-1}\right)$. These reports also indicate that as the potential becomes more negative, the donor character of the active site on the copper electrode increases and shifts $v(\mathrm{C} \equiv \mathrm{N})$ to lower wavenumbers as a result of the perturbation of a partial charge transfer reaction (the charged radical gives rise to a band at $\left.2090 \mathrm{~cm}^{-1}\right)$. The authors indicate that coordination through the nitrile substituent should give rise to a band above that observed for the parent compound..$^{25,26,27}$ It was found that as the concentration of the adsorbate was decreased the $A_{1}$ modes located at $2240 \mathrm{~cm}^{-1}$ and 1195 $\mathrm{cm}^{-1}$ decreased in intensity and the $\mathrm{B}_{2}$ modes located at $1217 \mathrm{~cm}^{-1}$ and $1420 \mathrm{~cm}^{-1}$ increased in intensity. ${ }^{26}$ This was correlated with a change in adsorbate orientation from an end-on (adsorption through the nitrogen on the aromatic ring) to a flat-on adsorption. 


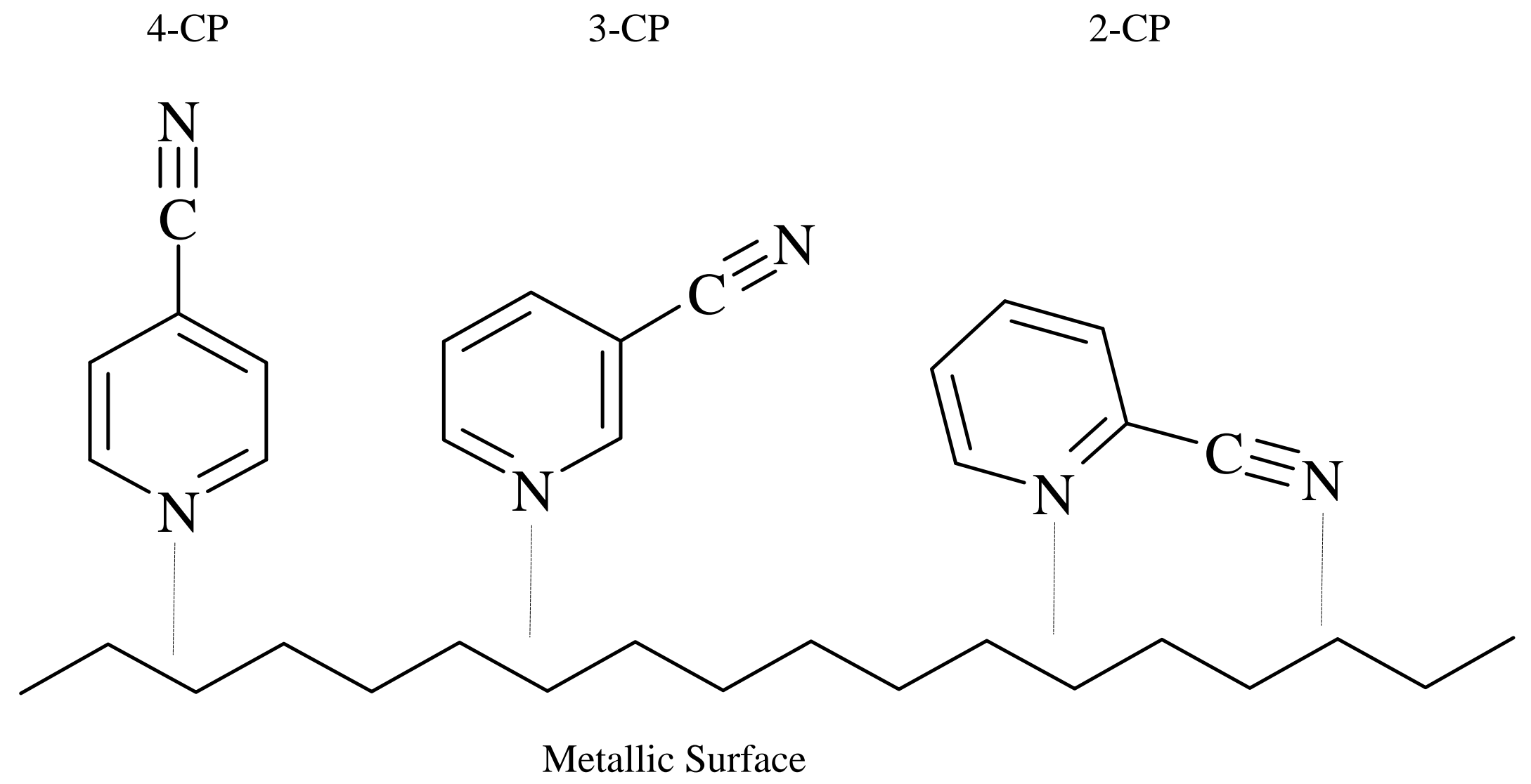

Figure 1-1 Orientation of cyanopyridines (4-CP, 3-CP and 2-CP) adsorbed onto a metallic surface. 


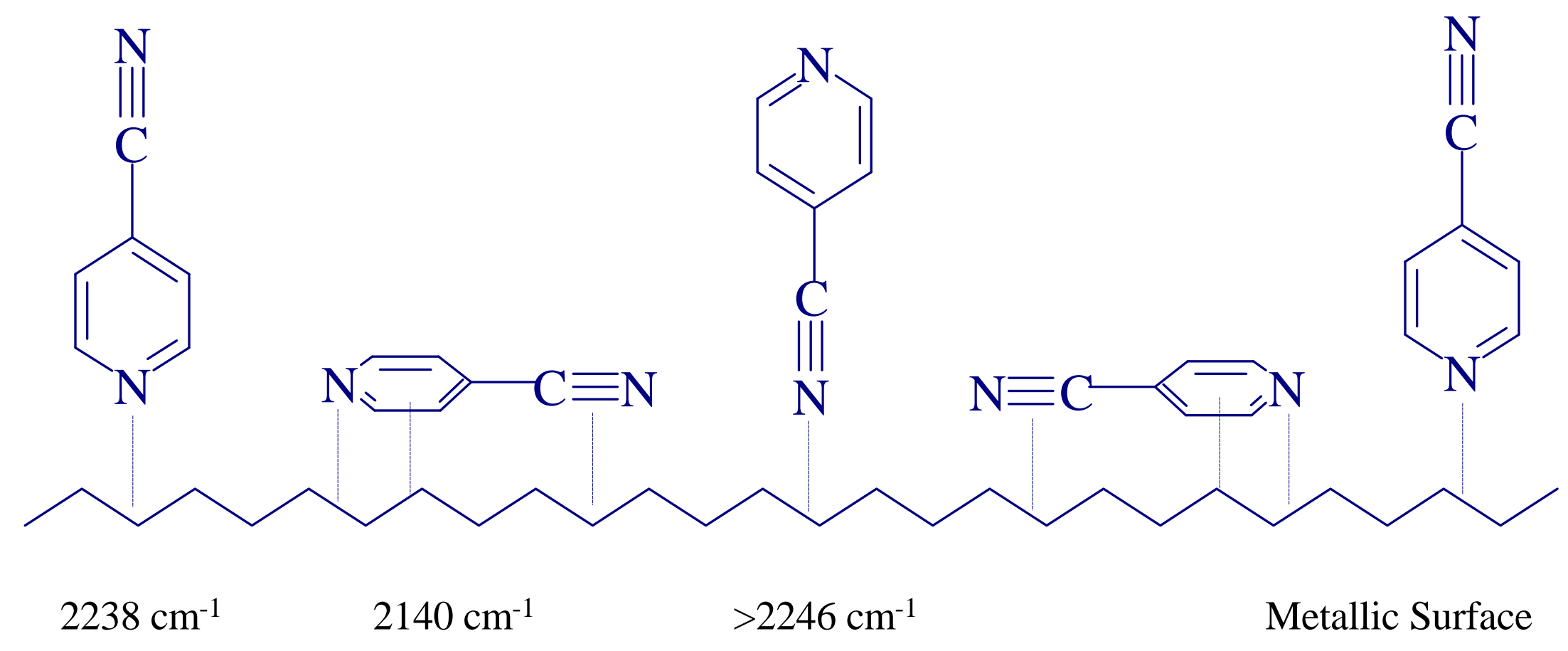

Figure 1-2 Orientation of cyanopyridines (4-CP, 3-CP and 2-CP) adsorbed onto a metallic surface [v(CN) is indicated]. 
The debate concerning the foundations of the SER effect is still in the process of being defined. ${ }^{28}$ The theoretical approaches to SERS consists of two different ideas, the electromagnetic mechanism (EM) and chemical/molecular interactions (CM). ${ }^{29,30}$ Contributions from these effects are contained in the equation for the induced dipole moment $(\mu)$, as shown below.

\section{Induced Molecular Dipole $(\mu)$}

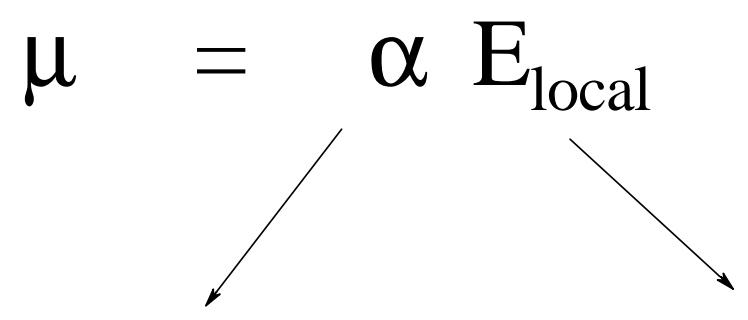

CM: Molecular polarizability $(\alpha)$ is increased due to a charge transfer during the formation of a metal-molecule complex.

EM: Local electromagnetic field increases due to excitation of the surface plasmons by both the incident and scattered light.

EM theory is based on the idea that an enhancement of the electromagnetic field near the metal surface occurs when an incident photon interacts with the EM field. ${ }^{29,30}$ This process is affected by the radius and shape of the metal particles and the spectral effects are similar to those of resonance Raman spectra (i.e., an enhancement of intensity). The CM theory states that enhancement occurs due to a change in the molecular polarizability of the adsorbate caused by physical or chemical interactions between the adsorbate molecule and the surface..$^{30,31}$ This theory is more sensitive to the nature of the adsorbate molecule and explains the observation that SERS differs from the spectra of the same species in solution. 
Different metals in metal colloids have differing contributions from each component in the SERS mechanism. ${ }^{11,23,32}$ The EM is primarily a characteristic of the colloidal metals and leads to an enhancement that is nearly independent of the adsorbed molecule. ${ }^{33}$ The distinguishing features of each type of metallic colloid include the area of contact between the dispersed colloidal particles and the dispersion medium, as well as the energy associated with creating and maintaining these interfaces. The $\mathrm{CM}$ exploits a resonance in the molecule-metal effective polarizability. ${ }^{23}$ This mechanism is sensitive to the presence of "active sites" on the metal and provides details of the molecule-metal bond. The actual charge transfer during the adsorption of organonitriles on the different metal surfaces and the resulting orientation, symmetry and chemical interaction will contribute to an understanding of the contributors to surface enhancement. 


\section{REFERENCES}

1. J. A. Creighton, Anal. Proc. 30, 28 (1993).

2. T. M. Cotton, J. Kim and G. Chumanov, J. Raman Spectrosc. 22, 729 (1991).

3. M. Fleischmann, P.J. Hendra and A. J. McQuillan, Physics Letters 2 26, 163-166 (1974).

4. D. L. Jeanmaire and R. P. Van Duyne, Electroanal. Chem. 84, 1-20 (1977).

5. W. Suetaka, Surface Infrared and Raman Spectroscopy, Methods and Applications. Plenum Press, New York (1995).

6. M. S. Sibbald, G. Chumanov and T. M. Cotton, J. Phys. Chem. 100, 4672-4676 (1996).

7. A Ruperez and J. J. Laserna, in Modern Techniques in Raman Spectroscopy, edited by J. J. Laserna, p. 240. Wiley, Chichester (1996).

8. A. M. Ahern and R. L. Garrell, Anal. Chem. 59, 2816-2818 (1987).

9. A. Kudelski and J. Bukowska, Vib. Spectrosc. 10, 335-339 (1996).

10. K. U. Von Raben et. al., J. Phys. Chem. 88, 5290-5296 (1984).

11. D. S. Wang, H. Chew and M. Kerker, Applied Optics 14 19, 2256-2257 (1980).

12. G. Chumanov, K. Sokolov, B. W. Gregory and T. M. Cotton, J. Phys. Chem. 99, 9466 (1995).

13. D. Meisel and P. C. Lee, J. Phys. Chem. 86, 3391 (1982).

14. J. A. Creighton, C. G. Blatchford and M. G. Albrecht, J. Chem. Soc., Faraday Trans. 2 75, 790 (1979).

15. J. A. Creighton, M.S. Alvarez, D.A. Weltz, S. Garoff and M. W. Kim, J. Phys. Chem. 87, 4793 (1983).

16. J. Turkevich, P. C. Sevenson and J. Hiller, Discuss Faraday Soc. 1155 (1951).

17. C. S. Allen and R. P. Van Duyne, Chem. Phys. Lett. 63, 455 (1979).

18. M. Fleischmann, P. J. Hendra and A. J. McQuillan, Chem. Phys. Lett. 26, 123 (1974). 
19. J. Pate, A. Leiden, B. J. Bozlee and R. L. Garrell, J. Raman Spectrosc. 14, 477 (1983).

20. C. M. Coyle and P. W. Jagodzinski, J. Raman Spectrosc. 29, 757-762 (1998).

21. D. De Caro, H. Wally, C. Amiens and B. Chaudret, J. Chem. Soc., Chem. Comm., 1891-1892 (1994).

22. R. Woods and G. A. Hope. Colloids and Surfaces A - Physicochemical and Engineering Aspects 146, 63-74 (1999).

23. J. A. Creighton, Surface Sci. 173, 665-672 (1986).

24. C. S. Allen, PhD Thesis, Northwestern University (1980); University Microfilms, AAG8104683.

25. J. C. Rubim, J. Electroanal. Chem. 220, 339 (1987).

26. J. C. Rubim and O. J. Sala, J. Mol. Struct. 145, 157 (1986).

27. J. C. Rubim, I. G. R. Gutz and O. Sala, Chem. Phys. Lett. 111, 117-122 (1984).

28. J. Billmann, G. Kovacs and A. Otto, Science 92, 153-173 (1980).

29. H. Metiu and P. Das, Ann. Rev. Phys. Chem. 35, 507-536 (1984).

30. A. G. Brolo, D. E. Irish and B. D. Smith, J. Mol. Struc. 405, 29-44 (1997).

31. S. S. Jha, Surface Sci. 158, 190-216 (1985).

32. F. Farha and R. T. Iwamoto, Inorg. Chem. 6 4, 844-848 (1965).

33. A. Otto, Appl. Surface Sci. 6, 309 (1980). 


\section{CHAPTER 2}

\section{4-Cyanopyridine Adsorbed on Copper Colloids}

\section{$2.1 \quad$ INTRODUCTION}

We have collected SERS for 4-cyanopyridine (4-CP) adsorbed on copper colloids (see Figure 2-1). Our SERS data for substituted pyridines mixed with copper colloids are significantly different from that observed with gold, silver, and copper electrodes. Studies of cyanopyridines on silver electrodes indicate an enhancement of the $\mathrm{C} \equiv \mathrm{N}$ stretching normal mode signal $[\mathrm{v}(\mathrm{C} \equiv \mathrm{N})]$ that is dependent upon the position of the substituent on the aromatic ring. ${ }^{1-3}$ Further studies showed that there is a dependence of the SERS intensity on the applied potential when isomeric forms of cyanopyridine are adsorbed on silver electrodes. ${ }^{4}$ Similar trends were observed for the adsorption of 4-CP on gold and copper electrodes. ${ }^{5}$ Spectra obtained for pyridine adsorbed onto copper colloids and electrochemically roughened copper electrodes are similar, although a greater enhancement was observed with the electrodes. ${ }^{6}$ We began our studies of cyanopyridines on copper colloids to investigate the differences in the SER spectra and adsorption mechanisms for gold and copper colloids and electrodes.

We present herein the results for non-labeled and isotopically labeled 4-cyanopyridines (4-CP, 4-CP- $\left.{ }^{15} \mathrm{~N}\right)$ mixed with copper and gold colloids. The SER spectra for the copper colloids are markedly different from those obtained when 4-CP is adsorbed onto copper, gold and silver electrodes. ${ }^{1-5}$ It is proposed that excess borohydride used in the 


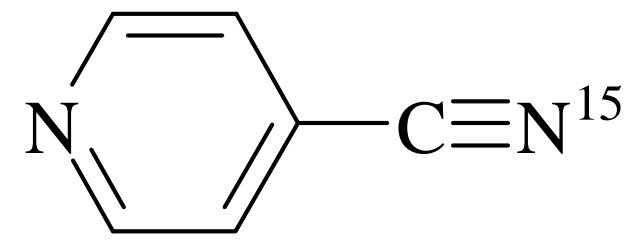

$4-\mathrm{CP}^{15} \mathrm{~N}$

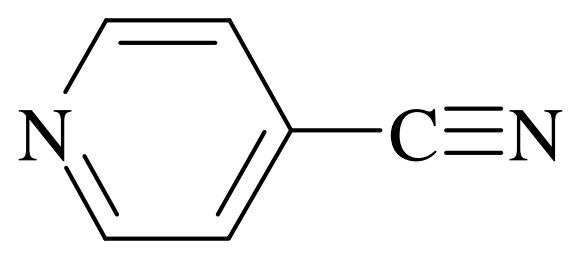

4-CP

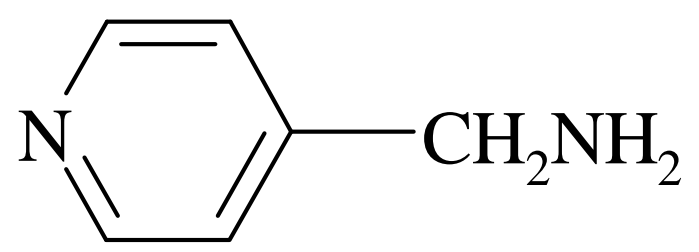

4-AMP

Figure 2-1 Molecular structures for 4-cyanopyridine (4-CP), 4-cyanopyridine- ${ }^{15} \mathrm{~N}\left(4-\mathrm{CP}-{ }^{15} \mathrm{~N}\right)$ and 4 - aminomethylpyridine (4-AMP). 
preparation of the colloid reduces 4-CP to 4-aminomethylpyridine (4-AMP) and that the observed SERS is of 4-AMP on the colloidal surface.

\subsection{EXPERIMENTAL}

\section{Colloid Preparation}

The preparation of the copper colloids is based on the borohydride reduction of $\mathrm{Cu}^{2+}$. An aqueous solution of copper (II) sulfate (Aldrich Chemical Co., Milwaukee, WI; 99.99\%) $\left(2 \times 10^{-2} \mathrm{M}, 0.15 \mathrm{~mL}\right)$ was added to a trisodium citrate solution (Aldrich; $\left.99 \%\right)\left(2.8 \times 10^{-3} \mathrm{M}\right.$, $2.0 \mathrm{~mL}$ ) followed by the addition of a freshly prepared solution of sodium borohydride (Aldrich; 99\%) $\left(2 \times 10^{-2} \mathrm{M}, 1.0 \mathrm{~mL}\right)$ in $1.9 \times 10^{-2} \mathrm{M}$ sodium hydroxide (Fisher Scientific Co., Pittsburgh, PA; 98\%). All colloidal solutions were prepared in disposable borosilicate glass culture tubes with water passed through a Barnstead/Thermolyne (Dubuque, IA) Nanopure Water Model D4541 purification system. The colloid, which starts as a pale yellow-brown color becomes a dark reddish-brown. The red color is indicative of particle sizes ranging from 10 to $20 \mathrm{~nm}$ and gives rise to an absorption band at $564 \mathrm{~nm}^{7}$ After the colloid was allowed to age for two hours, an aqueous solution of the 4-CP (Aldrich; $98 \%)\left(1 \times 10^{-3} \mathrm{M}\right.$, $0.30 \mathrm{~mL}$ ) was added to the culture tube. The final concentration of the 4-CP was approximately $9 \times 10^{-5} \mathrm{M}$. Upon addition of the 4-CP, the colloid changes to a dark greybrown color due to aggregation and has an absorption band at $570 \mathrm{~nm}$. A band at $296 \mathrm{~nm}$ indicative of the adsorbate is also observed. The copper colloid with $4-\mathrm{CP}-{ }^{15} \mathrm{~N}$ has absorption bands at $571 \mathrm{~nm}$ and $305 \mathrm{~nm}$. These shifts in the spectra are indicative of molecule-surface

interaction in the colloidal system. ${ }^{8}$ Previous work indicates that the addition of the adsorbate 
before or after aging of the colloid results in no significant difference in the SER spectra. ${ }^{6}$ Both procedures have been followed and no differences were observed for the current system. The excess borohydride provides a buffer against oxidation of the copper particles. The high $\mathrm{pH}$ of the colloid solution stabilizes the borohydride ions, while the trisodium citrate minimizes colloid precipitation. The copper colloids are stable for approximately 24 hours if stored in a well-stoppered container. Data collection of the SER spectra of the cyanopyridines adsorbed onto the copper colloids was begun 80 minutes after the addition of the adsorbate solution to the colloid.

The preparation of the gold colloid began with the dissolution of $\mathrm{HAuCl}_{4}$ (Aldrich, 99.99\%) (240 mg) in $500 \mathrm{~mL}$ of water which was then heated to boiling. ${ }^{9}$ A solution of $1 \%$ w/w sodium citrate (Aldrich, $99 \%)(50 \mathrm{~mL}$ ) was added. Immediately after the addition of the sodium citrate the solution changed from a pale to a bright yellow color and then to a dark red wine color (absorption band at $523 \mathrm{~nm}$ ). ${ }^{7}$ The solution was maintained at boiling for 2 hours. Raman samples were prepared by adding $4-\mathrm{CP}\left(0.3 \mathrm{~mL}, 1 \times 10^{-3} \mathrm{M}\right)$ to $2.7 \mathrm{~mL}$ of the gold colloid solution in a disposable borosilicate glass culture tube. The color changed to a dark violet/purple with an absorption maxima at $563 \mathrm{~nm}$ indicative of aggregation due to the presence of the adsorbate. The SER spectra were collected starting 80 minutes after the addition of the cyanopyridine.

4-Aminomethylpyridine (Aldrich, 98\%) was adsorbed onto copper colloids using the procedures described above. Spectra of the parent compound were collected as the neat liquid contained in standard melting point capillary tubes. 
In order to investigate the potential oxidation of the copper systems, the colloids were also studied under anaerobic conditions. Anaerobic preparation of the copper colloids was performed using the same chemical ratios as listed above with the following differences in treatment. The components of the copper colloids were permitted to set in an argon atmosphere while argon gas at 7 psi was bubbled through the solutions. The initial solutions were treated with argon gas for 3 hours to provide sufficient deoxygenation prior to preparation of the copper colloid. The argon gas was also bubbled through the aging copper colloid and for approximately 1 hour after addition of the 4-CP before sealing the sample in preparation for spectral collection.

In order to investigate the oxidation state of copper required for the reduction process, copper colloids were prepared using different initial states of copper. Colloids were prepared using the methods described above, but with different copper salts [copper (II) sulfate (Aldrich; 99.99\%) and copper (I) chloride (Aldrich; 97\%).

\section{Spectra Collection}

Raman data was collected using two spectrometers. One system consisted of a Coherent Inc. (Santa Clara, CA) $\mathrm{Kr}^{+}$laser operating at $647.1 \mathrm{~nm}$ which provided $20 \mathrm{~mW}$ at the sample. A $270^{\circ}$ geometry was used for collection of the scattered radiation which was analyzed with a Spex Industries (Edison, NJ) Triplemate system equipped with a 1200 groves/mm grating and a Princeton Instruments CCD detector operating at $115 \mathrm{~K}$. The second system consisted of a Lexel (Fremont, CA) Ramanion $\mathrm{Kr}^{+}$laser operating at $647.1 \mathrm{~nm}$ which provided $20 \mathrm{~mW}$ at the sample. A Spex Industries Triplemate system equipped with a 600 grooves/mm grating and an Oxford CCD detector operating at $135 \mathrm{~K}$ was used for 
detection. A $90^{\circ}$ geometry was used for collection of scattered radiation. The instruments were calibrated with indene and benzonitrile and reported frequencies are accurate to $\pm 5 \mathrm{~cm}^{-}$ ${ }^{1}{ }^{10}$ The absorption spectra were recorded with a Perkin Elmer (Norwalk, CT) Lambda-6 UV-VIS spectrophotometer.

Preparation of isonicotinamide ${ }^{15} \mathrm{~N}$<smiles>NC(=O)c1cc[n+](N)cc1</smiles>

Ammonia $-{ }^{15} \mathrm{~N}$ (Aldrich, 98\%) (20 mmol) was introduced over 2 hours into a solution of isonicotinoyl chloride - hydrochloride (Aldrich, $95 \%$ ) (2.0 g, $10 \mathrm{mmol}$ ) in $100 \mathrm{~mL}$ of ethyl ether/THF cooled in an acetone/dry ice bath. ${ }^{11}$ After 2 hours, a white solid formed, and the mixture was allowed to cool to room temperature with stirring. The mixture was filtered, the solid (ammonium chloride $\left.-{ }^{15} \mathrm{~N}\right)$ was washed with ethyl ether $(5 \times 15 \mathrm{~mL})$ and the filtrate was concentrated until crystallization occurred. The crystals were treated with benzene $(100 \mathrm{~mL})$ and heated until the product dissolved. The mixture was allowed to cool and recrystallize overnight at $10^{\circ} \mathrm{C}$. The crystals of isonicotinamide- ${ }^{15} \mathrm{~N}(0.422 \mathrm{~g})$ were obtained by filtering and washing with cold benzene (5 x $10 \mathrm{~mL})$. Percent yield: $21.18 \%$. NMR- ${ }^{1} \mathrm{H}$ 5.64-5.96 $(2 \mathrm{H}, \mathrm{d}), 7.65(2 \mathrm{H}, \mathrm{d}), 8.7(2 \mathrm{H}, \mathrm{d})$.

Preparation of 4-Cyanopyridine ${ }^{15} \mathrm{~N}$

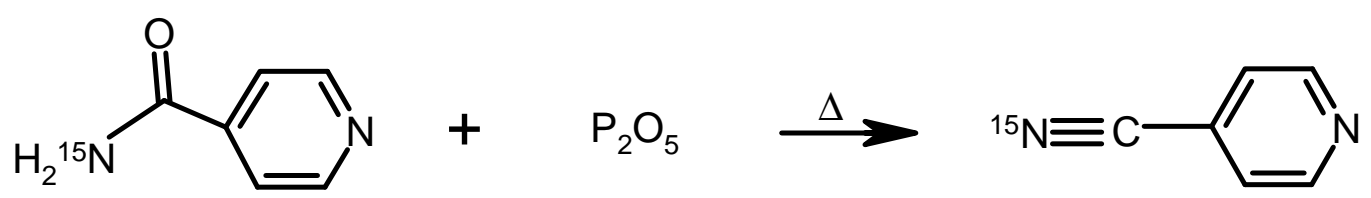


Isonicotinamide- ${ }^{15} \mathrm{~N}(0.2 \mathrm{~g}, 1.7 \mathrm{mmol})$ and phosphorous pentoxide $(0.24 \mathrm{~g}, 1.7 \mathrm{mmol})$ were carefully mixed in a $50 \mathrm{~mL}$ round bottom flask equipped with a distillation head. ${ }^{12}$ The mixture was rapidly melted with a flame until effervescence ceased. Heating was continued until distillation of the 4-cyanopyridine- ${ }^{15} \mathrm{~N}$ was completed $(0.0655 \mathrm{~g})$. Percent yield: 32.75\%. NMR- ${ }^{1} \mathrm{H} 7.5(2 \mathrm{H}, \mathrm{d}, J=5.9 \mathrm{~Hz}), 8.82(2 \mathrm{H}, \mathrm{d}, J=7.6 \mathrm{~Hz})$.

Isonicotinamide- ${ }^{-15} \mathrm{~N}$ and 4 -cyanopyridine $-{ }^{15} \mathrm{~N}$ were characterized with NMR spectra as reported above. The Raman spectrum of the $4-\mathrm{CP}_{-}{ }^{15} \mathrm{~N}$ shows a shift in the nitrile stretching signal from $2246 \mathrm{~cm}^{-1}$ to $2218 \mathrm{~cm}^{-1}$ (see Figure 2-2).

\subsection{RESULTS AND DISCUSSION}

The SER spectra obtained when 4-CP and 4-CP- ${ }^{15} \mathrm{~N}$ are mixed with copper colloids and the normal Raman spectrum of 4-CP are shown in Figures 2-2 and 2-3. The observed frequencies with tentative assignments are presented in Table 2-1. Upon adsorption, $v(\mathrm{C} \equiv \mathrm{N})$ at $2246 \mathrm{~cm}^{-1}$ is not observed even though this is the most intense signal in the spectrum of the parent molecule. In addition, the bands at $776 \mathrm{~cm}^{-1}\left(\mathrm{C} \equiv \mathrm{N}\right.$ sensitive), $550 \mathrm{~cm}^{-1}(\mathrm{C} \equiv \mathrm{N}$ sensitive $), 461 \mathrm{~cm}^{-1}(\mathrm{C} \equiv \mathrm{N}$ sensitive $), 365 \mathrm{~cm}^{-1}\left(\mathrm{C} \equiv \mathrm{N}\right.$ sensitive) and $169 \mathrm{~cm}^{-1}[(\mathrm{C} \equiv \mathrm{N})]$ are all absent. ${ }^{13}$ The $1194 \mathrm{~cm}^{-1}$ band $[\beta(\mathrm{CH})]$ on the SER spectrum is observed with a partner of equal intensity near $1215 \mathrm{~cm}^{-1}$ in the spectrum of the adsorbed species. The disappearance of $v(\mathrm{C} \equiv \mathrm{N})$ was unexpected because it was observed in previous studies of 4-CP on silver and copper electrodes. ${ }^{2-5}$

Comparison of the collected data for 4-CP adsorbed onto a copper colloids [i.e., complete loss of $v(\mathrm{C} \equiv \mathrm{N})]$ with previous reports (see Chapter 1) suggests that 4-CP is not 


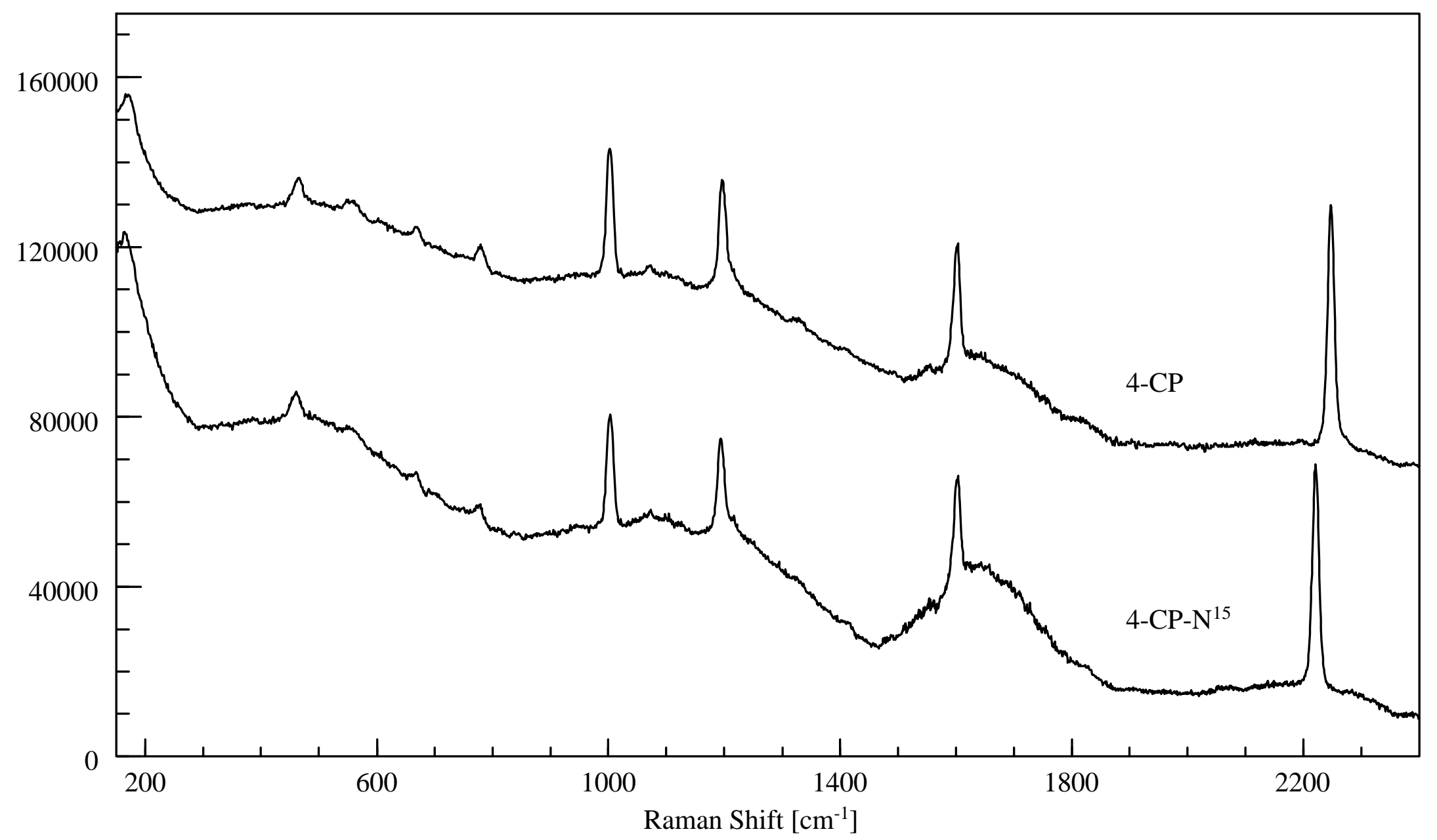

Figure 2-2 Raman spectra of 4-cyanopyridine (4-CP) and isotopically labeled 4-cyanopyridine- ${ }^{15} \mathrm{~N}\left(4-\mathrm{CP}-{ }^{15} \mathrm{~N}\right)$ in aqueous solution. 


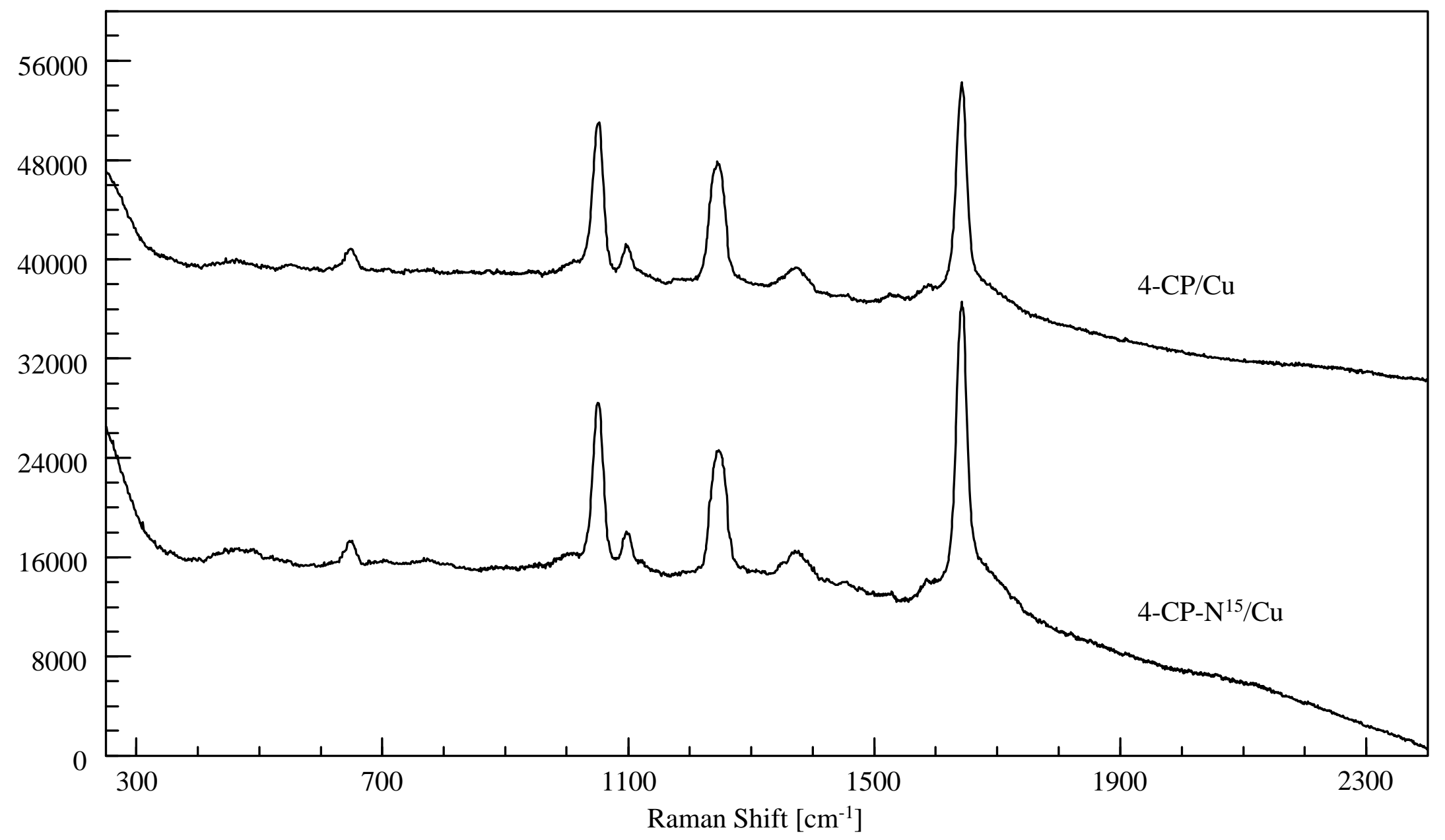

Figure 2-3 SERS of 4-cyanopyridine (4-CP) and isotopically labeled 4-cyanopyridine- ${ }^{15} \mathrm{~N}\left(4-\mathrm{CP}-{ }^{15} \mathrm{~N}\right)$ adsorbed onto copper $(/ \mathrm{Cu})$ colloids. 
TABLE 2-1: Raman Frequencies $\left(\mathrm{cm}^{-1}\right)$ of 4-Cyanopyridine (4-CP) and 4-Cyanopyridine- ${ }^{15} \mathrm{~N}\left(4-\mathrm{CP}-{ }^{15} \mathrm{~N}\right)$ in Aqueous Solution $(2.0 \mathrm{M})$ and Adsorbed onto Copper $(/ \mathrm{Cu})$ and Gold $(/ \mathrm{Au})$ Colloids.

\begin{tabular}{|c|c|c|c|c|c|c|}
\hline Assignment $^{\mathrm{a}}$ & 4-CP (2.0 M) & $4-\mathrm{CP}-{ }^{15} \mathrm{~N}$ & 4-CP/Cu & 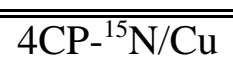 & 4-CP/Au & 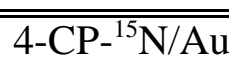 \\
\hline$\gamma(\mathrm{C} \equiv \mathrm{N})$ & 169 & 162 & - & - & - & 163 \\
\hline $\mathrm{C} \equiv \mathrm{N}$ sensitive & - & - & - & - & - & 265 \\
\hline $\mathrm{C} \equiv \mathrm{N}$ sensitive & 365 & 385 & - & - & 384 & 381 \\
\hline $\mathrm{C} \equiv \mathrm{N}$ sensitive & 461 & 461 & - & - & - & - \\
\hline- & - & - & 500 & - & 485 & 475 \\
\hline $\mathrm{C} \equiv \mathrm{N}$ sens,$\delta(\mathrm{C} \equiv \mathrm{N})$ & 550 & 491 & - & - & - & - \\
\hline$\phi(\mathrm{CC})$ & 560 & 563 & - & - & - & 557 \\
\hline- & - & - & 605 & 608 & - & - \\
\hline$\alpha(\mathrm{CCC})$ & 664 & 671 & 668 & 665 & 665 & 643 \\
\hline- & - & - & - & - & - & 726 \\
\hline $\mathrm{C} \equiv \mathrm{N}$ sensitive & 776 & 778 & - & - & 792 & 782 \\
\hline- & - & - & 797 & 806 & - & - \\
\hline$\gamma(\mathrm{CH})$ & - & - & 841 & 843 & 839 & 826 \\
\hline- & - & 957 & - & - & - & - \\
\hline ring breathing & 1001 & 1003 & 1018 & 1019 & 1022 & 1018 \\
\hline$\beta(\mathrm{CH})$ & 1068 & 1078 & 1065 & 1065 & 1063 & 1060 \\
\hline- & - & 1120 & - & - & - & 1111 \\
\hline- & - & - & 1148 & - & - & 1157 \\
\hline$\beta(\mathrm{CH})$ & 1194 & 1194 & 1212 & 1209 & 1198 & 1192 \\
\hline$\beta(\mathrm{CH}), \alpha(\mathrm{CC})$ & - & - & 1216 & 1220 & 1217 & 1212 \\
\hline
\end{tabular}


TABLE 2-1: $\quad$ (Continued)

\begin{tabular}{|c|c|c|c|c|c|c|}
\hline Assignment & 4-CP $(2.0 \mathrm{M})$ & 4-CP- ${ }^{15} \mathrm{~N}$ & 4-CP/Cu & $\overline{4 \mathrm{CP}^{-15} \mathrm{~N} / \mathrm{Cu}}$ & 4-CP/Au & 4-CP- ${ }^{15} \mathrm{~N} / \mathrm{Au}$ \\
\hline- & - & - & - & - & - & 1221 \\
\hline- & - & - & - & 1267 & - & 1255 \\
\hline- & - & 1308 & - & - & - & 1310 \\
\hline$\beta(\mathrm{CH})$ & 1327 & - & 1339 & 1339 & - & - \\
\hline- & - & - & - & 1355 & - & - \\
\hline- & 1412 & - & 1423 & 1423 & 1420 & 1411 \\
\hline$v(\mathrm{CC}, \mathrm{CN})$ & 1492 & - & 1498 & 1494 & - & 1505 \\
\hline$v(C C)$ & 1549 & 1547 & 1552 & 1554 & - & - \\
\hline$v(\mathrm{CC})$ & 1601 & 1604 & 1609 & 1608 & 1611 & 1605 \\
\hline- & - & - & - & - & - & 1686 \\
\hline$v(C \equiv N)$ & 2246 & 2218 & - & - & 2238 & 2211 \\
\hline
\end{tabular}


lying flat-on when adsorbed to the copper colloids because the $2240 \mathrm{~cm}^{-1}, 1420 \mathrm{~cm}^{-1}, 1217$ $\mathrm{cm}^{-1}$, and $1195 \mathrm{~cm}^{-1}$ bands do not change intensities as expected relative to spectra bands of the free molecule. It is anticipated that the primary interaction will occur through the nitrogen in the pyridine ring. In order to understand the observed spectrum of 4-CP with the copper colloids we have collected SER spectra of 4-CP adsorbed onto gold colloids, and have prepared $4-\mathrm{CP}-{ }^{15} \mathrm{~N}$ and collected SER spectra for it with copper and gold colloids.

The SER spectrum collected for 4-CP adsorbed on a gold colloid is shown in Figure 2-4 (with the spectrum of the parent 4-CP and 4-CP with a copper colloid), and the frequencies and tentative assignments are presented in Table 2-1. In the gold colloid system, $\mathrm{v}(\mathrm{C} \equiv \mathrm{N})$ is present and shifted down by $10 \mathrm{~cm}^{-1}$ to $2236 \mathrm{~cm}^{-1}$. This observed frequency matches that reported by Rubim and coworkers when 4-CP was adsorbed onto a copper electrode in an end-on orientation. ${ }^{5}$ The ring modes at $1605 \mathrm{~cm}^{-1}, 1195 \mathrm{~cm}^{-1}$, and $1017 \mathrm{~cm}^{-1}$ shift to higher wavenumbers which is consistent with adsorption through the nitrogen in the ring. ${ }^{4,5}$ This suggests that the nitrile group experiences only minor interaction with the surface and undergoes very little change upon adsorption.

The Raman frequencies and tentative assignments of $4-\mathrm{CP}-{ }^{15} \mathrm{~N}$ are presented in Table 2-1. Isotopic shifts are observed for $\nu(C \equiv N), \beta(C H), \delta(C \equiv N)$, and the $\mathrm{C} \equiv \mathrm{N}$ sensitive bands at $664 \mathrm{~cm}^{-1}, 550 \mathrm{~cm}^{-1}$, and $365 \mathrm{~cm}^{-1}$ in the spectrum of the parent molecule. The SER spectra

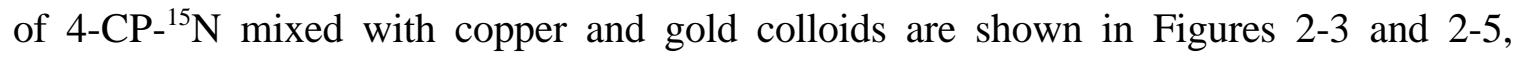
respectively, and the frequencies and tentative assignments are presented in Table 2-1. Shifts attributed to isotopic substitution are observed for $v(C \equiv N), \delta(C \equiv N)$, and the weak ring mode at $1490 \mathrm{~cm}^{-1}$ in the spectrum of $4-\mathrm{CP}_{-}{ }^{15} \mathrm{~N}$ on gold colloids. In addition, new bands are 


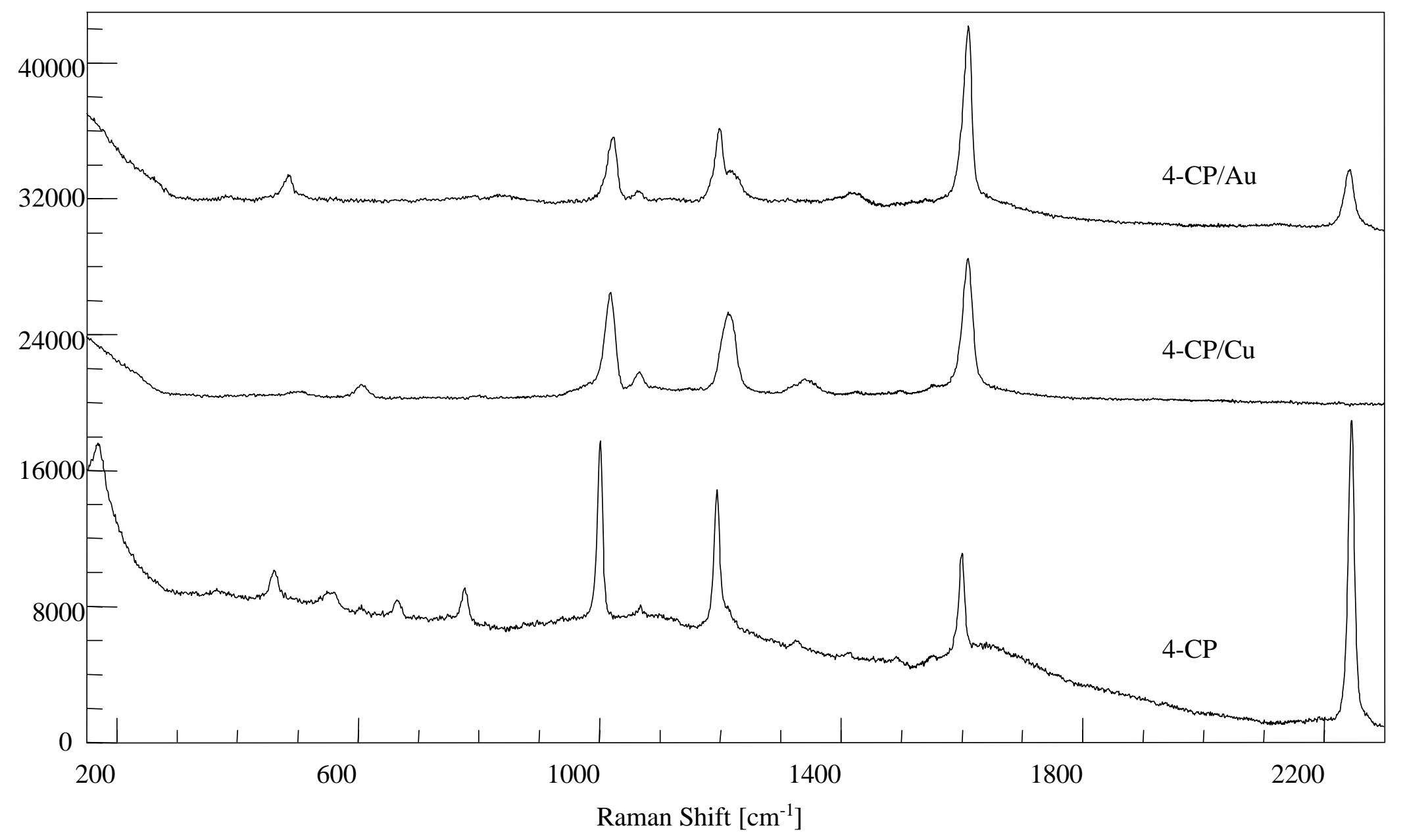

Figure 2-4 Raman spectra of 4-cyanopyridine (4-CP) and SERS of 4-CP adsorbed onto copper (/Cu) and gold $(/ \mathrm{Au})$ colloids. 


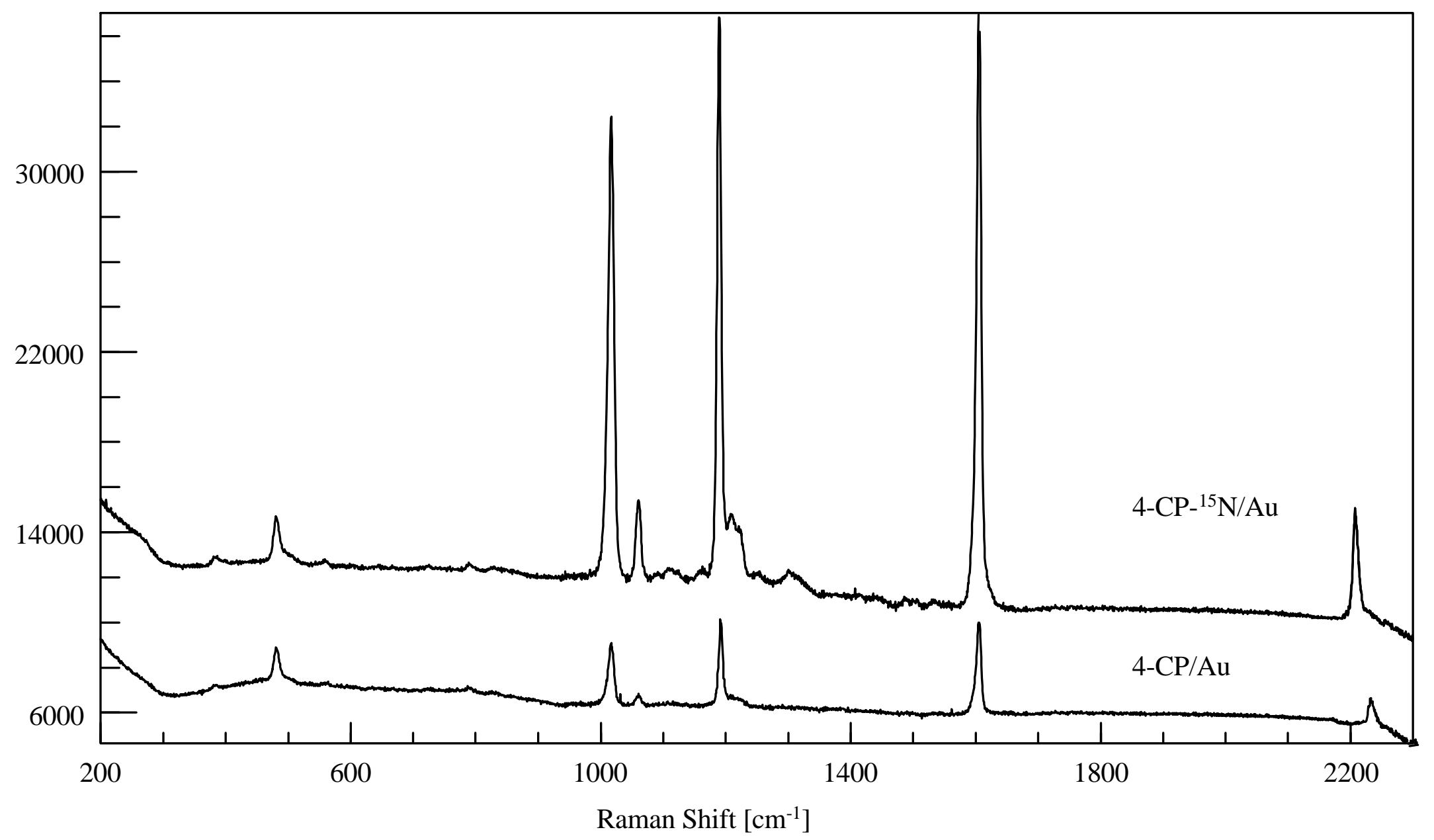

Figure 2-5 SERS of 4-cyanopyridine (4-CP) and isotopically labeled 4-cyanopyridine- ${ }^{15} \mathrm{~N}\left(4-\mathrm{CP}-{ }^{15} \mathrm{~N}\right)$ adsorbed onto gold (/Au) colloids. 
observed at $1310 \mathrm{~cm}^{-1}$ and $1255 \mathrm{~cm}^{-1}$ in the SER spectrum of $4-\mathrm{CP}_{-}{ }^{15} \mathrm{~N}$. The spectra observed for 4-CP and 4-CP- ${ }^{15} \mathrm{~N}$ with the gold colloids are consistent with adsorption of the molecule in an end-on orientation with primary interaction through the nitrogen in the ring. However, virtually identical spectra are observed for $4-\mathrm{CP}$ and $4-\mathrm{CP}_{-}{ }^{15} \mathrm{~N}$ on copper colloids. These experiments were carefully repeated and are reproducible. In addition, the spectra observed with the copper colloids contain no signals from modes that contain significant contributions from the $\mathrm{C} \equiv \mathrm{N}$ group. The fact that no isotopic frequency shifts are observed indicates that the $\mathrm{C} \equiv \mathrm{N}$ stretching normal mode does not couple with the ring modes and also indicates that the $\mathrm{C} \equiv \mathrm{N}$ moiety does not become a $\mathrm{C}=\mathrm{N}$ moiety and appear below $1700 \mathrm{~cm}^{-1}$.

The disappearance of the nitrile stretching signal in the SER spectra of 4-CP with copper colloids could be the result of observing the spectra of other species (not 4-CP) in the solution. For instance, we could observe the spectra of the colloid or its components. ${ }^{16}$ Raman spectra of copper colloids that we have collected show no observable bands. Garrell ${ }^{17}$ and coworkers reported that interferences due to borohydride would give rise to bands at $610 \mathrm{~cm}^{-1}$ and $920 \mathrm{~cm}^{-1}$, but with no observation of SERS. Although a band at $608 \mathrm{~cm}^{-1}$ in the spectrum of 4-CP with a copper colloid is reported, this signal is not observed in the spectrum of $4-\mathrm{CP}_{-}{ }^{15} \mathrm{~N}$, and a SER spectrum is observed. Therefore it is assumed that interference by borohydride is not occurring.

Chemical removal of the nitrile group with subsequent adsorption of a pyridine-like species is possible. The observed spectra does not support the possibility of a pyridine-like species since the collected spectrum is significantly different from the spectra observed for pyridine on copper surfaces. . $^{2,6,18}$ 
We believe that a reduction of the nitrile group by excess sodium borohydride from the colloid preparation is a reasonable explanation for the data observed when 4-CP interacts with a copper colloid mixture. ${ }^{19}$ We propose that a transition metal assisted borohydride reduction of the nitrile to an amine with the product (4-aminomethylpyridine) adsorbing to the colloid surface adequately accounts for the observed spectra. ${ }^{20}$ The reaction is depicted as follows.

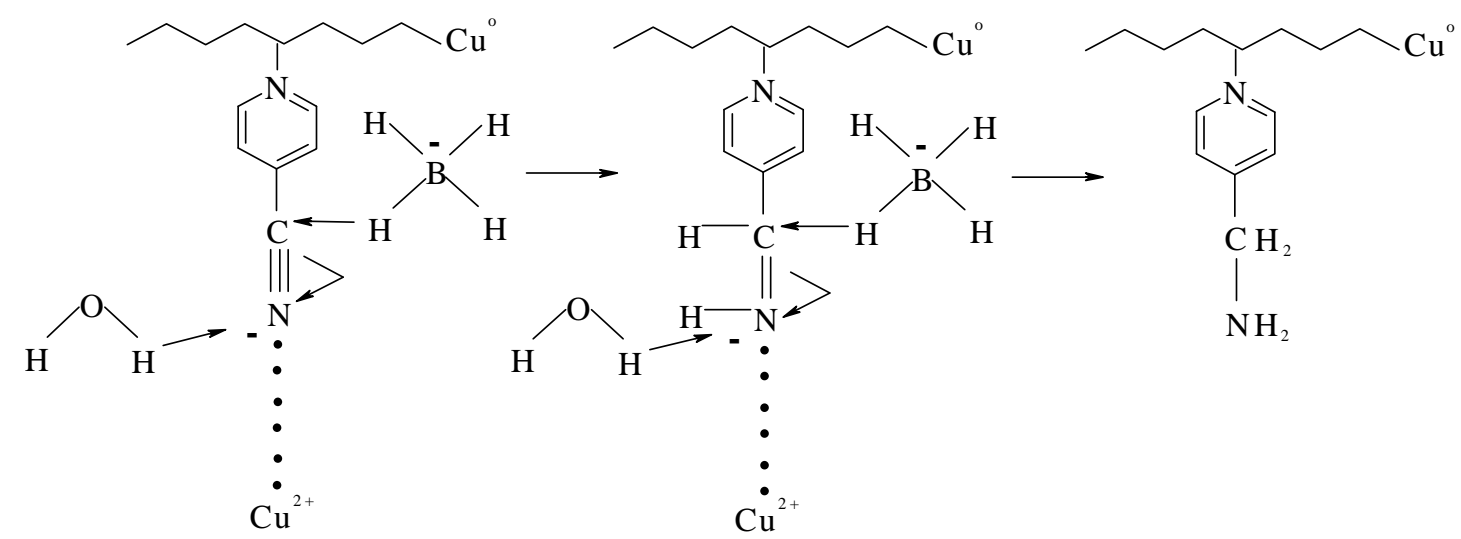

The spectra of 4-aminomethylpyridine (4-AMP), 4-AMP adsorbed onto a copper colloid and 4-CP mixed with a copper colloid are shown in Figure 2-6. It can be seen that 4AMP on a copper colloidal surface and 4-CP mixed with a copper colloid solution generate identical spectra within experimental error. The observed Raman frequencies and tentative assignments for neat 4-AMP, and 4-AMP and 4-CP with the copper colloids are presented in Table 2-2.

Our spectral patterns and frequencies are in agreement with the SER spectra collected for 4-AMP on silver electrodes ${ }^{21}$. This includes the doublet near $1210 \mathrm{~cm}^{-1}$ which is a distinguishing feature in the spectrum. This would indicate that the adsorbate is not altered 


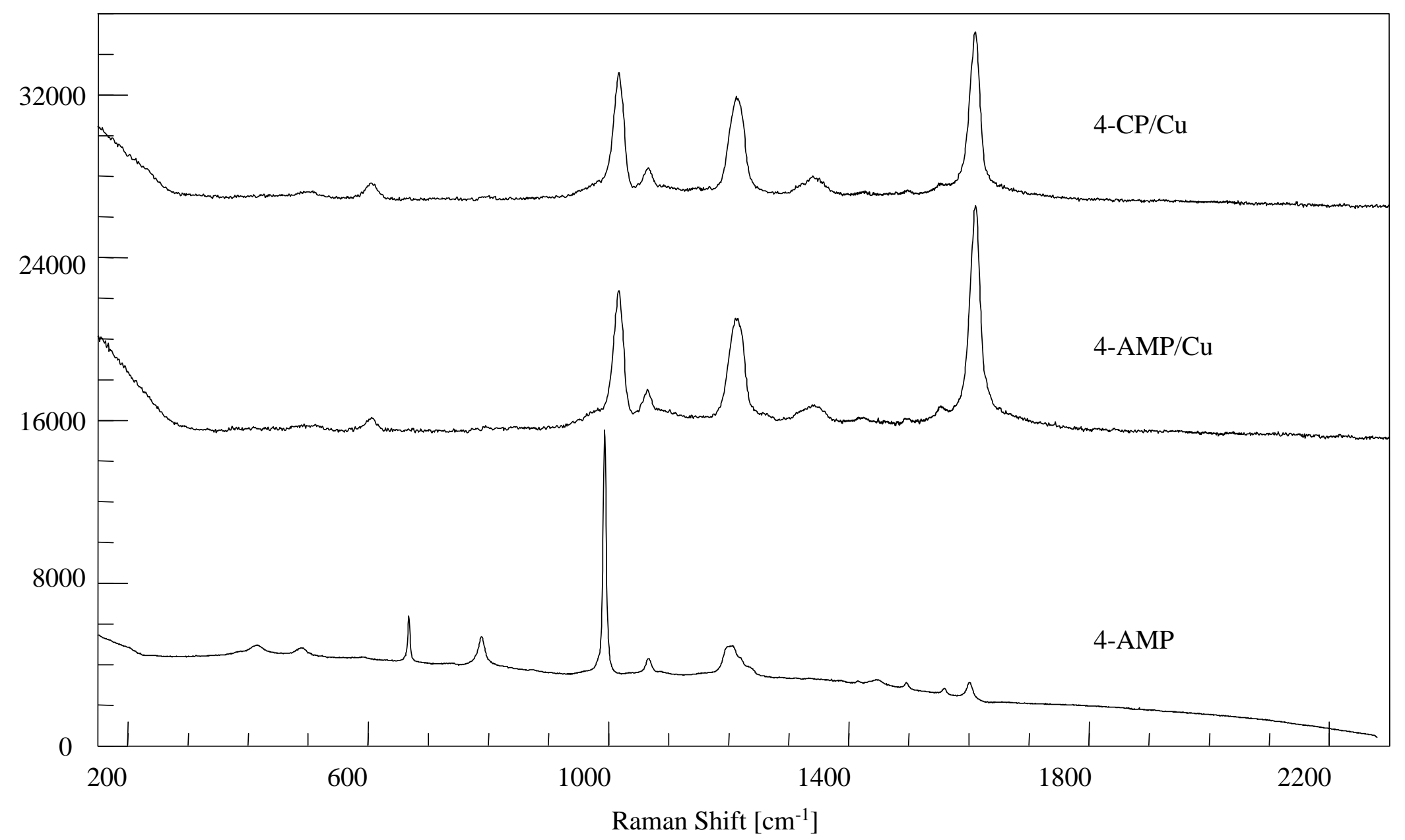

Figure 2-6 Raman spectra of 4-aminomethylpyridine (4-AMP) and SERS of 4-AMP and 4-CP adsorbed onto copper $(/ \mathrm{Cu})$ colloids. 
TABLE 2-2: Raman Frequencies $\left(\mathrm{cm}^{-1}\right)$ of Neat 4-Aminomethylpyridine (4-AMP) and Adsorbed on Copper (/Cu) Colloids and 4-Cyanopyridine (4-CP) Adsorbed on Copper Colloids.

\begin{tabular}{|c|c|c|c|}
\hline Assignment $^{\mathrm{a}}$ & 4-AMP liquid & 4-AMP/Cu & $4-\mathrm{CP} / \mathrm{Cu}$ \\
\hline $\mathrm{S}$ & 415 & - & - \\
\hline Ring deformation & 490 & 500 & 500 \\
\hline$\gamma\left(\mathrm{NH}_{2}\right)$ & 592 & 606 & 605 \\
\hline $\mathrm{S}$ & 667 & 664 & 668 \\
\hline$\gamma(\mathrm{CH})$ & 736 & - & - \\
\hline$v(C C)$ & 788 & 796 & 797 \\
\hline $\mathrm{S}$ & - & 841 & 841 \\
\hline$\beta(\mathrm{CH})$ & 876 & - & - \\
\hline Ring breathing & 994 & 1017 & 1018 \\
\hline$\beta\left(\mathrm{NH}_{2}\right), \beta(\mathrm{CH})$ & 1067 & 1064 & 1065 \\
\hline S & - & - & 1148 \\
\hline$\beta(\mathrm{CH})$ & 1206 & 1210 & 1212 \\
\hline$\beta(\mathrm{CH}), \alpha(\mathrm{CC})$ & 1219 & 1215 & 1216 \\
\hline $\mathrm{S}$ & 1232 & - & - \\
\hline$\beta(\mathrm{CH})$ & - & 1340 & 1339 \\
\hline $\mathrm{S}$ & 1416 & 1420 & 1423 \\
\hline$v(\mathrm{CC})$ & 1447 & - & - \\
\hline$v(\mathrm{CC})$ & 1497 & 1497 & 1498 \\
\hline$v(\mathrm{CC})$ & 1560 & 1552 & 1552 \\
\hline$v(C C)$ & 1602 & 1610 & 1609 \\
\hline
\end{tabular}

a. Based on Ref. 21 and 22. 
upon adsorption, and that the SERS is of 4-AMP on the surface of the copper surface. It is noted that 4-AMP adsorbs to the surface through the nitrogen in the pyridine ring as expected.

The gold colloids in the previously described experiments are prepared without borohydride as a reducing agent. The overall SER spectrum is consistent with adsorption through the nitrogen in the pyridine ring. We have prepared gold colloids using borohydride and have found that the signal due to $v(\mathrm{C} \equiv \mathrm{N})$ is still present. These results indicate that borohydride ions must act in concert with the copper metal and thus, the nature of the metal is important in the nitrile reduction process.

Deoxygenated copper colloids were utilized to determine whether oxidation of the copper surface is occurring and if this facilitates the reduction process. Copper colloids were prepared under anaerobic conditions (argon atmosphere) and the spectrum of 4-CP adsorbed onto these deoxygenated colloids is shown in Figure 2-7. The observed wavenumbers and tentative assignments are presented in Table 2-3. The aerobic and anaerobic samples give similar spectra. There are little to no shifts in the reported frequencies and the spectral patterns are identical. Based on these results, it can be stated that the presence or absence of oxygen does not facilitate nor hinder the transition metal-assisted reduction process.

The proposed reduction mechanism does not specify the oxidation state of the copper required for the reduction to occur. In order to address this issue, the preparation of copper colloids was performed using various forms of copper $\left(\mathrm{Cu}^{+2}\right.$, and $\left.\mathrm{Cu}^{+1}\right)$. The SERS collected for the different oxidation states of copper are shown in Figure 2-8. The observed wavenumbers and tentative assignments are reported in Table 2-3. Based on the spectral 


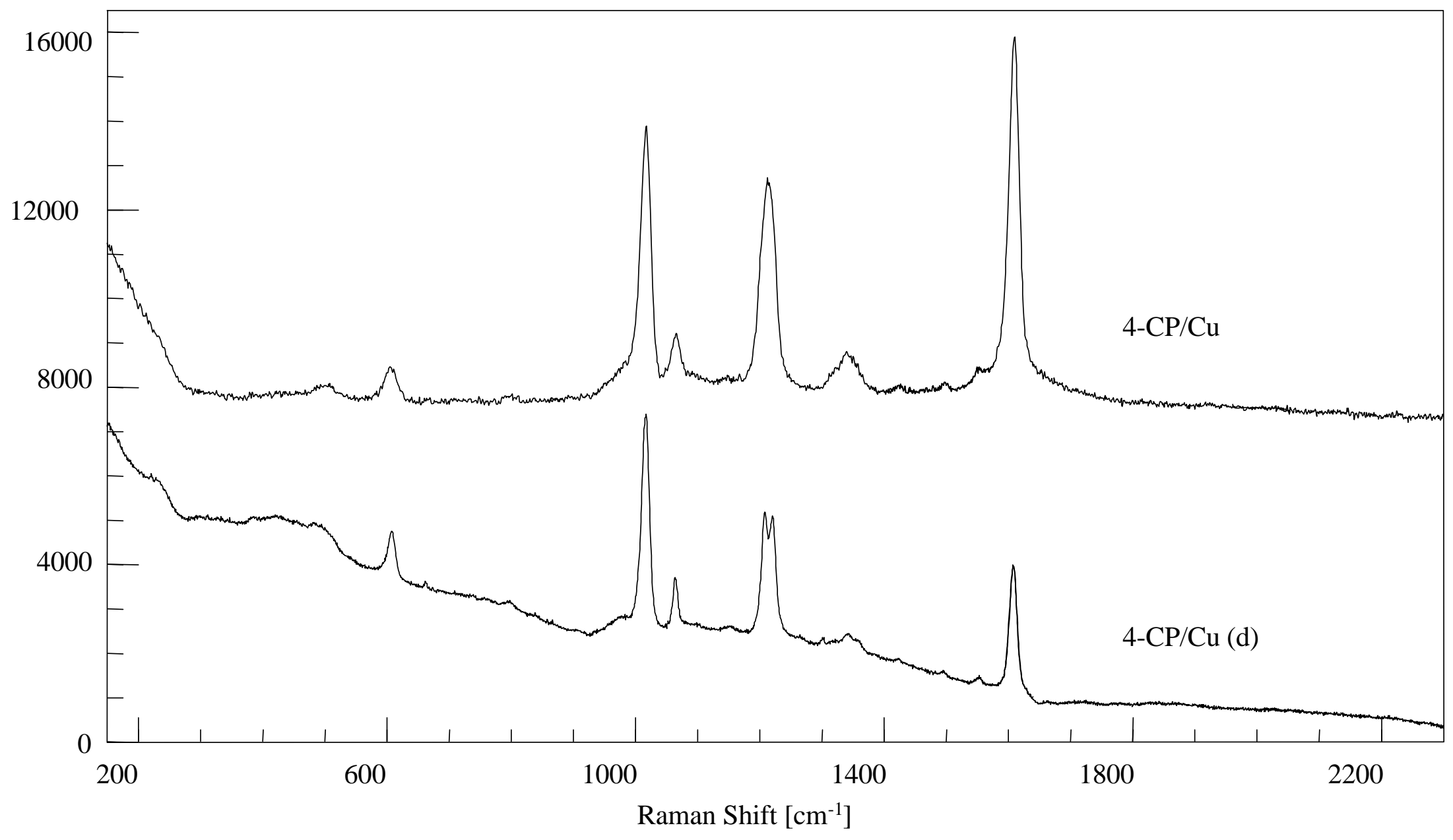

Figure 2-7 SERS of 4-cyanopyridine (4-CP) adsorbed onto copper colloids prepared under aerobic (/Cu) and deoxygenated $(/ \mathrm{Cu}(\mathrm{d}))$ conditions. 
TABLE 2-3: Raman Frequencies $\left(\mathrm{cm}^{-1}\right)$ of 4-Cyanopyridine (4-CP) Adsorbed on Copper Colloids Prepared From $\mathrm{Cu}^{+2}\left(/ \mathrm{Cu}^{\circ}(\mathrm{II})\right), \mathrm{Cu}^{+1}\left(/ \mathrm{Cu}^{\circ}(\mathrm{I})\right)$ and Under Deoxygenated Conditions $(/ \mathrm{Cu}(\mathrm{d}))$.

\begin{tabular}{|c|c|c|c|}
\hline Assignment $^{\mathrm{a}}$ & $4-\mathrm{CP} / \mathrm{Cu}^{\circ}(\mathrm{II})$ & $4-\mathrm{CP} / \mathrm{Cu}^{\circ}(\mathrm{I})$ & 4-CP/Cu (d) \\
\hline $\mathrm{S}$ & - & 390 & 385 \\
\hline Ring deformation & 500 & 505 & 492 \\
\hline$\gamma\left(\mathrm{NH}_{2}\right)$ & 605 & 611 & 607 \\
\hline $\mathrm{S}$ & - & 649 & - \\
\hline $\mathrm{S}$ & 668 & 665 & - \\
\hline$v(\mathrm{CC})$ & 797 & 799 & 797 \\
\hline $\mathrm{S}$ & 841 & 842 & - \\
\hline Ring breathing & 1018 & 1017 & 1016 \\
\hline$\beta\left(\mathrm{NH}_{2}\right), \beta(\mathrm{CH})$ & 1065 & 1064 & 1064 \\
\hline $\mathrm{S}$ & 1148 & 1154 & 1151 \\
\hline$\beta(\mathrm{CH})$ & 1212 & 1208 & 1207 \\
\hline$\beta(\mathrm{CH}), \alpha(\mathrm{CC})$ & 1216 & 1219 & 1219 \\
\hline $\mathrm{S}$ & - & 1261 & 1263 \\
\hline$\beta(\mathrm{CH})$ & 1339 & 1340 & 1343 \\
\hline $\mathrm{S}$ & 1423 & 1424 & 1422 \\
\hline$v(\mathrm{CC})$ & 1498 & 1495 & 1496 \\
\hline$v(C C)$ & 1552 & 1553 & 1553 \\
\hline$v(\mathrm{CC})$ & 1609 & 1608 & 1608 \\
\hline
\end{tabular}

a. Based on Ref. 21 and 22. 


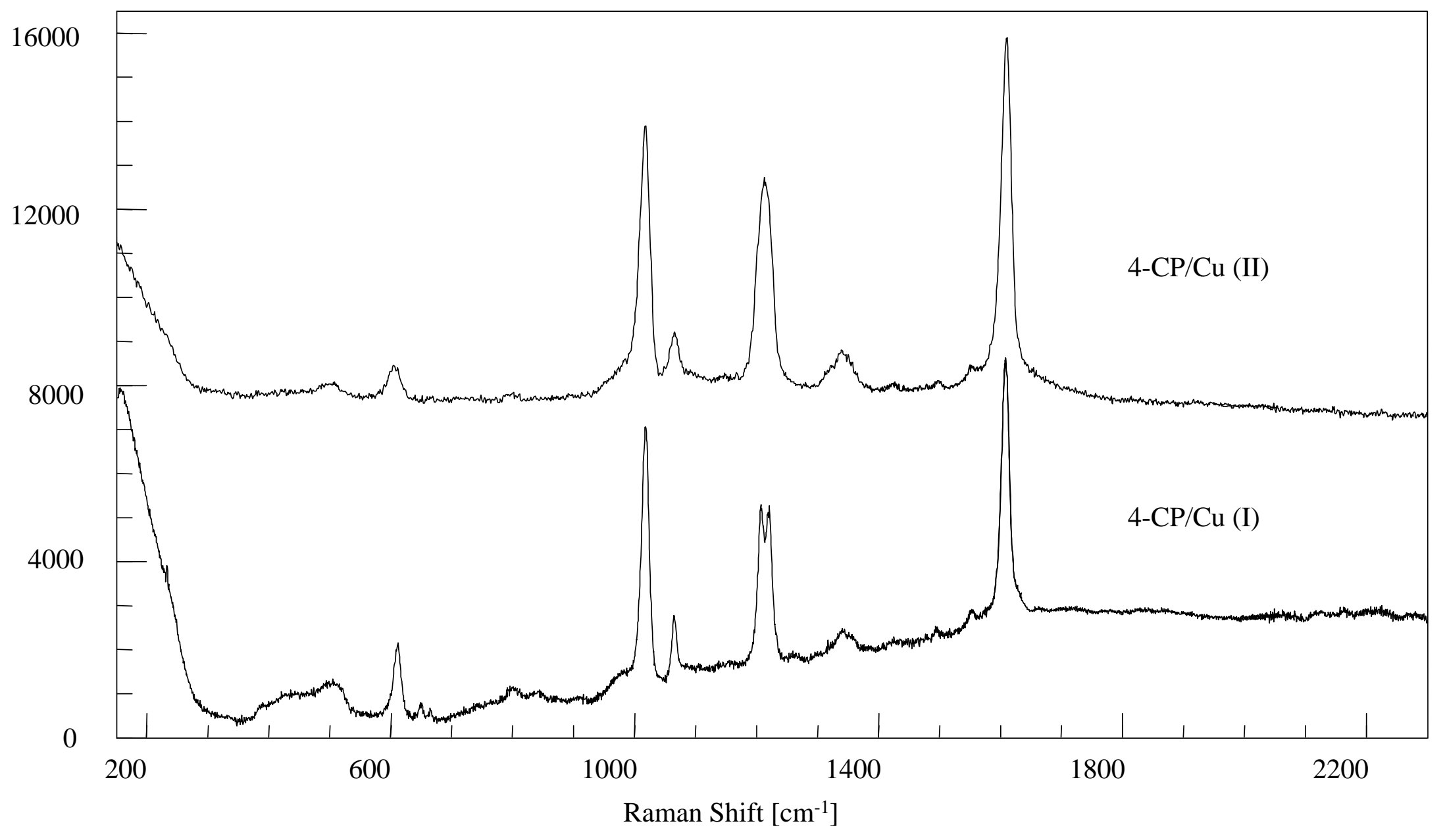

Figure 2-8 SERS of 4-cyanopyridine (4-CP) adsorbed onto copper colloids prepared from $\mathrm{Cu}^{+1}\left(/ \mathrm{Cu}^{(\mathrm{I}))}\right.$ and $\mathrm{Cu}^{+2}$ $(/ \mathrm{Cu}(\mathrm{II}))$ reduction. 
data for the preparation using $\mathrm{Cu}^{+2}$ and $\mathrm{Cu}^{+1}$ the initial state of the copper used is not important. We should also note that the excess of borohydride in solution precludes the existence of copper ions in the colloidal media; i.e., reduction of all copper ions occurs. ${ }^{23}$ Thus, the reduction is facilitated by $\mathrm{Cu}^{\circ}$ in the colloidal state.

In order to verify that colloidal copper metal is required for the reduction of the nitrile group, a series of experiments in which we added gold colloid to the 4-CP/copper colloid system and copper (II) colloid to the 4-CP/gold colloid system were completed. The SERS collected in these experiments are seen in Figures 2-9, 2-10, 2-11 and 2-12. Initially, 4-CP was adsorbed onto the surface of a gold colloid (this being the point of reference with the observation of a nitrile stretching band at $2243 \mathrm{~cm}^{-1}$ ). In order to determine if the presence of $\mathrm{Cu}^{+2}$ facilitates the reduction of the nitrile group, $\mathrm{Cu}(\mathrm{II}) \mathrm{SO}_{4}$ was added to the 4-CP/Au (as seen in Figure 2-9). The resulting SER spectrum is identical to 4-CP/Au. An increase in SERS intensity is observed upon the addition of the $\mathrm{Cu}(\mathrm{II}) \mathrm{SO}_{4}$ is due to $\mathrm{SO}_{4}{ }^{2-}$ ions. The presence of $\mathrm{SO}_{4}{ }^{2-}$ ions has been known to promote aggregation of colloidal systems which causes an increase in the observed SER signal. ${ }^{24}$ In order to further determine that the $\mathrm{Cu}^{+2}$ is not an important factor, $\mathrm{BH}_{4}^{-}$was added to 4-CP/Au containing $\mathrm{Cu}(\mathrm{II}) \mathrm{SO}_{4}$. As shown in Figure 2-9, the SERS are identical for all three cases and so the addition of $\mathrm{Cu}^{+2}$ with borohydride plays no role in the metal-assisted reduction of the nitrile group of 4-CP. Thus, the presence of $\mathrm{Cu}^{+2}$ and $\mathrm{BH}_{4}^{-}$does not catalyze the reduction of the nitrile group. This is consistent with prior studies involving $\mathrm{Cu}^{+2} \cdot{ }^{25}$ 


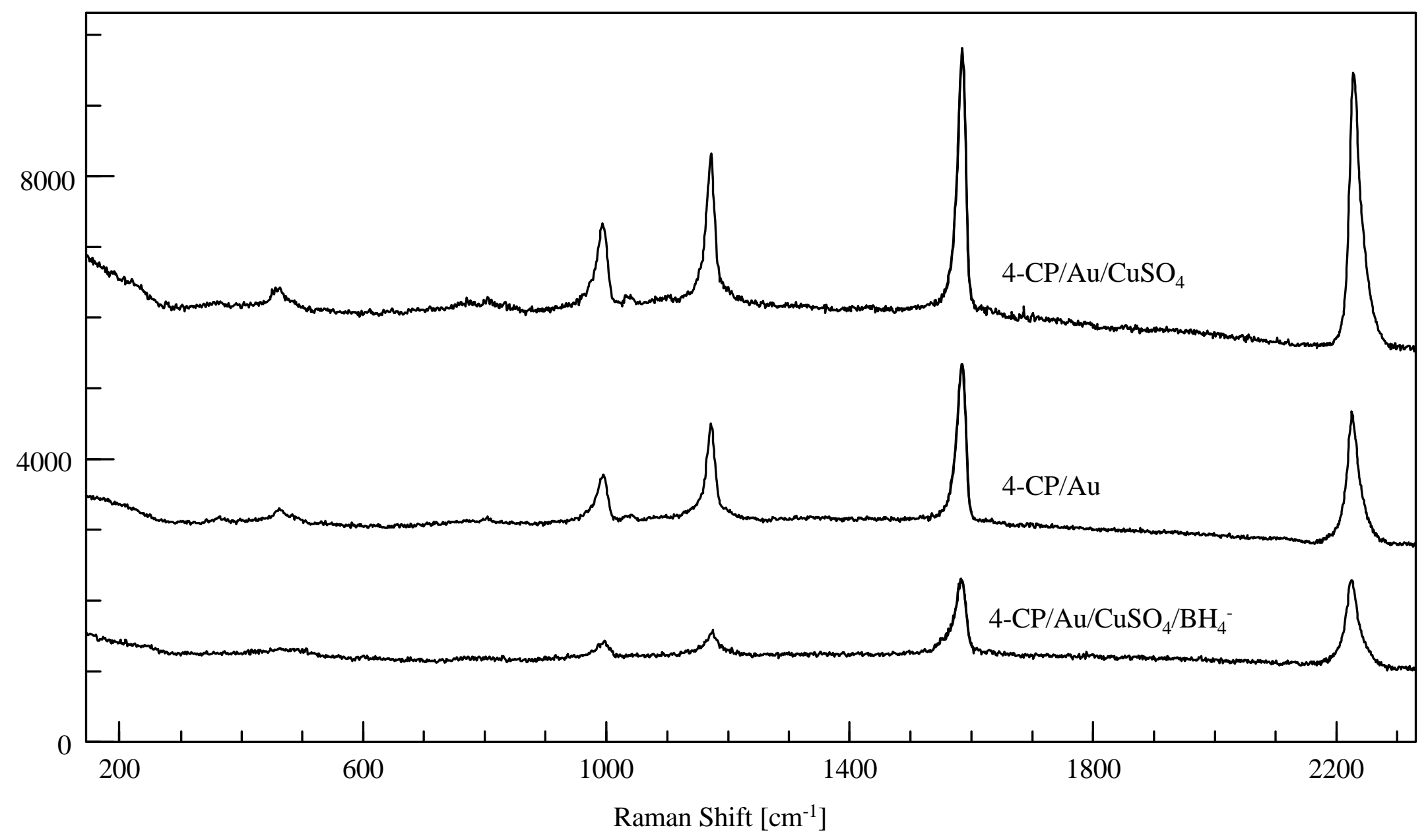

Figure 2-9 SERS of 4-cyanopyridine (4-CP) adsorbed onto a gold colloid (/Au), a gold colloid with $\mathrm{CuSO}_{4}$ added $\left(/ \mathrm{Au} / \mathrm{CuSO}_{4}\right)$, and a gold colloid with $\mathrm{CuSO}_{4}$ and borohydride added $\left(/ \mathrm{Au} / \mathrm{CuSO}_{4} / \mathrm{BH}_{4}{ }^{-}\right)$. 


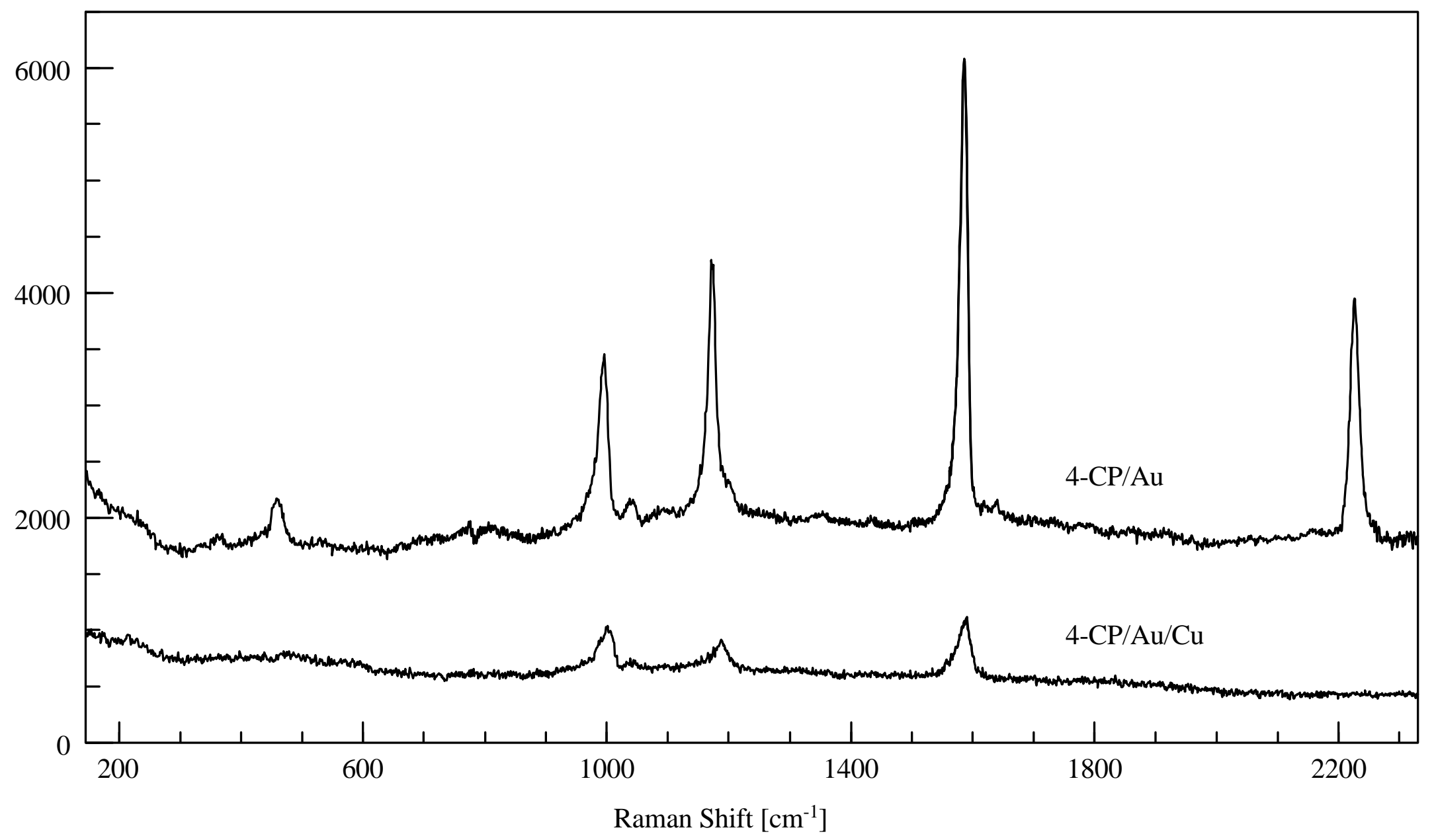

Figure 2-10 SERS of 4-cyanopyridine (4-CP) adsorbed onto a gold colloid (/Au) and after the addition of a copper colloid (/4-CP/Au/Cu). 


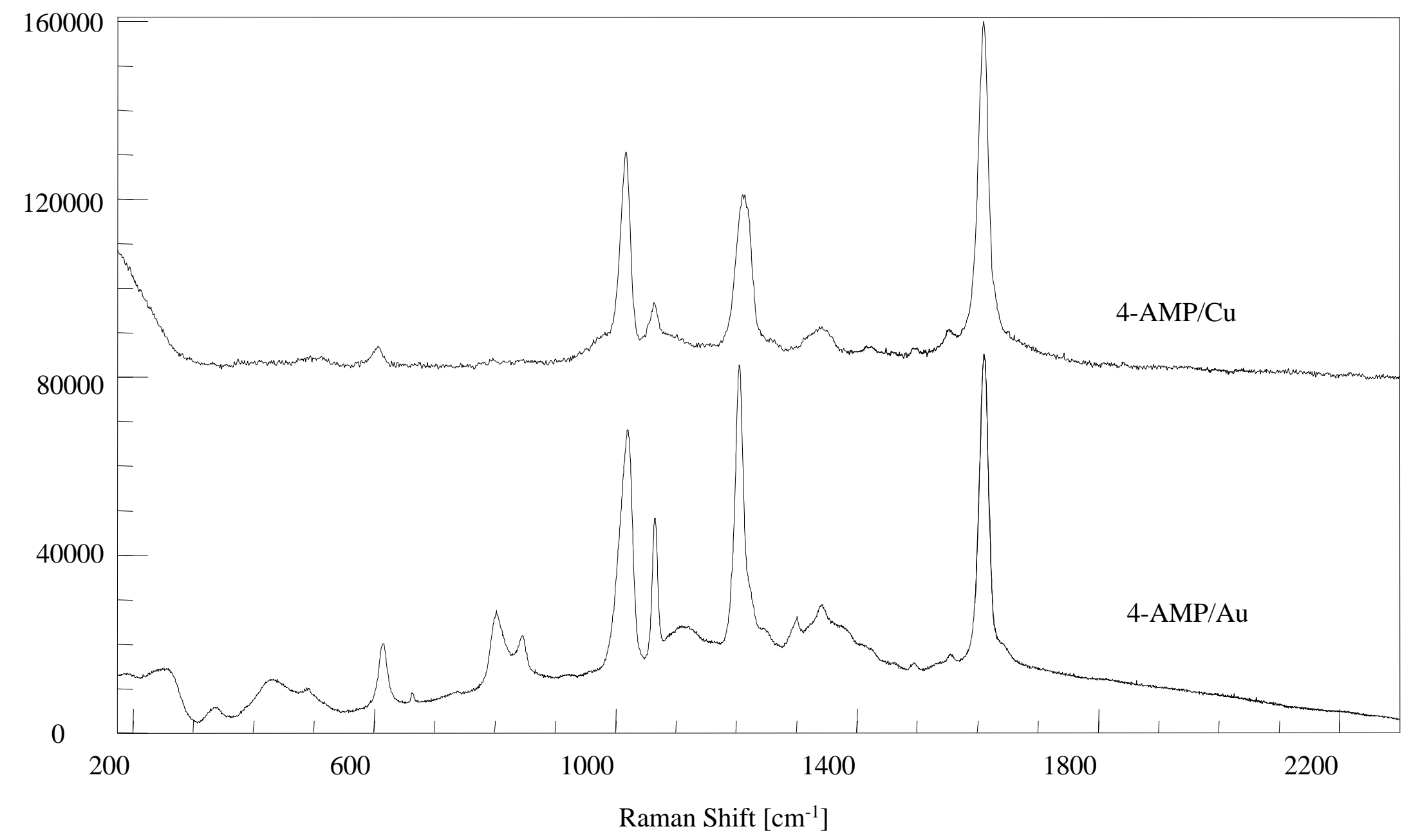

Figure 2-11 SERS of 4-aminomethylpyridine (4-AMP) adsorbed on gold (Au/) and copper (/Cu) colloids. 


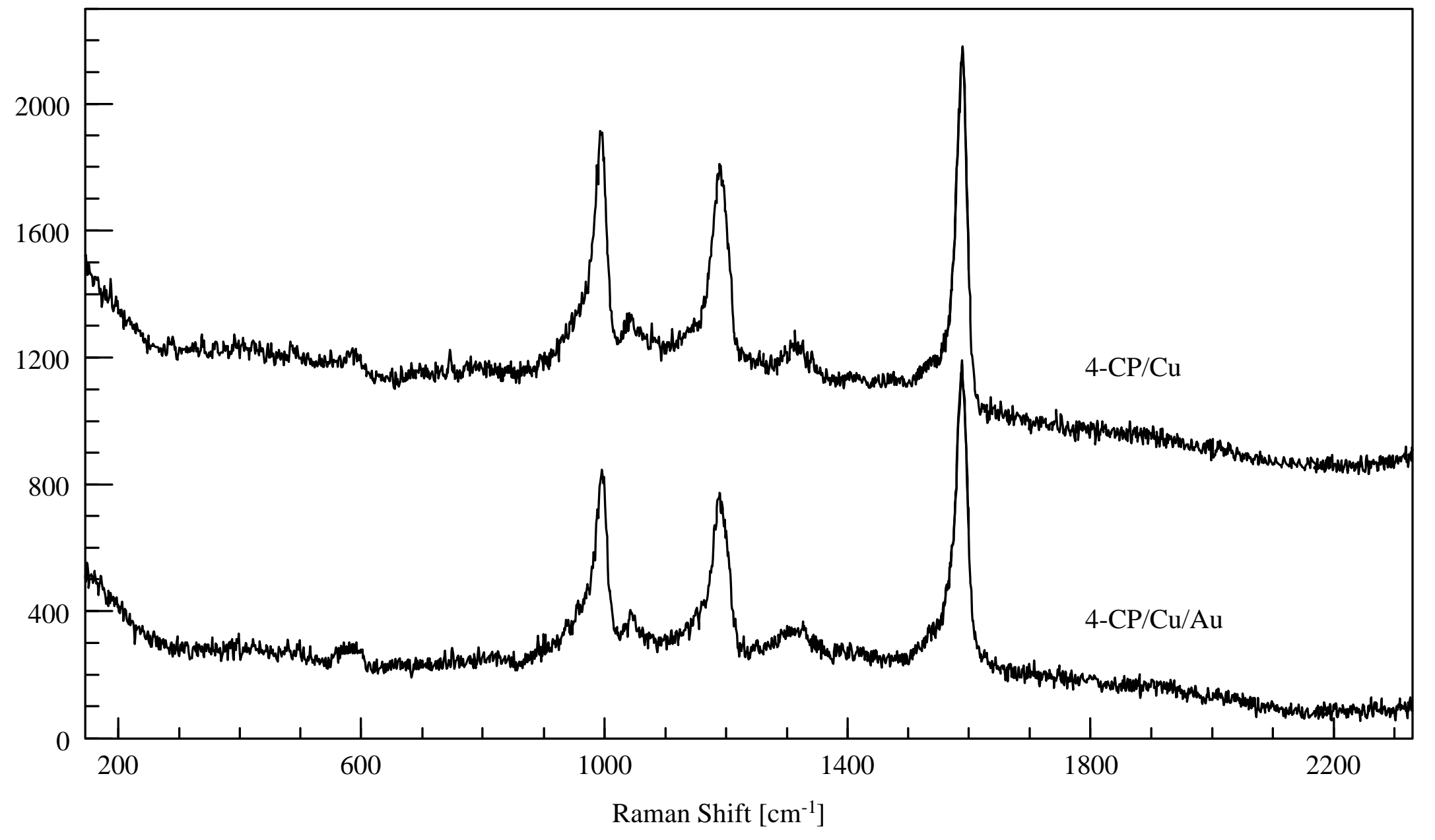

Figure 2-12 SERS of 4-cyanopyridine (4-CP) adsorbed onto a copper colloid (/Cu) and after the addition of a gold colloid (/4-CP/Cu/Au). 
The role of $\mathrm{Cu}^{\circ}$ in the colloidal form in the reduction of the nitrile group was investigated and the results are shown in Figures 2-10, 2-11 and 2-12. 4-CP was adsorbed onto a gold colloid (see Figure 2-10). To this system, a copper colloid (consisting of $\mathrm{Cu}^{\circ}$ and $\left.\mathrm{BH}_{4}^{-}\right)$was added. The resulting SERS shows a disappearance of $v(\mathrm{C} \equiv \mathrm{N})$ and produces a spectrum identical to that collected for 4-CP mixed with a copper colloid. This indicates that the presence of $\mathrm{Cu}^{\circ}$ in colloidal form is necessary for reduction of the nitrile substituent. This does not, however, indicate whether we are observing the reduction product of 4-CP on the surface of a copper colloid or a gold colloid. In order to determine this, 4-AMP was adsorbed on a gold colloid for comparison with 4-AMP on a copper colloid (see Figure 2-11). The spectral patterns show distinct differences which suggest that the SERS observed for 4$\mathrm{CP}$ adsorbed on a gold colloid and copper colloid mixture is that of 4-AMP on a copper colloid (refer back to Figure 2-10). The opposite experiment was carried out and the results are shown in Figure 2-12. For this particular case, 4-CP was mixed with a copper colloid and then a gold colloid was added to the system. There was no observable change in the SERS. This indicates that the addition of a gold colloid does not reverse the reduction of the nitrile substituent or remove the 4-AMP from the copper colloidal surface. Thus, colloidal $\mathrm{Cu}^{\circ}$ facilitates reduction of the nitrile group with no indications of a reversible process.

The issue of timing of the reaction was addressed. In prior investigations utilizing an electrode surface, a reduction of 4-cyanopyridine to 4-aminomethylpyridine was performed. ${ }^{4}$ The reduction reaction involved a step in which the molecule was adsorbed flat onto the metal surface before the complete transfer of an electron from the molecule to the metal could occur. In the explanation of that reaction, the molecule must first interact with the metal 
surface in a flat-on orientation, then subsequently undergo a reduction of the nitrile substituent to an amino group. Thus, the reduction involves a step in which the molecule is adsorbed before the complete transfer of an electron occurs between the metal and the molecule.

A series of concentration experiments were performed to investigate the orientation of the 4-CP mixed with both gold and copper colloids. The SERS for these experiments are shown in Figures 2-13, 2-14 and 2-15. The observed Raman frequencies and tentative assignments are reported in Table 2-4. The adsorbate concentrations were varied from $0.2 \mathrm{M}$ to $1 \times 10^{-6} \mathrm{M}$ and the same preparation methods were used for the colloidal samples. The detection of Raman bands of the free molecule in aqueous solution begins at concentrations of $1 \times 10^{-2} \mathrm{M}$. Based on the SERS of 4-CP on a gold colloid, the $v(\mathrm{C} \equiv \mathrm{N})$ band present at $2238 \mathrm{~cm}^{-1}$ is indicative of an end-on orientation. Since the 4-CP undergoes a reduction of the nitrile substituent upon adsorption onto a copper colloid, $v(C \equiv N)$ is not observed and the orientation is assumed to be in a flat-on fashion based on prior discussion (vide supra).

The SER spectra of the various concentrations of 4-CP mixed with copper colloids demonstrate a difference in spectral pattern and frequencies at higher concentrations. The differences in SER spectra begin at adsorbate concentrations of $5.7 \times 10^{-2} \mathrm{M}$. At this particular solution, the concentration of the 4-CP is equivalent to that of the borohydride in the colloidal system. At concentrations of 4-CP above that of the borohydride, a band in the nitrile stretching region is still not detected until a concentration of 4-CP at $2.9 \times 10^{-2} \mathrm{M}$ is 


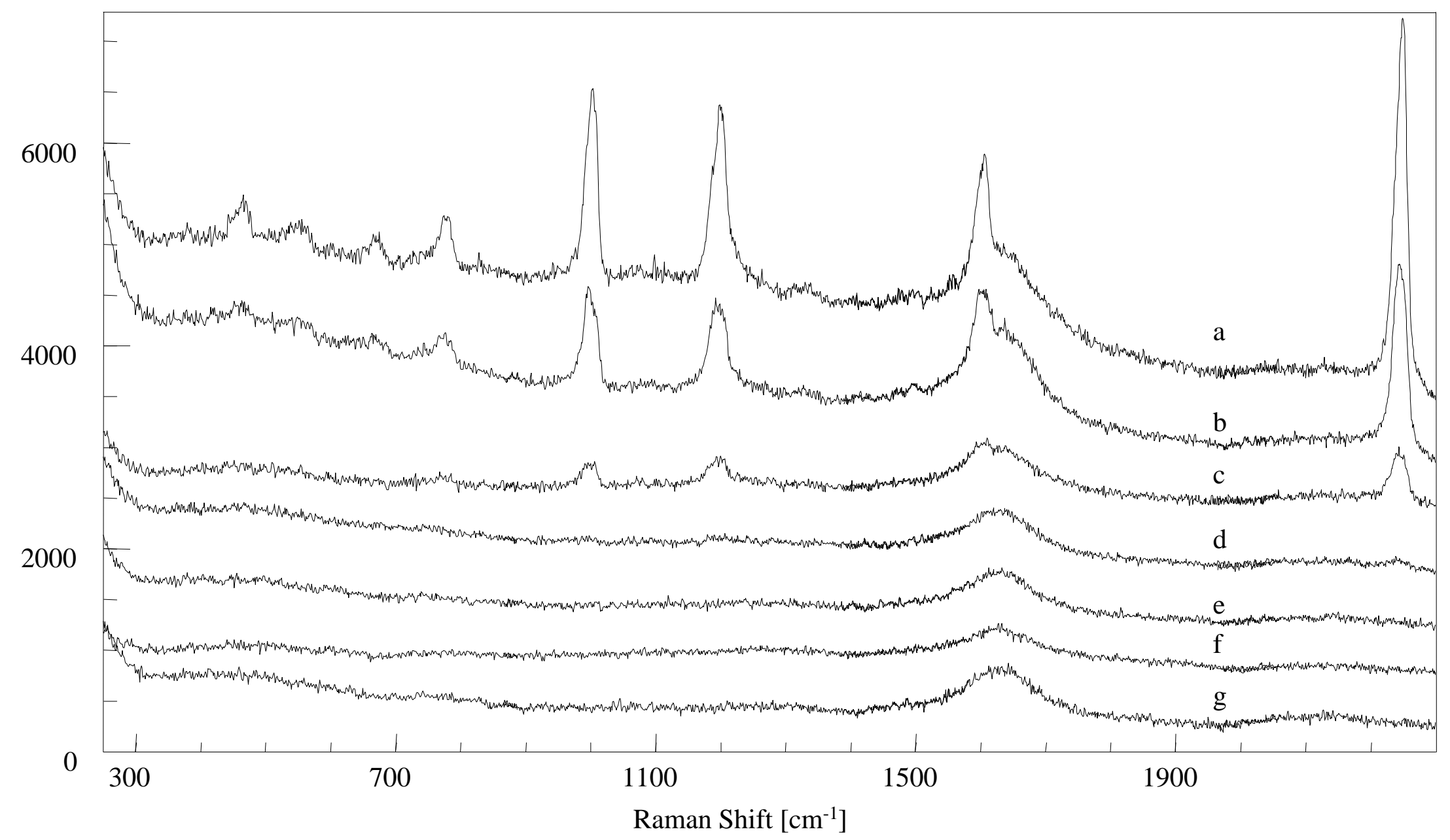

Figure 2-13 Raman spectra of 4-cyanopyridine (4-CP) in aqueous solutions: (a) $0.2 \mathrm{M}$, (b) $0.1 \mathrm{M}$, (c) $6.56 \times 10^{-2} \mathrm{M}$, (d) $0.01 \mathrm{M}$, (e) $1 \times 10^{-3} \mathrm{M}$, (f) $1 \times 10^{-4} \mathrm{M}$, and (g) $1 \times 10^{-6} \mathrm{M}$. 


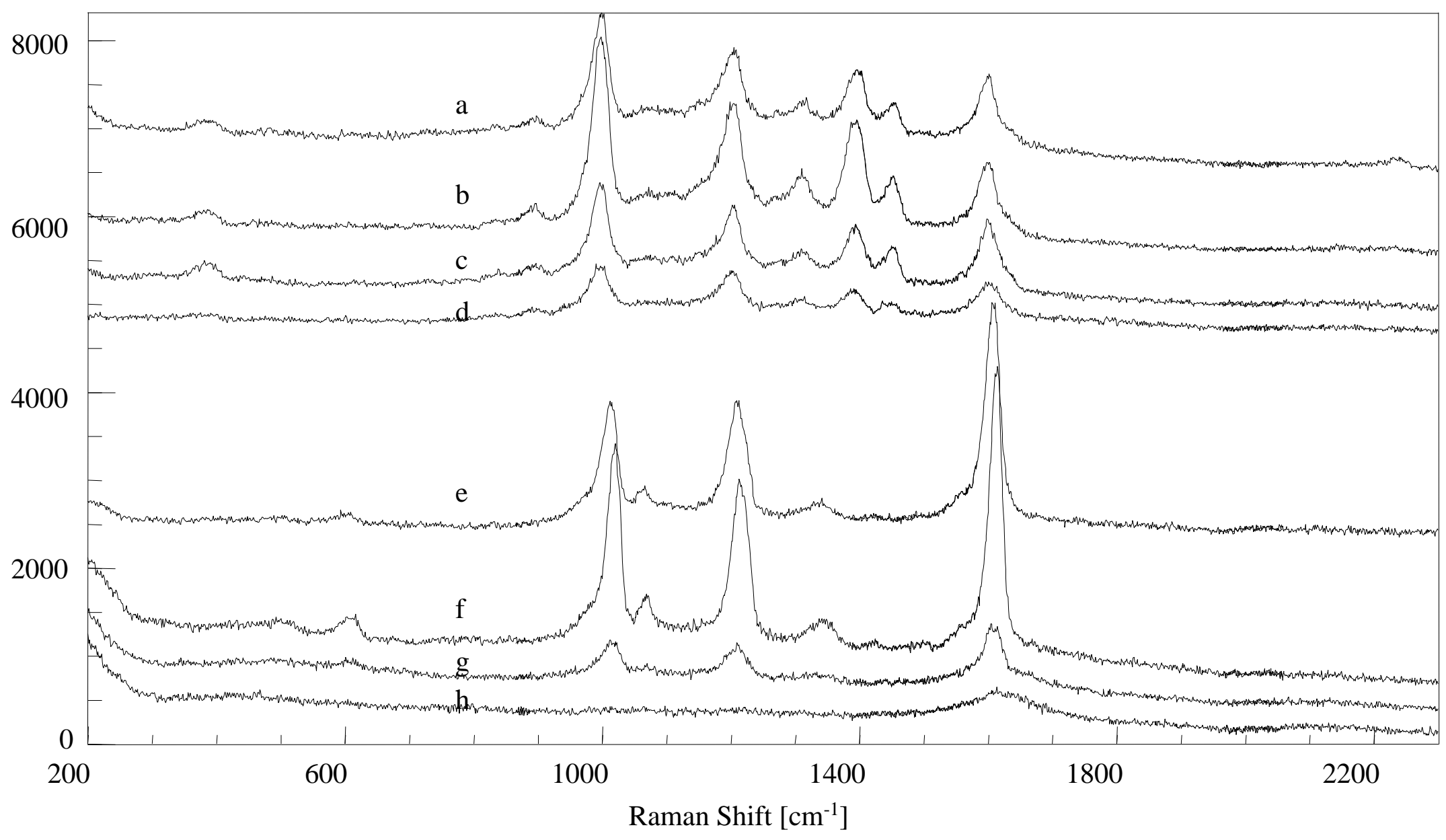

Figure 2-14 SERS of 4-cyanopyridine (4-CP) adsorbed onto copper colloids at various concentrations: (a) $0.2 \mathrm{M}$ $(600 \mu \mathrm{L}),(\mathrm{b}) 0.2 \mathrm{M}(300 \mu \mathrm{L}),(\mathrm{c}) 0.1 \mathrm{M}(300 \mu \mathrm{L})$, (d) $6.56 \times 10^{-2} \mathrm{M}(300 \mu \mathrm{L}),(\mathrm{e}) 0.01 \mathrm{M}(300 \mu \mathrm{L})$, (f) $1 \times 10^{-3} \mathrm{M}(300 \mu \mathrm{L}),(\mathrm{g}) 1 \times 10^{-4} \mathrm{M}(300 \mu \mathrm{L})$, and (h) $1 \times 10^{-6} \mathrm{M}(300 \mu \mathrm{L})$. 


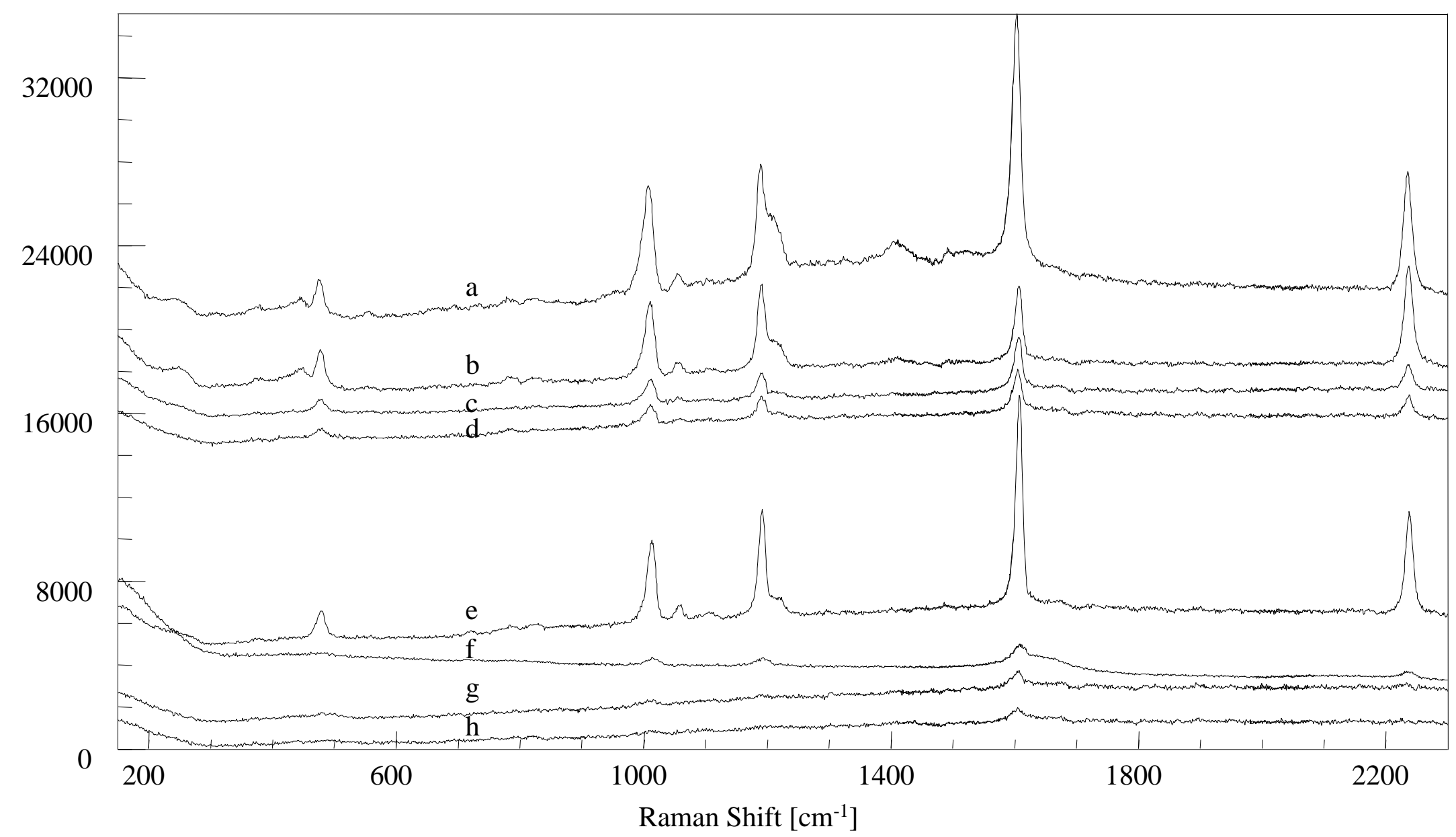

Figure 2-15 SERS of 4-cyanopyridine (4-CP) adsorbed onto gold colloids at various concentrations: (a) $0.2 \mathrm{M}$ $(600 \mu \mathrm{L})$, (b) $0.2 \mathrm{M}(300 \mu \mathrm{L}),(\mathrm{c}) 0.1 \mathrm{M}(300 \mu \mathrm{L})$, (d) $6.56 \times 10^{-2} \mathrm{M}(300 \mu \mathrm{L}),(\mathrm{e}) 0.01 \mathrm{M}(300 \mu \mathrm{L})$, (f) $1 \times 10^{-3} \mathrm{M}(300 \mu \mathrm{L}),(\mathrm{g}) 1 \times 10^{-4} \mathrm{M}(300 \mu \mathrm{L})$, and (h) $1 \times 10^{-6} \mathrm{M}(300 \mu \mathrm{L})$. 
TABLE 2-4: Raman Frequencies $\left(\mathrm{cm}^{-1}\right)$ of 4-Cyanopyridine (4-CP) Adsorbed onto Copper (/Cu) Colloids at Various Concentrations.

\begin{tabular}{lllllll}
\hline \hline Assignment $^{\mathrm{a}}$ & & & & & & \\
& $\begin{array}{l}4-\mathrm{CP} / \mathrm{Cu} \\
\left(2.9 \times 10^{-2} \mathrm{M}\right)^{\mathrm{b}}\end{array}$ & $\begin{array}{l}4-\mathrm{CP} / \mathrm{Cu} \\
\left(1.7 \times 10^{-2} \mathrm{M}\right)\end{array}$ & $\begin{array}{l}4-\mathrm{CP} / \mathrm{Cu} \\
\left(8.7 \times 10^{-3} \mathrm{M}\right)\end{array}$ & $\begin{array}{l}4 \mathrm{CP} / \mathrm{Cu} \\
\left(5.7 \times 10^{-3} \mathrm{M}\right)\end{array}$ & $\begin{array}{l}4-\mathrm{CP} / \mathrm{Cu} \\
\left(8.7 \times 10^{-4} \mathrm{M}\right)\end{array}$ & $\begin{array}{l}4-\mathrm{CP} / \mathrm{Cu} \\
\left(8.7 \times 10^{-5} \mathrm{M}\right)\end{array}$ \\
& $(0.2 \mathrm{M})$ & $(0.2 \mathrm{M})$ & $(0.1 \mathrm{M})$ & $\left(6.56 \times 10^{-2} \mathrm{M}\right)$ & $(0.01 \mathrm{M})$ & $\left(1 \times 10^{-3} \mathrm{M}\right)$ \\
\hline \hline
\end{tabular}

\begin{tabular}{|c|c|c|c|c|c|c|}
\hline S & - & 298 & 303 & - & - & - \\
\hline $\mathrm{C} \equiv \mathrm{N}$ sensitive & 386 & 386 & 387 & 391 & - & \\
\hline Ring deformation & - & - & - & - & 502 & 499 \\
\hline$\gamma\left(\mathrm{NH}_{2}\right)$ & - & - & - & - & 604 & 608 \\
\hline$\gamma(\mathrm{CH})$ & 835 & 834 & 838 & 834 & - & - \\
\hline$S^{\prime}$ & 898 & 895 & 895 & 893 & - & - \\
\hline ring breathing & 998 & 998 & 998 & 998 & 1012 & 1020 \\
\hline$\beta\left(\mathrm{NH}_{2}\right), \beta(\mathrm{CH})$ & - & - & - & - & 1065 & 1069 \\
\hline$S^{21}$ & - & 1107 & 1109 & - & - & - \\
\hline $\bar{S}$ & 1150 & - & 1151 & - & - & - \\
\hline$\beta(\mathrm{CH})$ & 1204 & 1203 & 1204 & 1201 & 1208 & 1213 \\
\hline$\beta(\mathrm{CH}), \alpha(\mathrm{CC})$ & - & - & - & - & 1217 & 1220 \\
\hline $\mathrm{S}$ & 1270 & 1268 & 1275 & - & - & - \\
\hline$S$ & 1312 & 1310 & 1310 & 1307 & - & - \\
\hline$\beta(\mathrm{CH})$ & - & - & - & - & 1340 & 1342 \\
\hline$v(C C, C \equiv N)$ & 1395 & 1394 & 1394 & 1391 & - & - \\
\hline $\mathrm{S}$ & - & - & - & - & 1421 & 1423 \\
\hline$v(C C)$ & 1453 & 1451 & 1451 & 1447 & - & - \\
\hline$v(C C)$ & - & - & - & - & - & 1496 \\
\hline$v(C C)$ & 1600 & 1600 & 1598 & 1600 & 1607 & 1610 \\
\hline$v(C \equiv N)$ & 2238 & - & - & - & - & - \\
\hline
\end{tabular}

b. Final concentration of 4-CP in copper system. 
present. The appearance of new SER bands and frequencies in the spectra could be due to two possibilities. First, the increase in adsorbate concentration and resulting change in surface orientation (flat-on to end-on) would cause the enhancement of new SER bands (based on symmetry rules). Second, the nitrile reduction ceases due to lack of copper and borohydride ions and the observed SERS is of both 4-CP and 4-AMP adsorbed on the copper surface. Bands at $391 \mathrm{~cm}^{-1}(\mathrm{C} \equiv \mathrm{N}$ sensitive $), 834 \mathrm{~cm}^{-1}\left(\gamma\left(\mathrm{NH}_{2}\right)\right), 895 \mathrm{~cm}^{-1}, 1307 \mathrm{~cm}^{-1}, 1391 \mathrm{~cm}^{-1}$ $(v(C C, C \equiv N))$, and $1447 \mathrm{~cm}^{-1}(v(C C))$ indicate the presence of both 4-CP and 4-AMP on the metal surface. The disappearance of bands associated with 4-AMP at $502 \mathrm{~cm}^{-1}$ (Ring deformation), $604 \mathrm{~cm}^{-1}\left(\gamma\left(\mathrm{NH}_{2}\right)\right), 1065 \mathrm{~cm}^{-1}\left(\beta\left(\mathrm{NH}_{2}\right), \beta(\mathrm{CH})\right), 1217 \mathrm{~cm}^{-1}(\beta(\mathrm{CH}), \alpha(\mathrm{CC}))$, $1340 \mathrm{~cm}^{-1}(\beta(\mathrm{CH})), 1421 \mathrm{~cm}^{-1}$, and $1496 \mathrm{~cm}^{-1}(\mathrm{v}(\mathrm{CC}))$ suggest that the observed molecule on the surface is no longer predominantly the amino species. The shifts to lower energies in the modes associated with the aromatic ring at $998 \mathrm{~cm}^{-1}$ (ring breathing), $1201 \mathrm{~cm}^{-1}(\beta(\mathrm{CH}))$, and $1600 \mathrm{~cm}^{-1}(\mathrm{v}(\mathrm{CC}))$ would indicate a change in surface orientation to an end-on alignment.

The SER spectra of the various concentrations of 4-CP adsorbed onto gold colloids demonstrate no changes in spectral pattern or frequencies as concentration is increased. The increase in adsorbate concentration contributes to an increase in the SERS intensity, but with no shift in the nitrile stretching band found at $2238 \mathrm{~cm}^{-1}(\mathrm{v}(\mathrm{C} \equiv N))$. These results verify that the adsorption of 4-CP at any concentration occurs in an end-on fashion on gold colloids. 


\subsection{CONCLUSIONS}

Dramatic differences are observed between the SER spectrum of 4-CP mixed with a copper colloid and the spectrum of 4-CP on a gold colloid. Specifically, the nitrile stretching band is missing in the SERS involving the copper colloid. $4-\mathrm{CP}-{ }^{15} \mathrm{~N}$ was prepared and the SER spectrum collected. This spectrum indicates that the nitrile stretching band is not coupled with the ring modes or shifted to lower wavenumbers as a $-\mathrm{C}=\mathrm{N}$ moiety. The data are adequately explained by a transition metal-assisted borohydride reduction of 4-CP to 4-AMP. SER spectra of these molecules in the presence of copper colloids are identical within experimental error. The nitrile stretching signal was observed when a gold colloid was prepared by borohydride reduction, indicating the metal selectivity of the reaction. Experiments utilizing deoxygenated solutions and different copper salts for the preparation of the copper colloids showed no effect on the reduction mechanism. Concentration experiments with gold and copper colloids indicate that the orientation upon adsorption is metal dependent. Upon adsorption onto gold colloids, the 4-CP aligns in an end-on fashion, while studies on copper indicate that the orientation goes from a flat-on to an end-on orientation as concentration of 4-AMP is increased. At higher concentrations of 4-CP mixed with the copper colloids, the presence of both 4-CP and its' reduction product, 4-AMP, is observed in the SERS. Additionally, the mixing of copper and gold colloids with 4-CP showed that the molecules undergo the reduction process due to the interaction of colloidal $\mathrm{Cu}^{\circ}$ with the 4-CP, even after adsorption onto gold colloids. 


\section{REFERENCES}

1. C. S. Allen and R. P. Van Duyne, Chem. Phys. Lett. 63, 455 (1979).

2. M. Fleischmann, P. J. Hendra and A. J. McQuillan, Chem. Phys. Lett. 26, 123 (1974).

3. C. S. Allen, PhD Thesis, Northwestern University (1980); University Microfilms, AAG8104683.

4. J. C. Rubim, J. Electroanal. Chem. 220, 339 (1987).

5. J. C. Rubim and O. J. Sala, J. Mol. Struct. 145, 157 (1986).

6. J. A. Creighton, M.S. Alvarez, D.A. Weltz, S. Garoff and M. W. Kim, J. Phys. Chem. 87, 4793 (1983).

7. J. A. Creighton and D. G. Eadon, J. Chem. Soc., Faraday Trans. 24 87, 3881-3891 (1991).

8. O. Siiman, L. A. Bumm, R. Callaghan, C. G. Blatchford and M. Kerker, J. Phys. Chem. 87, 1014 (1983).

9. D. Meisel and P. C. Lee, J. Phys. Chem. 86, 3391 (1982).

10. D. P. Strommen and K. Nakamoto, Laboratory Raman Spectroscopy, p. 64, WileyInterscience, New York (1984).

11. D. G. Ott, Syntheses With Stable Isotopes of Carbon, Nitrogen and Oxygen, pp. 79-80, Wiley, New York (1981).

12. J. B. Lambert, W. L. Oliver and J. D. Roberts, J. Am. Chem. Soc. 22 87, 5085-5090 (1965).

13. J. H. S. Green and D. J. Harrison, Spectrochim. Acta, Part A 33, 75 (1977).

14. J. A. Creighton, C. G. Blatchford and M. G. Albrecht, J. Chem. Soc., Faraday Trans. 2 75, 790 (1979).

15. J. C. Rubim, I. G. R. Gutz and O. Sala, Chem. Phys. Lett. 111, 117-122 (1984).

16. S. Sanchez-Cortez and J. V. Garcia-Ramos, J. Raman Spectrosc. 29, 365-371 (1998).

17. T. M. Herne and R. L. Garrell, Anal. Chem. 63, 2290 (1991). 
18. J. Pate, A. Leiden, B. J. Bozlee and R. L. Garrell, J. Raman Spectrosc. 14, 477 (1983).

19. H. C. Brown and B. C. Subba Rao, J. Am. Chem. Soc. 78, 2582 (1956).

20. J. O. Osby, S. W. Heinzmann and B. Ganem, J. Am. Chem. Soc. 108, 67 (1986).

21. M. L. A. Temperini, J. C. Rubim, O. Sala, A. H. Jubert, M. E. Chacon Vilalba and P. J. Aymonino, J. Raman Spectrosc. 22, 301 (1991).

22. G. Varsanyi, Assignments for Vibrational Spectra of Seven Hundred Benzene Derivatives, pp. 11-35, 69. Wiley, New York (1974).

23. J. Rothe, J. Hormes, H. Bonnemann, W. Brijoux and K. Siepen, J. Am. Chem. Soc. 120, 6019-6023 (1998).

24. S. Schneider, H. Grau, P. Halbig, P. Freunscht and U. Nickel, J. Raman Spectrosc. 27, 57-68 (1996).

25. Barry M. Trost, ed., Comprehensive Organic Synthesis, pp. 580-583. Pergamon Press, Oxford (1991). 


\section{CHAPTER 3}

\section{Isomeric Effects of 4-, 3-, and 2-Cyanopyridines Adsorbed onto Copper Colloids}

\subsection{INTRODUCTION}

In the original study of surface enhanced Raman (SER) scattering from pyridine adsorbed on silver electrodes it was noted that some vibrational modes were enhanced more than others. ${ }^{1-5}$ The reason for this is that vibrational modes are enhanced due to the direction of the induced dipole moment change with respect to the metal surface.

Using the image dipole model of SERS, predictions can be made about the dependence of enhancement on molecular orientation. ${ }^{6}$ If the Raman scattering is treated semi-classically, then the Raman shifted light is seen as arising from an oscillating electric dipole in the molecule. To a first approximation this dipole is oriented along the bond axis for a bond stretching motion. When such a dipole is brought near a metal surface, classical electrostatics predicts that the dipole will induce an image dipole in the metal surface. ${ }^{6}$ For dipoles parallel to the metal surface, this image dipole is opposite in direction and cancellation occurs. However, if the dipole is perpendicular to the metal surface then addition is constructive. Based on this classical model, it is predicted that vibrations parallel to the metal surface should show smaller enhancements than those perpendicular to the surface. Thus, modes which are normal to the adsorption surface would demonstrate the greatest amount of enhancement upon attachment. ${ }^{7}$ Additionally, the more symmetric a vibrational normal mode, the greater the amount of observed enhancement. ${ }^{3,8}$ Based on these premises, normal 
modes which have a dipole moment charge normal to the metal surface would show the largest enhancement whether they are classified as symmetric or antisymmetric modes. Thus, relative enhancement intensities can be used to determine the orientation of the molecule on the surface.

Previous studies by Van Duyne and Rubim of cyanopyridines adsorbed onto silver electrodes indicate a surface enhancement of the nitrile stretching normal mode that is dependent upon the position of the nitrile substituent on the aromatic ring. ${ }^{3,5,6,9}$ Van Duyne showed that there was a decrease in intensity of $v(\mathrm{C} \equiv \mathrm{N})$ as the nitrile was moved from the 4- to the 3- to the 2-positions for 4-CP, 3-CP, and 2-CP on silver electrodes (see Figure 3-1). This was interpreted as an enhancement controlled by the interaction of the nitrile moiety with the metal surface as determined by its position on the pyridine ring and hence orientation with respect to the metal surface. As the molecule tends to a flat-on orientation the intensity of $v(\mathrm{C} \equiv \mathrm{N})$ is lowered. It was assumed that adsorption was occurring primarily through the lone pair electrons of the nitrogen in the aromatic ring as had been previously reported. ${ }^{3,5,6,9}$

Rubim later found that the orientation of the molecule was dependent upon the applied potential and at certain potentials, an actual reduction of 4-CP to 4-aminomethylpyridine (4AMP) would occur. ${ }^{5,9}$ Subsequent studies showed the dependence of SERS intensity on the applied potential for different vibrational modes of 4-CP molecules adsorbed onto a silver electrode ${ }^{5,9,10}$ This was based on the idea that at different applied potentials the concentration of the adsorbate on the surface would increase with steric effects forcing part of the molecules to be adsorbed end-on ( $\sigma$-interaction; i.e. changed from flat-on orientation). This 
$\underset{\mathrm{N}}{\mathrm{N}} \longrightarrow \mathrm{C}$

4-CP

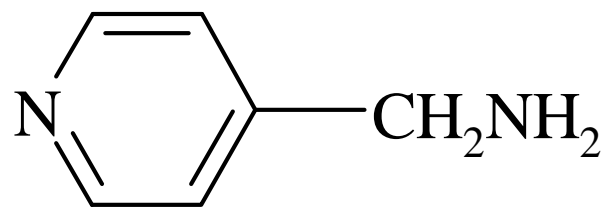

4-AMP

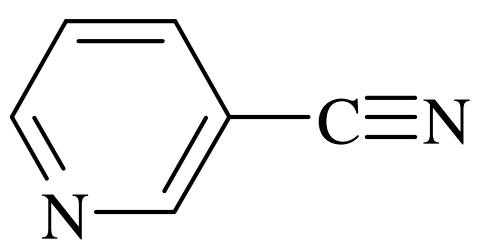

3-CP

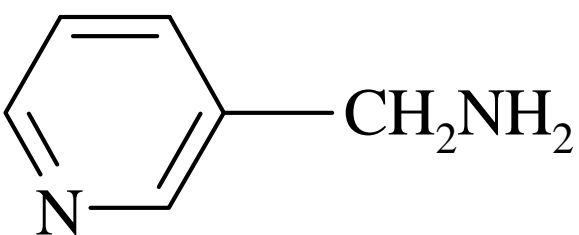

3-AMP

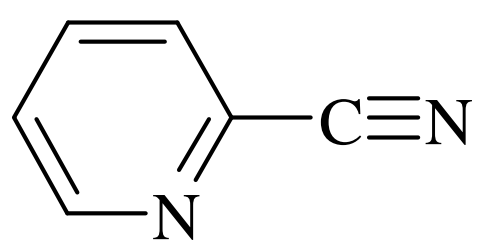

2-CP

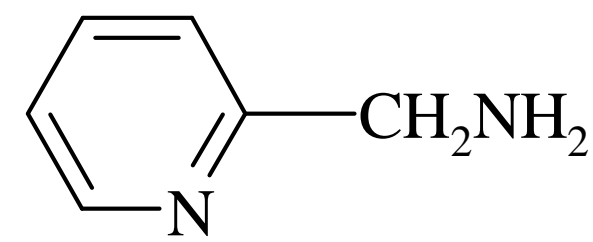

2-AMP

Figure 3-1 Molecular structures for the isomeric forms of cyanopyridine (4-CP, 3-CP, and 2-CP) and the isomeric forms of aminomethylpyridine (4-AMP, 3-AMP, and 2-AMP). 
causes selected vibrational modes to change from parallel to perpendicular relative to the metal surface, resulting in an increase in SER effect observed for those motions.

In those studies, it was consistently found that the more symmetric the form of cyanopyridine (4-CP>3-CP>2-CP) the greater the SERS effect and the less complicated the spectra since some modes experience very strong enhancement. The more asymmetric forms of $\mathrm{CP}$ produced spectra that were more complicated due to the appearance of both the symmetric and asymmetric SERS bands. The generation of particular bands in SERS provides insight into the orientation and site of attachment for each isomeric form of the molecule on the metal surface. ${ }^{11-14}$

These investigations indicate that the mode of bonding for all three isomers is via the nitrogen in the aromatic ring, however in the case of 2-CP, coordination also occurs via the nitrile nitrogen. ${ }^{3,6,15-18}$ The different bonding interaction of the nitrile group in 2-CP is responsible for a different bonding geometry that results in the enhancement of antisymmetric vibrational modes.

We have extended the study of 4-CP mixed with copper colloids to include isomeric forms of the cyanopyridine. Isomers of cyanopyridine provide different orientations of the nitrile group with respect to the plane of the metal surface (assuming pyridine nitrogen coordination). Determination of whether the transition metal-assisted borohydride reduction proceeds regardless of the nitrile position relative to the surface will provide insight into steric inhibition of the reduction process and the necessity of surface adsorption prior to reduction. SERS of the isomeric forms of $\mathrm{CP}$ will provide insight into the mechanism of surface- 
enhancement through the degree of enhancement observed and the nature of the spectral bands that are enhanced (symmetric vs. antisymmetric vibrational modes).

\subsection{EXPERIMENTAL}

\section{Colloid Preparation}

The preparation of the copper colloids is based on the borohydride reduction of $\mathrm{Cu}^{2+}$ as described in Chapter 2.2. ${ }^{19}$ All colloidal solutions were prepared in disposable borosilicate glass culture tubes with water passed through a Barnstead/Thermolyne (Dubuque, IA) Nanopure Water Model D4541 purification system. The colloid, which starts as a pale yellow-brown color becomes a dark reddish-brown. The red color is indicative of particle sizes ranging from 10 to $20 \mathrm{~nm}$ and gives rise to an absorption band at $564 \mathrm{~nm} \cdot{ }^{20}$ After the colloid was allowed to age for two hours, an aqueous solution of the $\mathrm{CP}$ (4-CP, 3-CP, and 2-CP) (Aldrich; 98\%; Aldrich; 98\%; Aldrich; 99\%) (1 x 10-3 M, $0.30 \mathrm{~mL})$ was added. The final concentration of the $\mathrm{CP}$ was approximately $9 \times 10^{-5} \mathrm{M}$. Upon addition of the $\mathrm{CP}$, the colloid changes to a dark grey-brown color due to aggregation and has an absorption band at $570 \mathrm{~nm}$. A band at $296 \mathrm{~nm}$ indicative of the adsorbate is also observed. The shifts in the spectra are indicative of aggregation and molecule-surface interaction in the colloidal system..$^{21}$ Data collection of the SER spectra of the cyanopyridines adsorbed onto the copper colloids was begun 80 minutes after the addition of the adsorbate solution to the colloid.

The preparation of the gold colloid is described in Chapter 2.2. ${ }^{22}$ Raman samples were prepared by adding $\mathrm{CP}(4-\mathrm{CP}, 3-\mathrm{CP}$, and $2-\mathrm{CP})\left(0.3 \mathrm{~mL}, 1 \times 10^{-3} \mathrm{M}\right)$ to $2.7 \mathrm{~mL}$ of the gold colloid solution in borosilicate glass culture tubes. The color changed to a dark 
violet/purple with an absorption maxima at $563 \mathrm{~nm}$ indicative of aggregation due to the presence of the adsorbate. The SER spectra were collected starting 80 minutes after the addition of the cyanopyridine.

Aminomethylpyridines (4-AMP, 3-AMP, and 2-AMP) (Aldrich; 98\%; Aldrich; 99\%; Aldrich; 99\%) were adsorbed onto copper colloids using the procedures described above. Spectra of the parent compounds were collected as the neat liquid contained in standard melting point capillary tubes.

Anaerobic preparation of the copper colloids was performed using the same chemical ratios as listed above with the same procedure described in Section 2.2.

Additional copper colloids were prepared using methods described above, but with different initial states of copper salts for reduction [copper(II) sulfate (Aldrich; $99.99 \%$ and copper(I) chloride (Aldrich; 97\%).

Experimental parameter for collection were identical to those described in Section 2.2.

\subsection{RESULTS AND DISCUSSION}

The SER spectra of the three isomers of cyanopyridine (4-CP, 3-CP, and 2-CP) mixed with copper colloids are shown in Figure 3-2. The observed wavenumbers with tentative assignments for 3-CP and 2-CP are presented in Tables 3-1 and 3-2 . Upon adsorption, the $v(\mathrm{C} \equiv \mathrm{N})$ stretching band is not observed within the $2000 \mathrm{~cm}^{-1}$ to $2300 \mathrm{~cm}^{-1}$ 


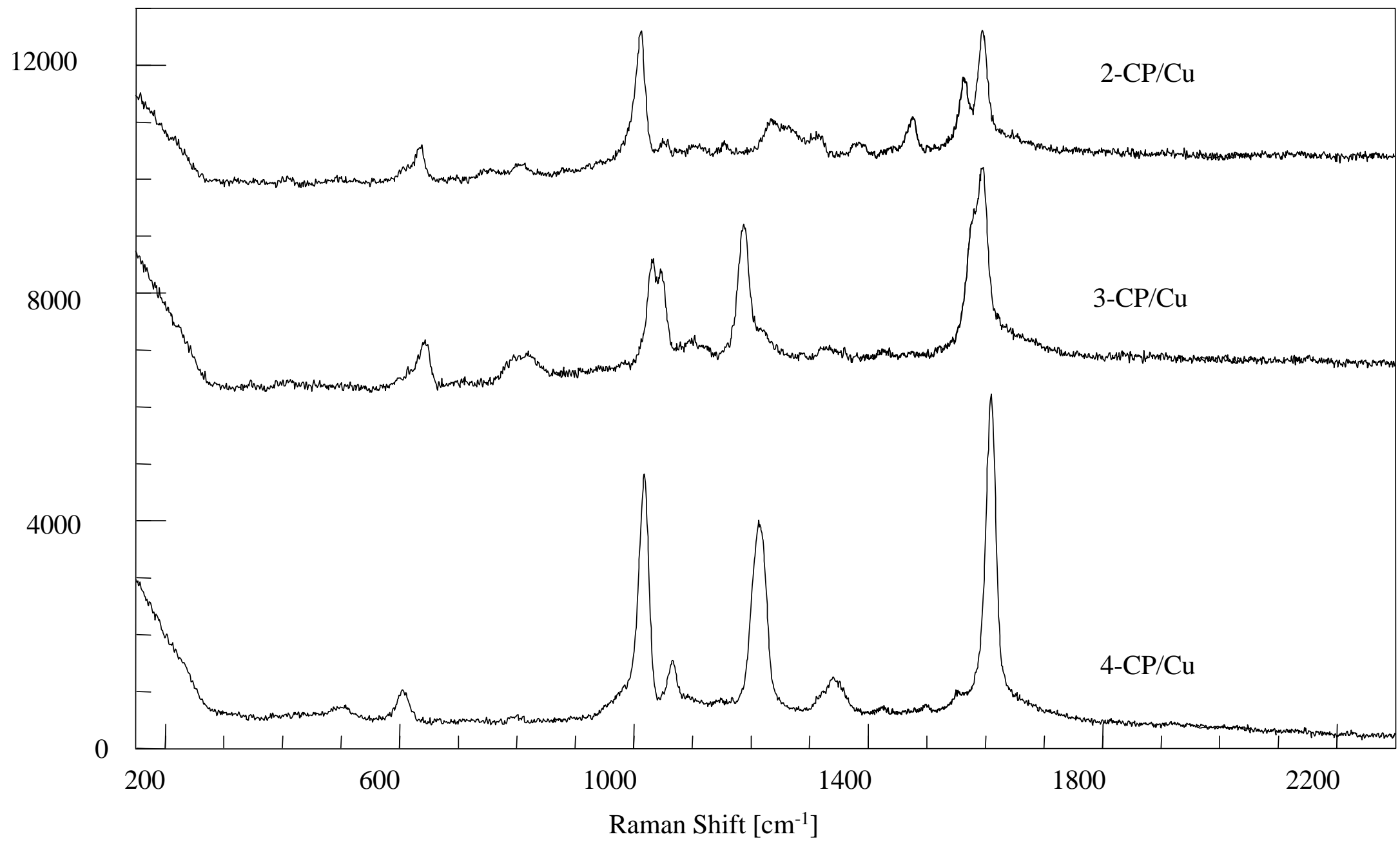

Figure 3-2 SERS of cyanopyridines (4-, 3-, and 2-CP) adsorbed onto copper colloids (/Cu). 
TABLE 3-1: Raman Frequencies $\left(\mathrm{cm}^{-1}\right)$ of 3-Cyanopyridine (3-CP) in Aqueous Solution (2.0M) and Adsorbed on Copper (/Cu) and Gold (/Au) Colloids.

\begin{tabular}{|c|c|c|c|}
\hline Assignment $^{\mathrm{a}}$ & 3-CP (2.0 M) & $3-\mathrm{CP} / \mathrm{Cu}$ & 3-CP/Au \\
\hline $\mathrm{C} \equiv \mathrm{N}$ sens, $\delta(\mathrm{CN})$ & 172 & - & 189 \\
\hline$\phi(\mathrm{CC}), \mathrm{C} \equiv \mathrm{N}$ sens, $\gamma(\mathrm{CN})$ & 360 & - & 362 \\
\hline $\mathrm{S}$ & - & 347 & - \\
\hline$\phi(\mathrm{CC}), \mathrm{C} \equiv \mathrm{N}$ sens, $\gamma(\mathrm{CN})$ & 399 & - & 400 \\
\hline $\mathrm{S}$ & - & 414 & - \\
\hline $\mathrm{C} \equiv \mathrm{N}$ sens, $\delta(\mathrm{CN})$ & 475 & - & 474 \\
\hline$\phi(\mathrm{CC}), \mathrm{C} \equiv \mathrm{N}$ sens, $\gamma(\mathrm{CN})$ & 554 & - & 539 \\
\hline $\mathrm{S}$ & - & 620 & - \\
\hline$\alpha(\mathrm{CCC})$ & 635 & 644 & 643 \\
\hline $\mathrm{S}$ & - & 699 & - \\
\hline $\mathrm{C} \equiv \mathrm{N}$ sensitive & 782 & 797 & 792 \\
\hline $\mathrm{S}$ & - & 820 & - \\
\hline $\mathrm{S}$ & - & 928 & - \\
\hline $\mathrm{S}$ & 994 & 983 & - \\
\hline Ring & 1032 & 1030 & 1028 \\
\hline$\beta(\mathrm{CH})$ & 1039 & 1045 & 1052 \\
\hline S & 1060 & - & - \\
\hline $\mathrm{S}$ & - & 1098 & - \\
\hline $\mathrm{S}$ & 1127 & 1120 & 1119 \\
\hline$\beta(\mathrm{CH})$ & 1192 & 1188 & 1192 \\
\hline $\mathrm{C} \equiv \mathrm{N}$ sensitive & 1216 & 1216 & 1211 \\
\hline$\alpha(\mathrm{CC})$ & 1241 & - & - \\
\hline $\mathrm{S}$ & - & - & 1296 \\
\hline$\beta(\mathrm{CH})$ & 1342 & 1334 & - \\
\hline $\mathrm{S}$ & - & - & 1369 \\
\hline$v(\mathrm{CC}, \mathrm{CN})$ & 1423 & 1426 & 1425 \\
\hline$v(\mathrm{CC}, \mathrm{CN})$ & 1477 & 1478 & 1474 \\
\hline$v(\mathrm{CC})$ & 1572 & 1581 & 1566 \\
\hline$v(C C)$ & 1593 & 1595 & 1598 \\
\hline$v(\mathrm{CN})$ & 2240 & - & 2235 \\
\hline
\end{tabular}

a. Based on Ref.23. 
TABLE 3-2: Raman Frequencies $\left(\mathrm{cm}^{-1}\right)$ of 2-Cyanopyridine (2-CP) in Aqueous Solution $(2.0 \mathrm{M})$ and Adsorbed on Copper (/Cu) and Gold (/Au) Colloids.

\begin{tabular}{|c|c|c|c|}
\hline Assignment $^{\mathrm{a}}$ & $2-\mathrm{CP}(2.0 \mathrm{M})$ & $2-\mathrm{CP} / \mathrm{Cu}$ & 2-CP/Au \\
\hline $\mathrm{C} \equiv \mathrm{N}$ sens,$\delta(\mathrm{CN})$ & 175 & - & - \\
\hline$\phi(\mathrm{CC}), \mathrm{C} \equiv \mathrm{N}$ sens, $\gamma(\mathrm{CN})$ & 364 & - & 375 \\
\hline $\mathrm{S}$ & 402 & 410 & - \\
\hline $\mathrm{S}$ & - & - & 449 \\
\hline $\mathrm{C} \equiv \mathrm{N}$ sens,$\delta(\mathrm{CN})$ & 482 & - & 488 \\
\hline $\mathrm{S}$ & - & 501 & - \\
\hline $\mathrm{C} \equiv \mathrm{N}$ sens, $\delta(\mathrm{CN})$ & 554 & - & 546 \\
\hline $\mathrm{S}$ & - & 614 & - \\
\hline$\alpha(\mathrm{CCC})$ & 636 & 637 & 634 \\
\hline $\mathrm{S}$ & 741 & 750 & - \\
\hline $\mathrm{C} \equiv \mathrm{N}$ sensitive & 779 & - & 775 \\
\hline $\mathrm{S}$ & - & 807 & - \\
\hline Ring & 1001 & 1011 & 1019 \\
\hline$\beta(\mathrm{CH})$ & 1048 & 1052 & 1070 \\
\hline$\beta(\mathrm{CH})$ & 1095 & - & - \\
\hline $\mathrm{S}$ & - & 1105 & - \\
\hline$\beta(\mathrm{CH})$ & 1161 & 1153 & - \\
\hline $\mathrm{C} \equiv \mathrm{N}$ sensitive & 1206 & - & 1228 \\
\hline $\mathrm{S}$ & 1234 & 1235 & - \\
\hline$\alpha(\mathrm{CC})$ & 1258 & 1259 & - \\
\hline$\beta(\mathrm{CH})$ & 1295 & - & 1292 \\
\hline $\mathrm{S}$ & - & 1314 & - \\
\hline $\mathrm{S}$ & - & - & 1377 \\
\hline $\mathrm{S}$ & - & 1383 & - \\
\hline$v(\mathrm{CC}, \mathrm{CN})$ & 1437 & - & - \\
\hline$v(\mathrm{CC}, \mathrm{CN})$ & 1469 & 1475 & 1464 \\
\hline $\mathrm{S}$ & - & - & 1512 \\
\hline$v(C C)$ & 1573 & 1563 & 1565 \\
\hline$v(C C)$ & 1587 & 1594 & 1613 \\
\hline$v(C \equiv N)$ & 2243 & - & 2226 \\
\hline
\end{tabular}

a. Based on Ref. 23. 
region for any of the isomers. Therefore, reduction of the nitrile group is occurring despite orientation on the surface.

The absence of the $v(\mathrm{C} \equiv \mathrm{N})$ band is due to the proposed metal-assisted borohydride reduction of the nitrile group to an aminomethyl substituent during the adsorption process. For verification of the this reduction, the isomeric forms of the reduction products (3-AMP and 2-AMP) were collected on copper colloids.

The SER spectrum of 3-AMP adsorbed on a copper colloidal surface, as well as the Raman spectrum of the parent are shown in Figure 3-3. The observed wavenumbers and tentative assignments are presented in Table 3-3. It can be seen that 3-CP mixed with a copper colloid and 3-AMP adsorbed onto a copper surface generate identical spectra within experimental error. In the Raman of the parent 3-AMP, the strongest band is associated with the ring breathing vibration $\left(1030 \mathrm{~cm}^{-1}\right)$. In the SERS of 3-AMP on copper and 3-CP mixed with a copper colloid, the bands at $1594 \mathrm{~cm}^{-1}(\mathrm{v}(\mathrm{CC})), 1578 \mathrm{~cm}^{-1}(\mathrm{v}(\mathrm{CC})), 1095 \mathrm{~cm}^{-1}$ $(\beta(\mathrm{CH})), 1046 \mathrm{~cm}^{-1}\left(\beta\left(\mathrm{NH}_{2}\right), \beta(\mathrm{CH})\right)$, and $1029 \mathrm{~cm}^{-1}$ (ring breathing) show the greatest amount of enhancement. ${ }^{24,25}$ These bands are all associated with the symmetric ring modes of the reduction product and coincide with adsorption via the pyridine nitrogen. ${ }^{9}$

The SER spectrum of 2-AMP adsorbed on a copper colloidal surface and the corresponding Raman spectrum of the parent are shown in Figure 3-4. The observed wavenumbers and tentative assignments are presented in Table 3-4. It can be seen that 2-CP mixed with a copper surface and 2-AMP adsorbed onto a copper surface generate identical spectra within experimental error. In the Raman of 2-AMP, the strongest Raman bands are 


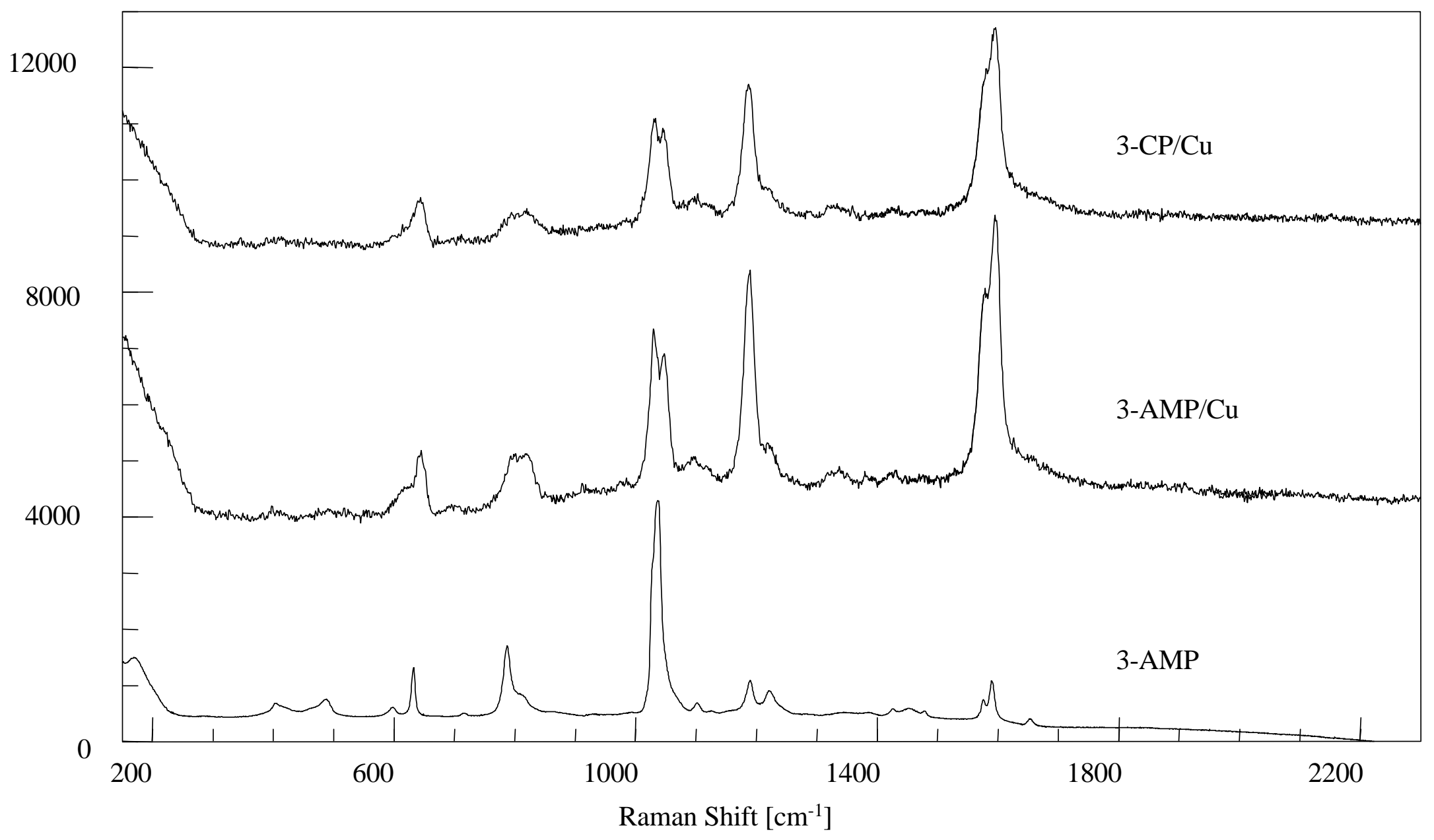

Figure 3-3 Raman spectra of neat 3-aminomethylpyridine (3-AMP) and SERS of 3-AMP and 3-CP adsorbed onto copper colloids $(/ \mathrm{Cu})$. 
TABLE 3-3: $\quad$ Raman Frequencies $\left(\mathrm{cm}^{-1}\right)$ of Neat 3-Aminomethylpyridine (3-AMP) and Adsorbed on Copper (/Cu) Colloids and 3Cyanopyridine (3-CP) in Aqueous Solution (2.0 M) and Adsorbed on Copper Colloids.

\begin{tabular}{|c|c|c|c|c|c|}
\hline 3-AMP Assignment ${ }^{\mathrm{a}}$ & 3-AMP liquid & 3-AMP/Cu & $3-\mathrm{CP} / \mathrm{Cu}$ & 3-CP liquid & 3-CP Assignment ${ }^{\mathrm{a}}$ \\
\hline $\mathrm{S}$ & 167 & - & - & 172 & $\mathrm{C} \equiv \mathrm{N}$ sens,$\delta(\mathrm{CN})$ \\
\hline $\mathrm{S}$ & - & 344 & 347 & - & - \\
\hline $\mathrm{S}$ & - & - & - & 360 & $\phi(\mathrm{CC}), \mathrm{C} \equiv \mathrm{N}$ sens, $\gamma(\mathrm{CN})$ \\
\hline $\mathrm{S}$ & 404 & 407 & 414 & 399 & $\phi(\mathrm{CC}), \mathrm{C} \equiv \mathrm{N}$ sens, $\gamma(\mathrm{CN})$ \\
\hline $\mathrm{S}$ & - & - & - & 475 & $\mathrm{C} \equiv \mathrm{N}$ sens, $\delta(\mathrm{CN})$ \\
\hline Ring deformation & 493 & 491 & - & - & - \\
\hline $\mathrm{S}$ & - & - & - & 554 & $\phi(\mathrm{CC}), \mathrm{C} \equiv \mathrm{N}$ sens, $\gamma(\mathrm{CN})$ \\
\hline$\gamma\left(\mathrm{NH}_{2}\right)$ & 598 & - & - & - & - \\
\hline $\mathrm{S}$ & - & 625 & 620 & - & - \\
\hline$\alpha(\mathrm{CCC})$ & 633 & 645 & 644 & 635 & $\alpha(\mathrm{CCC})$ \\
\hline $\mathrm{S}$ & - & 698 & 699 & - & $\phi(\mathrm{CC})$ \\
\hline $\mathrm{S}$ & 716 & - & - & - & - \\
\hline$v(C C)$ & 788 & 799 & 797 & 782 & $\mathrm{C} \equiv \mathrm{N}$ sensitive \\
\hline S & 811 & 819 & 820 & - & - \\
\hline $\mathrm{S}$ & 932 & 928 & 928 & - & - \\
\hline$\alpha(\mathrm{CC})$ & 954 & - & - & - & - \\
\hline $\mathrm{S}$ & 994 & 980 & 983 & 994 & - \\
\hline Ring breathing & 1030 & 1029 & 1030 & 1032 & Ring \\
\hline$\beta\left(\mathrm{NH}_{2}\right), \beta(\mathrm{CH})$ & 1038 & 1046 & 1045 & 1039 & $\beta(\mathrm{CH})$ \\
\hline $\mathrm{S}$ & - & - & - & 1060 & - \\
\hline $\mathrm{S}$ & 1102 & 1095 & 1098 & - & - \\
\hline
\end{tabular}


TABLE 3-3:

(Continued)

\begin{tabular}{|c|c|c|c|c|c|}
\hline 3-AMP Assignment ${ }^{\mathrm{a}}$ & 3-AMP liquid & 3-AMP/Cu & $3-\mathrm{CP} / \mathrm{Cu}$ & 3-CP liquid & 3-CP Assignment ${ }^{\mathrm{a}}$ \\
\hline$\overline{\mathrm{S}}$ & 1126 & 1121 & 1120 & 1127 & - \\
\hline$\beta(\mathrm{CH})$ & 1191 & 1189 & 1188 & 1192 & $\beta(\mathrm{CH})$ \\
\hline $\mathrm{S}$ & - & - & - & 1216 & $\mathrm{C} \equiv \mathrm{N}$ sensitive \\
\hline$\beta\left(\mathrm{NH}_{2}\right), \beta(\mathrm{CH})$ & 1224 & 1218 & 1216 & - & - \\
\hline $\mathrm{S}$ & - & - & - & 1241 & $\alpha(\mathrm{CC})$ \\
\hline$\beta(\mathrm{CH})$ & - & 1336 & 1334 & 1342 & $\beta(\mathrm{CH})$ \\
\hline S & 1350 & - & - & - & - \\
\hline $\mathrm{S}$ & 1387 & 1386 & - & - & - \\
\hline S & 1428 & 1426 & 1426 & 1423 & $v(\mathrm{CC}, \mathrm{CN})$ \\
\hline$v(C C)$ & 1454 & - & - & - & - \\
\hline$v(C C)$ & 1479 & 1476 & 1478 & 1477 & $v(\mathrm{CC}, \mathrm{CN})$ \\
\hline$v(C C)$ & 1577 & 1578 & 1581 & 1572 & $v(C C)$ \\
\hline$v(C C)$ & 1592 & 1594 & 1595 & 1593 & $v(C C)$ \\
\hline$v(C C)$ & 1657 & - & - & - & - \\
\hline $\mathrm{S}$ & - & - & - & 2240 & $v(\mathrm{CN})$ \\
\hline
\end{tabular}

a. Based on Ref. 23, 24 and 25. 


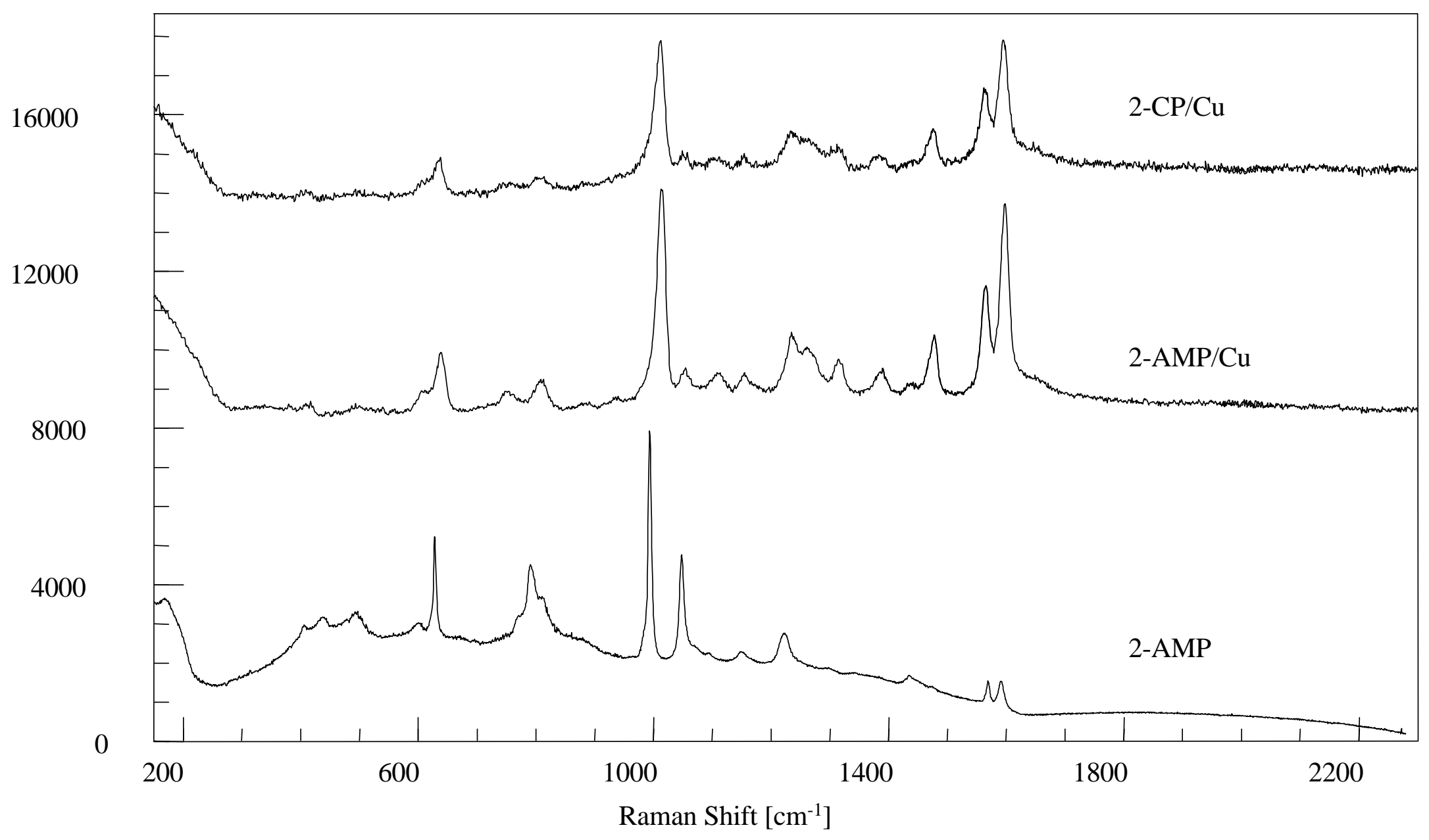

Figure 3-4 Raman spectra of neat 2-aminomethylpyridine (2-AMP) and SERS of 2-AMP and 2-CP adsorbed onto copper colloids $(/ \mathrm{Cu})$. 
TABLE 3-4: $\quad$ Raman Frequencies $\left(\mathrm{cm}^{-1}\right)$ of Neat 2-Aminomethylpyridine (2-AMP) and Adsorbed on Copper (/Cu) Colloids and 2Cyanopyridine (2-CP) in Aqueous Solution (2.0 M) and Adsorbed on Copper Colloids.

\begin{tabular}{|c|c|c|c|c|c|}
\hline 2-AMP Assignment ${ }^{\mathrm{a}}$ & 2-AMP liquid & 2-AMP/Cu & $2-\mathrm{CP} / \mathrm{Cu}$ & 2-CP liquid & 2-CP Assignment ${ }^{\mathrm{a}}$ \\
\hline $\mathrm{S}$ & 194 & - & - & 175 & $\mathrm{C} \equiv \mathrm{N}$ sens, $\delta(\mathrm{CN})$ \\
\hline $\mathrm{S}$ & - & - & - & 364 & $\phi(\mathrm{CC}), \mathrm{C} \equiv \mathrm{N}$ sens, $\gamma(\mathrm{CN})$ \\
\hline $\mathrm{S}$ & 407 & 412 & 410 & 402 & - \\
\hline $\mathrm{S}$ & 437 & - & - & - & - \\
\hline $\mathrm{S}$ & - & - & - & 482 & $\mathrm{C} \equiv \mathrm{N}$ sens, $\delta(\mathrm{CN})$ \\
\hline Ring deformation & 500 & 500 & 501 & - & - \\
\hline $\mathrm{S}$ & - & - & - & 554 & $\mathrm{C} \equiv \mathrm{N}$ sens, $\delta(\mathrm{CN})$ \\
\hline$\gamma\left(\mathrm{NH}_{2}\right)$ & 603 & 611 & 614 & - & - \\
\hline$\alpha(\mathrm{CCC})$ & 627 & 639 & 637 & 636 & $\alpha(\mathrm{CCC})$ \\
\hline S & 768 & 751 & 750 & 741 & - \\
\hline S & - & - & - & 779 & $\mathrm{C} \equiv \mathrm{N}$ sensitive \\
\hline$v(C C)$ & 791 & 809 & 807 & - & - \\
\hline $\mathrm{S}$ & 812 & - & - & - & - \\
\hline $\mathrm{S}$ & - & 884 & - & - & - \\
\hline $\mathrm{S}$ & 927 & 935 & - & - & - \\
\hline Ring breathing & 994 & 1013 & 1011 & 1001 & Ring \\
\hline$\beta\left(\mathrm{NH}_{2}\right), \beta(\mathrm{CH})$ & 1048 & 1055 & 1052 & 1048 & $\beta(\mathrm{CH})$ \\
\hline $\mathrm{S}$ & 1094 & - & - & 1095 & $\beta(\mathrm{CH})$ \\
\hline S & - & 1110 & 1105 & - & - \\
\hline$\beta(\mathrm{CH})$ & 1152 & 1154 & 1153 & 1161 & $\beta(\mathrm{CH})$ \\
\hline S & - & - & - & 1206 & $\mathrm{C} \equiv \mathrm{N}$ sensitive \\
\hline
\end{tabular}


TABLE 3-4:

(Continued)

\begin{tabular}{|c|c|c|c|c|c|}
\hline 2-AMP Assignment $t^{\mathrm{a}}$ & 2-AMP liquid & 2-AMP/Cu & $2-\mathrm{CP} / \mathrm{Cu}$ & 2-CP liquid & 2-CP Assignment ${ }^{\mathrm{a}}$ \\
\hline$\beta\left(\mathrm{NH}_{2}\right), \alpha(\mathrm{CC})$ & 1224 & 1235 & 1235 & 1234 & - \\
\hline$\alpha(\mathrm{CC})$ & - & 1262 & 1259 & 1258 & $\alpha(\mathrm{CC})$ \\
\hline S & - & - & - & 1295 & $\beta(\mathrm{CH})$ \\
\hline $\mathrm{S}$ & - & 1315 & 1314 & - & - \\
\hline S & - & 1388 & 1383 & - & - \\
\hline$v(C C)$ & 1436 & 1436 & - & 1437 & $v(\mathrm{CC}, \mathrm{CN})$ \\
\hline$v(\mathrm{CC})$ & 1475 & 1478 & 1475 & 1469 & $v(\mathrm{CC}, \mathrm{CN})$ \\
\hline$v(\mathrm{CC})$ & 1570 & 1565 & 1563 & 1573 & $v(C C)$ \\
\hline$v(C C)$ & 1593 & 1596 & 1594 & 1587 & $v(C C)$ \\
\hline $\mathrm{S}$ & - & - & - & 2243 & $v(\mathrm{C} \equiv \mathrm{N})$ \\
\hline
\end{tabular}

a. Based on Ref. 23, 24 and 25. 
$1048 \mathrm{~cm}^{-1}\left(\gamma\left(\mathrm{NH}_{2}\right), \beta(\mathrm{CH})\right), 994 \mathrm{~cm}^{-1}$ (ring breathing), $791 \mathrm{~cm}^{-1}(\mathrm{v}(\mathrm{CC}))$, and $627 \mathrm{~cm}^{-1}$ $\left(\gamma\left(\mathrm{NH}_{2}\right)\right){ }^{24,25}$ In the SERS of 2-AMP on copper and 2-CP mixed with copper, the bands associated with the amino group at $1235 \mathrm{~cm}^{-1}\left(\left(\beta\left(\mathrm{NH}_{2}\right), \alpha(\mathrm{CC})\right), 1055 \mathrm{~cm}^{-1}\left(\beta\left(\mathrm{NH}_{2}\right), \beta(\mathrm{CH})\right)\right.$, and $611 \mathrm{~cm}^{-1}\left(\gamma\left(\mathrm{NH}_{2}\right)\right)$ undergo shifts to higher frequencies due to interaction via both the ring nitrogen and the amino nitrogen. ${ }^{15}$ In the SERS, the bands at $1596 \mathrm{~cm}^{-1}(\mathrm{v}(\mathrm{CC})), 1565 \mathrm{~cm}^{-1}$ ( $v(C C)), 1478 \mathrm{~cm}^{-1}(\mathrm{v}(\mathrm{CC})), 1013 \mathrm{~cm}^{-1}$ (ring), and $639 \mathrm{~cm}^{-1}(\alpha(\mathrm{CCC}))$ exhibit the greatest amount of surface enhancement. The SER spectra of 2-AMP are more complex than the other isomeric forms of AMP which is due to additional modes of the molecule (probably antisymmetric) having a dipole charge perpendicular to the surface. The SER signals also demonstrate that the enhancement factor is less for 2-AMP than 4-AMP and 3-AMP presumably due to lower molecular symmetry.

Deoxygenated copper colloids were used to determine whether oxidation of the copper surfaces is occurring and if this facilitates the reduction process. The copper colloids were prepared and mixing with 3-CP and 2-CP was carried under argon atmosphere. The spectral results for 3-CP and 2-CP mixed with the deoxygenated colloids are shown in Figures 3-5 and 3-6. The observed wavenumbers and tentative assignments are presented in Tables 3-5 and 3-6. As shown, the spectra for both conditions give similar spectra. There are no shifts within experimental error in the observed frequencies and the spectral patterns are identical. Based on these results it was determined that the presence or absence of oxygen does not facilitate nor hinder the borohydride reduction mechanism for these two forms of cyanopyridine. 


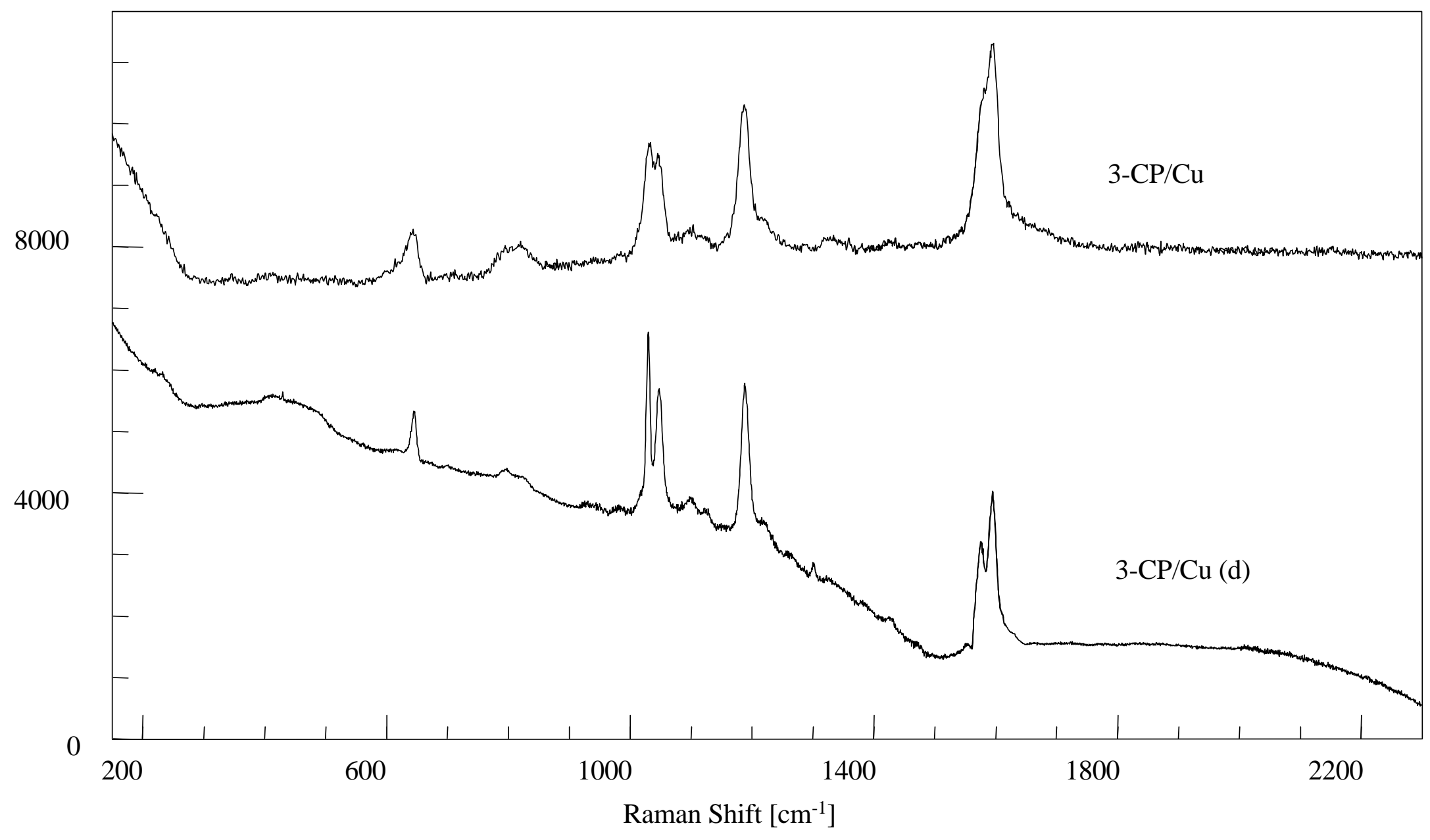

Figure 3-5 SERS of 3-cyanopyridine (3-CP) adsorbed onto copper colloids prepared under aerobic $(/ \mathrm{Cu})$ and deoxygenated $(/ \mathrm{Cu}(\mathrm{d}))$ conditions. 


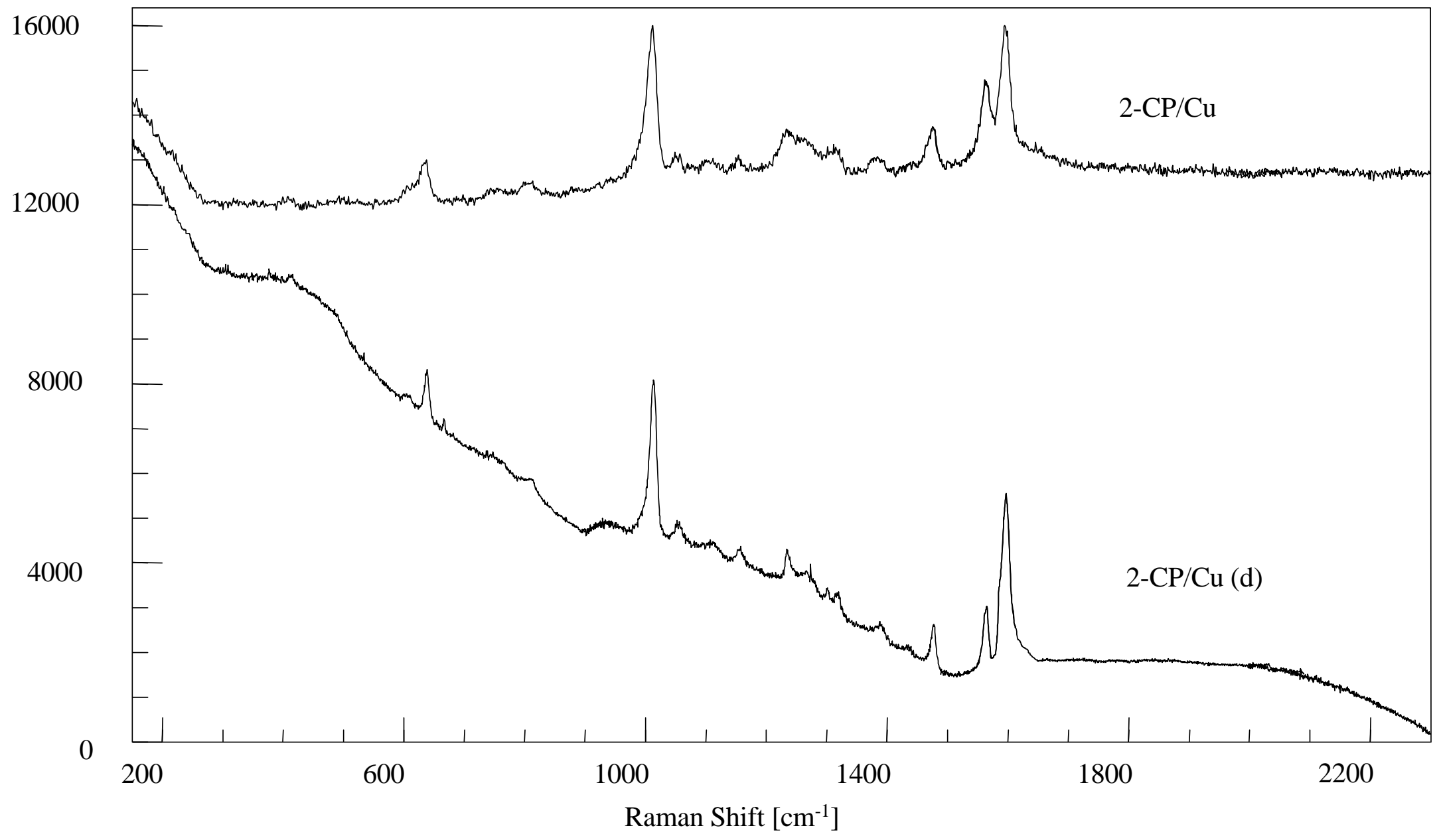

Figure 3-6 SERS of 2-cyanopyridine (2-CP) adsorbed onto copper colloids prepared under aerobic $(/ \mathrm{Cu})$ and deoxygenated $(/ \mathrm{Cu}(\mathrm{d}))$ conditions. 
TABLE 3-5: Raman Frequencies $\left(\mathrm{cm}^{-1}\right)$ of 3-Cyanopyridine (3-CP) Adsorbed on Copper Colloids Prepared From $\mathrm{Cu}^{+2}\left(/ \mathrm{Cu}^{\circ}(\mathrm{II})\right), \mathrm{Cu}^{+1}\left(/ \mathrm{Cu}^{\circ}(\mathrm{I})\right)$ and Under Deoxygenated Conditions (/Cu(d)).

\begin{tabular}{|c|c|c|c|}
\hline Assignment $^{\mathrm{a}}$ & $3-\mathrm{CP} / \mathrm{Cu}^{\circ}(\mathrm{II})$ & $3-\mathrm{CP} / \mathrm{Cu}^{\circ}(\mathrm{I})$ & $3-\mathrm{CP} / \mathrm{Cu}(\mathrm{d})$ \\
\hline $\mathrm{S}$ & 347 & 344 & - \\
\hline $\mathrm{S}$ & 414 & - & - \\
\hline $\mathrm{S}$ & 620 & 623 & 616 \\
\hline$\alpha(\mathrm{CCC})$ & 644 & 648 & 644 \\
\hline S & 699 & 704 & 700 \\
\hline $\mathrm{S}$ & 797 & 800 & 796 \\
\hline $\mathrm{S}$ & 820 & 825 & 824 \\
\hline S & 928 & - & 930 \\
\hline$\alpha(\mathrm{CC})$ & - & 949 & - \\
\hline $\mathrm{S}$ & 983 & 984 & 983 \\
\hline Ring breathing & 1030 & 1031 & 1029 \\
\hline$\beta\left(\mathrm{NH}_{2}\right), \beta(\mathrm{CH})$ & 1045 & 1048 & 1047 \\
\hline $\mathrm{S}$ & 1098 & 1100 & 1099 \\
\hline S & 1120 & 1122 & 1123 \\
\hline$\beta(\mathrm{CH})$ & 1188 & 1188 & 1188 \\
\hline$\beta\left(\mathrm{NH}_{2}\right), \alpha(\mathrm{CC})$ & 1216 & 1222 & 1219 \\
\hline $\mathrm{S}$ & - & 1261 & 1262 \\
\hline$\beta(\mathrm{CH})$ & 1334 & 1330 & 1328 \\
\hline S & - & 1385 & - \\
\hline$v(C C)$ & 1426 & 1427 & 1426 \\
\hline$v(C C)$ & 1478 & 1475 & 1475 \\
\hline S & - & - & 1550 \\
\hline$v(C C)$ & 1581 & 1575 & 1577 \\
\hline$v(C C)$ & 1595 & 1595 & 1595 \\
\hline
\end{tabular}

a. Based on Ref. 24 and 25. 
TABLE 3-6: Raman Frequencies $\left(\mathrm{cm}^{-1}\right)$ of 2-Cyanopyridine (2-CP) Adsorbed on Copper Colloids Prepared From $\mathrm{Cu}^{+2}\left(/ \mathrm{Cu}^{\circ}(\mathrm{II})\right), \mathrm{Cu}^{+1}\left(/ \mathrm{Cu}^{\circ}(\mathrm{I})\right)$ and Under Deoxygenated Conditions $(/ \mathrm{Cu}(\mathrm{d}))$.

\begin{tabular}{lccc}
\hline \hline & & & \\
Assignment & & \\
& $2-\mathrm{CP} / \mathrm{Cu}^{\circ}(\mathrm{II})$ & $2-\mathrm{CP} / \mathrm{Cu}^{\circ}(\mathrm{I})$ & $2-\mathrm{CP} / \mathrm{Cu}(\mathrm{d})$ \\
\hline \hline $\mathrm{S}$ & & & \\
Ring deformation & 410 & 411 & 412 \\
$\gamma\left(\mathrm{NH}_{2}\right)$ & 501 & - & - \\
$\alpha(\mathrm{CCC})$ & 614 & 607 & 605 \\
$\mathrm{~S}$ & 637 & 638 & 637 \\
$v(\mathrm{CC})$ & 750 & 748 & 747 \\
Ring breathing & 807 & 810 & 811 \\
$\beta(\mathrm{NH})$ & $\beta(\mathrm{CH})$ & 1011 & 1014 \\
$\mathrm{~S}$ & 1052 & 1054 & 1054 \\
$\beta(\mathrm{CH})$ & 1105 & 1110 & 1110 \\
$\beta(\mathrm{CH}), \alpha(\mathrm{CC})$ & 1153 & 1155 & 1155 \\
$\alpha(\mathrm{CC})$ & 1235 & 1234 & 1234 \\
$\mathrm{~S}$ & 1259 & 1267 & 1266 \\
$\mathrm{~S}$ & 1314 & 1318 & 1317 \\
$v(\mathrm{CC})$ & 1383 & 1388 & 1388 \\
$v(\mathrm{CC})$ & - & 1434 & - \\
$v(\mathrm{CC})$ & 1475 & 1477 & 1476 \\
$v(\mathrm{CC})$ & 1563 & 1564 & 1564 \\
& 1594 & 1597 & \\
\hline \hline
\end{tabular}

a. Based on Ref. 24 and 25 . 
In order to confirm the state of copper that is required in the borohydride reduction, and that the isomer differences play no role in the reduction reaction, 3-CP and 2-CP were mixed with copper surfaces prepared using different oxidation states of copper $\left(\mathrm{Cu}^{+2}\right.$, and $\left.\mathrm{Cu}^{+1}\right)$. The SERS collected for $\mathrm{Cu}^{\circ}(\mathrm{I})$ and $\mathrm{Cu}^{\circ}$ (II) with 3-CP and 2-CP are shown in Figures 3-7 and 3-8, respectively. The observed wavenumbers and tentative assignments are reported in Table 3-5 and 3-6. Based on the data, the initial state of the copper used in the preparation of the copper colloid is not important since identical spectra were collected for all three isomers adsorbed onto the different copper colloids. Thus, the presence of a copper colloid (assumed to be $\mathrm{Cu}^{\circ}$ ) and borohydride is required for the reduction reaction to proceed (just as we found for 4-CP) and the differences in isomeric form plays no role in the process.

The SER spectra obtained when 3-CP is mixed with gold and copper colloids and the normal Raman spectrum of 3-CP are shown in Figure 3-9. The observed wavenumbers and tentative assignments are presented in Table 3-1. Upon adsorption onto a copper colloid, the $v(C \equiv N)$ at $2240 \mathrm{~cm}^{-1}$ is not observed and the nitrile sensitive bands at $1216 \mathrm{~cm}^{-1}, 782 \mathrm{~cm}^{-}$ ${ }^{1}, 554 \mathrm{~cm}^{-1}, 475 \mathrm{~cm}^{-1}, 399 \mathrm{~cm}^{-1}, 360 \mathrm{~cm}^{-1}$, and $172 \mathrm{~cm}^{-1}$ are absent. ${ }^{23}$ The bands associated with the symmetric ring modes of the parent 3-CP are the most enhanced in the SERS on copper colloids. These are found at $1032 \mathrm{~cm}^{-1}(\mathrm{ring}), 1039 \mathrm{~cm}^{-1}(\beta(\mathrm{CH})), 1192 \mathrm{~cm}^{-1}(\beta(\mathrm{CH}))$, and $1593 \mathrm{~cm}^{-1}(\mathrm{v}(\mathrm{CC}))$. The $1216 \mathrm{~cm}^{-1}$ band $(\mathrm{C} \equiv \mathrm{N}$ sensitive $)$ in the Raman spectrum is of equal intensity to the $1192 \mathrm{~cm}^{-1}(\beta(\mathrm{CH}))$, however, in the SERS the $1216 \mathrm{~cm}^{-1}$ band is absent. This indicates that the nitrile substituent is no longer present. Additionally, 


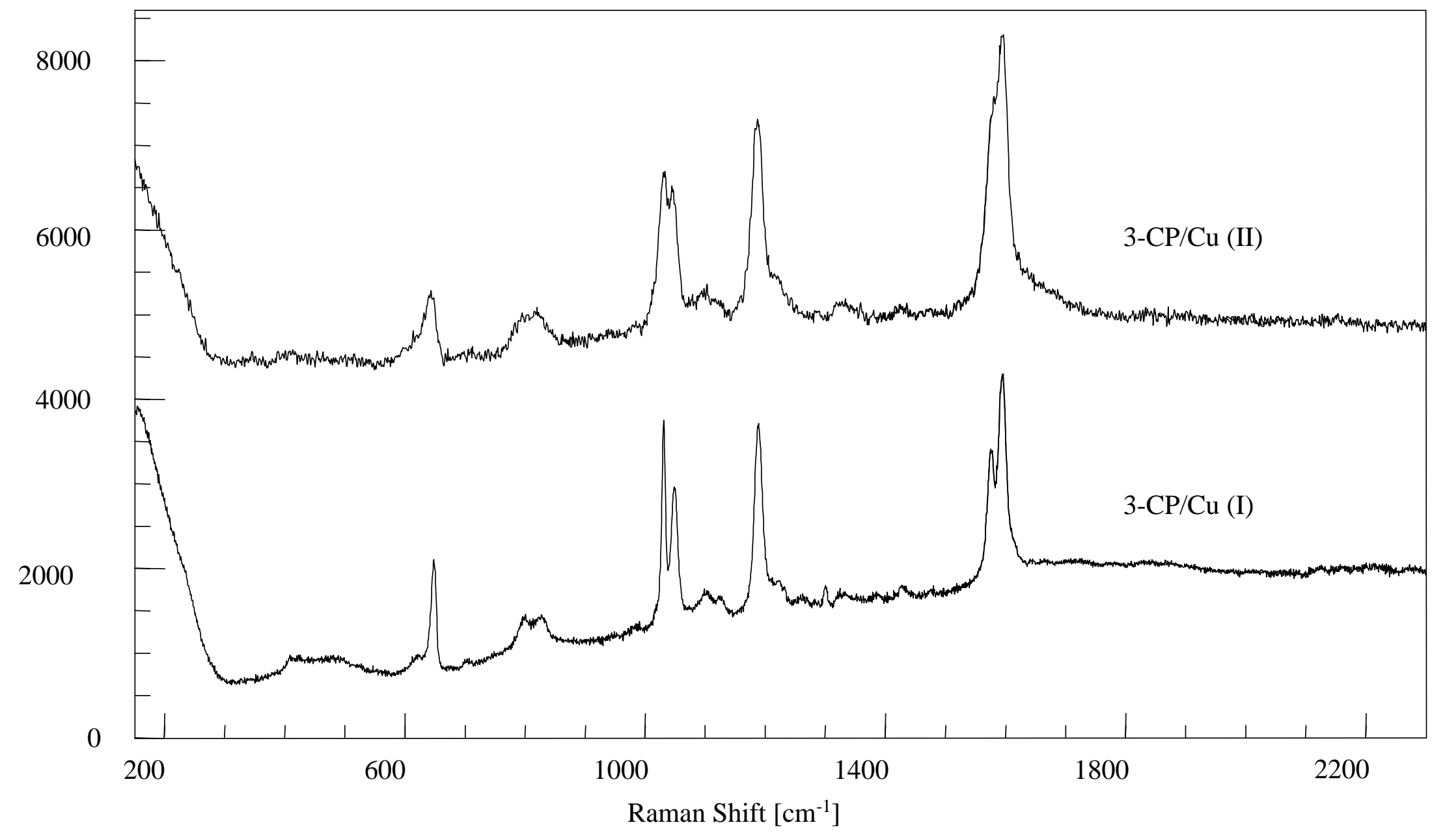

Figure 3-7 SERS of 3-cyanopyridine (3-CP) adsorbed onto copper colloids prepared from $\mathrm{Cu}^{+1}(/ \mathrm{Cu}(\mathrm{I}))$ and $\mathrm{Cu}^{+2}$ (/Cu (II)) reduction. 


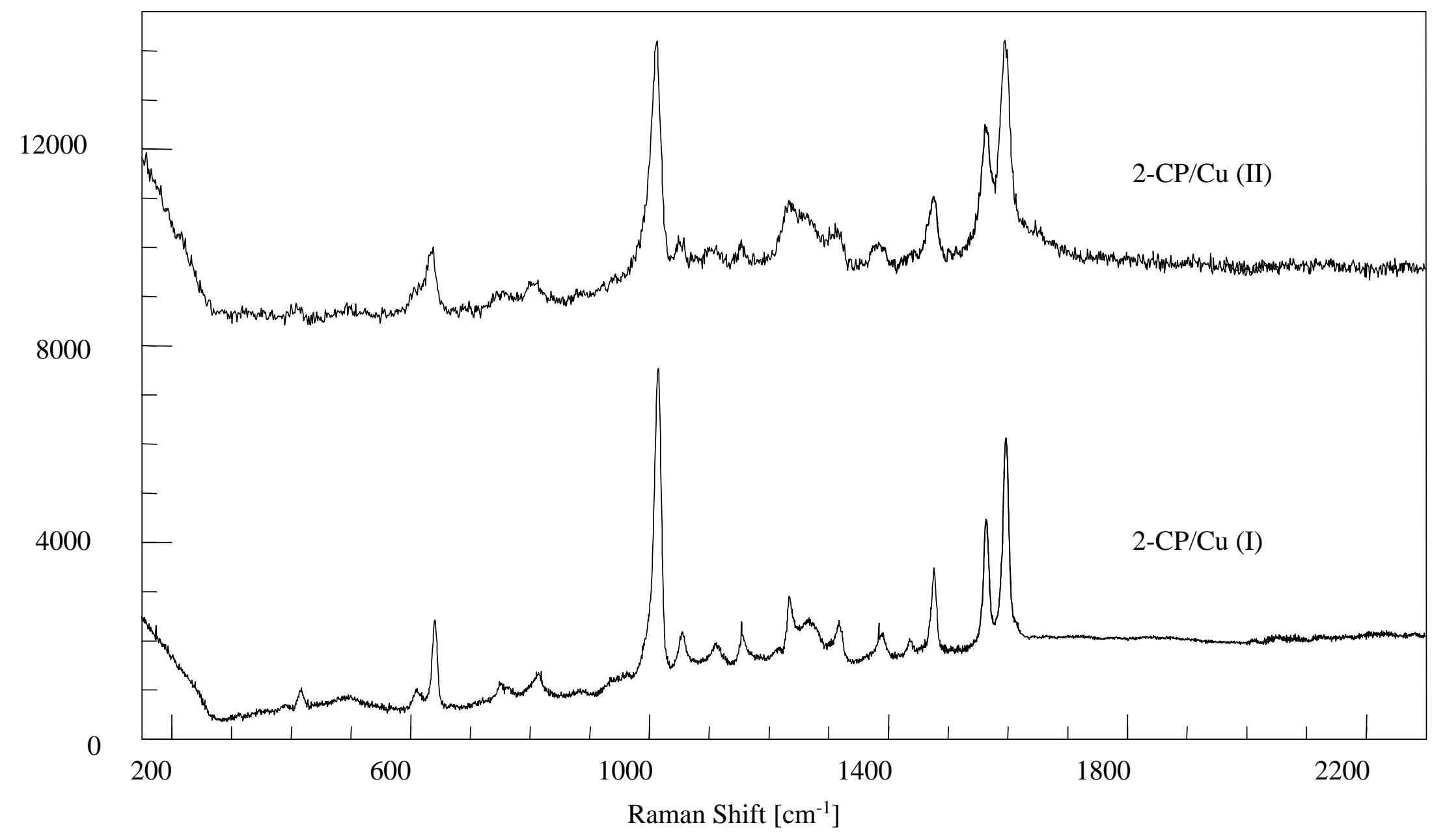

Figure 3-8 SERS of 2-cyanopyridine (2-CP) adsorbed onto copper colloids prepared from $\mathrm{Cu}^{+1}(/ \mathrm{Cu}(\mathrm{I}))$ and $\mathrm{Cu}^{+2}$ $(/ \mathrm{Cu}$ (II)) reduction. 


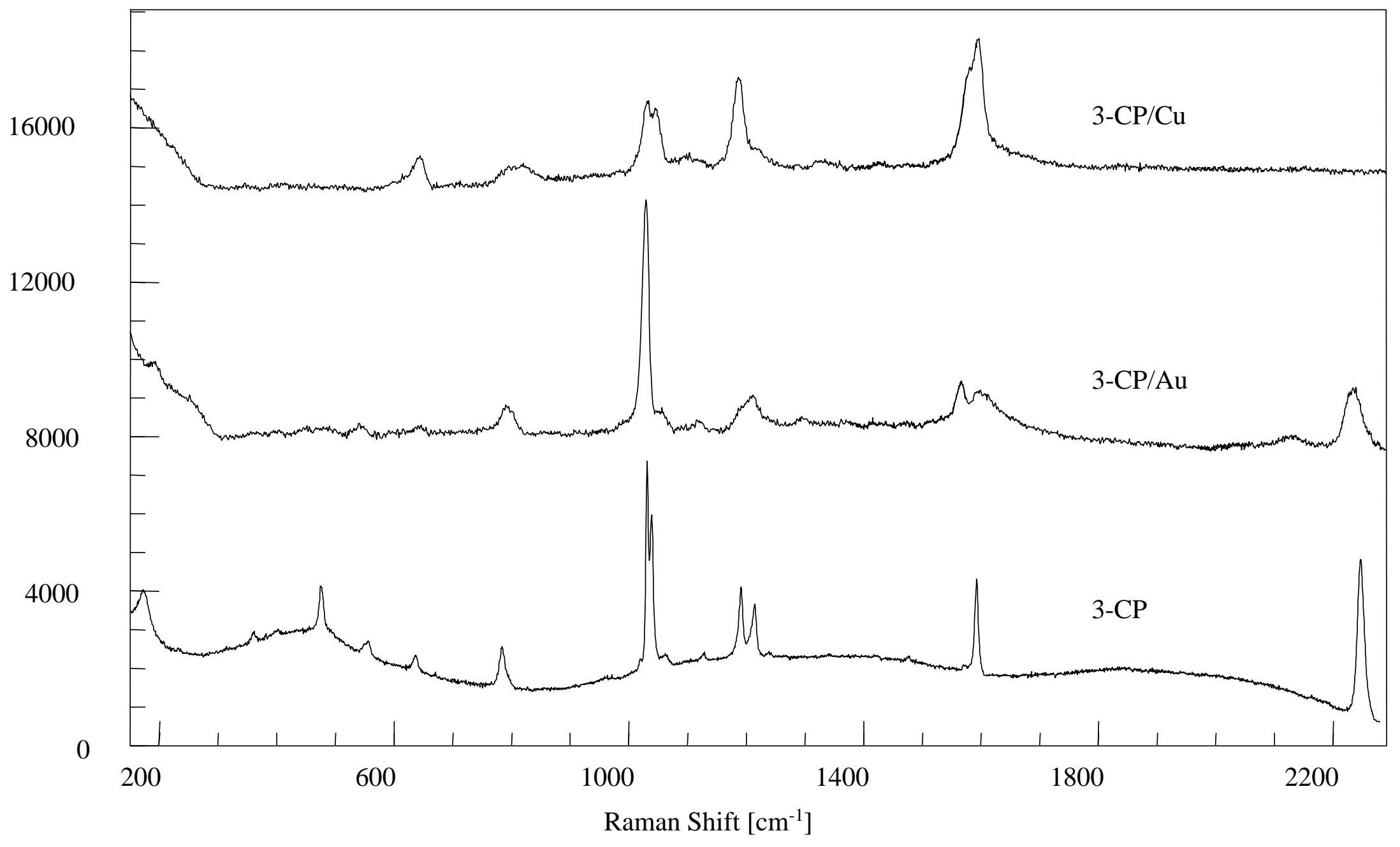

Figure 3-9 Raman spectra of 3-cyanopyridine (3-CP) and SERS of 3-CP adsorbed onto copper (/Cu) and gold (/Au) colloids. 
the $1572 \mathrm{~cm}^{-1}(\mathrm{v}(\mathrm{CC}))$ in the Raman is enhanced to almost equal intensity to the $1595 \mathrm{~cm}^{-1}$ $(v(C C))$ in the SERS. These features support adsorption occurring via the pyridine nitrogen as seen in prior studies. ${ }^{3,6}$ Relative to the SERS collected for 4-CP mixed with a copper colloid, the amount of enhancement observed for the 3-CP is less. Two insights are gained from the adsorption of 3-CP in compared to 4-CP: (1) the adsorption is based on a weaker interaction with the metal surface as indicated by the weaker surface enhancement; and (2) the lower the molecular symmetry, the lower the surface enhancement observed.

In the SER spectrum of 3-CP adsorbed on a gold colloid, a $v(\mathrm{C} \equiv \mathrm{N})$ signal is present and shifted to the red by $5 \mathrm{~cm}^{-1}$ to $2235 \mathrm{~cm}^{-1}$. This observed wavenumber coincides with values reported when 3-CP is adsorbed onto copper and silver electrodes in an end-on configuration with adsorption via the pyridine nitrogen. ${ }^{3,6}$ The most significant change in relative intensity of SERS for 3-CP adsorbed onto a gold colloid is that the $1032 \mathrm{~cm}^{-1}$ ring breathing mode dominates over the other modes associated with the aromatic ring. This would indicate that the interaction between the molecule and the colloidal surface is an end-on orientation causing this particular mode to become aligned perpendicular relative to the metal surface, and thus, resulting in the greatest surface enhancement. The ring modes at $1595 \mathrm{~cm}^{-}$ ${ }^{1}, 1192 \mathrm{~cm}^{-1}, 1052 \mathrm{~cm}^{-1}$, and $1028 \mathrm{~cm}^{-1}$ shift to higher wavenumbers, which is consistent with adsorption via the nitrogen on the aromatic ring. ${ }^{3,5,6,9}$ These observations confirm that the primary adsorption site for 3-CP is via the nitrogen on the aromatic ring.

The SERS of 2-CP mixed with gold and copper colloids and the Raman spectrum of 2-CP are shown in Figure 3-10. The observed Raman frequencies and tentative assignments 


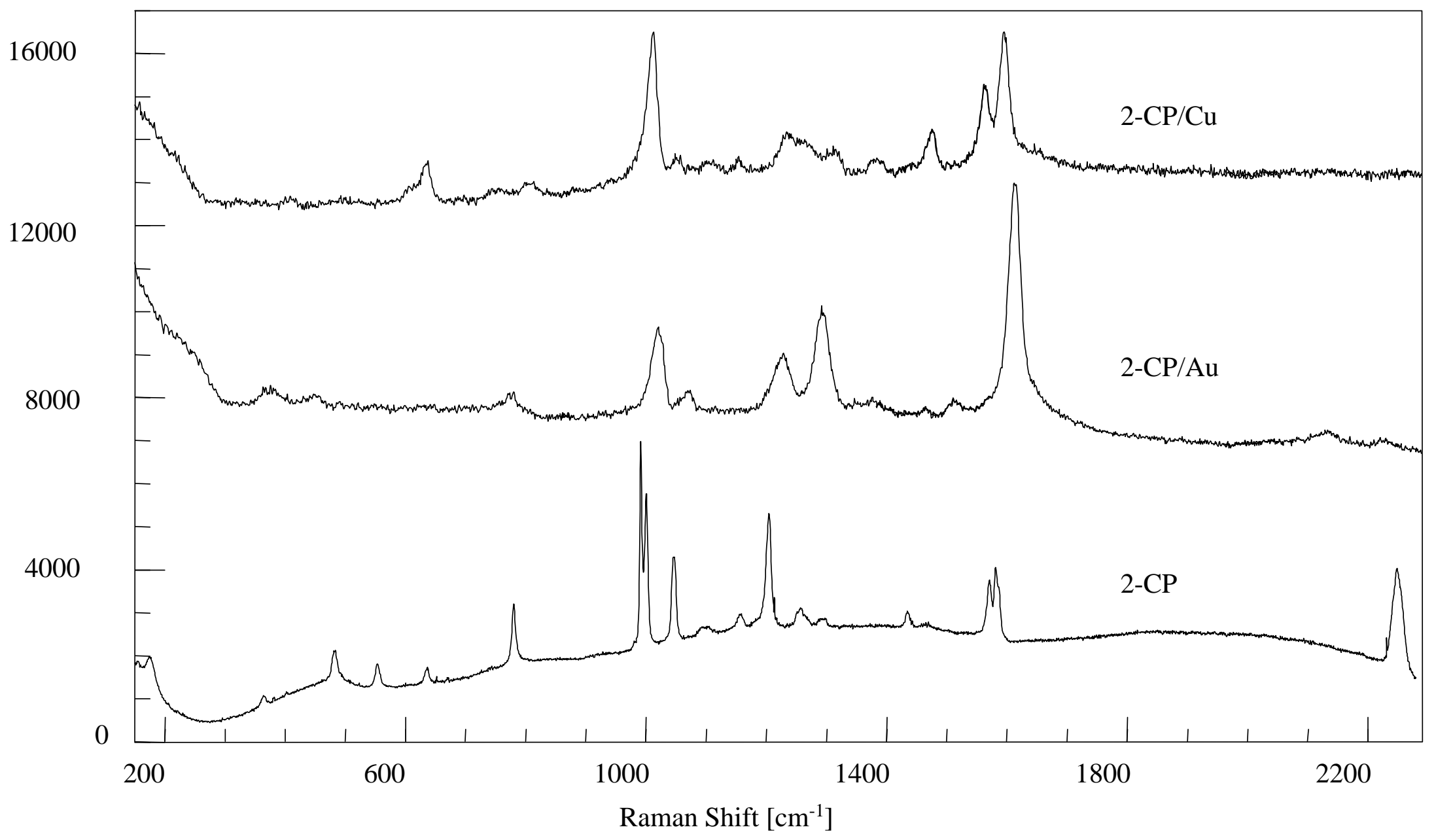

Figure 3-10 Raman spectra of 2-cyanopyridine (2-CP) and SERS of 2-CP adsorbed onto copper (/Cu) and gold (/Au) colloids. 
are reported in Table 3-2. The Raman of 2-CP appears more complex than 4-CP and 3-CP due to lower molecular symmetry. The SERS of 2-CP mixed with a copper colloid shows the absence of the $2243 \mathrm{~cm}^{-1}(\mathrm{v}(\mathrm{C} \equiv \mathrm{N}))$ band. The nitrile sensitive bands at $1206 \mathrm{~cm}^{-1}, 779 \mathrm{~cm}^{-}$ ${ }^{1}, 554 \mathrm{~cm}^{-1}, 482 \mathrm{~cm}^{-1}, 364 \mathrm{~cm}^{-1}$, and $175 \mathrm{~cm}^{-1}$ disappear in the SER spectrum. ${ }^{23}$ The relative shifts of the ring modes to $1594 \mathrm{~cm}^{-1}, 1563 \mathrm{~cm}^{-1}, 1475 \mathrm{~cm}^{-1}$ and $1011 \mathrm{~cm}^{-1}$ from $1587 \mathrm{~cm}^{-1}$, $1573 \mathrm{~cm}^{-1}, 1469 \mathrm{~cm}^{-1}$, and $1001 \mathrm{~cm}^{-1}$, respectively, all correspond to adsorption occurring via the pyridine nitrogen. ${ }^{6}$ The observation of large positive shifts in the ring modes has been interpreted as being indicative of nitrile bonding. ${ }^{15}$ The complexity of the SERS for 2-CP and observed blue shifts would indicate that the bonding of 2-CP when mixed with the copper surface involves coordination via both the pyridine and nitrile nitrogens. ${ }^{3}$ The complexity of the SERS in comparison with 4- and 3-CP mixed with copper is due to the proximity of the substituent group relative to the metal surface. The SER spectrum shows the appearance of more asymmetric modes which means that the dipole change of these modes are oriented perpendicular to the surface. The overall enhancement factor of the 2-CP is considerably less than observed for 4-CP and 3-CP.

In the SER spectrum of 2-CP adsorbed on a gold colloid, a signal due to $v(C \equiv N)$ is present and shifted $17 \mathrm{~cm}^{-1}$ to $2226 \mathrm{~cm}^{-1}$. This suggests that the orientation of the molecule is partially a flat-on orientation due to interaction between the gold surface and both nitrogen adsorption sites. ${ }^{15,18}$ Coordination via the nitrile band should give rise to a signal above that of the parent $\mathrm{v}(\mathrm{C} \equiv \mathrm{N})$ mode $^{26-28}$ and adsorption via the nitrile nitrogen in a flat-on orientation results in bands lower than the parent $\mathrm{v}(\mathrm{C} \equiv \mathrm{N}) .^{29,30}$ The intensity of the nitrile band for 2-CP on the gold colloid is weak with respect to the other primary ring modes present in the SER 
spectrum which indicates weak interaction between the nitrile nitrogen and the metal surface. The nitrile sensitive bands undergo shifts in the SERS to $1464 \mathrm{~cm}^{-1}, 1228 \mathrm{~cm}^{-1}, 775 \mathrm{~cm}^{-1}, 546$ $\mathrm{cm}^{-1}, 488 \mathrm{~cm}^{-1}$, and $375 \mathrm{~cm}^{-1}$ which are indicative of adsorption via the nitrile nitrogen. ${ }^{23}$ Due to the weak conjugation of the nitrile group with respect to the aromatic ring, shifts in the nitrile sensitive bands represent interactions of the cyano group with the surface. The dominant bands in the SERS found at $1613 \mathrm{~cm}^{-1}(\mathrm{~V}(\mathrm{CC})), 1292 \mathrm{~cm}^{-1}(\beta(\mathrm{CH})), 1228 \mathrm{~cm}^{-1}$ $(\mathrm{C} \equiv \mathrm{N})$, and $1019 \mathrm{~cm}^{-1}$ (ring) are shifted to higher frequencies which are indicative of adsorption via both nitrogens present in the molecule. ${ }^{3}$

Based on the SERS collected for all three forms of the adsorbates and their respective counterparts, we can report that the reduction is consistent for all forms of cyanopyridine. The Raman frequencies for all three isomers of cyanopyridine with the respective reduction products are reported in Table 3-7. It can be seen that all three isomers produce SERS with the strongest enhanced modes being associated with the symmetric ring modes. The spectral pattern appears to become more complicated as the substituent moves from the 4- to 3- to 2- position on the ring. This is indicative of the symmetry of the molecule and the adsorption occurring primarily through the nitrogen on the ring for 4-CP and 3-CP and through both nitrogens for 2-CP.

Based on the symmetry rules of SERS theory, one would expect that the more symmetric the adsorbate/molecule the greater the SER enhancement observed. ${ }^{3,6,9}$ Consistent with this theory, the adsorption of 4-CP shows greater enhancement than 3-CP, and 3-CP greater than 2-CP. When comparing the cyanopyridines (4-CP to 3-CP to 2-CP) we find an increase in enhancement of antisymmetric modes compared to the symmetric 
TABLE 3-7: $\quad$ Raman Frequencies $\left(\mathrm{cm}^{-1}\right)$ of Cyanopyridines (4-, 3-, and 2-CP) and Aminomethylpyridines (4-, 3-, and 2-AMP) Adsorbed onto Copper (/Cu) Colloids.

\begin{tabular}{|c|c|c|c|c|c|c|}
\hline Assignment $^{\mathrm{a}}$ & $4-\mathrm{CP} / \mathrm{Cu}$ & 4-AMP/Cu & $3-\mathrm{CP} / \mathrm{Cu}$ & 3-AMP/Cu & $2-\mathrm{CP} / \mathrm{Cu}$ & 2-AMP/Cu \\
\hline $\mathrm{S}$ & 371 & - & 347 & 347 & - & - \\
\hline$\gamma\left(\mathrm{C}-\mathrm{NH}_{2}\right)$ & - & - & 414 & 407 & 410 & 412 \\
\hline Ring deformation & 500 & 500 & - & 491 & 501 & 500 \\
\hline$\gamma\left(\mathrm{NH}_{2}\right)$ & 605 & 606 & 620 & 625 & 614 & 611 \\
\hline$\alpha(\mathrm{CCC})$ & 668 & 664 & 644 & 645 & 637 & 639 \\
\hline S & - & - & - & - & - & - \\
\hline $\mathrm{S}$ & - & - & 699 & 698 & - & - \\
\hline$\gamma(\mathrm{CH}), \mathrm{NH}_{2}$ sens. & - & - & - & - & 750 & 751 \\
\hline $\mathrm{v}(\mathrm{CC})$ & 797 & 796 & 797 & 799 & - & - \\
\hline $\mathrm{S}$ & - & - & - & - & 807 & 809 \\
\hline$\gamma(\mathrm{CH})$ & - & - & 820 & 819 & - & - \\
\hline S & 841 & 841 & - & - & - & - \\
\hline $\mathrm{S}$ & - & - & - & - & - & 884 \\
\hline$\beta(\mathrm{CH})$ & - & - & 928 & 928 & - & 935 \\
\hline $\mathrm{S}$ & - & - & 983 & 980 & - & - \\
\hline Ring breathing & 1018 & 1017 & 1030 & 1029 & 1011 & 1013 \\
\hline$\beta\left(\mathrm{NH}_{2}\right), \beta(\mathrm{CH})$ & 1065 & 1064 & 1045 & 1046 & 1052 & 1055 \\
\hline $\mathrm{S}$ & - & - & 1098 & 1095 & - & - \\
\hline$\beta(\mathrm{CH})$ & - & - & - & - & 1105 & 1110 \\
\hline S & - & - & 1120 & 1121 & - & - \\
\hline $\mathrm{S}$ & 1148 & - & - & - & 1153 & 1154 \\
\hline
\end{tabular}


TABLE 3-7: $\quad$ (Continued)

\begin{tabular}{|c|c|c|c|c|c|c|}
\hline Assignment $^{\mathrm{a}}$ & $4-\mathrm{CP} / \mathrm{Cu}$ & 4-AMP/Cu & $3-\mathrm{CP} / \mathrm{Cu}$ & 3-AMP/Cu & $2-\mathrm{CP} / \mathrm{Cu}$ & 2-AMP/Cu \\
\hline$\beta(\mathrm{CH})$ & 1212 & 1210 & 1188 & 1189 & - & - \\
\hline$\beta(\mathrm{CH}), \alpha(\mathrm{CC})$ & 1216 & 1215 & 1216 & 1218 & - & - \\
\hline $\mathrm{S}$ & - & - & - & - & 1235 & 1235 \\
\hline$\alpha(\mathrm{CC})$ & - & - & - & - & 1259 & 1262 \\
\hline $\mathrm{S}$ & - & - & - & - & 1314 & 1315 \\
\hline$\beta(\mathrm{CH})$ & 1339 & 1340 & 1334 & 1336 & - & - \\
\hline S & - & - & - & 1386 & 1383 & 1388 \\
\hline $\mathrm{S}$ & 1423 & 1420 & 1426 & 1426 & - & - \\
\hline$v(C C)$ & - & - & - & - & - & 1436 \\
\hline S & - & - & - & - & 1475 & 1478 \\
\hline$v(C C)$ & 1498 & 1497 & 1478 & 1476 & - & - \\
\hline$v(\mathrm{CC})$ & 1552 & 1552 & 1581 & 1578 & 1563 & 1565 \\
\hline$v(C C)$ & 1609 & 1610 & 1595 & 1594 & 1594 & 1596 \\
\hline
\end{tabular}

a. Based on Ref. 24 and 25. 
modes of the molecules. The complexity of the spectra of the 2-CP adsorbed on the metal colloids would indicate possible interactions of both the nitrogens with the surface.

It can be imagined that the relative enhancements might be a function of the distance of the substituent from the metal surface, although if there is a strong electronic "communication" between the amino group and the pyridine ring, one would expect that the distance of the amino group from the surface would not affect the SERS intensity. ${ }^{31}$ Since any distance dependence would reduce the intensity of $4-\mathrm{CP}$ relative to $2-\mathrm{CP}$, it appears that any distance effects are much weaker than the orientation effects.

\subsection{CONCLUSIONS}

The SERS collected for the three cyanopyridines adsorbed onto the surface of copper colloids exhibit a complete disappearance of the nitrile stretching normal mode which is due to a metal-assisted reduction of the nitrile group to an amino group. Adsorption of the reduction products (aminomethylpyridines) occurs primarily through the pyridine nitrogen. The SERS of 2-AMP exhibit strong contributions due to the interaction of the amino substituent with the metal surface, thus indicating adsorption via both nitrogens.

The orientation specificity of SER scattering has been demonstrated. The SER spectra for all three isomeric forms of cyanopyridines adsorbed onto copper colloids supports the theory that the normal modes with substantial perpendicular components relative to the surface show the largest enhancement. In addition, the 4-cyanopyridine spectrum shows generally greater surface enhancement than the SERS of 3- and 2-cyanopyridine. Thus, observation of specific SER bands can provide insight into the orientation of the adsorbates 
relative to the colloidal surfaces as well as the identity of the molecular moiety that attaches to the surface. 


\section{REFERENCES}

1. C. S. Allen and R. P. Van Duyne, Chem. Phys. Lett. 63, 455 (1979).

2. U. Wenning, B. Pettinger and H. Wetzel, Chem. Phys. Lett. 70, 49-54 (1980).

3. C. S. Allen, G. C. Schatz and R. P. Van Duyne, Chem. Phys. Lett. 75, 201-205 (1980).

4. M. L. A. Temperini, H. C. Chagas and O. Sala, Chem. Phys. Lett. 79, 75-78 (1981).

5. J. C. Rubim and O. Sala, J. Mol. Spectrosc. 145, 157-172 (1986).

6. C. S. Allen, PhD Thesis, Northwestern University (1980); University Microfilms, AAG8104683.

7. G. T. Merklin and P. R. Griffiths, J. Phys. Chem. B 101, 5810-5813 (1997).

8. J. A. Creighton, Anal. Proc. 30, 28 (1993).

9. J. C. Rubim, J. Electroanal. Chem. 220, 339 (1987).

10. C. S. Allen and R. P. Van Duyne, J. Am. Chem. Soc. 103, 7497-7501 (1981).

11. S. Sanchez-Cortes and J. V. Garcia-Ramos, J. Raman Spectrosc. 29, 365-371 (1998).

12. R. L. Garrell, Anal. Chem. 6 61, 401A (1989).

13. L. E. Camafeita, S. Sanchez-Cortes and J. V. Garcia-Ramos, J. Raman Spectrosc. 26, 149-154 (1995).

14. J. A. Creighton, Surface Sci. 158, 211-221 (1985).

15. F. Farha and R. T. Iwamoto, Inorg. Chem. 4, 844 (1965).

16. D. G. Brewer and P. T. T. Wong, Can. J. Chem. 44, 1407 (1966).

17. J. Burgess, Spectrochim. Acta 24A, 1645 (1968).

18. L. El-Sayed and R. O. Ragsdale, J. Inorg. Nucl. Chem. 30, 651 (1968).

19. J. A. Creighton, M.S. Alvarez, D.A. Weltz, S. Garoff and M. W. Kim, J. Phys. Chem. 87, 4793 (1983). 
20. J. A. Creighton and D. G. Eadon, J. Chem. Soc., Faraday Trans. 24 87, 3881-3891 (1991).

21. O. Siiman, L. A. Bumm, R. Callaghan, C. G. Blatchford and M. Kerker, J. Phys. Chem. 87, 1014 (1983).

22. D. Meisel and P. C. Lee, J. Phys. Chem. 86, 3391 (1982).

23. J. H. S. Green and D. J. Harrison, Spectrochim. Acta, Part A 33, 75 (1977).

24. M. L. A. Temperini, J. C. Rubim, O. Sala, A. H. Jubert, M. E. Chacon Vilalba and P. J. Aymonino, J. Raman Spectrosc. 22, 301(1991).

25. G. Varsanyi, Assignments for Vibrational Spectra of Seven Hundred Benzene Derivatives, pp. 11-35. Wiley, New York (1974).

26. H. J. Coever and C. Curran, J. Am. Chem. Soc. 80, 3522 (1958).

27. W. Gerrard, M. F. Lappert, H. Pyszora and J. W. Wallis, J. Chem. Soc. 2182 (1960).

28. M. Kubota and S. R. Schulze, Inorg. Chem. 3, 853 (1964).

29. H. Chang, L. J. Lee and U. H. Sheu, J. Chinese Chem. Soc. 40, 413-418 (1993).

30. C. S. Allen and R. P. Van Duyne, J. Am. Chem. Soc. 103, 7497-7501 (1981).

31. Q. Ye, J. Fang, and L. Sun, J. Phys. Chem. 101, 8221-8224 (1997). 


\section{CHAPTER 4}

\section{Other Nitrile Adsorbates on Copper Colloids}

\subsection{INTRODUCTION}

In order to distinguish whether the reduction mechanism is unique for the case of cyanopyridines mixed with copper colloids (as shown in Chapters 2 and 3), other nitrile containing molecules were mixed with both copper and gold colloids. The molecules included in this study are benzonitrile (BN), 1,4-dicyanobenzene (1,4-DCB), acetonitrile (AN) and hexanenitrile (HN) (see Figure 4-1). These molecules were chosen to delineate the importance of two molecular characteristics in the reduction process. These characteristics are the presence of a pyridine moiety and the proximity of the cyano group to the ring. These results will help define the generality of the reduction process in the copper colloidal system.

\subsection{EXPERIMENTAL}

\section{Colloidal Preparation}

The copper and gold colloids were prepared as follows. The preparation of the copper colloids is based on the borohydride reduction of $\mathrm{Cu}^{2+}$ as described in Chapter 2.2. ${ }^{1}$ The copper colloid, which starts as a pale yellow-brown color becomes a dark reddish-brown indicative of particle sizes ranging from 10 to $20 \mathrm{~nm}$ and give rise to an absorption band at $564 \mathrm{~nm} .{ }^{3}$ The copper colloids were allowed to age for two hours prior to adsorption of the organonitriles. The preparation of the gold colloid by citrate reduction is described in 


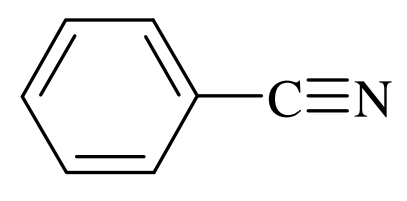

BN

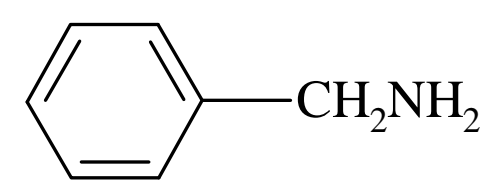

BA

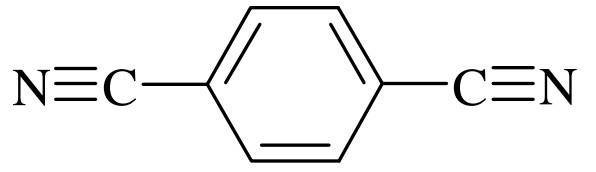

$1,4-\mathrm{DCB}$

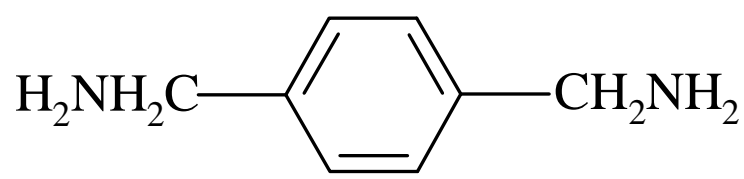

XY

$$
\mathrm{CH}_{3}-\mathrm{C} \equiv \mathrm{N}
$$

AN

$$
\mathrm{CH}_{3}-\mathrm{CH}_{2} \mathrm{NH}_{2}
$$

EA

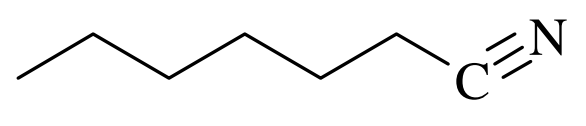

HN

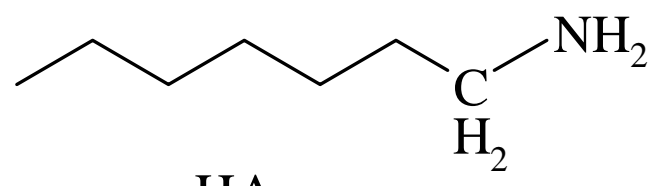

HA

Figure 4-1 Molecular structures for benzonitrile (BN), benzylamine (BA), 1,4-dicyanobenzene (1,4-DCB), xylylenediamine (XY), acetonitrile (AN), ethylamine (EA), hexanenitrile (HN) and hexylamine (HA). 
Chapter 2.2. ${ }^{2}$ The gold colloid exhibits an absorption band at $523 \mathrm{~nm}$ upon aging. ${ }^{3}$ All colloidal solutions were prepared in disposable borosilicate glass culture tubes with water passed through a Barnstead/Thermolyne (Dubuque, IA) Nanopure Water Model D4541 purification system.

The samples were prepared by adding $0.300 \mathrm{~mL}$ of each adsorbate to $3.150 \mathrm{~mL}$ of each of the aged colloids. The following adsorbates were used without further purification: benzonitrile (Aldrich chemical Co., Milwaukee, WI; 99.9\%), benzylamine (Aldrich; 99\%), 1,4-dicyanobenzene (Aldrich; 98\%), xylylenediamine (Aldrich; 99\%), acetonitrile (Aldrich; 99.9\%), ethylamine 97\%), hexanenitrile (Aldrich; 98\%), and hexylamine (Aldrich; 99\%). Data collection of the SER spectra of the organonitriles adsorbed onto the copper colloids was begun 80 minutes after the addition of the adsorbate solution to the colloid.

Data collection parameters are also defined in Chapter 2.2.

\subsection{RESULTS AND DISCUSSION}

Spectra were collected for all adsorbates on copper and gold colloids, and for the parent compounds and possible reduction products.

\section{Benzonitrile and Benzylamine}

The SER spectra obtained when benzonitrile $(\mathrm{BN})$ is mixed with gold and copper colloids and the Raman spectrum of the parent BN are shown in Figure 4-2. The observed wavenumbers and tentative assignments are presented in Table 4-1. Upon mixing with a copper colloid, the $v(C \equiv N)$ disappears, although it is the strongest band in the Raman 


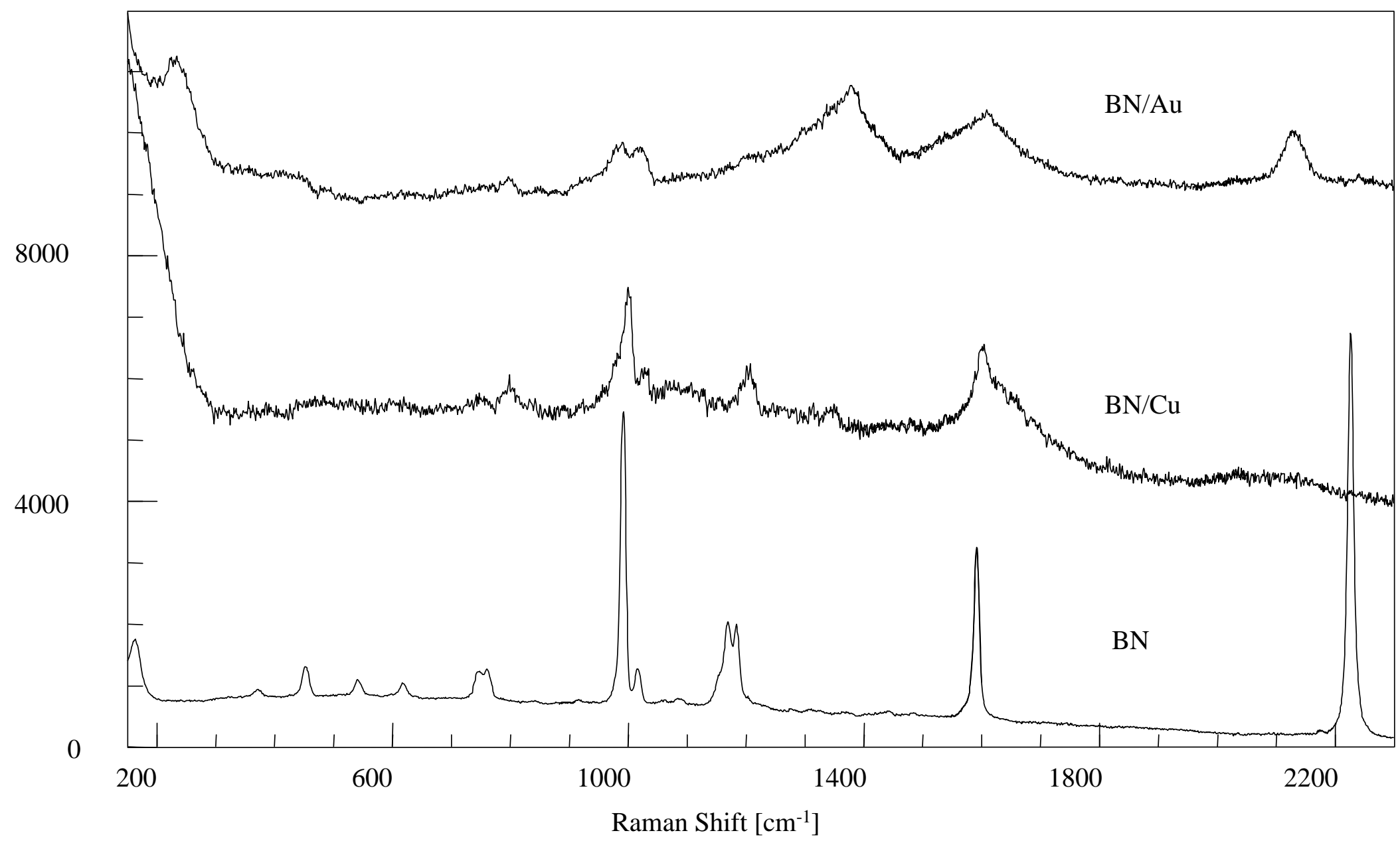

Figure 4-2 Raman spectra of neat benzonitrile (BN) and SERS of BN adsorbed onto copper (/Cu) and gold (/Au) colloids. 
TABLE 4-1: $\quad$ Raman Frequencies $\left(\mathrm{cm}^{-1}\right)$ of Neat Benzonitrile $(\mathrm{BN})$ and Neat Benzylamine (BA) and Adsorbed onto Copper $(/ \mathrm{Cu})$ and Gold (/Au) Colloids.

\begin{tabular}{|c|c|c|c|c|c|c|c|}
\hline Assignment $^{\mathrm{a}}$ & $\mathrm{BN}$ liquid & $\mathrm{BN} / \mathrm{Au}$ & $\mathrm{BN} / \mathrm{Cu}$ & $\mathrm{BA} / \mathrm{Cu}$ & $\mathrm{BA} / \mathrm{Au}$ & BA liquid & Assignment $^{\mathrm{a}}$ \\
\hline$\gamma(\mathrm{C} \equiv \mathrm{N})$ & 169 & - & - & - & - & - & - \\
\hline $\mathrm{S}$ & - & 244 & - & - & 238 & - & - \\
\hline $\mathrm{C} \equiv \mathrm{N}$ sensitive & 378 & - & - & - & 343 & - & - \\
\hline S & - & - & - & - & 399 & 402 & - \\
\hline $\mathrm{C} \equiv \mathrm{N}$ sensitive & 459 & 439 & 455 & 454 & - & - & - \\
\hline $\mathrm{S}$ & - & - & - & - & - & 484 & $\mathrm{CH}_{2} \mathrm{NH}_{2}$ sensitive \\
\hline $\mathrm{C} \equiv \mathrm{N}$ sensitive & 547 & - & - & - & - & - & - \\
\hline $\mathrm{S}$ & - & - & 599 & 604 & 601 & - & - \\
\hline$\alpha(\mathrm{CCC})$ & 622 & - & - & - & - & 621 & $\alpha(\mathrm{CCC})$ \\
\hline$\gamma(\mathrm{CH})$ & 749 & - & 747 & 744 & - & 736 & $\gamma(\mathrm{CH})$ \\
\hline $\mathrm{C} \equiv \mathrm{N}$ sensitive & 761 & - & - & - & - & - & - \\
\hline Ring & - & - & 791 & 793 & 803 & 791 & $\mathrm{CH}_{2} \mathrm{NH}_{2}$ sensitive \\
\hline $\mathrm{S}$ & - & - & - & 831 & - & - & - \\
\hline$\gamma(\mathrm{CH})$ & 927 & - & 937 & - & - & - & - \\
\hline $\mathrm{S}$ & - & - & 981 & 984 & 983 & - & - \\
\hline Ring breathing & 1001 & 998 & 1000 & 997 & - & 1003 & Ring breathing \\
\hline$\beta(\mathrm{CH})$ & 1024 & 1020 & 1028 & 1028 & - & 1030 & $\beta(\mathrm{CH})$ \\
\hline$\beta(\mathrm{CH})$ & 1068 & - & - & - & - & - & - \\
\hline $\mathrm{S}$ & 1096 & - & - & - & - & - & - \\
\hline$\beta(\mathrm{CH})$, Ring & 1178 & - & - & - & - & 1164 & $\beta(\mathrm{CH})$ \\
\hline $\mathrm{C} \equiv \mathrm{N}$ sensitive & 1192 & - & - & - & - & 1186 & $\beta(\mathrm{CH})$, Ring \\
\hline
\end{tabular}


TABLE 4-1: $\quad$ (Continued)

\begin{tabular}{|c|c|c|c|c|c|c|c|}
\hline Assignment $^{\mathrm{a}}$ & $\mathrm{BN}$ liquid & $\mathrm{BN} / \mathrm{Au}$ & $\mathrm{BN} / \mathrm{Cu}$ & $\mathrm{BA} / \mathrm{Cu}$ & $\mathrm{BA} / \mathrm{Au}$ & BA liquid & Assignment $^{\mathrm{a}}$ \\
\hline $\mathrm{S}$ & - & - & 1203 & 1202 & 1207 & 1208 & $\gamma\left(\mathrm{CH}_{2}\right)$ \\
\hline $\mathrm{S}$ & 1287 & - & - & - & - & - & - \\
\hline $\mathrm{S}$ & 1319 & - & - & - & - & - & - \\
\hline $\mathrm{S}$ & 1335 & - & 1348 & 1343 & - & - & - \\
\hline $\mathrm{S}$ & 1373 & - & - & - & 1381 & - & - \\
\hline$v(\mathrm{CC})$ & 1448 & 1449 & - & - & 1440 & - & - \\
\hline $\mathrm{S}$ & - & - & - & - & - & 1465 & $v(C C)$ \\
\hline $\mathrm{S}$ & 1492 & - & - & - & - & - & - \\
\hline $\mathrm{S}$ & - & - & - & - & - & 1591 & $v(\mathrm{CC})$ \\
\hline$v(C C)$ & 1600 & 1608 & 1602 & 1600 & 1601 & 1607 & $v(C C)$ \\
\hline$v(C \equiv N)$ & 2229 & 2131 & - & - & - & - & - \\
\hline
\end{tabular}

a. Based on Ref. 4-8. 
spectrum of the parent molecule $\left(2229 \mathrm{~cm}^{-1}\right)$. Additionally, the bands $1192 \mathrm{~cm}^{-1}(\mathrm{C} \equiv \mathrm{N}$ sensitive $), 761 \mathrm{~cm}^{-1}(\mathrm{C} \equiv \mathrm{N}$ sensitive $), 547 \mathrm{~cm}^{-1}(\mathrm{C} \equiv \mathrm{N}$ sensitive $), 459 \mathrm{~cm}^{-1}(\mathrm{C} \equiv \mathrm{N}$ sensitive $), 378$ $\mathrm{cm}^{-1}(\mathrm{C} \equiv \mathrm{N}$ sensitive $)$, and $169 \mathrm{~cm}^{-1}(\mathrm{C} \equiv \mathrm{N}$ sensitive $)$ all disappear. ${ }^{4-7}$ The strongest bands in the SERS are associated with the symmetric modes of the pyridine ring; $1602 \mathrm{~cm}^{-1}(\mathrm{v}(\mathrm{CC}))$ and $1000 \mathrm{~cm}^{-1}$ (ring breathing). These modes are also the strongest bands in the Raman spectrum of BN. The appearance of a band at $1203 \mathrm{~cm}^{-1}\left(\gamma\left(\mathrm{CH}_{2}\right)\right)$ indicates that a reduction of the nitrile substituent has occurred. The disappearance of the nitrile band was unexpected based on previous investigations of $\mathrm{BN}$ on other metal surfaces ${ }^{9-12}$, but easy to explain based on our recent work.

As noted in Chapter 3, when the nitrile frequency is lower than the free molecule, then the orientation is assumed to be in a flat-on configuration. When the nitrile frequency is higher or near the free molecule, then the orientation is assumed to be in an end-on configuration. The SERS of BN adsorbed onto a gold colloid shows the presence of a nitrile stretching signal at $2131 \mathrm{~cm}^{-1}$. This frequency indicates that adsorption is occurring via the nitrogen on the cyano group in a flat-on configuration. ${ }^{13-15}$ The band at $449 \mathrm{~cm}^{-1}(\mathrm{C} \equiv \mathrm{N}$ sensitive) undergoes a shift to a lower a frequency, while the ring modes of $1608 \mathrm{~cm}^{-1}$ $(\mathrm{v}(\mathrm{CC})), 1449 \mathrm{~cm}^{-1}(\mathrm{v}(\mathrm{CC})), 1020 \mathrm{~cm}^{-1}(\beta(\mathrm{CH}))$, and $998 \mathrm{~cm}^{-1}$ (ring breathing) undergo very little shift. ${ }^{4-8}$ This would indicate that the interaction occurs between the metal surface and the ring. The relative enhancement of both the symmetric and antisymmetric modes ${ }^{16}$, specifically the detection of the SER band at $1449 \mathrm{~cm}^{-1}(\mathrm{~V}(\mathrm{CC}))^{9}$ indicates that the orientation of the molecule is in a flat-on fashion which is consistent with the lowered $v(C \equiv N)$. 
The SERS collected is relatively weak for the adsorption of BN onto both the copper and gold colloids. This is due to the fact that the interaction between the substituent and the metal surface is relatively weak. ${ }^{17}$ The gold colloid does not aggregate well upon adsorption of BN. Regardless of the weak aggregation, a nitrile band is still present in the SERS. The copper colloids mixed with BN show weak signs of aggregation (slight color change), and so the relative intensity of the SER bands are greater for copper than for gold.

The SER spectra obtained when benzylamine (BA) and BN are adsorbed onto copper colloids and the Raman spectrum of BA are shown in Figure 4-3. The observed wavenumbers and tentative assignments are presented in Table 4-1. The SERS of BA and $\mathrm{BN}$ with copper colloids are identical in spectral pattern and frequencies (within experimental error). In addition, the Raman bands of $1607 \mathrm{~cm}^{-1}(\mathrm{v}(\mathrm{CC})), 1208 \mathrm{~cm}^{-1}\left(\gamma\left(\mathrm{CH}_{2}\right)\right), 1030 \mathrm{~cm}^{-1}$ $(\beta(\mathrm{CH}))$, and $1003 \mathrm{~cm}^{-1}$ (ring) in the spectrum of BA are all shifted to lower frequencies in the SERS relative to the parent molecule. ${ }^{4,8}$ This indicates adsorption via the nitrogen on the amino group with an orientation in a flat-on fashion relative to the metal surface based on the shifts to lower frequencies.

The SERS of BN mixed with a copper colloid demonstrates that a transition metalassisted borohydride reduction of the nitrile group to an amino group occurs. Therefore, adsorption in a flat-on configuration involving the nitrile interacting with the surface does not hinder the reaction. In addition, a pyridine ring is not essential for the reaction to proceed. 


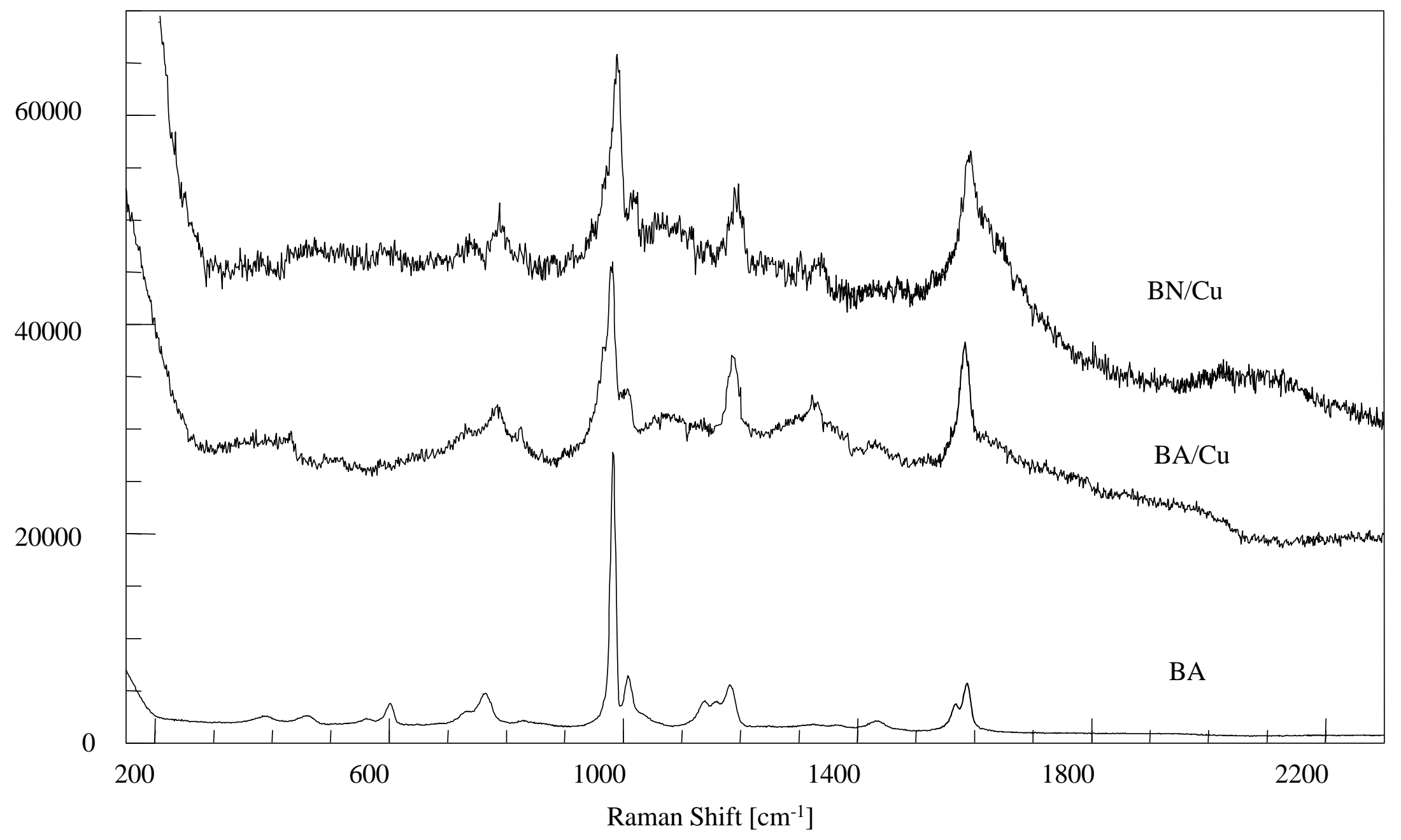

Figure 4-3 Raman spectra of neat benzylamine (BA) and SERS of BA and BN adsorbed onto copper (/Cu) colloids. 


\section{1,4-Dicyanobenzene and Xylylenediamine}

The SER spectra obtained when 1,4-dicyanobenzene (1,4-DCB) is mixed with gold and copper colloids and the Raman of 1,4-DCB are shown in Figure 4-4. The observed wavenumbers and tentative assignments are presented in Table 4-2. Upon mixing with a copper colloid, the $v(C \equiv N)$ band disappears. In addition, the bands of $1234 \mathrm{~cm}^{-1}(C \equiv N$ sensitive), $1211 \mathrm{~cm}^{-1}(C \equiv N$ sensitive $), 517 \mathrm{~cm}^{-1}(C \equiv N$ sensitive $), 378 \mathrm{~cm}^{-1}(C \equiv N$ sensitive $)$, and $208 \mathrm{~cm}^{-1}(\mathrm{C} \equiv \mathrm{N}$ sensitive $)$ are absent in the SER spectra. ${ }^{18}$ The strongest signals in the SERS are associated with the symmetric modes of the aromatic ring: $1613 \mathrm{~cm}^{-1}(v(C C)), 1203$ $\mathrm{cm}^{-1}(\beta(\mathrm{CH})), 1186 \mathrm{~cm}^{-1}\left(\beta(\mathrm{CH})\right.$, ring), $831 \mathrm{~cm}^{-1}$ (ring, $\left.\gamma(\mathrm{CH})\right)$ and $804 \mathrm{~cm}^{-1}$ (ring, $\left.\gamma(\mathrm{CH})\right)$. It is interesting to note that the bands at $831 \mathrm{~cm}^{-1}$ and $1203 \mathrm{~cm}^{-1}$ are correlated with Ramaninactive but infrared-active vibrations. This occurrence has been reported frequently ${ }^{19-22}$ and has been attributed to a symmetry reduction of the adsorbed molecules. ${ }^{23-25}$ The disappearance of the nitrile stretching signal would suggest that a reduction of the nitrile groups of 1,4-DCB is occurring.

1,4-DCB transforms according to the $\mathrm{D}_{2 \mathrm{~h}}$ point group. The two $-\mathrm{C} \equiv \mathrm{N}$ stretching motions will be classified as symmetric $\left(\mathrm{A}_{1 \mathrm{~g}}\right)$ and antisymmetric $\left(\mathrm{B}_{1 \mathrm{~g}}\right)$. Selection rules show that only the $A_{1 g}$ mode will be Raman active and so only one band will be observed in the $v(C \equiv N)$ region. If both $-C \equiv N$ groups are reduced then no signals are expected in the $v(C \equiv N)$ region. If only one $-\mathrm{C} \equiv \mathrm{N}$ group is reduced then the resultant molecule will possess $\mathrm{C}_{\mathrm{s}}$ point group symmetry and a signal due to the remaining $-\mathrm{C} \equiv \mathrm{N}$ group should be observed. The data indicates that both $-\mathrm{C} \equiv N$ groups are reduced since no signals are observed in the $v(C \equiv N)$ region. 


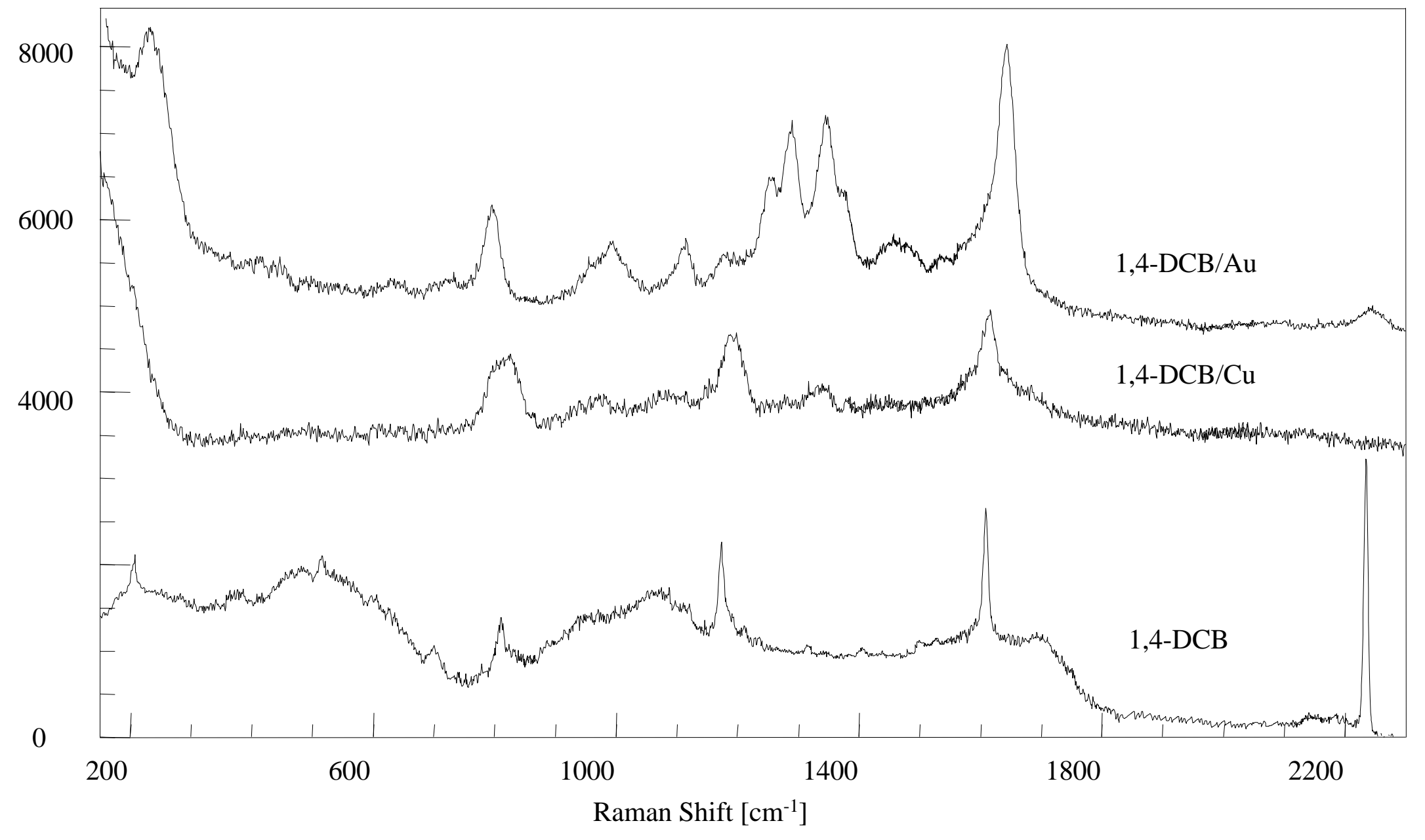

Figure 4-4 Raman spectra of 1,4-dicyanobenzene (1,4-DCB) in aqueous (2.0 M) and SERS of 1,4-DCB adsorbed onto copper $(/ \mathrm{Cu})$ and gold $(/ \mathrm{Au})$ colloids. 
TABLE 4-2: $\quad$ Raman Frequencies $\left(\mathrm{cm}^{-1}\right)$ of 1,4-Dicyanobenzene (1,4-DCB) $(2.0 \mathrm{M})$ and Xylylenediamine $(\mathrm{XY})(2.0 \mathrm{M})$ and Adsorbed onto Copper $(/ \mathrm{Cu})$ and Gold $(/ \mathrm{Au})$ Colloids.

\begin{tabular}{|c|c|c|c|c|c|c|c|}
\hline Assignment $^{\mathrm{a}}$ & $1,4-\mathrm{DCB}(2.0 \mathrm{M})$ & 1,4-DCB/Au & $1,4-\mathrm{DCB} / \mathrm{Cu}$ & $\mathrm{XY} / \mathrm{Cu}$ & $\mathrm{XY} / \mathrm{Au}$ & $\mathrm{XY}(2.0 \mathrm{M})$ & Assignment $^{\mathrm{a}}$ \\
\hline$\gamma(\mathrm{C} \equiv \mathrm{N})$ & 208 & 234 & - & - & 239 & - & - \\
\hline $\mathrm{S}$ & - & - & 313 & 315 & - & - & - \\
\hline $\mathrm{S}$ & - & 409 & - & - & 350 & - & - \\
\hline $\mathrm{C} \equiv \mathrm{N}$ sensitive & 378 & - & - & - & - & 384 & $\mathrm{CH}_{2} \mathrm{NH}_{2}$ sensitive \\
\hline $\mathrm{S}$ & 483 & - & - & - & - & - & - \\
\hline $\mathrm{C} \equiv \mathrm{N}$ sensitive & 517 & - & - & - & - & - & - \\
\hline $\mathrm{S}$ & - & - & - & - & 577 & - & - \\
\hline $\mathrm{S}$ & - & - & - & - & 618 & - & - \\
\hline$\alpha(\mathrm{CCC})$ & 631 & 629 & 636 & 639 & - & 640 & $\alpha(\mathrm{CCC})$ \\
\hline$\gamma(\mathrm{CC})$ & 701 & 720 & - & - & - & - & - \\
\hline $\mathrm{S}$ & - & 796 & 804 & 802 & 804 & 804 & $\mathrm{CH}_{2} \mathrm{NH}_{2}$ sensitive \\
\hline Ring, $\gamma(\mathrm{CH})$ & 811 & - & - & - & - & - & - \\
\hline $\mathrm{S}$ & - & - & 831 & 832 & 829 & 826 & $v\left(\mathrm{C}-\mathrm{NH}_{2}\right)$ \\
\hline $\mathrm{S}$ & - & - & - & - & 921 & - & - \\
\hline $\mathrm{S}$ & - & - & 948 & 948 & 955 & 949 & $\gamma(\mathrm{CH})$ \\
\hline $\mathrm{S}$ & - & - & 977 & 978 & - & - & - \\
\hline Ring breathing & - & 992 & - & - & 1001 & 1002 & Ring breathing \\
\hline$\beta(\mathrm{CH})$ & - & - & 1099 & 1099 & - & 1072 & $\beta(\mathrm{CH}), \beta\left(\mathrm{NH}_{2}\right)$ \\
\hline $\mathrm{S}$ & - & 1113 & 1120 & - & 1114 & - & - \\
\hline $\mathrm{S}$ & - & - & 1154 & 1157 & - & - & - \\
\hline$\beta(\mathrm{CH})$, Ring & 1173 & 1177 & 1186 & 1186 & 1190 & 1185 & $\beta(\mathrm{CH})$, Ring \\
\hline
\end{tabular}


TABLE 4-2: $\quad$ (Continued)

\begin{tabular}{|c|c|c|c|c|c|c|c|}
\hline Assignment $^{\mathrm{a}}$ & $1,4-\mathrm{DCB}(2.0 \mathrm{M})$ & 1,4-DCB/Au & $1,4-\mathrm{DCB} / \mathrm{Cu}$ & $\mathrm{XY} / \mathrm{Cu}$ & $\mathrm{XY} / \mathrm{Au}$ & $\mathrm{XY}(2.0 \mathrm{M})$ & Assignment $^{\mathrm{a}}$ \\
\hline $\mathrm{S}$ & - & - & 1203 & 1202 & 1198 & 1198 & $\gamma\left(\mathrm{CH}_{2}\right)$ \\
\hline $\mathrm{C} \equiv \mathrm{N}$ sensitive & 1211 & - & - & - & - & - & - \\
\hline $\mathrm{C} \equiv \mathrm{N}$ sensitive & 1234 & - & - & - & - & - & - \\
\hline $\mathrm{S}$ & - & 1255 & 1268 & 1267 & - & 1276 & $\mathrm{CH}_{2} \mathrm{NH}_{2}$ sensitive \\
\hline $\mathrm{S}$ & - & 1289 & - & - & 1292 & - & - \\
\hline$\beta(\mathrm{CH}), \mathrm{v}(\mathrm{CC})$ & 1315 & - & - & - & - & - & - \\
\hline $\mathrm{S}$ & - & 1346 & 1340 & 1343 & - & 1357 & $\gamma\left(\mathrm{CH}_{2}\right)$ \\
\hline $\mathrm{S}$ & - & 1375 & 1380 & 1382 & 1374 & 1389 & $\beta\left(\mathrm{CH}_{2}\right)$ \\
\hline$v(C C)$ & 1405 & - & - & - & - & - & - \\
\hline$v(C C)$ & - & 1464 & - & - & 1430 & 1461 & $v(\mathrm{CC})$ \\
\hline $\mathrm{S}$ & 1499 & - & - & - & - & 1511 & - \\
\hline$v(C C)$ & 1526 & 1533 & - & - & - & - & - \\
\hline $\mathrm{S}$ & - & - & - & - & 1565 & 1578 & $v(\mathrm{CC})$ \\
\hline$v(C C)$ & 1609 & 1643 & 1613 & 1613 & 1611 & 1615 & $v(\mathrm{CC})$ \\
\hline$v(\mathrm{C} \equiv \mathrm{N})$ & 2234 & 2246 & - & - & - & - & - \\
\hline
\end{tabular}

a. Based on Ref. 4,5 and 18 . 
The signals which undergo enhancement are all associated with the symmetric ring modes. The lack of strong signals due to antisymmetric modes indicates that the orientation of the molecule with respect to the colloidal surface permits optimal enhancement of the symmetric modes. This would suggest that the molecule is oriented in an end-on fashion.

A very weak signal for $v(C \equiv N)$ is observed when $1,4-D C B$ is adsorbed on a gold colloid. The band is blue shifted by $12 \mathrm{~cm}^{-1}$ to $2246 \mathrm{~cm}^{-1}$. This shift to a higher frequency is indicative of adsorption via a nitrile nitrogen. ${ }^{13,14}$ Considering the rigidity of the molecular frame of 1,4-DCB, end-on coordination via a nitrogen lone pair would allow only one of the two nitrile groups to interact effectively with the metal. In other SER studies of 1,4-DCB on metal electrodes, two $v(C \equiv N)$ signal were observed; one was due to an end-on coordinated $-\mathrm{C} \equiv \mathrm{N}$ group while the other was due to the free ligand. ${ }^{26,27}$ The observation of a single broad $v(\mathrm{C} \equiv \mathrm{N})$ band in the SERS indicates that the two nitrile groups exist in a similar chemical environment on the metal surface. Thus, both of the nitrile groups interact effectively with the surface and the molecular plane lies flat with respect to the surface.

The disappearance of the nitrile stretching signal in the SERS of 1,4-DCB mixed with a copper colloid is due to a transition metal-assisted borohydride reduction described in Chapter 2. In order to verify this reaction, the SERS for the reduction product, xylylenediamine, has been collected.

The SERS collected when xylylenediamine (XY) and 1,4-DCB are mixed with copper colloids and the Raman spectrum of XY are shown in Figure 4-5. The observed wavenumbers and tentative assignments are reported in Table 4-2. The adsorption of both 


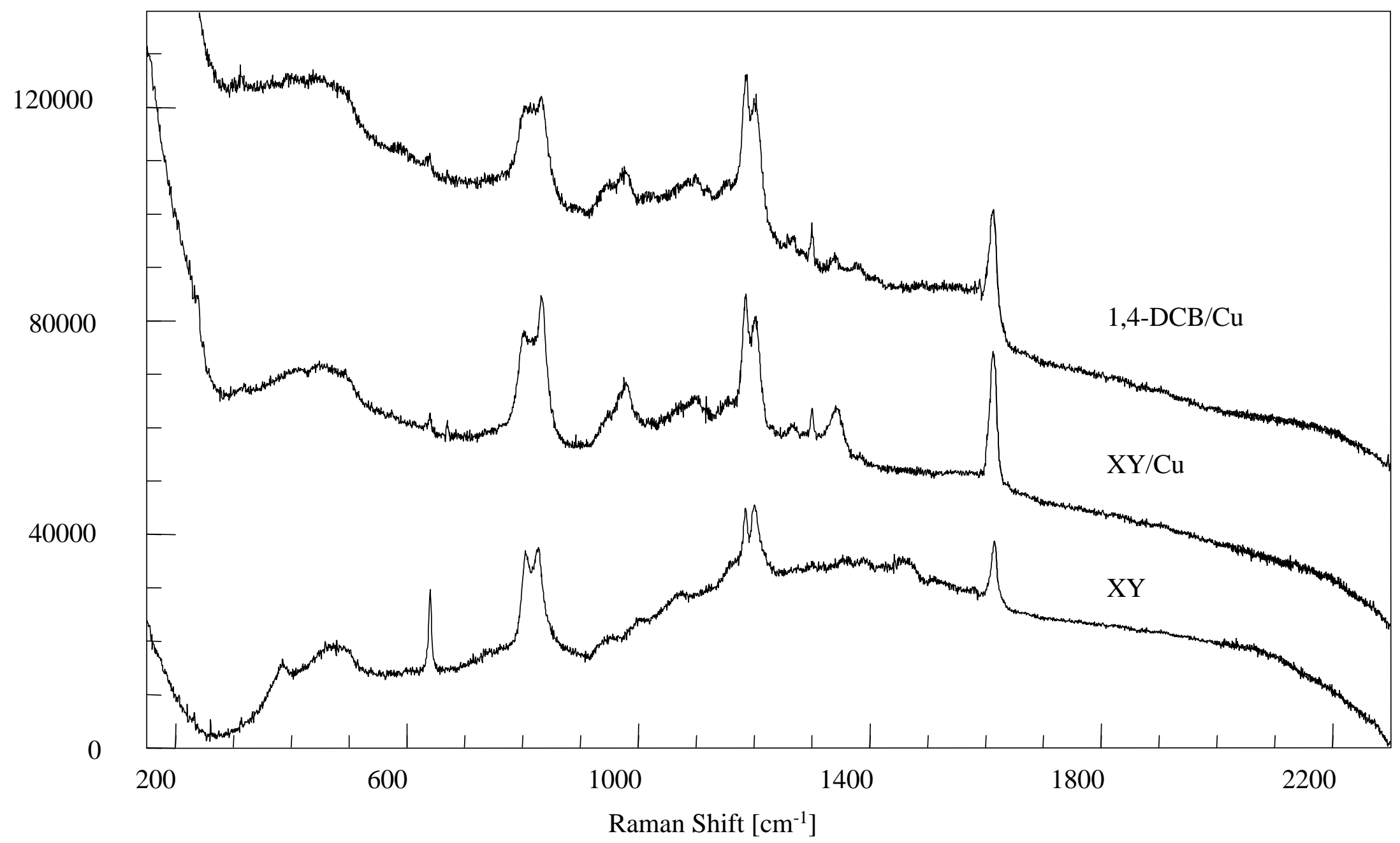

Figure 4-5 Raman spectra of xylylenediamine (XY) in aqueous (2.0 M) and SERS of XY and 1,4-DCB adsorbed onto copper $(/ \mathrm{Cu})$ colloids. 
$\mathrm{XY}$ and 1,4-DCB mixed with copper colloids generate identical spectra. Additionally, the SERS is very similar to the Raman of the free molecule of XY. The bands $1267 \mathrm{~cm}^{-1}$ $\left(\mathrm{CH}_{2} \mathrm{NH}_{2}\right.$ sensitive $), 832 \mathrm{~cm}^{-1}\left(v\left(\mathrm{C}-\mathrm{NH}_{2}\right)\right)$, and $802 \mathrm{~cm}^{-1}\left(\mathrm{CH}_{2} \mathrm{NH}_{2}\right.$ sensitive $)$ all undergo shifts (as seen in Table 4-2) indicative of interactions between the amino group(s) and the metal surface..$^{28}$ The dominant signals present in the SERS are $1613 \mathrm{~cm}^{-1}(\mathrm{v}(\mathrm{CC})), 1343 \mathrm{~cm}^{-1}$ $\left(\gamma\left(\mathrm{CH}_{2}\right)\right), 1202 \mathrm{~cm}^{-1}\left(\gamma\left(\mathrm{CH}_{2}\right)\right), 1186 \mathrm{~cm}^{-1}\left(\beta\left(\mathrm{CH}_{2}\right)\right.$, ring $), 832 \mathrm{~cm}^{-1}\left(\mathrm{v}\left(\mathrm{C}-\mathrm{NH}_{2}\right)\right)$, and $802 \mathrm{~cm}^{-1}$ $\left(\mathrm{CH}_{2} \mathrm{NH}_{2}\right.$ sensitive) ${ }^{4,5,18}$ The observed red-shifts of the modes associated with the aromatic ring indicate adsorption via the amino moiety in a flat-on orientation. ${ }^{18}$ The shifts observed for those bands associated with the $-\mathrm{NH}_{2}$ group indicate an interaction between the amino group and the metal surface. The simplicity of the SERS and the observation of no additional bands associated with the amino group indicate that identical behavior is occurring for both amino substituents. The similarities in the spectra of the parent XY and the SERS of XY adsorbed onto copper colloids indicates attachment on the surface via both of the amino groups in a flat-on configuration.

The SERS of 1,4-DCB mixed with copper colloids demonstrates a transition metalassisted borohydride reduction of the nitrile groups. The spectra also exhibit characteristics indicative of adsorption via both of the amino groups in a flat-on arrangement with respect to the metal surface. 
Acetonitrile and Ethylamine

The SER spectra obtained when acetonitrile (AN) is mixed with gold and copper colloids and the Raman of AN are shown in Figure 4-6. The observed wavenumbers and tentative assignments are presented in Table 4-3. The Raman of AN exhibit strong bands at $2290 \mathrm{~cm}^{-1}\left(v\left(\mathrm{CH}_{3}\right), \mathrm{C} \equiv \mathrm{N}\right.$ sensitive $), 2252 \mathrm{~cm}^{-1}(\mathrm{v}(\mathrm{C} \equiv \mathrm{N})), 1375 \mathrm{~cm}^{-1}\left(\mathrm{v}\left(\mathrm{CH}_{3}\right)\right), 919 \mathrm{~cm}^{-1}(\mathrm{C} \equiv \mathrm{N}$ sensitive), and $376 \mathrm{~cm}^{-1}(\mathrm{C} \equiv \mathrm{N}$ sensitive $) .{ }^{29,30}$ Upon adsorption to a copper colloid, the SERS of AN shows no $v(C \equiv N)$ signal and very little indication of any SERS. The lack of surface enhancement indicates a weak interaction between the molecule and the metal surface. Due to the lack of SERS observed, it is hard to predict if any reduction of the nitrile group is occurring with this data alone.

A signal for $\mathrm{v}(\mathrm{C} \equiv \mathrm{N})$ is observed at $2129 \mathrm{~cm}^{-1}$ when $\mathrm{AN}$ is adsorbed to a gold colloid. This shift to a lower frequency is indicative of adsorption via the nitrile nitrogen in a flat-on orientation. ${ }^{13-15}$ The SERS is relatively weak with bands exhibited at $1613 \mathrm{~cm}^{-1}, 1292 \mathrm{~cm}^{-1}$, $1019 \mathrm{~cm}^{-1}$, and $450 \mathrm{~cm}^{-1}$. The SERS of AN on gold is very different from the NR of the free molecule. The lack of surface enhancement signifies the weak adsorption of the AN molecules with the gold surface.

Based on the disappearance of the nitrile stretching signal in the SERS of AN mixed with a copper colloid and the weak surface enhancement it is difficult to determine whether a transition metal-assisted borohydride reduction occurs. SERS for the potential reduction product, ethylamine has been collected in order to address this issue. 


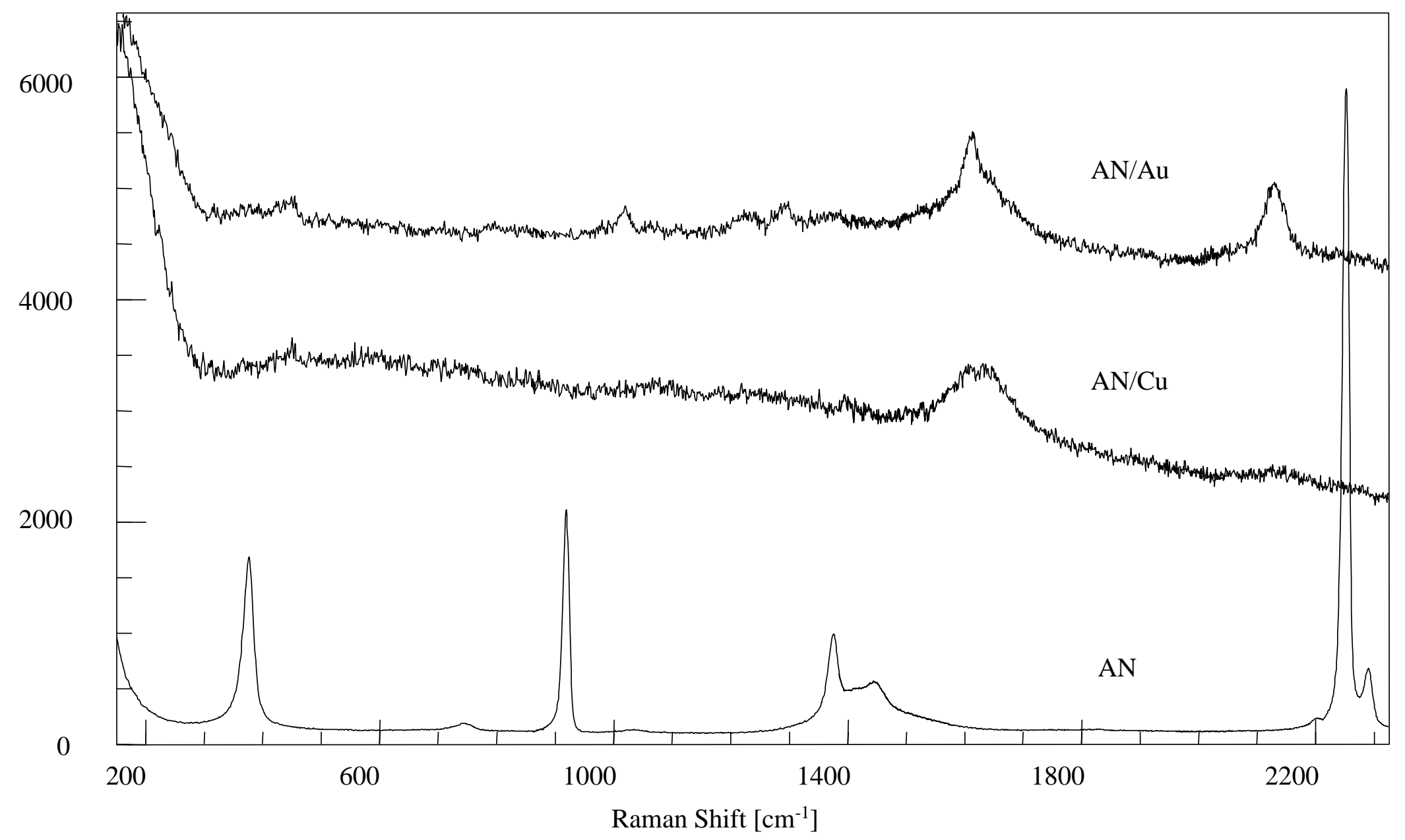

Figure 4-6 Raman spectra of neat acetonitrile (AN) and SERS of AN adsorbed onto copper (/Cu) and gold (/Au) colloids. 
TABLE 4-3: Raman Frequencies $\left(\mathrm{cm}^{-1}\right)$ of Neat Acetonitrile (AN) and Neat Ethylamine (EA) and Adsorbed onto Copper (/Cu) and Gold (/Au) Colloids.

\begin{tabular}{|c|c|c|c|c|c|c|c|}
\hline Assignment $^{\mathrm{a}}$ & AN liquid & $\mathrm{AN} / \mathrm{Au}$ & $\mathrm{AN} / \mathrm{Cu}$ & $\mathrm{EA} / \mathrm{Cu}$ & $\mathrm{EA} / \mathrm{Au}$ & EA liquid & Assignment $^{\mathrm{a}}$ \\
\hline $\mathrm{S}$ & - & 221 & - & - & 225 & - & - \\
\hline $\mathrm{C} \equiv \mathrm{N}$ sensitive & 376 & - & - & - & - & - & - \\
\hline $\mathrm{S}$ & - & - & - & - & - & 416 & $\beta\left(\mathrm{C}-\mathrm{NH}_{2}\right)$ \\
\hline $\mathrm{S}$ & - & 450 & 450 & - & 449 & - & - \\
\hline $\mathrm{S}$ & 744 & - & - & - & - & - & - \\
\hline $\mathrm{S}$ & - & 797 & - & - & - & - & - \\
\hline $\mathrm{S}$ & - & - & - & - & - & 882 & $v(C C)$ \\
\hline $\mathrm{C} \equiv \mathrm{N}$ sensitive & 919 & - & - & - & - & - & - \\
\hline $\mathrm{S}$ & - & - & 983 & 976 & 986 & - & - \\
\hline $\mathrm{S}$ & - & 1019 & - & - & 1010 & 1004 & $\delta\left(\mathrm{CH}_{3}\right)$ \\
\hline$\beta\left(\mathrm{CH}_{3}\right)$ & 1034 & - & - & - & - & 1051 & $\mathrm{NH}_{2}$ sensitive \\
\hline $\mathrm{S}$ & - & - & 1073 & 1062 & - & 1079 & $\mathrm{NH}_{2}$ sensitive \\
\hline $\mathrm{S}$ & - & 1226 & - & - & - & 1129 & $\beta\left(\mathrm{CH}_{3}\right)$ \\
\hline $\mathrm{S}$ & - & - & - & - & 1234 & 1237 & - \\
\hline $\mathrm{S}$ & - & 1292 & - & - & 1290 & 1298 & $\beta\left(\mathrm{NH}_{2}\right), \beta\left(\mathrm{CH}_{2}\right)$ \\
\hline $\mathrm{S}$ & - & - & - & - & - & 1359 & $\beta\left(\mathrm{CH}_{2}\right)$ \\
\hline$v\left(\mathrm{CH}_{3}\right)$ & 1375 & 1368 & - & - & 1374 & - & - \\
\hline$\delta\left(\mathrm{CH}_{3}\right)$ & 1444 & - & - & - & - & 1455 & $\delta\left(\mathrm{CH}_{3}\right)$ \\
\hline $\mathrm{S}$ & - & - & - & - & 1530 & - & $v(\mathrm{CC})$ \\
\hline $\mathrm{S}$ & - & 1613 & 1610 & 1610 & 1610 & - & $v(C C)$ \\
\hline $\mathrm{H}_{2} \mathrm{O}$ & - & - & 1627 & 1625 & - & - & $\mathrm{H}_{2} \mathrm{O}$ \\
\hline
\end{tabular}


TABLE 4-3:

(Continued)

\begin{tabular}{|c|c|c|c|c|c|c|c|}
\hline Assignment $^{\mathrm{a}}$ & AN liquid & $\mathrm{AN} / \mathrm{Au}$ & $\mathrm{AN} / \mathrm{Cu}$ & $\mathrm{EA} / \mathrm{Cu}$ & $\mathrm{EA} / \mathrm{Au}$ & EA liquid & Assignment $^{\mathrm{a}}$ \\
\hline $\mathrm{S}$ & 2200 & - & - & - & - & - & - \\
\hline$v(C \equiv N)$ & 2252 & 2129 & - & - & - & - & - \\
\hline$v\left(\mathrm{CH}_{3}\right), \mathrm{C} \equiv \mathrm{N}$ sens. & 2290 & - & - & - & - & - & - \\
\hline
\end{tabular}

a. Based on Ref. 29-32. 
The SERS collected for ethylamine (EA) and AN mixed with copper colloids and the Raman spectrum of EA are shown in Figure 4-7. The observed wavenumbers and tentative assignments are reported in Table 4-3. The adsorption of both EA and AN mixed with copper colloids generate very weak SERS. The SERS bands detected are $1625 \mathrm{~cm}^{-1}$ (water), $1610 \mathrm{~cm}^{-1}(\mathrm{v}(\mathrm{CC})), 1062 \mathrm{~cm}^{-1}\left(\mathrm{NH}_{2}\right.$ sensitive $)$, and $976 \mathrm{~cm}^{-1}$ are very similar to the bands that occur in the SERS of AN mixed with copper colloid, namely $1627 \mathrm{~cm}^{-1}$ (water), $1610 \mathrm{~cm}^{-1}$ ( $v(\mathrm{CC})), 1073 \mathrm{~cm}^{-1}\left(\mathrm{v}\left(\mathrm{NH}_{2}\right.\right.$ sensitive), and $983 \mathrm{~cm}^{-1}$. The subtle differences in the SERS bands for AN and EA mixed with copper colloids indicate that the molecules are similar in nature but oriented in two different configurations onto the copper surface. However, due to the lack of surface enhancement in the SERS, which provides information pertaining to whether a reduction reaction is occurring, we cannot report that a reduction is occurring.

The weak interaction between AN and EA on copper and gold colloids demonstrate that the chemical mechanism plays a dominant role in surface enhancement. Although significant aggregation was observed during the adsorption process, the resulting SERS was weak as a result of the minimal interaction between the substrate and the colloidal surface. Thus, the chemical interaction between the adsorbate and the metal surface limits the observation of the SER effect.

The SERS of AN with both copper and gold colloids indicate that the absence of the aromatic ring limits the ability of the molecule to sufficiently interact with the metal surface. 


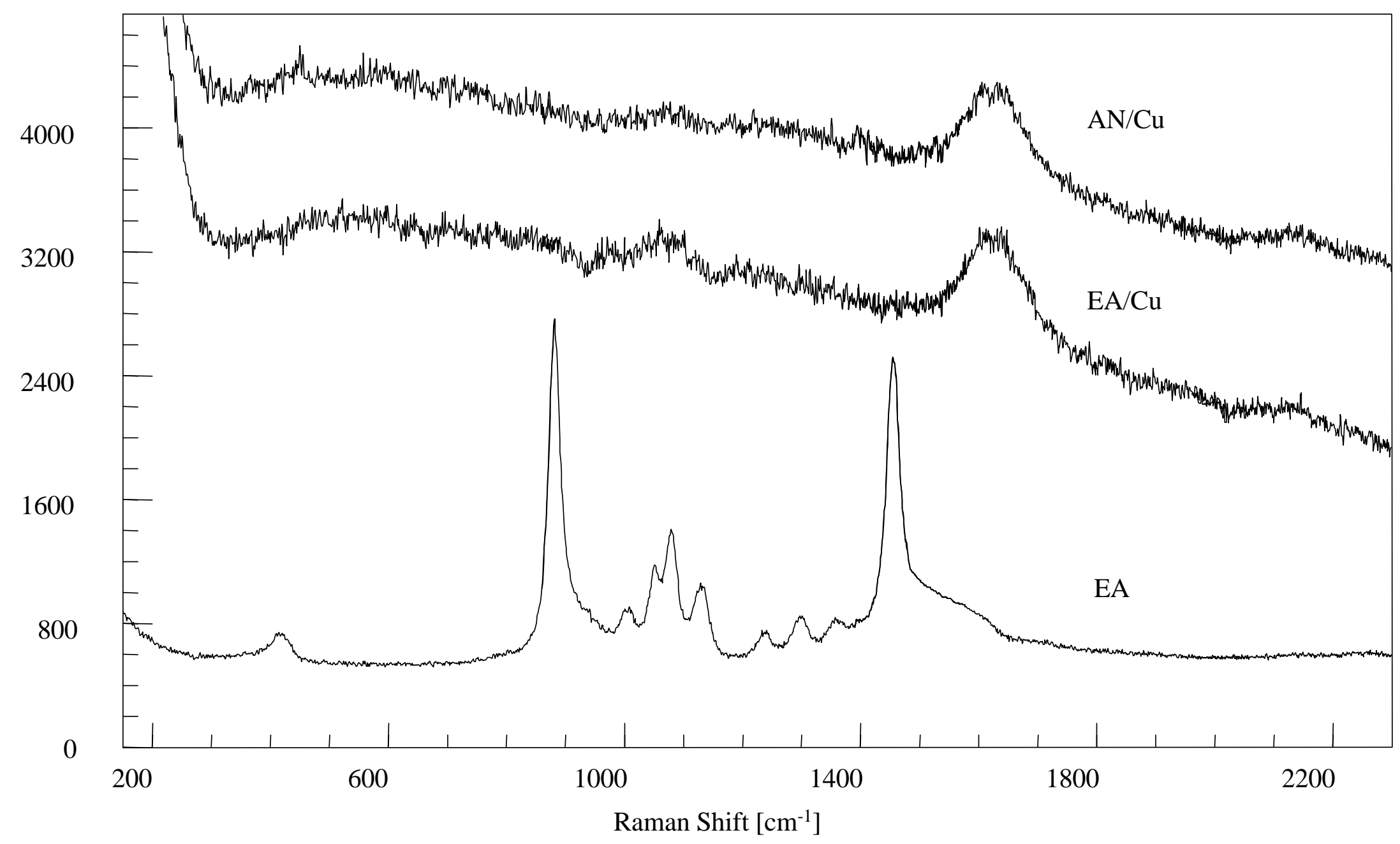

Figure 4-7 Raman spectra of neat ethylamine (EA) and SERS of EA and AN adsorbed onto copper (/Cu) colloids. 


\section{Hexanenitrile and Hexylamine}

The SER spectra obtained when hexanenitrile $(\mathrm{HN})$ is mixed with gold and copper colloids and the Raman of HN are shown in Figure 4-8. The observed wavenumbers and tentative assignments are presented in Table 4-4. Upon mixing with a copper colloid, the SERS of HN shows no $v(C \equiv N)$ signal. The Raman of HN exhibit strong Raman bands at $2245 \mathrm{~cm}^{-1}(\mathrm{v}(\mathrm{C} \equiv \mathrm{N})), 1146 \mathrm{~cm}^{-1}\left(\delta\left(\mathrm{CH}_{2}\right)\right), 1307 \mathrm{~cm}^{-1}, 1114 \mathrm{~cm}^{-1}, 1068 \mathrm{~cm}^{-1}\left(\beta\left(\mathrm{CH}_{2}\right)\right), 831$

$\mathrm{cm}^{-1}$, and $368 \mathrm{~cm}^{-1}(\mathrm{C} \equiv \mathrm{N}$ sensitive $) .{ }^{29,30}$ In the $\mathrm{SER}$ spectrum, the nitrile sensitive modes associated with the HN molecule are absent. The strongest bands in the SERS consist of the vibrations associated with the bending motions of the alkyl chain: $1595 \mathrm{~cm}^{-1}\left(\beta\left(\mathrm{CH}_{2}\right)\right)$ and $1004 \mathrm{~cm}^{-1}\left(\beta\left(\mathrm{CH}_{3}\right)\right)$. The nitrile group nitrogen is assumed to be the only point of adsorption onto the copper surface. The absence of the nitrile stretching signal indicates that a reduction of the cyano group to an amino group has occurred.

A signal for $\mathrm{v}(\mathrm{C} \equiv \mathrm{N})$ at $2130 \mathrm{~cm}^{-1}$ is observed when $\mathrm{HN}$ is adsorbed to a gold colloid. This shift to a lower frequency is indicative of adsorption via the nitrile nitrogen in a flat-on orientation. ${ }^{13-15}$ The SERS for adsorption onto gold colloids demonstrates stronger surface enhancement which indicates a stronger interaction between $\mathrm{HN}$ and the gold surface. The strongest bands observed in the SERS are $1380 \mathrm{~cm}^{-1}\left(\mathrm{v}\left(\mathrm{CH}_{3}\right)\right), 1015 \mathrm{~cm}^{-1}\left(\beta\left(\mathrm{CH}_{3}\right)\right)$, and 247 $\mathrm{cm}^{-1}(\mathrm{C} \equiv \mathrm{N}$ sensitive $){ }^{29,30}$ The shifts in these bands from those observed for the free molecule (see Table 4-4) confirm that the orientation of the $\mathrm{HN}$ molecules are flat-on relative to the metal surface with coordination via the nitrile nitrogen. ${ }^{15,28}$ 


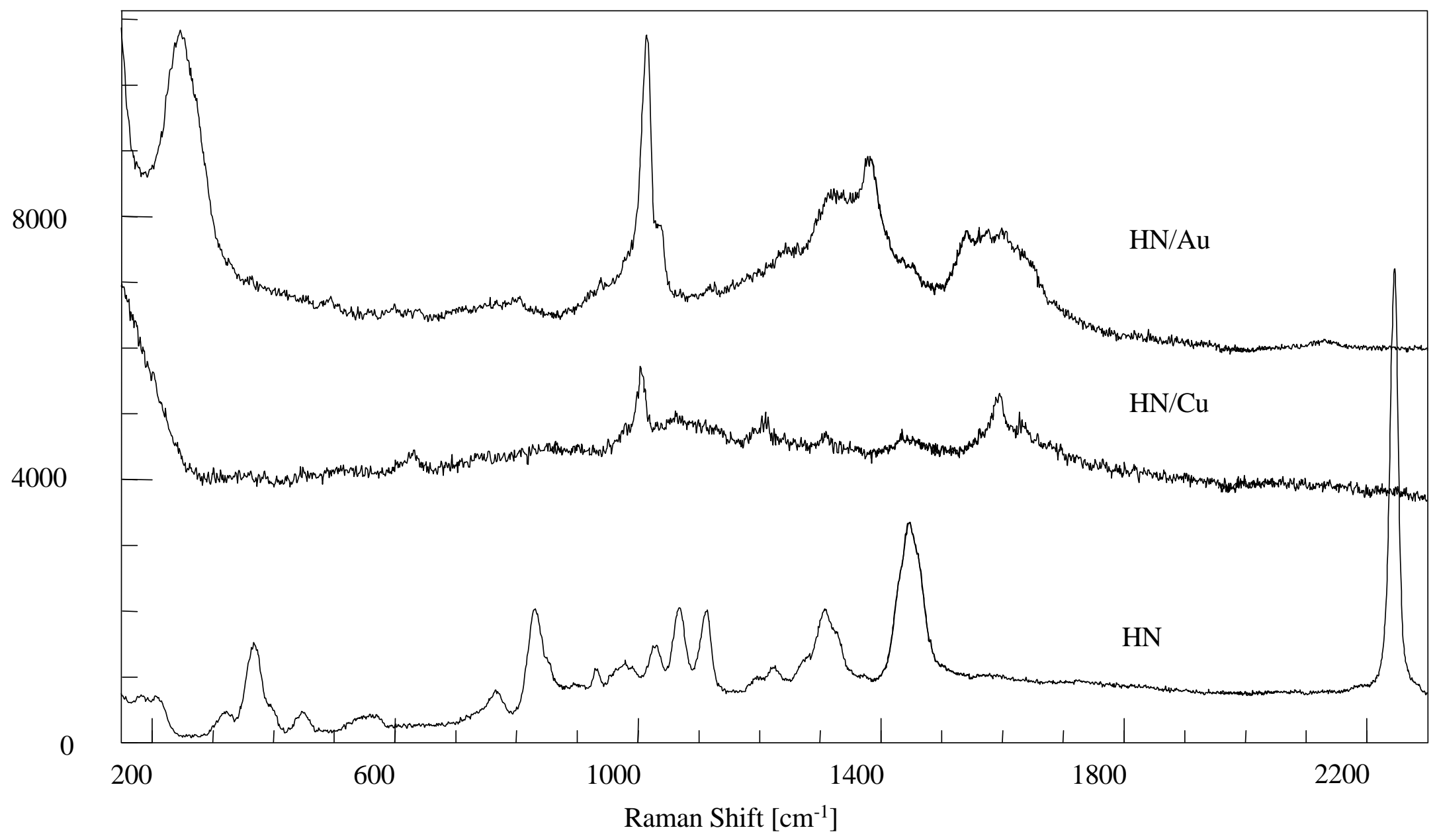

Figure 4-8 Raman spectra of neat hexanenitrile (HN) and SERS of HN adsorbed onto copper $(/ \mathrm{Cu})$ and gold $(/ \mathrm{Au})$ colloids. 
TABLE 4-4: Raman Frequencies $\left(\mathrm{cm}^{-1}\right)$ of Neat Hexanenitrile (HN) and Neat Hexylamine (HA) and Adsorbed onto Copper (/Cu) and Gold (/Au) Colloids.

\begin{tabular}{|c|c|c|c|c|c|c|c|}
\hline Assignment $^{\mathrm{a}}$ & HN liquid & $\mathrm{HN} / \mathrm{Au}$ & $\mathrm{HN} / \mathrm{Cu}$ & $\mathrm{HA} / \mathrm{Cu}$ & $\mathrm{HA} / \mathrm{Au}$ & HA liquid & Assignment $^{\mathrm{a}}$ \\
\hline $\mathrm{S}$ & 183 & - & - & - & - & - & - \\
\hline $\mathrm{C} \equiv \mathrm{N}$ sensitive & 208 & - & - & - & - & - & - \\
\hline $\mathrm{S}$ & - & 247 & - & - & 253 & - & - \\
\hline $\mathrm{S}$ & - & - & - & - & - & 308 & - \\
\hline $\mathrm{S}$ & 322 & - & - & - & - & - & - \\
\hline $\mathrm{C} \equiv \mathrm{N}$ sensitive & 368 & - & - & - & - & 355 & - \\
\hline $\mathrm{S}$ & - & - & - & - & - & 400 & $\beta\left(\mathrm{C}-\mathrm{NH}_{2}\right)$ \\
\hline $\mathrm{S}$ & 449 & 449 & 448 & 450 & 450 & 434 & - \\
\hline $\mathrm{S}$ & - & - & - & 526 & - & 499 & $\mathrm{NH}_{2}$ sensitive \\
\hline$\delta(\mathrm{CH}), v(\mathrm{CC})$ & 555 & - & - & - & - & - & - \\
\hline $\mathrm{S}$ & - & 600 & - & - & - & - & - \\
\hline $\mathrm{S}$ & - & 637 & 628 & 621 & - & - & - \\
\hline $\mathrm{S}$ & 766 & - & - & - & - & - & - \\
\hline $\mathrm{S}$ & - & 806 & - & - & 810 & 811 & - \\
\hline $\mathrm{S}$ & 831 & - & - & - & - & 848 & $v\left(\mathrm{C}-\mathrm{NH}_{2}\right)$ \\
\hline $\mathrm{S}$ & - & - & - & - & - & 883 & $\delta\left(\mathrm{CH}_{3}\right)$ \\
\hline $\mathrm{S}$ & 900 & - & - & - & - & - & - \\
\hline $\mathrm{S}$ & - & - & - & - & - & 917 & $\gamma(\mathrm{CH})$ \\
\hline $\mathrm{S}$ & 930 & - & - & - & - & - & - \\
\hline $\mathrm{S}$ & 979 & - & - & 978 & - & 973 & - \\
\hline$\beta\left(\mathrm{CH}_{3}\right)$ & 1028 & 1015 & 1004 & - & 1015 & 1022 & $\beta\left(\mathrm{CH}_{2}\right)$ \\
\hline
\end{tabular}


TABLE 4-4: $\quad$ (Continued)

\begin{tabular}{|c|c|c|c|c|c|c|c|}
\hline Assignment $^{\mathrm{a}}$ & HN liquid & $\mathrm{HN} / \mathrm{Au}$ & $\mathrm{HN} / \mathrm{Cu}$ & $\mathrm{HA} / \mathrm{Cu}$ & $\mathrm{HA} / \mathrm{Au}$ & HA liquid & Assignment $^{\mathrm{a}}$ \\
\hline$\beta\left(\mathrm{CH}_{2}\right)$ & 1068 & 1035 & 1062 & 1066 & - & 1068 & $\beta\left(\mathrm{CH}_{2}\right), \mathrm{NH}_{2}$ sensitive \\
\hline $\mathrm{S}$ & 1114 & 1119 & - & 1129 & - & 1118 & $\beta\left(\mathrm{CH}_{2}\right)$ \\
\hline $\mathrm{S}$ & - & - & - & - & 1151 & 1169 & $\beta\left(\mathrm{CH}_{2}\right)$ \\
\hline $\mathrm{S}$ & 1196 & - & 1204 & - & - & - & - \\
\hline$v\left(\mathrm{CH}_{2}\right)$ & 1223 & - & - & 1217 & - & - & - \\
\hline $\mathrm{S}$ & - & 1243 & - & - & - & - & - \\
\hline $\mathrm{S}$ & 1280 & - & - & - & - & - & - \\
\hline $\mathrm{S}$ & 1307 & - & 1308 & 1311 & 1308 & 1298 & $\beta\left(\mathrm{NH}_{2}\right), \beta\left(\mathrm{CH}_{2}\right)$ \\
\hline $\mathrm{S}$ & - & 1322 & - & - & - & - & - \\
\hline $\mathrm{S}$ & - & - & - & - & - & 1349 & $\gamma\left(\mathrm{CH}_{2}\right)$ \\
\hline$v\left(\mathrm{CH}_{3}\right)$ & 1372 & 1380 & - & - & 1377 & - & - \\
\hline$\delta\left(\mathrm{CH}_{3}\right)$ & 1446 & - & 1432 & 1448 & 1437 & 1438 & $\delta\left(\mathrm{CH}_{3}\right)$ \\
\hline $\mathrm{S}$ & - & 1540 & - & - & 1550 & - & - \\
\hline $\mathrm{S}$ & - & 1577 & - & - & - & - & - \\
\hline$\beta\left(\mathrm{CH}_{3}\right)$ & - & 1599 & 1595 & 1615 & 1607 & 1605 & $v(C C)$ \\
\hline $\mathrm{S}$ & - & - & 1633 & - & - & - & - \\
\hline$v(C \equiv N)$ & 2245 & 2130 & - & - & - & - & - \\
\hline
\end{tabular}

a. Based on Ref. 29, 30 and 33. 
The disappearance of the nitrile stretching signal in the SERS of HN mixed with a copper colloid suggests the nitrile reduction. In order to determine whether a transition metal-assisted borohydride reduction occurs, the SERS for the potential reduction product, hexylamine, has been collected.

The SERS collected when hexylamine (HA) and HN are mixed with copper colloids and the Raman spectrum of HA are shown in Figure 4-9. The observed wavenumbers and tentative assignments are reported in Table 4-4. The adsorption of both HA and HN mixed with copper colloids generates weak SERS. The enhancement of HA is considerably less than that collected for $\mathrm{HN}$ with copper colloids. The bands at $1615 \mathrm{~cm}^{-1}(\mathrm{v}(\mathrm{CC})), 1448 \mathrm{~cm}^{-1}$ $\left(\delta\left(\mathrm{CH}_{2}\right)\right), 1066 \mathrm{~cm}^{-1}\left(\beta\left(\mathrm{CH}_{2}\right), \mathrm{NH}_{2}\right.$ sensitive $)$, and $450 \mathrm{~cm}^{-1}\left(\beta\left(\mathrm{C}-\mathrm{NH}_{2}\right)\right)$ are all associated with the amino component of HA. ${ }^{29,30,33}$ The blue shifts in the bands (compared to the parent frequencies) at $1615 \mathrm{~cm}^{-1}(\mathrm{v}(\mathrm{CC})), 1448 \mathrm{~cm}^{-1}\left(\delta\left(\mathrm{CH}_{3}\right)\right), 1311 \mathrm{~cm}^{-1}\left(\beta\left(\mathrm{CH}_{2}\right), \beta\left(\mathrm{NH}_{2}\right)\right), 1129$ $\mathrm{cm}^{-1}\left(\beta\left(\mathrm{CH}_{2}\right)\right), 1066 \mathrm{~cm}^{-1}\left(\beta\left(\mathrm{CH}_{2}\right), \mathrm{NH}_{2}\right.$ sensitive $\left.)\right), 978 \mathrm{~cm}^{-1}, 526 \mathrm{~cm}^{-1}\left(\mathrm{NH}_{2}\right.$ sensitive $)$, and $450 \mathrm{~cm}^{-1}$ indicate end-on adsorption to the colloidal surface. ${ }^{13-15,28}$ The SERS bands detected at $1615 \mathrm{~cm}^{-1}(\mathrm{v}(\mathrm{CC})), 1448 \mathrm{~cm}^{-1}\left(\delta\left(\mathrm{CH}_{3}\right)\right), 1311 \mathrm{~cm}^{-1}\left(\beta\left(\mathrm{CH}_{2}\right), \beta\left(\mathrm{NH}_{2}\right)\right), 1066 \mathrm{~cm}^{-1}\left(\beta\left(\mathrm{CH}_{2}\right)\right.$, $\mathrm{NH}_{2}$ sensitive)), $621 \mathrm{~cm}^{-1}$ and $450 \mathrm{~cm}^{-1}$ are very similar to the bands that occur in the SERS of $\mathrm{HN}$ mixed with copper colloid, namely $1595 \mathrm{~cm}^{-1}(\mathrm{v}(\mathrm{CC})), 1432 \mathrm{~cm}^{-1}\left(\delta\left(\mathrm{CH}_{3}\right)\right), 1308 \mathrm{~cm}^{-1}$ $\left(\beta\left(\mathrm{CH}_{2}\right), \beta\left(\mathrm{NH}_{2}\right)\right), 1062 \mathrm{~cm}^{-1}\left(\beta\left(\mathrm{CH}_{2}\right), \mathrm{NH}_{2}\right.$ sensitive $), 628 \mathrm{~cm}^{-1}$ and $448 \mathrm{~cm}^{-1} \cdot{ }^{29,30,33}$ The red shifts in the SERS bands for HN mixed with copper colloids at $1595 \mathrm{~cm}^{-1}(\mathrm{v}(\mathrm{CC})), 1432 \mathrm{~cm}^{-1}$ $\left(\delta\left(\mathrm{CH}_{3}\right)\right), 1308 \mathrm{~cm}^{-1}\left(\beta\left(\mathrm{CH}_{2}\right), \beta\left(\mathrm{NH}_{2}\right)\right), 1062 \mathrm{~cm}^{-1}\left(\beta\left(\mathrm{CH}_{2}\right), \mathrm{NH}_{2}\right.$ sensitive $\left.)\right)$, and $1004 \mathrm{~cm}^{-1}$ $\left(\beta\left(\mathrm{CH}_{2}\right)\right)$ indicate a flat-on configuration to the metal surface. These subtle 


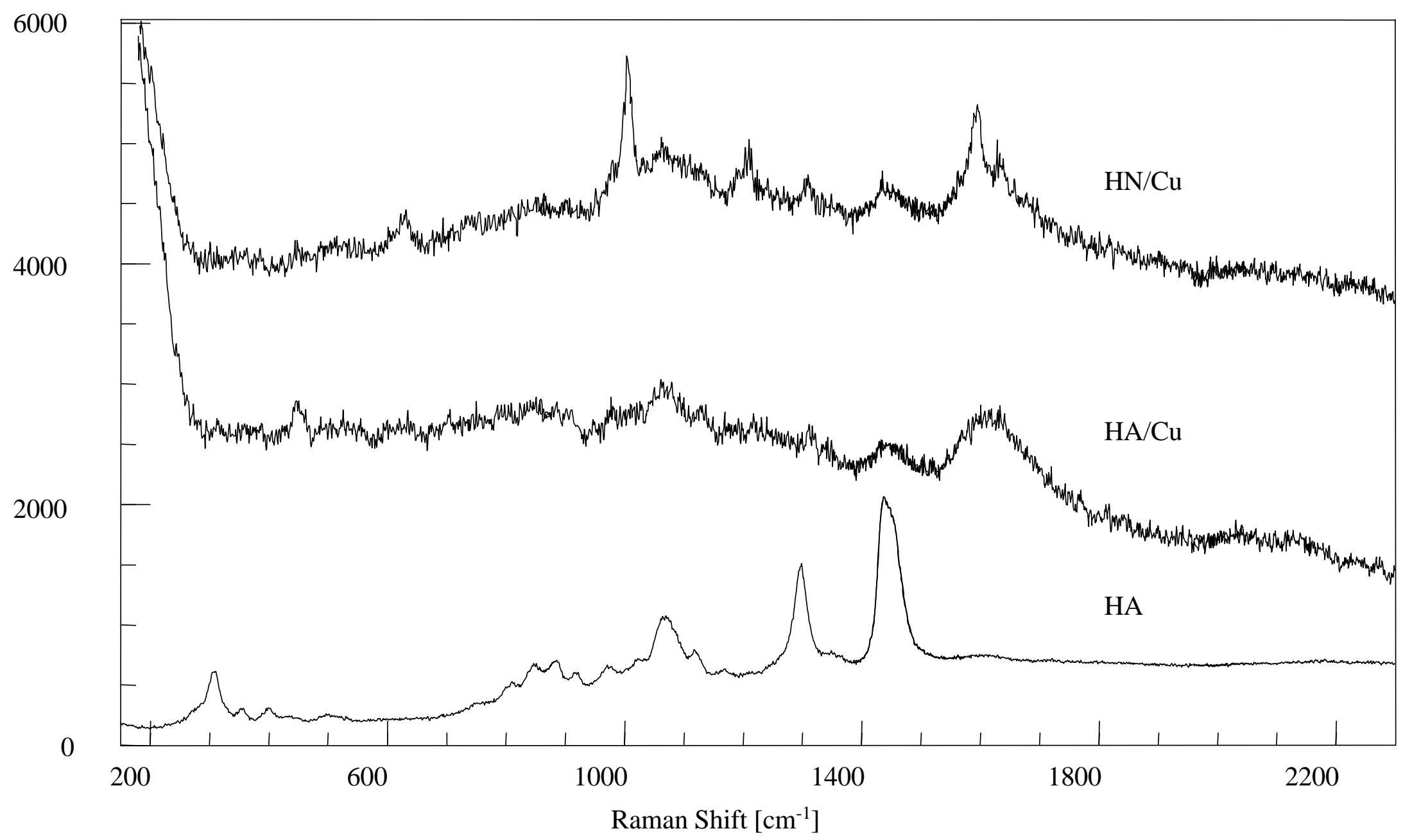

Figure 4-9 Raman spectra of neat hexylamine (HA) and SERS of HA and HN adsorbed onto copper (/Cu) colloids. 
differences in the SERS bands for HN and HA mixed with copper colloids and the disappearance of the $v(\mathrm{C} \equiv \mathrm{N})$ suggest that the molecules are the same, but oriented in two different configurations on the copper surface. The HN adsorbs onto the copper surface in a flat-on configuration prior to reduction, whereas the HA orients in an end-on fashion.

The SERS of HN and HA mixed with copper colloids demonstrates that a transition metal-assisted borohydride reduction occurs for HN mixed with copper colloids. The weak interaction between $\mathrm{HN}$ and $\mathrm{HA}$ on copper and gold colloids demonstrates that the chemical mechanism reflects the degree of surface enhancement observed. The differences in the resulting SERS when HN and HA are mixed with copper colloids indicates dissimilar orientations onto the copper surface. This data indicates that an alkyl chain may provide an alternative to a ring system.

\subsection{CONCLUSIONS}

The SERS collected for organonitriles adsorbed onto the surface of copper colloids exhibit a complete disappearance of the nitrile stretching normal mode. The absence of the nitrile stretching signal for the organonitriles is due to a metal-assisted reduction of the nitrile group to an amino group. Adsorption of alkyl organonitriles onto copper colloids demonstrate weak surface enhancement when compared with SERS of the aromatic organonitriles mixed with a copper colloid. The SERS of the alkyl organonitriles with both copper and gold colloids indicate that the absence of the aromatic ring plays a significant role in the ability of the molecule to sufficiently interact with the metal surface. 


\section{REFERENCES}

1. J. A. Creighton, M.S. Alvarez, D.A. Weltz, S. Garoff and M. W. Kim, J. Phys. Chem. 87, 4793 (1983).

2. D. Meisel and P. C. Lee, J. Phys. Chem. 86, 3391 (1982).

3. J. A. Creighton and D. G. Eadon, J. Chem. Soc., Faraday Trans. 24 87, 3881-3891 (1991).

4. G. Varsanyi, Assignments for Vibrational Spectra of Seven Hundred Benzene Derivatives, pp. 11-35, 69. Wiley, New York (1974).

5. G. Varsanyi, Vibrational Spectra of Benzene Derivatives, pp. 142-350, 375-380, Academic Press, New York (1969).

6. J. H. S. Green, Spectrochim. Acta 17, 607-613 (1961).

7. J. H. S. Green and D. J. Harrision, Spectrochim. Acta 32A, 1279-1286 (1976).

8. R. Sokoll and H. Hobert, J. of Catalysis 134, 409-421 (1992).

9. A. Bewick and S. Pons, Infrared Spectroscopy of the Electrode-Electrolyte Solution Interface, pp. 55-59.

10. H. J. Coever and C. Curran, J. Am. Chem. Soc. 80, 3522 (1958).

11. W. Gerrard, M. F. Lappert, H. Pyszora and J. W. Wallis, J. Chem. Soc., 2182 (1960).

12. M. Kubota and S. R. Schulze, Inorg. Chem. 3, 853 (1964).

13. J. C. Rubim and O. Sala, J. Mol. Struct. 145, 157-172 (1986).

14. H. Chang, L. J. Lee and U. H. Sheu, J. Chinese Chem. Soc. 40, 413-418 (1993).

15. C. S. Allen and R. P. Van Duyne, J. Am. Chem. Soc. 103, 7497-7501 (1981).

16. G. T. Merklin and P. R. Griffiths, J. Phys. Chem. B 101, 5810-5813 (1997).

17. H. Ueba, Surface Sci. 131, 347-366 (1983).

18. M. C. Castro-Pedrozo and G. W. King, J. Molec. Spectrosc. 73, 386-399 (1978). 
19. H. Park, S. B. Lee, K. Kim and M. S. Kim, J. Phys. Chem. 94, 7576 (1990).

20. G. R. Erdheim, R. L. Birke and J. R. Lombardi, Chem. Phys. Lett. 69, 495 (1980).

21. M. Moskovits, D. P. DiLella and K. J. Maynard, Langmuir 4, 67 (1988).

22. S. T. Oh, K. Kim and M. S. Kim, J. Mol. Struct. 243, 307 (1991).

23. J. K Sass, H. Neff, M. Moskovits and S. Holloway, J. Phys. Chem. 85, 521 (1981).

24. V. M. Hallmark and A. Campion, J. Phys. Chem. 84, 2933 (1986).

25. V. M. Hallmark and A. Campion, J. Phys. Chem. 84, 2942 (1986).

26. B. H. Loo, Y. G. Lee and D. O. Frazier, Chem. Phys. Lett. 119, 312 (1985).

27. B. H. Loo, Y. G. Lee and D. O. Frazier, J. Phys. Chem. 89, 4672 (1985).

28. E. Lee, S. S. Yi, M. S. Kim and K. Kim, J. Mol. Struct. 298, 47-54 (1993).

29. S. Kondo, Y. Koga, S. Saeki and W. B. Person, J. Phys. Chem. 88, 3152-3157 (1984).

30. M. E. Lippitsch, Chem. Phys. Lett. 1 74, 125-127 (1980).

31. D. E. Gardin and G. A. Samorjai, J. Phys. Chem. 96, 9424-9431 (1992).

32. Y. Hamada et. al., J. Mol. Spectrosc. 102, 123-147 (1983).

33. Wolff and H. Ludwig, J. Chem. Phys. 11 56, 5278-5283 (1972). 


\section{CHAPTER 5}

\section{Effects of Colloid Aggregation on the Surface Enhanced Raman Effect}

\section{$5.1 \quad$ INTRODUCTION}

Aggregation of colloidal particles provides a great deal of insight into the nature and level of surface-enhancement observed during adsorption processes. Since the studies of Faraday ${ }^{1}$, the addition of salts to metal sols resulted in color change and this was attributed to the aggregation of what were initially individual particles. ${ }^{2}$ Investigations have utilized the addition of salts to initiate aggregation of metallic colloids. ${ }^{3-7}$ Salts may cause aggregation of the metal colloids, may co-adsorb with the adsorbate or may promote desorption of the adsorbates from the metal surfaces. The response of the colloid and the adsorbate to the addition of salts can be used to characterize colloidal self-assembly and adsorbate/surface interactions. $^{8}$

The dependence of the SER enhancement mechanism on the aggregation of colloidal systems has been an issue since the discovery of surface enhancement. ${ }^{9-11}$ The response of the system to the addition of salts can provide insight into adsorbate orientation. ${ }^{3,12,13}$ Results that permit a comparison of the electromagnetic (plasmon) enhancement mechanism and the adsorbate/surface chemical interaction mechanism can be obtained. This is due to the fact that the SER effect changes based on the metal/adsorbate interactions during the adsorption process. 
Sodium salts were utilized to promote increased aggregation, co-adsorption, and desorption of the adsorbates from the colloidal surfaces. We have investigated the effects of sodium sulfate (aggregation), sodium chloride (co-adsorption), and sodium sulfide (desorption) on mixing of 4-, 3- and 2-cyanopyridines with copper and gold colloids. ${ }^{6,710}$ These results will be used to determine if the metal influences the degree of aggregation as well as the amount of enhancement observed.

\subsection{EXPERIMENTAL}

\section{Colloid Preparation}

The preparation of the copper colloids is based on the borohydride reduction of $\mathrm{Cu}^{2+}$ as described in Chapter 2.2. ${ }^{14}$ All colloidal solutions were prepared in disposable borosilicate glass culture tubes with water passed through a Barnstead/Thermolyne (Dubuque, IA) Nanopure Water Model D4541 purification system. The colloid, which starts as a pale yellow-brown color becomes a dark reddish-brown upon aging. The red color is indicative of particle sizes ranging from 10 to $20 \mathrm{~nm}$ and give rise to an absorption band at $564 \mathrm{~nm} .^{15}$ After the colloid was allowed to age for two hours, an aqueous solution of $\mathrm{CP}$ (4-CP, 3-CP, and 2-CP) (Aldrich; 98\%; Aldrich; 98\%; Aldrich; 99\%) (1 x 10-3 M, $0.30 \mathrm{~mL})$ was added. Upon addition of the $\mathrm{CP}$, the colloid changes to a dark grey-brown color due to aggregation and has an absorption band at $570 \mathrm{~nm}$. A band at $296 \mathrm{~nm}$ indicative of the adsorbate is also observed. The shifts in the spectra indicate aggregation and molecule-surface interactions in the colloidal system. ${ }^{16}$ Data collection of the SER spectra of the cyanopyridines adsorbed 
onto the copper colloids was begun 80 minutes after the addition of the adsorbate solution to the colloid.

The preparation of the gold colloid is described in Chapter 2.2. ${ }^{17}$ Raman samples were prepared by adding $\mathrm{CP}(4-\mathrm{CP}, 3-\mathrm{CP}$, and $2-\mathrm{CP})\left(0.3 \mathrm{~mL}, 1 \times 10^{-3} \mathrm{M}\right)$ to $2.7 \mathrm{~mL}$ of the gold colloid solution in borosilicate glass culture tubes. The color changed to a dark violet/purple with an absorption maxima at $563 \mathrm{~nm}$ indicative of aggregation due to the presence of the adsorbate. The SER spectra were collected starting 80 minutes after the addition of the cyanopyridine.

The colloidal samples of the cyanopyridines were prepared and then $0.03 \mathrm{~mL}$ of $\quad 0.1$ $\mathrm{M}$ of sodium salt was added to each sample after SERS (sans salt addition) were collected. The sodium salts utilized for these experiments were sodium sulfate (Aldrich; 99.99\%), sodium chloride (Aldrich; 99\%), and sodium sulfide (Aldrich; 99.99\%). Color changes were observed after each addition of each salt. Raman spectra were collected immediately after salt addition and for intervals up to a week after addition for the gold samples.

Experimental parameters of collection were identical to those described in Section 2.2.

\subsection{RESULTS AND DISCUSSION}

The SER spectra of the isomeric forms of cyanopyridine (4-CP, 3-CP, and 2-CP) mixed with copper colloids upon addition of the various salts are presented in Figures 5-1, 5-2, and 5-3. In each of these cases, 4-AMP showed the slowest rate of aggregation prior to and after salt addition, whereas 2-AMP showed the fastest rate of aggregation. The color 


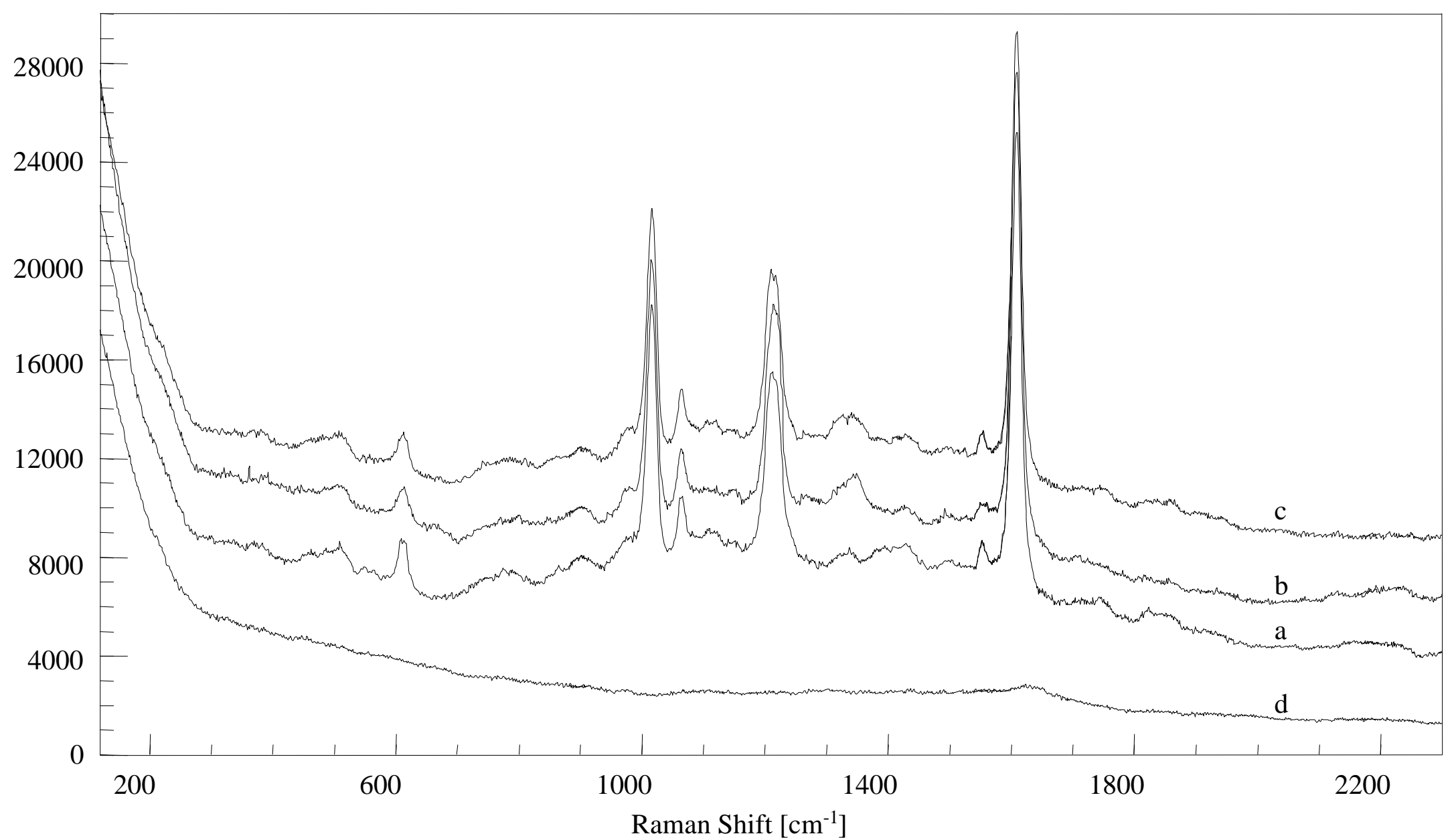

Figure 5-1 (a) SERS of 4-cyanopyridine (4-CP) adsorbed onto a copper colloid (/Cu), (b) SERS of 4-CP/Cu after the addition of $\mathrm{Na}_{2} \mathrm{SO}_{4}$, (c) SERS of 4-CP/Cu after the addition of $\mathrm{NaCl}$, and (d) SERS of 4-CP/Cu after the addition of $\mathrm{Na}_{2} \mathrm{~S}$. 


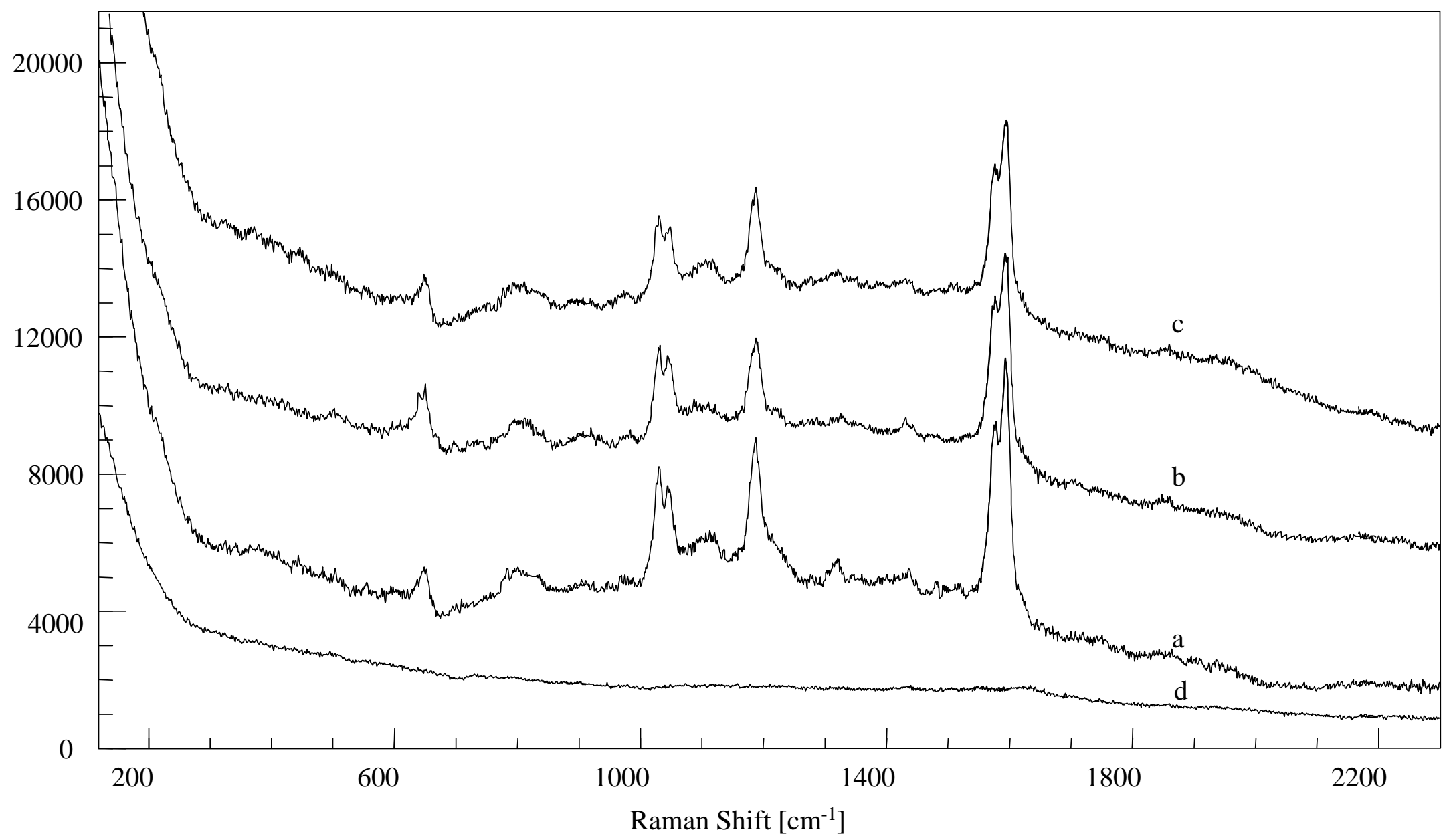

Figure 5-2 (a) SERS of 3-cyanopyridine (3-CP) adsorbed onto a copper colloid (/Cu), (b) SERS of 3-CP/Cu after the addition of $\mathrm{Na}_{2} \mathrm{SO}_{4}$, (c) SERS of 3-CP/Cu after the addition of $\mathrm{NaCl}$, and (d) SERS of 3-CP/Cu after the addition of $\mathrm{Na}_{2} \mathrm{~S}$. 


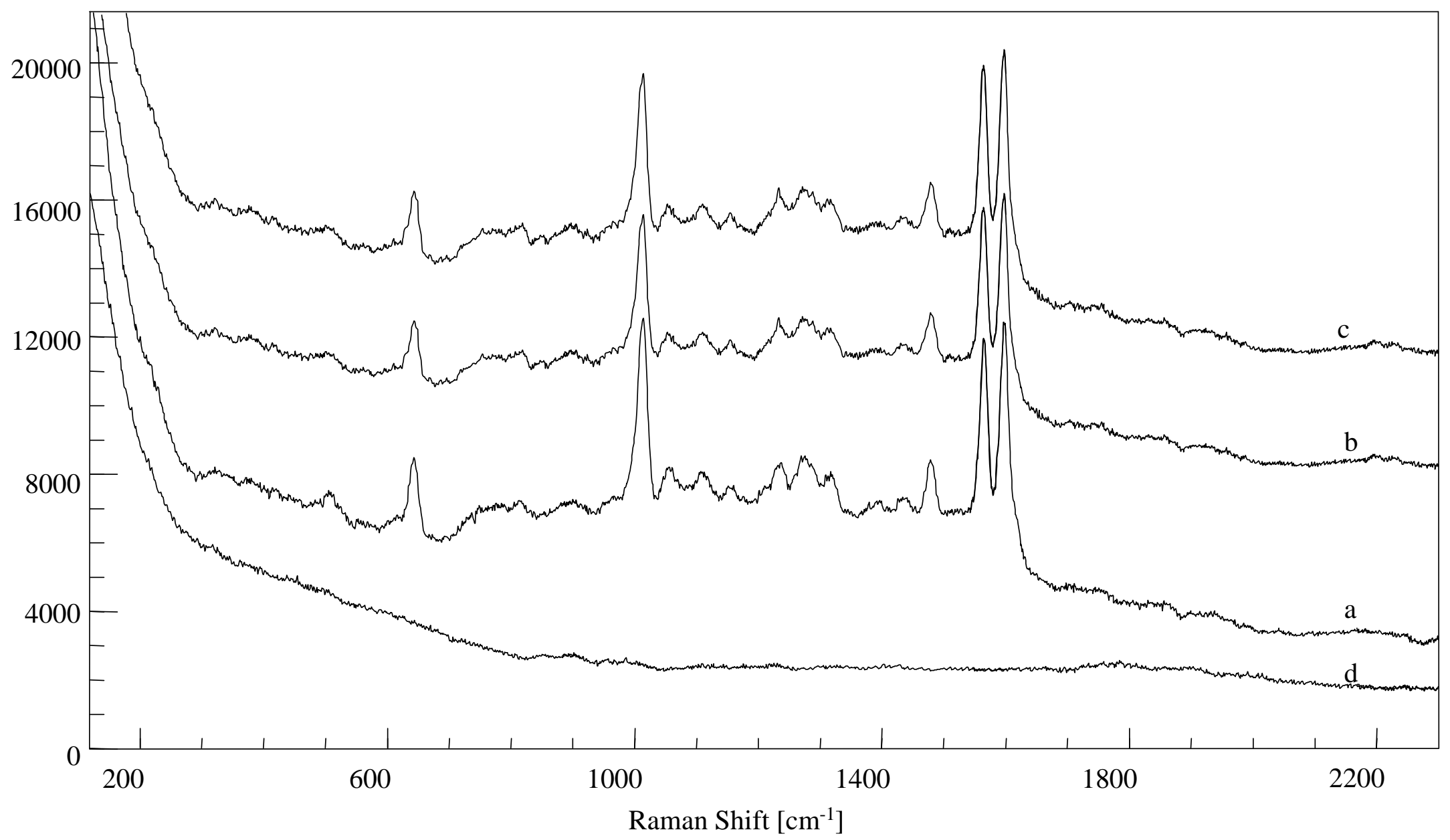

Figure 5-3 (a) SERS of 2-cyanopyridine (2-CP) adsorbed onto a copper colloid (/Cu), (b) SERS of 2-CP/Cu after the addition of $\mathrm{Na}_{2} \mathrm{SO}_{4}$, (c) SERS of 2-CP/Cu after the addition of $\mathrm{NaCl}$, and (d) SERS of 2-CP/Cu after the addition of $\mathrm{Na}_{2} \mathrm{~S}$. 
of copper colloids changed from dark red to a dark brown-grey upon increased aggregation due to salt addition. Despite the indication of additional aggregation and expected increase in the surface-enhancement, the SER spectra were generally identical in intensity and pattern before and after addition of sodium sulfate and sodium chloride for all three isomers. Sodium sulfide removed the adsorbates which resulted in the complete loss of any SER spectra.

Although prior investigations indicate that the addition of sodium sulfate and sodium chloride should increase the degree of surface-enhancement, the copper systems deviate from predicted behavior. ${ }^{4,5,12,13}$ Given the results of the anaerobic experiments involving the copper systems (see Chapters 2 and 3), we can eliminate the possibility that the presence of oxygen facilitates immediate aggregation since no decrease in enhancement was observed in anaerobic conditions.

Although the addition of the $\mathrm{SO}_{4}{ }^{2-}$ or the $\mathrm{Cl}^{-}$ions causes aggregation and concomitant color change, no additional surface enhancement is observed. This is due to the fact that the copper colloids are prepared via the borohydride reduction of copper (II) sulfate. The colloidal solution contains $\mathrm{SO}_{4}{ }^{2-}$ prior to adsorption of the cyanopyridines. Thus, aggregation of the colloids is manifested prior to the addition of the sodium salts. The lack of enhancement produced by the addition of the $\mathrm{Cl}^{-}$ions provides information concerning the effects of co-adsorption in copper colloidal systems. The SERS data indicate that coadsorption of $\mathrm{Cl}^{-}$ions with the cyanopyridines does not affect aggregation or enhancement of SERS signals for the copper colloidal system.

In order to verify this fact, the SER spectra of 4-AMP adsorbed onto copper colloids prepared by borohydride reduction of $\mathrm{Cu}^{+1}$ under conditions of salt addition are reported in 
Figure 5-4. The color of the adsorbed 4-AMP adsorbed onto the copper colloid changes from a faint dark red to a dark grey. Despite the indication of additional aggregation and expected increase in the surface-enhancement, the SER spectrum after the addition of the sodium sulfate was less than the original spectrum. This would indicate that aggregation occurs during the adsorption process due to the presence of $\mathrm{Cl}^{-}$ions during the preparation of the copper colloid. The SER spectrum after the addition of the sodium chloride demonstrate no change in intensity of the spectral pattern or observed frequencies. This would indicate that co-adsorption does not affect the level of enhancement observed in the SERS.

The SER spectra of 4-CP, 3-CP, and 2-CP adsorbed onto gold colloids under conditions of salt addition are reported in Figures 5-5, 5-6, and 5-7. Upon salt addition, a color change indicative of aggregation is observed for all three salts. SER spectra of the cyanopyridines adsorbed onto gold colloids indicate that there is a dependence of the enhancement mechanism on the effects of aggregation and salt co-adsorption upon addition of sodium sulfate and sodium chloride. An increase in enhancement of the SER signal is observed upon addition of these salts. This is in contrast to the results for the copper colloids where $\mathrm{SO}_{4}^{-}$was initially present in the colloidal solution. Although there appears to be greater aggregation (darker color change) due to the sodium sulfate, there is a larger enhancement due to the addition of sodium chloride. This would indicate that the coadsorption of $\mathrm{Cl}^{-}$contributes more to the enhancement effect than the aggregation caused by $\mathrm{SO}_{4}^{-}$. In the case of sodium sulfide, the successful removal of the adsorbates is observed by a complete loss of any SER spectra. 


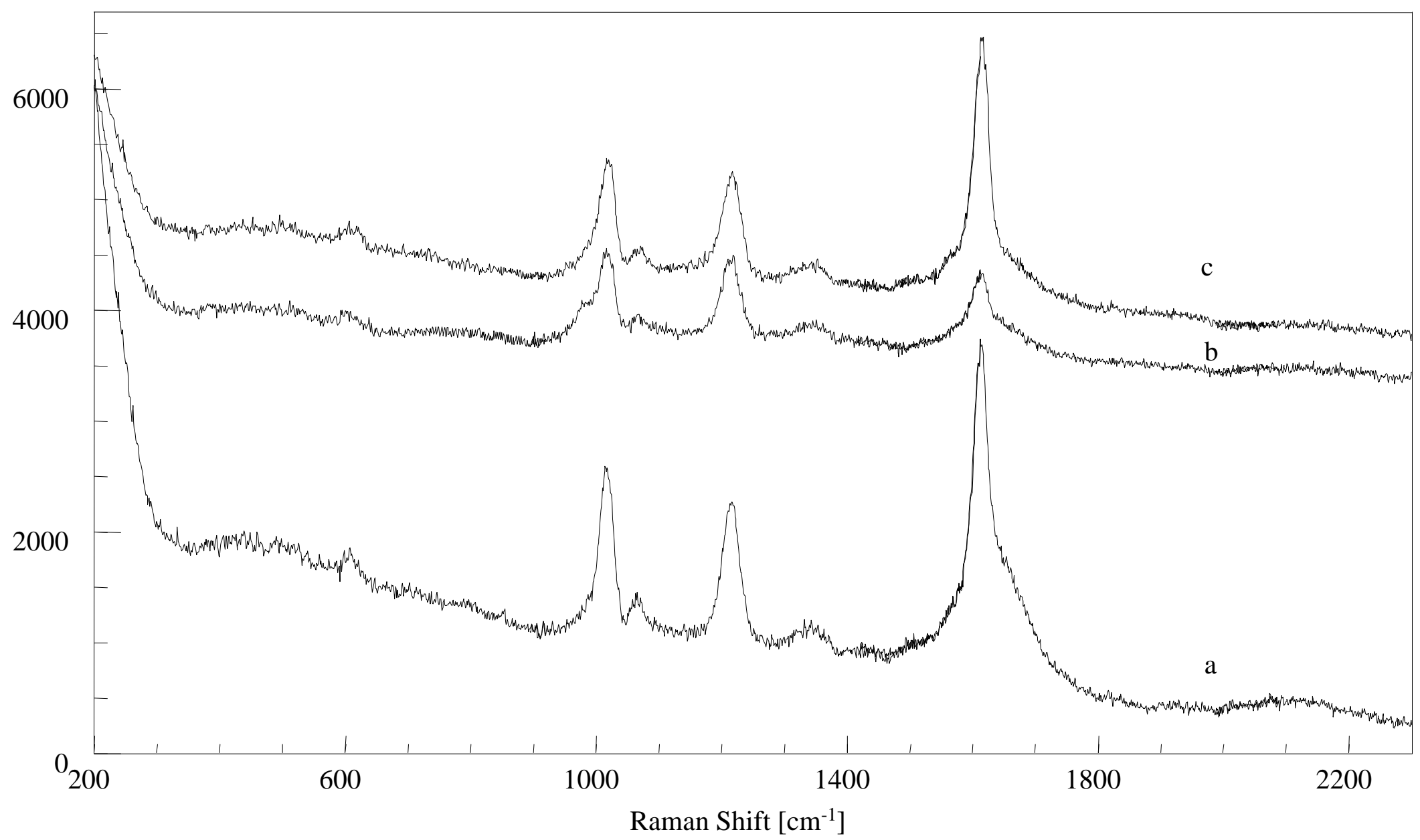

Figure 5-4 (a) SERS of 4-cyanopyridine (4-CP) adsorbed onto a copper colloid (/Cu(I)) prepared by borohydride reduction of $\mathrm{Cu}^{+1}$, (b) SERS of 4-CP/Cu(I) after the addition of $\mathrm{Na}_{2} \mathrm{SO}_{4}$, and (c) SERS of 4-CP/Cu(I) after the addition of $\mathrm{NaCl}$. 


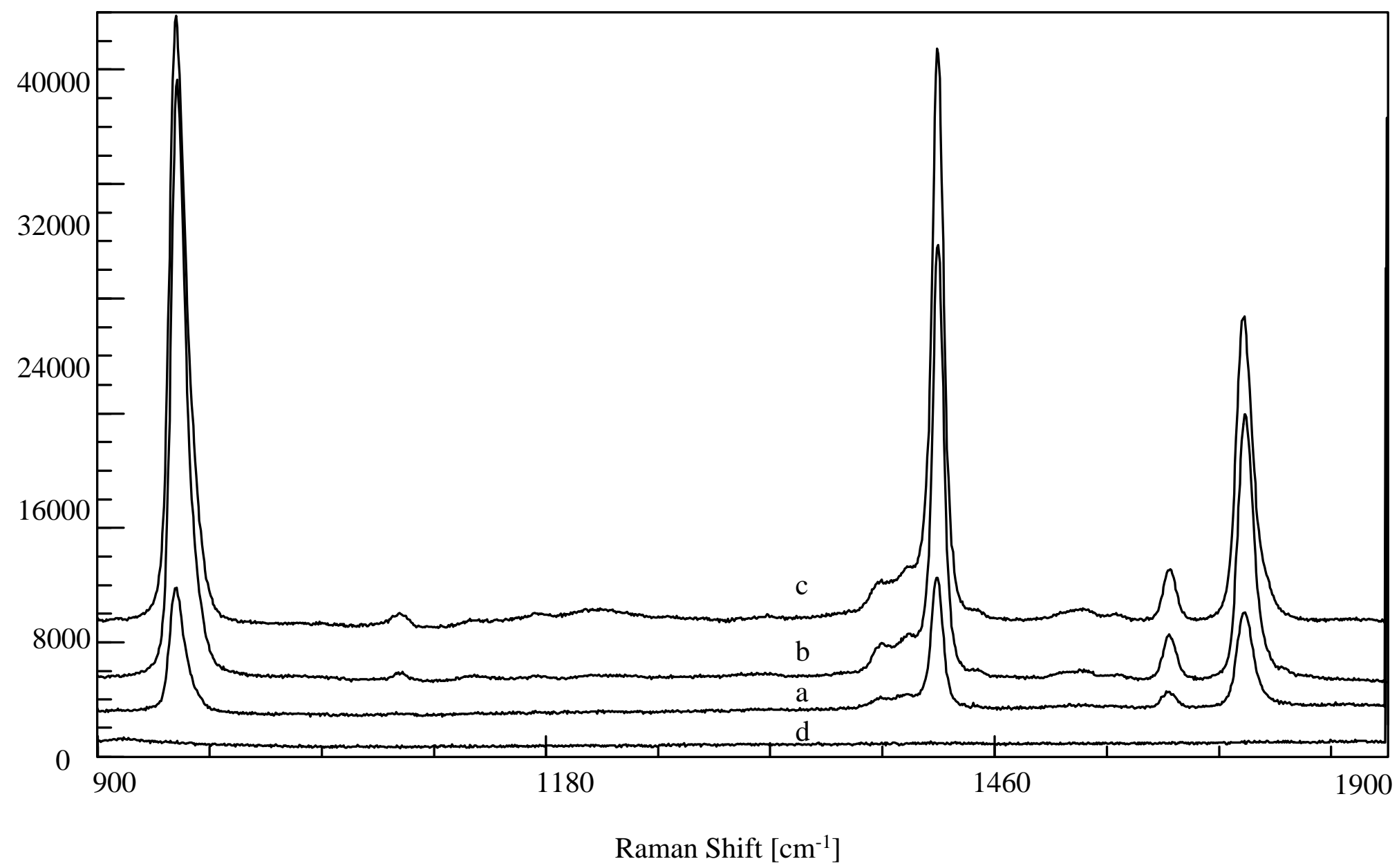

Figure 5-5 (a) SERS of 4-cyanopyridine (4-CP) adsorbed onto a gold colloid (/Au), (b) SERS of 4-CP/Au after the addition of $\mathrm{Na}_{2} \mathrm{SO}_{4}$, (c) SERS of 4-CP/Au after the addition of $\mathrm{NaCl}$, and (d) SERS of 4-CP/Au after the addition of $\mathrm{Na}_{2} \mathrm{~S}$. 


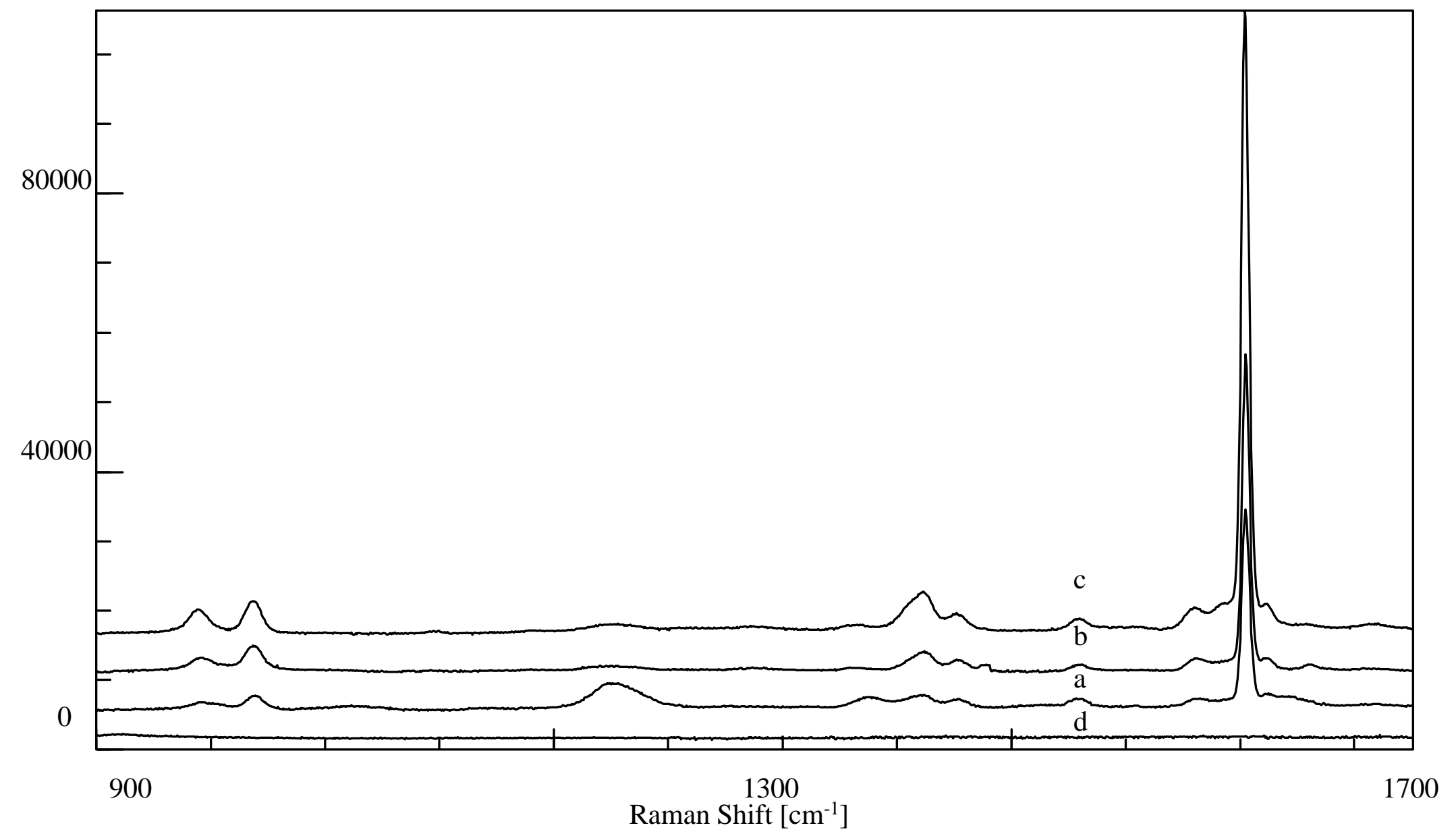

Figure 5-6 (a) SERS of 3-cyanopyridine (3-CP) adsorbed onto a gold colloid (/Au), (b) SERS of 3-CP/Au after the addition of $\mathrm{Na}_{2} \mathrm{SO}_{4}$, (c) SERS of 3-CP/Au after the addition of $\mathrm{NaCl}$, and (d) SERS of 3-CP/Au after the addition of $\mathrm{Na}_{2} \mathrm{~S}$. 


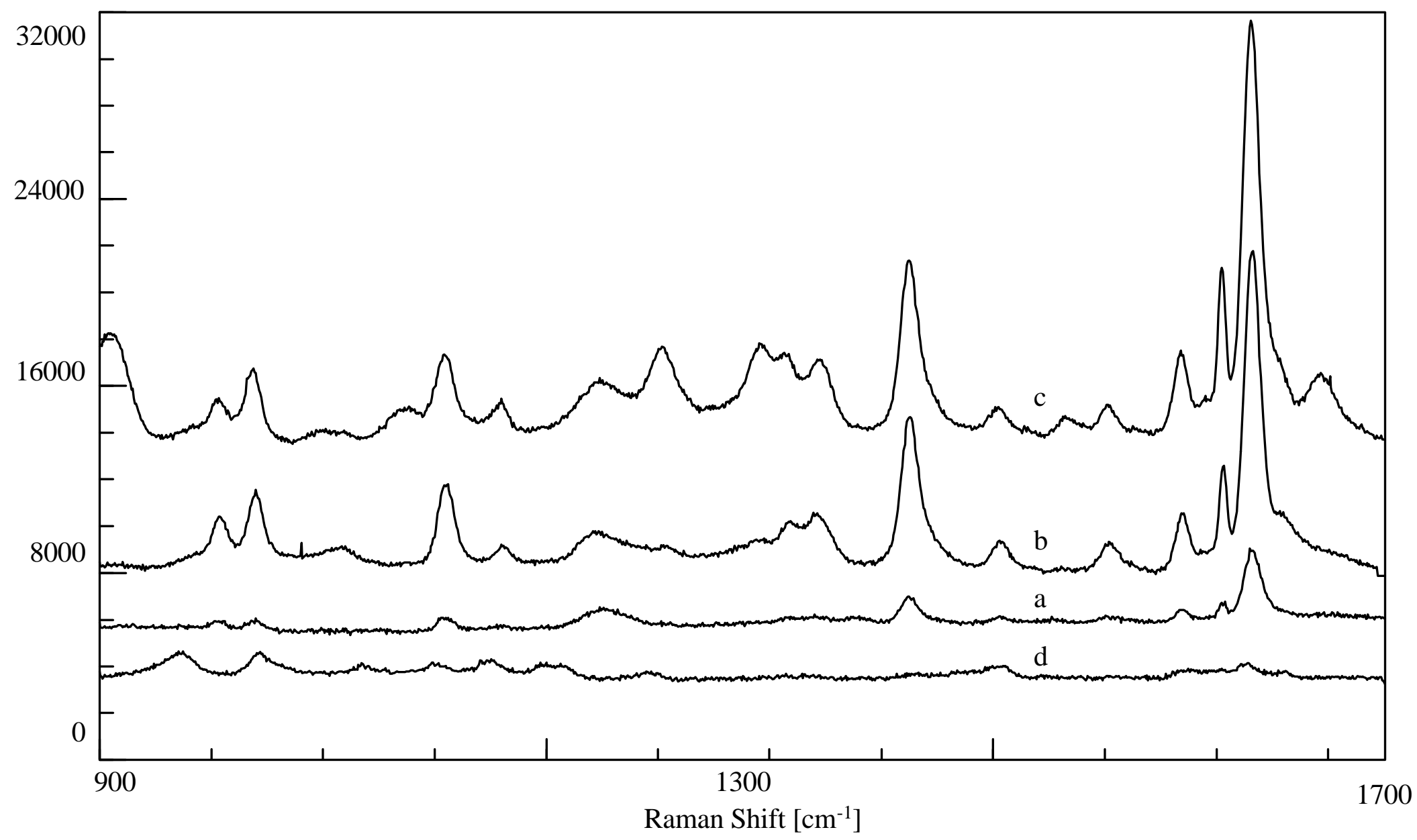

Figure 5-7 (a) SERS of 2-cyanopyridine (2-CP) adsorbed onto a gold colloid (/Au), (b) SERS of 2-CP/Au after the addition of $\mathrm{Na}_{2} \mathrm{SO}_{4}$, (c) SERS of 2-CP/Au after the addition of $\mathrm{NaCl}$, and (d) SERS of 2-CP/Au after the addition of $\mathrm{Na}_{2} \mathrm{~S}$. 
The effects of aggregation caused by the addition of $\mathrm{SO}_{4}^{-}$ions are related to the electromagnetic field mechanism proposed for SERS. ${ }^{9,13}$ This mechanism supposes that as the surface is aggregated and 'roughened' and the particle size and shape leads to a larger enhancement. This is exhibited in the case of all three isomeric forms of aminomethylpyridine adsorbed onto both copper and gold colloids. Although the SERS of the copper systems indicate no signs of increased enhancement, the presence of $\mathrm{SO}_{4}^{-}$in the colloidal system (from $\mathrm{Cu}(\mathrm{II}) \mathrm{SO}_{4}$ ) facilitates additional aggregation prior to salt addition.

The co-adsorption of sodium chloride onto the surface of the copper and gold colloids with AMP provides insight into the chemical mechanism of SERS. In the case of copper colloids, the adsorption of $\mathrm{Cl}^{-}$ions on the metal surface does not promote any additional enhancement compared to that provided by aggregation. This would indicate that the molecule/adsorbate interaction in the case of copper is optimized without the addition of subsequent molecules. However, in the case of the gold colloids this is not true. A greater degree of enhancement is observed upon addition of sodium chloride compared to the addition of sodium sulfate. This would indicate that for gold colloids aggregation is not as effective as both aggregation with $\mathrm{Cl}^{-}$co-adsorption in increasing the enhancement. The fact that the addition of $\mathrm{Cl}^{-}$ions promotes additional enhancement indicates that the chemical interaction between the co-adsorbed molecules with the metal surface plays a significant role in the SER effect.

In order to elucidate the effects of $\mathrm{Cl}^{-}$co-adsorption on the SERS intensity, a series of experiments were performed using 4-CP adsorbed onto a gold colloid with addition of various amounts of $\mathrm{NaCl}$. The resulting SERS are shown in Figure 5-8. Sodium chloride 


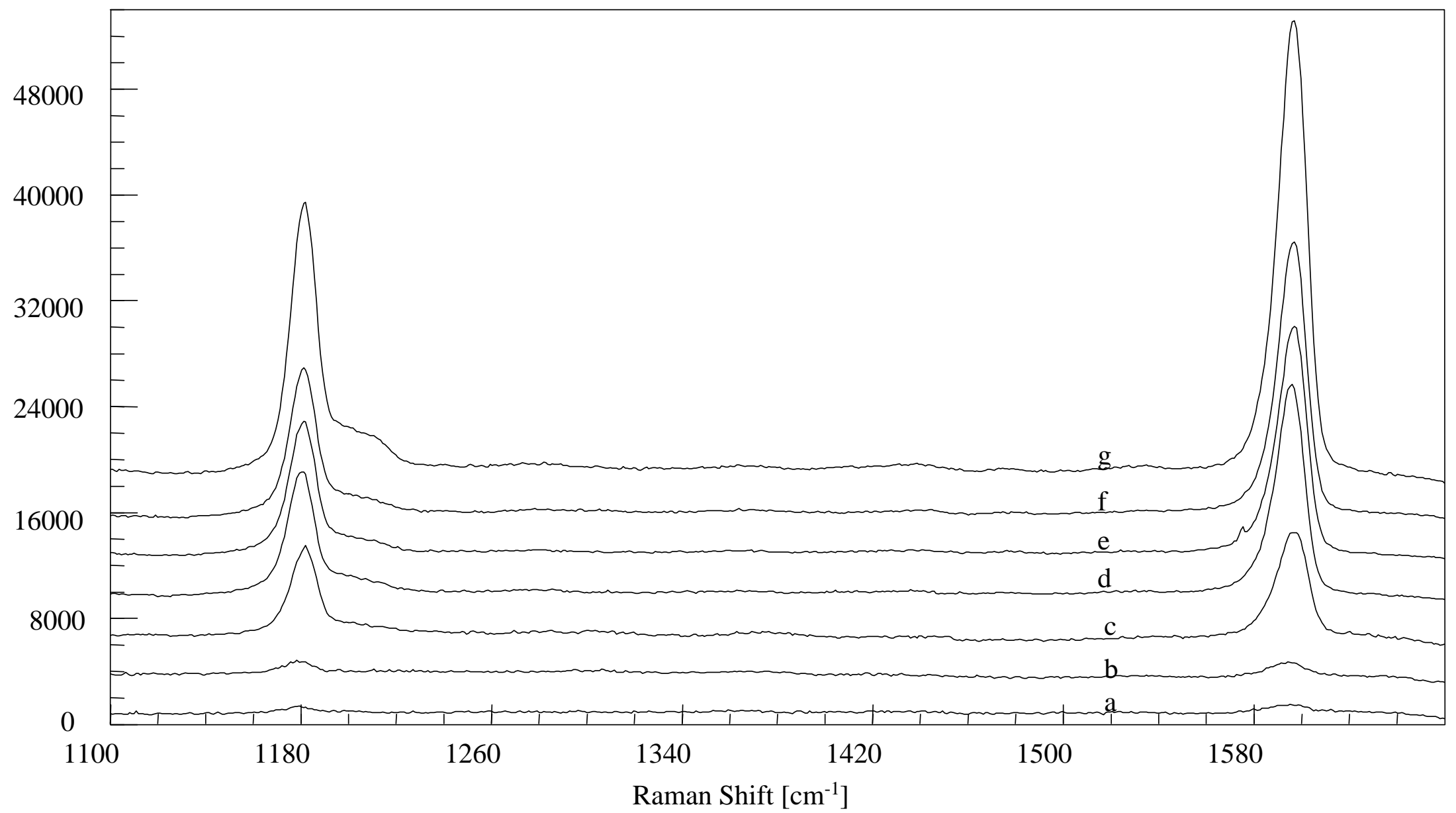

Figure 5-8 SERS of 4-cyanopyridine (4-CP) adsorbed onto a gold colloid (/Au) with the addition of various concentrations of $\mathrm{NaCl}$ : (a) 4-CP/Au with no $\mathrm{NaCl}$, (b) 4-CP/Au with $0.05 \mathrm{M} \mathrm{NaCl}$, (c) 4-CP/Au with $0.1 \mathrm{M} \mathrm{NaCl}$, (d) 4-CP/Au with $0.5 \mathrm{M} \mathrm{NaCl}$, (e) 4-CP/Au with $0.75 \mathrm{M} \mathrm{NaCl}$, (f) 4-CP/Au with $1.0 \mathrm{M}$ $\mathrm{NaCl}$, and (g) 4-CP/Au with 3.0 M NaCl. 
was added to gold colloids with adsorbed $4-\mathrm{CP}$ with final $\mathrm{NaCl}$ concentrations in the range $0.05 \mathrm{M}$ to $3.0 \mathrm{M}$. The resulting spectra show an increasing intensity with increasing concentration of sodium chloride added. The integrated intensity of the $1605 \mathrm{~cm}^{-1}$ line of 4-CP adsorbed on gold colloids was monitored and was found to increase with the concentration of the sodium chloride added to the sample (see Figure 5-9). This dependence of enhancement on salt concentration supports the importance of chemical interaction in the surface enhancement mechanism. This would indicate that in the case of gold colloids the chemical interaction between the adsorbed molecules and the metal surface dominate over the effects generated by aggregation.

In order to measure the degree of influence that aggregation plays in surface enhancement, similar experiments were performed using 4-CP adsorbed onto a gold colloid with the addition of sodium sulfate. The resulting SERS are shown in Fig. 5-10. The spectra show an increasing intensity with the addition of sodium sulfate with increasing concentrations up to $0.1 \mathrm{M}$. The addition of sodium sulfates above $0.1 \mathrm{M}$ results in a significant decrease in surface enhancement (see Figure 5-9). This decrease is due to precipitation of the colloid caused by fast aggregation. 

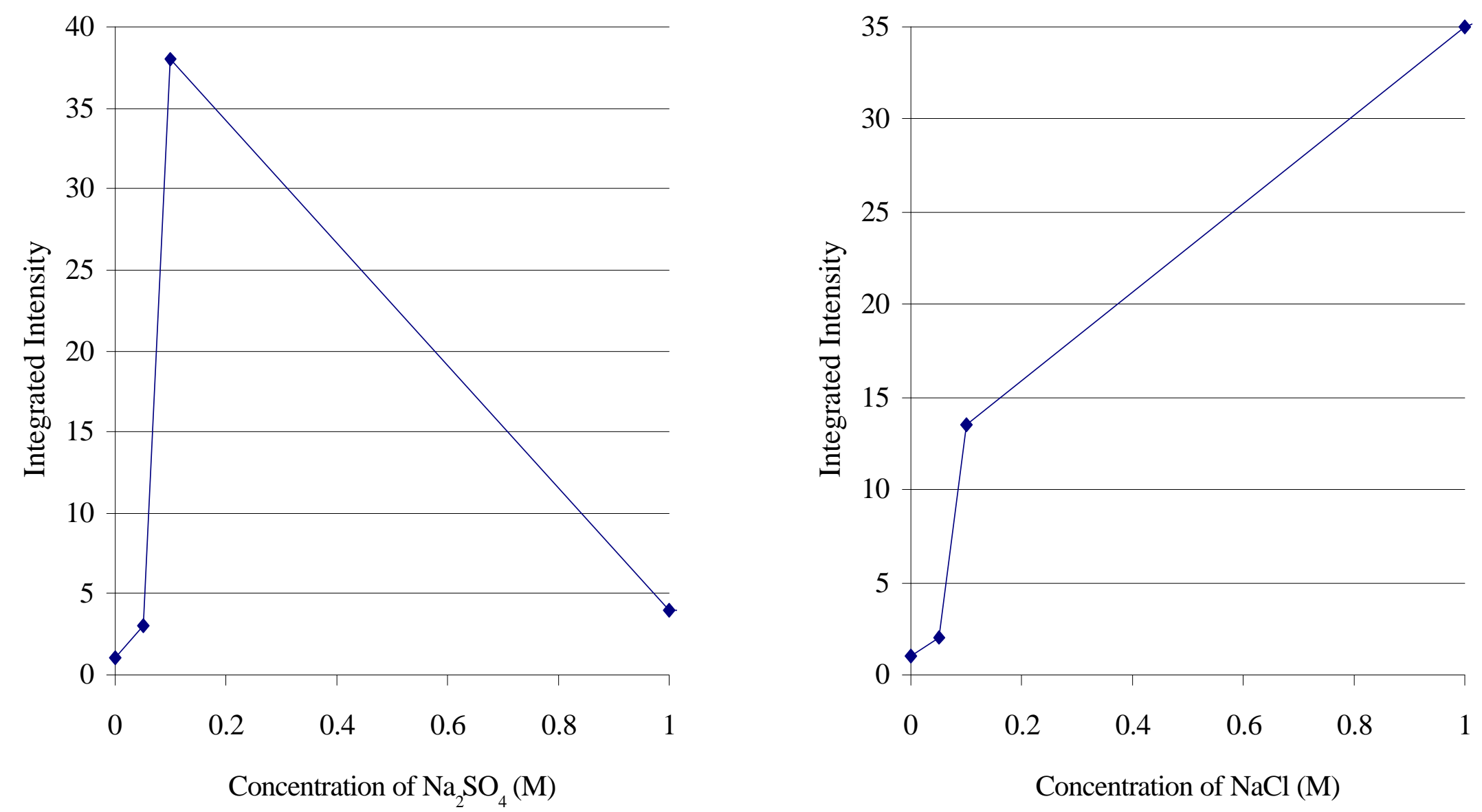

Figure 5-9 Dependence of relative integrated intensities of the $1605 \mathrm{~cm}^{-1}$ line as a function of concentration of $\mathrm{NaCl}$ and $\mathrm{Na}_{2} \mathrm{SO}_{4}$ in a sample of 4-CP/Au. 


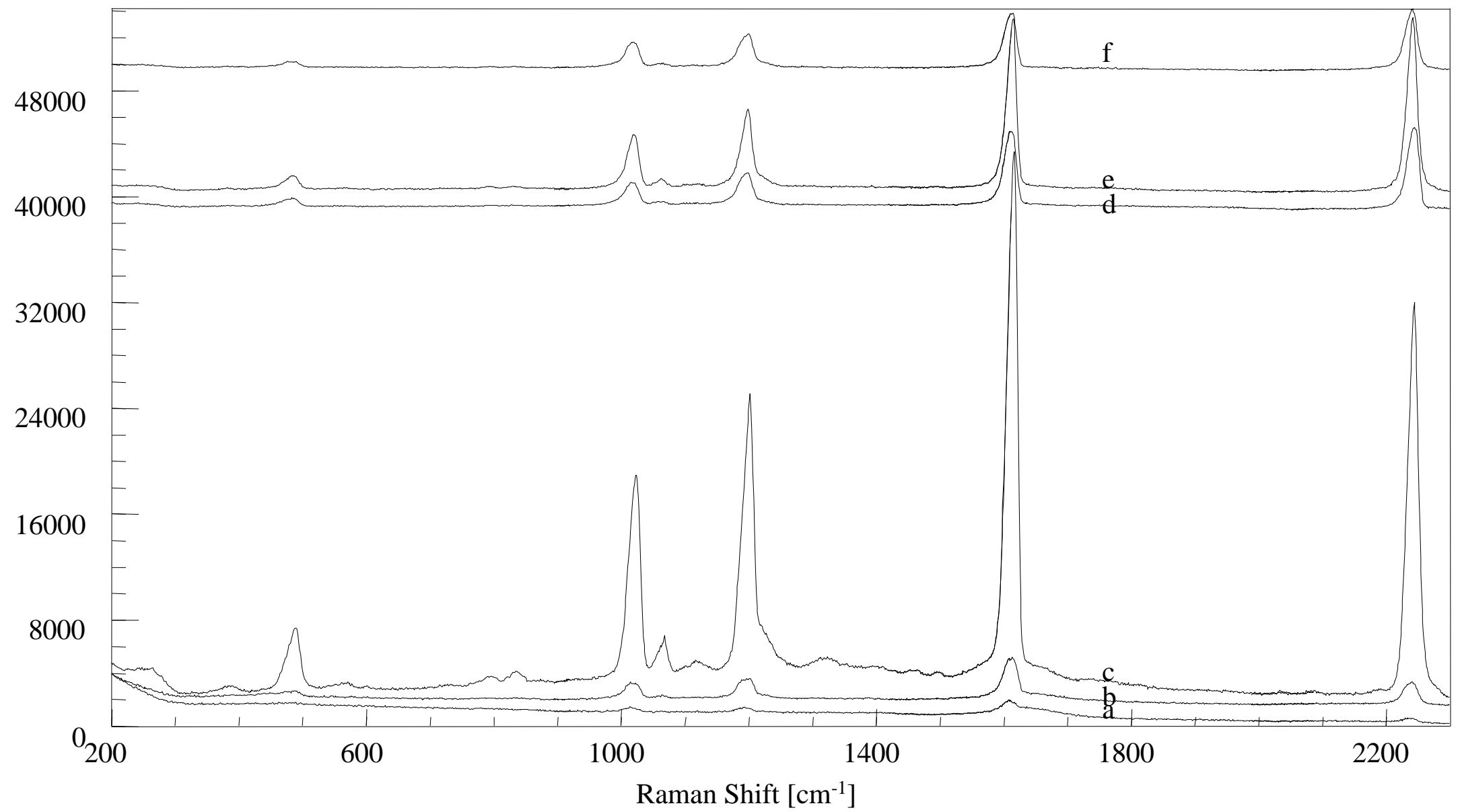

Figure 5-10 SERS of 4-cyanopyridine (4-CP) adsorbed onto a gold colloid (/Au) with the addition of various concentrations of $\mathrm{Na}_{2} \mathrm{SO}_{4}$ : (a) 4-CP/Au with no $\mathrm{Na}_{2} \mathrm{SO}_{4}$, (b) 4-CP/Au with $0.05 \mathrm{M} \mathrm{Na}_{2} \mathrm{SO}_{4}$, (c) 4-CP/Au with $0.1 \mathrm{M} \mathrm{Na}_{2} \mathrm{SO}_{4}$, (d) 4-CP/Au with $0.5 \mathrm{M} \mathrm{Na}_{2} \mathrm{SO}_{4}$, (e) 4-CP/Au with $1.0 \mathrm{M} \mathrm{Na}_{2} \mathrm{SO}_{4}$, and (f) 4-CP/Au with $3.0 \mathrm{M} \mathrm{Na}_{2} \mathrm{SO}_{4}$. 


\subsection{CONCLUSIONS}

The addition of sodium sulfate and sodium chloride appears to have no effect on the SERS enhancement mechanism of 4-, 3-, and 2-aminomethylpyridines (4-AMP, 3-AMP, and 2-AMP) on copper colloids. In the addition of sodium sulfate, aggregation is already promoted by the presence of $\mathrm{SO}_{4}{ }^{2-}$ ions present in the original copper colloid solution. The lack of intensity enhancement upon addition of $\mathrm{Cl}^{-}$ions indicates that co-adsorption plays no significant role in the degree of enhancement observed in the SERS for these systems.

The addition of sodium sulfate and sodium chloride to gold colloids with adsorbed cyanopyridines leads to an increase in the surface enhancement. The addition of $\mathrm{Cl}^{-}$ions promotes a larger surface enhancement than produced by the addition of $\mathrm{SO}_{4}{ }^{2-}$ ions. This indicates that the chemical interaction between the adsorbed molecules and the gold surface plays a dominant role in the SER mechanism compared to the plasmon/electromagnetic field mechanism.

The addition of sodium sulfide to both copper and gold colloids successfully desorbs the adsorbates from the metal surfaces resulting in no observable SERS. 


\section{REFERENCES}

1. M. Faraday, Phil. Trans. R. Soc. London 147, 145 (1857).

2. G. Mie, Ann. Physik 26, 377 (1908).

3. S. Schneider, H. Grau, P. Halbig, P. Freunscht and U. Nickel, J. Raman Spectrosc. 27, 57-68 (1996).

4. J. C. Rubim and O. Sala, J. Mol. Struct. 145, 157-172 (1986).

5. J. Aubard, E. Bagnasco and J. Pantigny, J. Phys. Chem. 99, 7075-7081 (1995).

6. H. Wetzel and H. Gerischer, Chem. Phys. Letters 3 76, 460-464 (1980).

7. E. J. Liang, C. Engert and W. Kiefer, Vib. Spectrosc. 8, 435-444 (1995).

8. H. Chew, D. Wang and M. Kerker, Phys. Rev. B 8 28, 4169-4178 (1984).

9. J. Pate, A. Leiden, B. J. Bozlee and R. L. Garrell, J. Raman Spectrosc. 14, 477 (1983).

10. M. Kerker, O. Siiman and D. Wang, J. Phys. Chem. 15 88, 3168-3170 (1984).

11. T. Xiao, Q. Ye and L. Sun, J. Phys. Chem. B 101, 632-638 (1997).

12. E. Lee, S. S. Yi, M. S. Kim and K. Kim, J. Mol. Spectrosc. 298, 47-54 (1993).

13. J. C. Rubim, I. G. R. Gutz and O. Sala, J. Mol. Struct. 101, 1-6 (1983).

14. J. A. Creighton, M.S. Alvarez, D.A. Weltz, S. Garoff and M. W. Kim, J. Phys. Chem. 87, 4793 (1983).

15. J. A. Creighton and D. G. Eadon, J. Chem. Soc., Faraday Trans. 24 87, 3881-3891 (1991).

16. O. Siiman, L. A. Bumm, R. Callaghan, C. G. Blatchford and M. Kerker, J. Phys. Chem. 87, 1014 (1983).

17. D. Meisel and P. C. Lee, J. Phys. Chem. 86, 3391 (1982). 


\section{CHAPTER 6}

\section{Cyanopyridines Adsorbed onto Silver Colloids}

\subsection{INTRODUCTION}

The surface potential of the different metals in metal colloids affect the contribution of the electromagnetic (EM) and chemical (CM) mechanisms to surface enhancement in SERS. The EM is primarily a characteristic of the colloidal metals and leads to an enhancement that is nearly independent of the adsorbed molecule. ${ }^{1}$ The distinguishing features of each type of metallic colloid include the area of contact between the disperse colloidal particles and the dispersion medium, as well as the energy associated with creating and maintaining these interfaces. The $\mathrm{CM}$ exploits a resonance in the molecule-metal effective polarizability. This mechanism is sensitive to the presence of "active sites" on the metal and provide details of the molecule-metal bond. ${ }^{1}$ The actual charge transfer of the adsorption of organonitriles onto the different metal surfaces and the resulting orientation, symmetry and chemical interaction will dispense understanding as to the contributing influences which generate surface enhancement.

The role of the metal in the amount of SERS observed and relative surface potential for SERS will be determined by the collection of the three isomeric forms of cyanopyridine on silver colloids prepared by borohydride and citrate reduction of $\mathrm{AgNO}_{3}$. This data will be compared to that collected on the copper and gold congeners (see Chapters 2 and 3). 


\subsection{EXPERIMENTAL}

The preparation of the citrate reduced silver colloids involves the dissolution of $\mathrm{AgNO}_{3}$ (Aldrich, 99.99\%; $90 \mathrm{mg}$ ) in $500 \mathrm{~mL}$ of water followed by heating until boiling. ${ }^{2} \mathrm{~A}$ solution of $1 \% \mathrm{w} / \mathrm{w}$ sodium citrate (Aldrich $99 \%)(10 \mathrm{~mL})$ was added. Immediately after the addition of the sodium citrate the solution changed to a yellowish brown color (absorption band at $390 \mathrm{~nm}) .{ }^{3}$ The solution was maintained at boiling for 2 hours. Raman samples were prepared by adding cyanopyridine $\left(0.3 \mathrm{~mL}, 1 \times 10^{-3} \mathrm{M}\right.$ (aq.)) to $2.7 \mathrm{~mL}$ of the silver colloid solution. The color changed to a grey/green with an absorption maxima at $394 \mathrm{~nm}$ indicative of aggregation due to the presence of the adsorbate. The SER spectra were collected starting 80 minutes after the addition of the cyanopyridine in the borosilicate glass culture tube.

The preparation of the borohydride reduced silver colloids involves the dissolution of $\mathrm{AgNO}_{3}$ (Aldrich, 99.99\%; $17 \mathrm{mg}$ ) in $100 \mathrm{~mL}$ of water. ${ }^{3}$ A solution of sodium borohydride (Aldrich; 99\%; $300 \mathrm{~mL}$ of $2 \times 10^{-3} \mathrm{M}$ (aq.)) was added rapidly and the solution stirred vigorously for 2 hours at room temperature. The colloid was allowed to sit for several hours without stirring prior to collection of spectra. Raman samples were prepared by adding cyanopyridine $\left(0.3 \mathrm{~mL}, 1 \times 10^{-3} \mathrm{M}\right.$ (aq.)) to $2.7 \mathrm{~mL}$ of the silver colloid solution in a borosilicate glass culture tube. The SER spectra were collected starting from 80 minutes after addition of the cyanopyridine up to 2 months after addition for aged samples.

\subsection{RESULTS AND DISCUSSION}

The SER spectra of 4-cyanopyridine (4-CP) adsorbed on each type of silver colloid are presented in Figure 6-1. The vibrational frequencies and tentative assignments are 


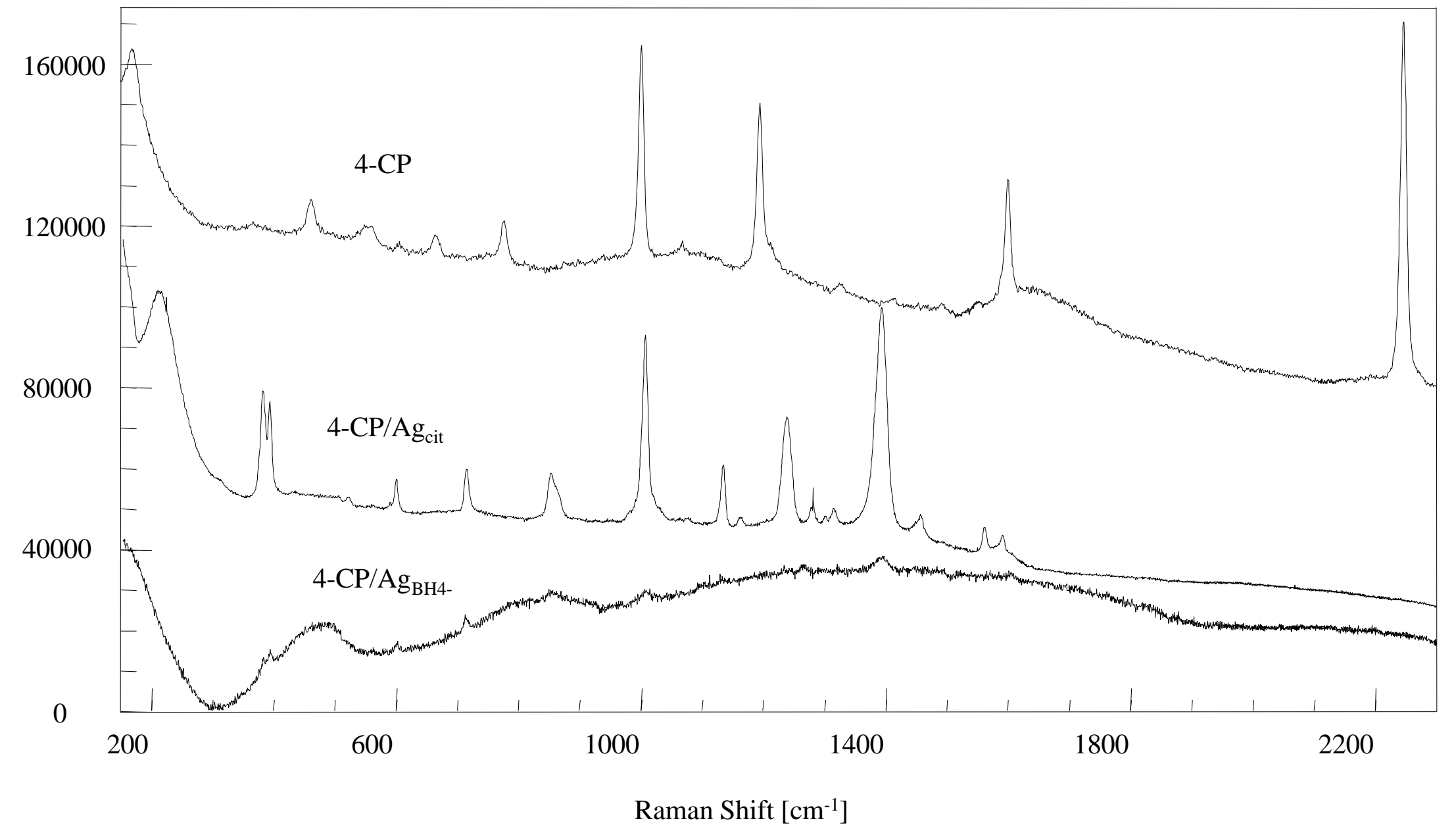

Figure 6-1 Raman spectra of 4-cyanopyridine (4-CP) and SERS of 4-CP adsorbed onto silver colloids prepared by citrate reduction $\left(/ \mathrm{Ag}_{\mathrm{cit}}\right)$ and borohydride reduction $\left(/ \mathrm{Ag}_{\mathrm{BH} 4-}\right)$. 
TABLE 6-1: Raman Frequencies $\left(\mathrm{cm}^{-1}\right)$ of 4-Cyanopyridine (4-CP) and Adsorbed on Silver Colloids Prepared by Borohydride Reduction $\left(/ \mathrm{Ag}^{\circ}{ }_{\mathrm{BH}} 4\right)$ and Citrate Reduction $\left(/ \mathrm{Ag}^{\circ}{ }_{\text {cit }}\right)$ and a Silver Electrode $\left(/ \mathrm{Ag}_{\text {elec }}\right)$.

\begin{tabular}{|c|c|c|c|c|}
\hline Assignment $^{\mathrm{a}}$ & 4-CP (2.0 M) & $4-\mathrm{CP} / \mathrm{Ag}^{\circ}{ }_{\mathrm{BH} 4}$ & $4-\mathrm{CP} / \mathrm{Ag}^{\circ}{ }_{\text {cit }}$ & 4-CP/Ag ${ }_{\text {elec }}{ }^{b}$ \\
\hline$\overline{\gamma(\mathrm{C} \equiv \mathrm{N})}$ & 169 & - & - & - \\
\hline $\mathrm{S}$ & - & - & 211 & 210 \\
\hline $\mathrm{C} \equiv \mathrm{N}$ sensitive & 365 & - & 383 & 376 \\
\hline $\mathrm{C} \equiv \mathrm{N}$ sens,$\phi(\mathrm{CC})$ & - & 390 & 392 & 396 \\
\hline $\mathrm{C} \equiv \mathrm{N}$ sensitive & 461 & 483 & 432 & 469 \\
\hline $\mathrm{C} \equiv \mathrm{N}$ sens,$\delta(\mathrm{C} \equiv \mathrm{N})$ & 550 & - & 520 & 553 \\
\hline$\phi(\mathrm{CC})$ & 560 & - & - & - \\
\hline S & - & 601 & 600 & - \\
\hline$\alpha(\mathrm{CCC})$ & 664 & - & - & 666 \\
\hline $\mathrm{S}$ & - & 713 & 714 & - \\
\hline $\mathrm{C} \equiv \mathrm{N}$ sensitive & 776 & - & - & 785 \\
\hline$\gamma(\mathrm{CH})$ & - & - & - & 823 \\
\hline $\mathrm{S}$ & - & 857 & 853 & - \\
\hline S & - & - & 863 & - \\
\hline$\gamma(\mathrm{CH})$ & - & - & - & 961 \\
\hline ring breathing & 1001 & 1008 & 1006 & 1006 \\
\hline$\beta(\mathrm{CH})$ & 1068 & - & 1075 & 1063 \\
\hline $\mathrm{S}$ & - & 1105 & - & - \\
\hline S & - & - & 1133 & - \\
\hline $\mathrm{S}$ & - & - & 1161 & - \\
\hline$\beta(\mathrm{CH})$ & 1194 & - & - & 1191 \\
\hline$\beta(\mathrm{CH}), \alpha(\mathrm{CC})$ & - & - & - & 1212 \\
\hline $\mathrm{C} \equiv \mathrm{N}$ sensitive & - & 1237 & 1237 & 1225 \\
\hline $\mathrm{S}$ & - & 1265 & 1277 & - \\
\hline$\beta(\mathrm{CH})$ & 1327 & - & 1314 & - \\
\hline $\mathrm{S}$ & - & 1391 & 1391 & 1380 \\
\hline $\mathrm{S}$ & 1412 & - & - & - \\
\hline$v(\mathrm{CC}, \mathrm{CN})$ & 1492 & - & 1455 & 1517 \\
\hline$v(C C)$ & 1549 & - & 1561 & 1572 \\
\hline$v(C C)$ & 1601 & 1605 & 1589 & 1601 \\
\hline$v(\mathrm{C} \equiv \mathrm{N})$ & 2246 & - & - & 2238 \\
\hline
\end{tabular}

a. Based on Ref. 4.

b. Based on Ref. 5 . 
reported in Table 6-1. The SERS of 4-CP adsorbed on silver colloids exhibit no $v(\mathrm{C} \equiv \mathrm{N})$ signal. The disappearance of this mode differs from previous studies of cyanopyridines adsorbed on silver electrodes. ${ }^{6-9}$

The adsorption of 4-CP on the borohydride colloids demonstrates very weak surface enhancement. Even upon sample aging (up to 2 months) with signs of increased aggregation, no increase in enhancement was observed in the SERS. This would indicate a weak interaction between the silver borohydride colloids and the adsorbate molecules.

The SERS of 4-CP adsorbed onto borohydride-based silver colloids do not contain bands due to modes that are sensitive to the nitrile substituent; $2246 \mathrm{~cm}^{-1}(v(C \equiv N)), 1492 \mathrm{~cm}^{-}$ ${ }^{1}(v(C C, C \equiv N)), 776 \mathrm{~cm}^{-1}(C \equiv N$ sensitive $), 550 \mathrm{~cm}^{-1}(\delta(C \equiv N)), 461 \mathrm{~cm}^{-1}(C \equiv N$ sensitive $), 365$ $\mathrm{cm}^{-1}(\mathrm{C} \equiv \mathrm{N}$ sensitive $)$, and $169 \mathrm{~cm}^{-1}(\gamma(\mathrm{C} \equiv \mathrm{N})){ }^{4}$ The bands that were found at $1605 \mathrm{~cm}^{-1}$ $(v(C C)), 1008 \mathrm{~cm}^{-1}$ (ring), and $390 \mathrm{~cm}^{-1}(\mathrm{C} \equiv \mathrm{N}$ sens., $\phi(C C))$ are similar to those found when 4-CP was adsorbed onto a silver electrode. ${ }^{7-9}$ Adsorption occurs via the nitrogen on the pyridine ring based on previous reports..$^{6-9}$

The disappearance of the nitrile frequency could suggest a reduction similar to that proposed with the copper colloids. In order to verify adsorption of 4-CP onto silver colloids without nitrile reduction we studied 4-CP adsorbed on citrate-based silver colloids. The study of 4-CP adsorbed on citrate-based colloids would assist in determining whether the presence of borohydride play a significant role in the adsorption process.

The SERS of 4-CP adsorbed onto silver colloids prepared by citrate reduction demonstrate strong surface enhancement. The disappearance of $v(C \equiv N)$ is observed. The bands $1455 \mathrm{~cm}^{-1}(v(C C, C \equiv N)), 1237 \mathrm{~cm}^{-1}(C \equiv N$ sensitive $), 520 \mathrm{~cm}^{-1}(\delta(C \equiv N)), 432 \mathrm{~cm}^{-1}$ 
( $C \equiv N$ sensitive), $392 \mathrm{~cm}^{-1}\left(C \equiv N\right.$ sens., $\phi(C C)$ ), and $383 \mathrm{~cm}^{-1}(C \equiv N$ sensitive) indicate the presence of a nitrile group with significant shifts in frequency. ${ }^{4}$ The spectral pattern of 4-CP adsorbed on the citrate-based silver colloids is similar to that found for adsorption on a silver electrode with the exception of the missing of $v(C \equiv N){ }^{5,7}$ The variation between the frequencies of 4-CP adsorbed on citrate-based silver colloids and a silver electrode are due to the potentials applied to the electrode. ${ }^{7-9}$ Systematic studies of the dependence of the SERS intensity and spectral pattern on the potential applied to a silver electrode have shown that at various potential regions the orientation changed based on the increase or decrease of surface coverage (concentration) of the 4-CP at the electrode surface. ${ }^{8,9}$ The differences in our data with that reported for 4-CP on a silver electrode provide insight into the molecular orientation on the colloidal surface. The shifts to lower frequencies represent a flat-on orientation with adsorption occurring via the nitrogen on the pyridine ring. ${ }^{10,11}$

The loss of the $v(\mathrm{C} \equiv N)$ signal could be due to a few possibilities. First, the conjugation of the nitrile group with the pyridine ring is insignificant and hence $v(C \equiv N)$ simply may not be observed in the SER spectrum. The only bands enhanced in this particular case are those modes associated directly with the pyridine ring. The observation of modes sensitive to the nitrile substituent would still be observed since they are primarily ring modes. Another possibility is that we are observing a different species or resonance form of 4-CP on the silver surface.

In order to determine the role of the nitrile group in the observation of SERS, 3-CP and 2-CP were adsorbed onto each type of silver colloid. The idea is that enhancement of the 
nitrile modes occur as the nitrile group gets closer to the metal surface and the point of adsorption (pyridine nitrogen).

The SERS of 3-cyanopyridine on both types of silver colloids are presented in Figure 6-2. The vibrational frequencies and tentative assignments are reported in Table 6-2. The SERS for 3-CP adsorbed on the silver colloids still exhibits no $v(C \equiv N)$ signal.

The SERS of 3-CP on the borohydride-based colloid exhibits slightly better surface enhancement than that observed for adsorption of 4-CP. This would signify a stronger (yet still weak) interaction between the silver borohydride colloids and the adsorbate molecules. This increase in surface enhancement could be provided by possible interaction between the nitrile group and the metal surface.

The SERS of 3-CP on borohydride-based colloids exhibits a complete disappearance of the nitrile stretching signal. The bands $787 \mathrm{~cm}^{-1}(C \equiv N$ sensitive $)$ and $464 \mathrm{~cm}^{-1}(\delta(C \equiv N))$ indicate the presence of the nitrile substituent. ${ }^{4}$ The bands at $1594 \mathrm{~cm}^{-1}(\mathrm{~V}(\mathrm{CC})), 1391 \mathrm{~cm}^{-1}$ $(\beta(\mathrm{CH})), 1030 \mathrm{~cm}^{-1}$ (ring), and $1006 \mathrm{~cm}^{-1}(\gamma(\mathrm{CH}))$ indicate adsorption via the nitrogen on the pyridine ring based on silver electrode results. ${ }^{5,7}$ The shifts to lower frequencies for the primary ring modes and the appearance of antisymmetric modes suggest a flat-on configuration. $5,7,10,11$

SERS of 3-CP adsorbed on citrate reduced colloids was also collected (as shown in Figure 6-2). The SERS of 3-CP adsorbed on these silver colloids demonstrate strong surface enhancement. The disappearance of the $\mathrm{v}(\mathrm{C} \equiv \mathrm{N})$ is observed. The bands at $1455 \mathrm{~cm}^{-1}(\mathrm{v}(\mathrm{CC}$, $C \equiv N)), 392 \mathrm{~cm}^{-1}(\phi(C C), C \equiv N$ sens., $\gamma(C \equiv N))$, and $383 \mathrm{~cm}^{-1}(\phi(C C), C \equiv N$ sens., $\gamma(C \equiv N))$ 


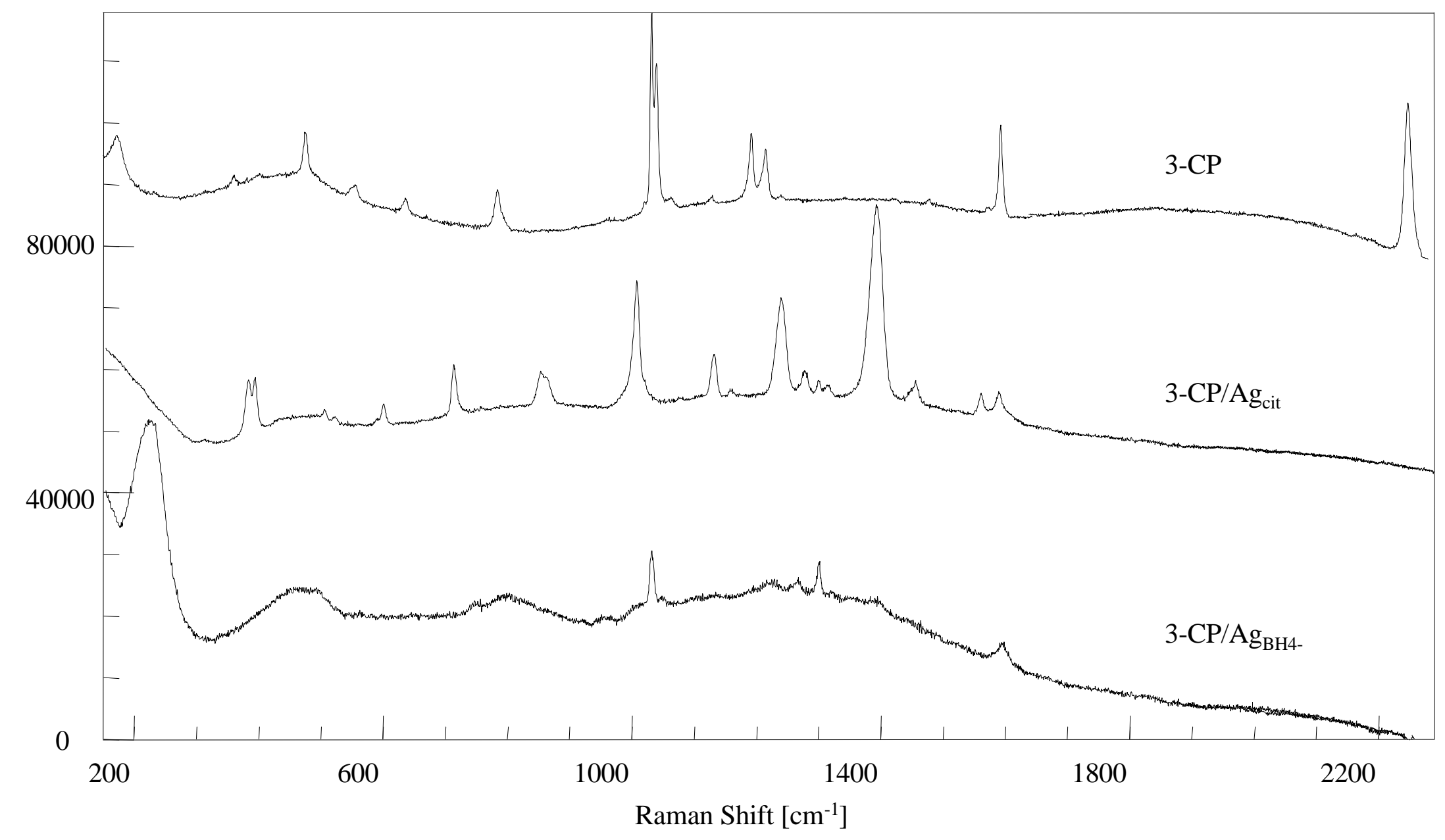

Figure 6-2 Raman spectra of 3-cyanopyridine (3-CP) and SERS of 3-CP adsorbed onto silver colloids prepared by citrate reduction $\left(/ \mathrm{Ag}_{\mathrm{cit}}\right)$ and borohydride reduction $\left(/ \mathrm{Ag}_{\mathrm{BH}}\right)$. 
TABLE 6-2: Raman Frequencies $\left(\mathrm{cm}^{-1}\right)$ of 3-Cyanopyridine (3-CP) and Adsorbed on Silver Colloids Prepared by Borohydride Reduction $\left(/ \mathrm{Ag}^{\circ}{ }_{\mathrm{BH}} 4\right)$ and Citrate Reduction $\left(/ \mathrm{Ag}^{\circ}{ }^{\circ}\right.$ it $)$ and a Silver Electrode $\left(/ \mathrm{Ag}_{\text {elec }}\right)$.

\begin{tabular}{|c|c|c|c|c|}
\hline Assignment $^{\mathrm{a}}$ & $3-\mathrm{CP}(2.0 \mathrm{M})$ & $3-\mathrm{CP} / \mathrm{Ag}^{\circ}{ }_{\mathrm{BH} 4}$ & $3-\mathrm{CP} / \mathrm{Ag}^{\circ}{ }_{\text {cit }}$ & $3-\mathrm{C}$ \\
\hline $\mathrm{C} \equiv \mathrm{N}$ sens,$\delta(\mathrm{CN})$ & 172 & - & - & - \\
\hline $\mathrm{S}$ & - & 219 & - & 208 \\
\hline $\mathrm{S}$ & - & - & 313 & - \\
\hline$\phi(\mathrm{CC}), \mathrm{C} \equiv \mathrm{N}$ sens, $\gamma(\mathrm{CN})$ & 360 & - & 383 & 360 \\
\hline$\phi(\mathrm{CC}), \mathrm{C} \equiv \mathrm{N}$ sens, $\gamma(\mathrm{CN})$ & 399 & - & 392 & 402 \\
\hline $\mathrm{C} \equiv \mathrm{N}$ sens,$\delta(\mathrm{CN})$ & 475 & 464 & - & 475 \\
\hline $\mathrm{S}$ & - & - & 504 & - \\
\hline $\mathrm{S}$ & - & - & 520 & - \\
\hline$\phi(\mathrm{CC}), \mathrm{C} \equiv \mathrm{N}$ sens, $\gamma(\mathrm{CN})$ & 554 & - & - & 548 \\
\hline $\mathrm{S}$ & - & - & 600 & - \\
\hline$\alpha(\mathrm{CCC})$ & 635 & - & - & 641 \\
\hline$\phi(\mathrm{CC})$ & - & - & 713 & 696 \\
\hline $\mathrm{C} \equiv \mathrm{N}$ sensitive & 782 & 787 & - & 790 \\
\hline $\mathrm{S}$ & - & - & 853 & - \\
\hline $\mathrm{S}$ & - & - & 861 & - \\
\hline$\gamma(\mathrm{CH})$ & 994 & 1006 & 1007 & 960 \\
\hline Ring & 1032 & 1030 & - & 1030 \\
\hline$\beta(\mathrm{CH})$ & 1039 & - & - & 1040 \\
\hline $\mathrm{S}$ & 1060 & - & 1076 & - \\
\hline $\mathrm{S}$ & - & - & - & 1094 \\
\hline$\beta(\mathrm{CH})$ & 1127 & - & 1131 & - \\
\hline
\end{tabular}


TABLE 6-2: $\quad$ (Continued)

\begin{tabular}{|c|c|c|c|c|}
\hline Assignment $^{\mathrm{a}}$ & $3-\mathrm{CP}(2.0 \mathrm{M})$ & $3-\mathrm{CP} / \mathrm{Ag}^{\circ}{ }_{\mathrm{BH} 4}$ & $3-\mathrm{CP} / \mathrm{Ag}^{\circ}$ cit & $3-\mathrm{CP} / \mathrm{Ag}_{\text {elec }}$ \\
\hline $\mathrm{S}$ & - & - & 1158 & - \\
\hline$\beta(\mathrm{CH})$ & 1192 & - & - & 1192 \\
\hline $\mathrm{C} \equiv \mathrm{N}$ sensitive & 1216 & - & - & 1208 \\
\hline$\alpha(\mathrm{CC})$ & 1241 & - & 1239 & - \\
\hline S & - & 1267 & 1278 & - \\
\hline $\mathrm{S}$ & - & 1299 & 1299 & - \\
\hline S & - & - & 1315 & - \\
\hline$\beta(\mathrm{CH})$ & 1342 & - & - & - \\
\hline$\beta(\mathrm{CH})$ & - & 1391 & 1392 & 1380 \\
\hline$v(\mathrm{CC}, \mathrm{CN})$ & 1423 & - & - & 1419 \\
\hline$v(\mathrm{CC}, \mathrm{CN})$ & 1477 & - & 1455 & - \\
\hline$v(\mathrm{CC})$ & 1572 & - & 1561 & 1567 \\
\hline$v(\mathrm{CC})$ & 1593 & 1594 & 1590 & 1589 \\
\hline$v(\mathrm{CN})$ & 2240 & - & - & 2237 \\
\hline
\end{tabular}


indicate the presence of a nitrile group (refer to Table 6-2). ${ }^{4}$ The reduction of the nitrile would be unlikely based on the observed frequencies and since borohydride ions are not present in solution. The strong SERS bands at $1392 \mathrm{~cm}^{-1}(\beta(\mathrm{CH})), 1239 \mathrm{~cm}^{-1}(\alpha(\mathrm{CC})), 1131$ $\mathrm{cm}^{-1}(\beta(\mathrm{CH})), 1007 \mathrm{~cm}^{-1}(\gamma(\mathrm{CH})), 713 \mathrm{~cm}^{-1}(\phi(\mathrm{CC})), 392 \mathrm{~cm}^{-1}(\phi(\mathrm{CC}), \mathrm{C} \equiv \mathrm{N}$ sens., $\gamma(\mathrm{C} \equiv \mathrm{N}))$, and $383 \mathrm{~cm}^{-1}(\phi(C C), C \equiv N$ sens., $\gamma(C \equiv N))$ indicate adsorption via the pyridine nitrogen in a flat-on configuration. ${ }^{5,710,11}$ These frequencies coincide with those of 3-CP adsorbed onto a silver electrode (with the exception of the absence of $v(C \equiv N)$ ) supporting a flat-on orientation.

It is interesting to note that the spectral pattern of 3-CP adsorbed on the citrate-based colloids is almost identical to that found of 4-CP adsorbed on citrate-based silver colloids. This could be due to two possibilities. First, the binding and orientation of the two different isomers is identical in nature and independent of the $-\mathrm{C} \equiv \mathrm{N}$ group and this leads to similar SERS. Another probability is that we are observing interfering species or co-adsorption of citrate on the silver surface. ${ }^{12-15}$ The collection of 2-CP on these silver colloids would provide a complete insight as to whether we are observing either of these possibilities due to isomeric differences in the CP molecules.

The SERS of 2-cyanopyridine on both types of silver colloids are presented in Figure 6-3. The vibrational frequencies and tentative assignments are reported in Table 6-3. The SERS of 2-CP adsorbed on the silver colloids contain no $v(C \equiv N)$ signal. This would indicate that for all three isomeric forms of cyanopyridine, the binding and orientation of the molecules onto the silver surfaces prevent detection of the nitrile group.

The adsorption of 2-CP on the borohydride-based silver colloids demonstrates 


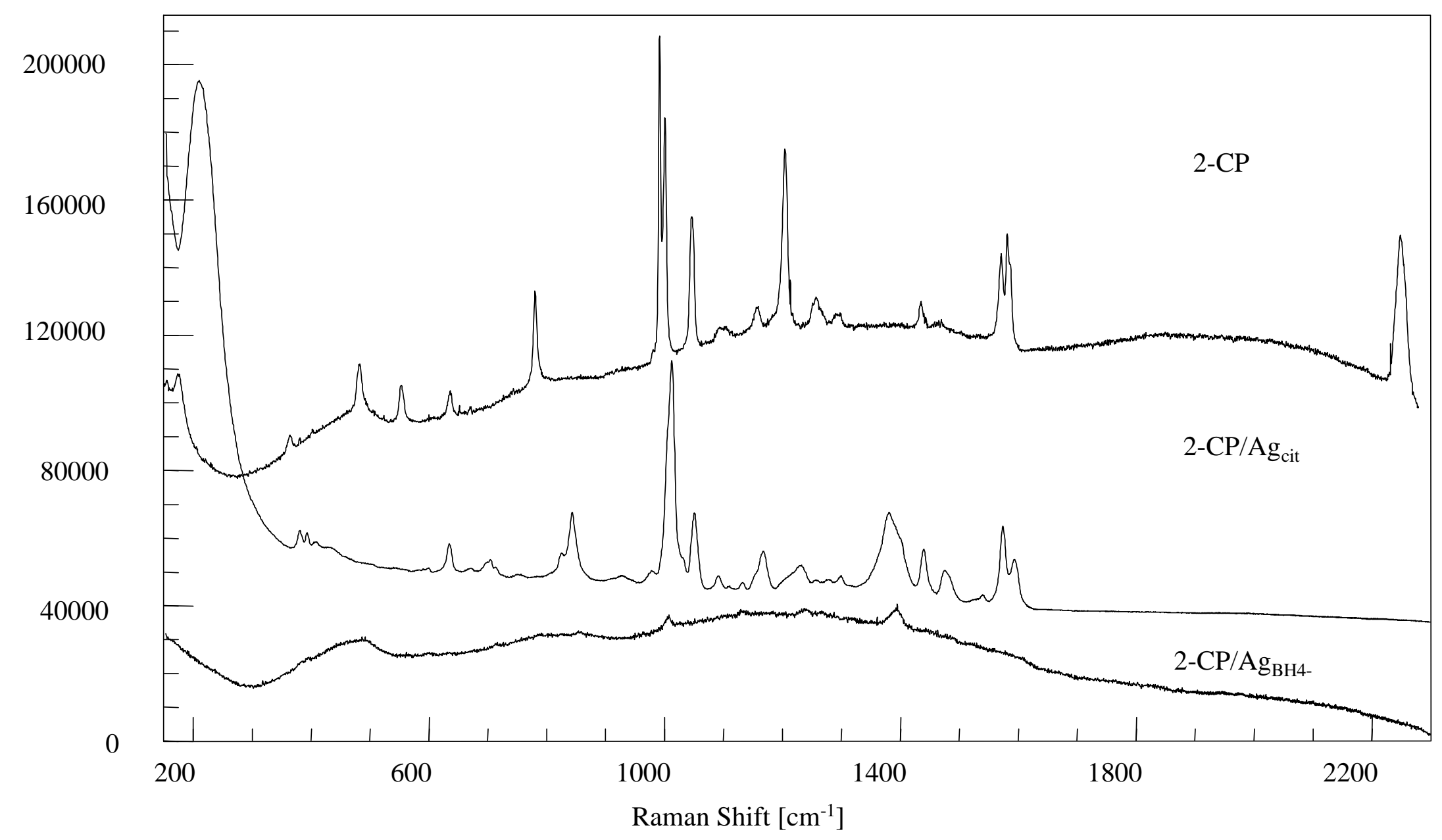

Figure 6-3 Raman spectra of 2-cyanopyridine (2-CP) and SERS of 2-CP adsorbed onto silver colloids prepared by citrate reduction $\left(/ \mathrm{Ag}_{\text {cit }}\right)$ and borohydride reduction $\left(/ \mathrm{Ag}_{\mathrm{BH} 4}\right)$. 
TABLE 6-3: Raman Frequencies $\left(\mathrm{cm}^{-1}\right)$ of 2-Cyanopyridine (2-CP) and Adsorbed on Silver Colloids Prepared by Borohydride Reduction $\left(/ \mathrm{Ag}^{\circ}{ }_{\mathrm{BH}} 4\right)$ and Citrate Reduction $\left(/ \mathrm{Ag}^{\circ}{ }_{\text {cit }}\right)$ and a Silver Electrode $\left(/ \mathrm{Ag}_{\text {elec }}\right)$.

\begin{tabular}{|c|c|c|c|c|}
\hline Assignment $^{\mathrm{a}}$ & $2-\mathrm{CP}(2.0 \mathrm{M})$ & $2-\mathrm{CP} / \mathrm{Ag}^{\circ}{ }_{\mathrm{BH} 4}$ & $2-\mathrm{CP} / \mathrm{Ag}^{\circ}{ }_{\mathrm{cit}}$ & $2-\mathrm{CP} / \mathrm{Ag}_{\text {elec }}{ }^{\mathrm{b}}$ \\
\hline $\mathrm{C} \equiv \mathrm{N}$ sens,$\delta(\mathrm{CN})$ & 175 & - & - & - \\
\hline $\mathrm{S}$ & - & - & 209 & 220 \\
\hline $\mathrm{C} \equiv \mathrm{N}$ sensitive & - & - & - & 334 \\
\hline$\phi(\mathrm{CC}), \mathrm{C} \equiv \mathrm{N}$ sens, $\gamma(\mathrm{CN})$ & 364 & - & 381 & - \\
\hline $\mathrm{S}$ & - & - & 394 & - \\
\hline $\mathrm{S}$ & 402 & - & 408 & - \\
\hline $\mathrm{S}$ & - & - & 433 & 440 \\
\hline $\mathrm{C} \equiv \mathrm{N}$ sensitive & - & - & - & 468 \\
\hline $\mathrm{C} \equiv \mathrm{N}$ sens, $\delta(\mathrm{CN})$ & 482 & 486 & - & 496 \\
\hline S & - & - & - & 515 \\
\hline $\mathrm{C} \equiv \mathrm{N}$ sens,$\delta(\mathrm{CN})$ & 554 & - & - & 551 \\
\hline $\mathrm{S}$ & - & 600 & 600 & - \\
\hline$\alpha(\mathrm{CCC})$ & 636 & - & 635 & 658 \\
\hline$\phi(\mathrm{CC})$ & - & - & 670 & 689 \\
\hline $\mathrm{S}$ & - & - & 704 & - \\
\hline $\mathrm{S}$ & - & 713 & 713 & - \\
\hline $\mathrm{S}$ & 741 & - & 752 & 740 \\
\hline $\mathrm{C} \equiv \mathrm{N}$ sensitive & 779 & - & - & - \\
\hline $\mathrm{S}$ & - & - & 825 & - \\
\hline $\mathrm{C} \equiv \mathrm{N}$ sensitive & - & 856 & 842 & 856 \\
\hline $\mathrm{S}$ & - & - & 927 & - \\
\hline $\mathrm{S}$ & - & - & 978 & - \\
\hline Ring & 1001 & 1006 & 1012 & 1017 \\
\hline
\end{tabular}




\section{TABLE 6-3:}

(Continued)

\begin{tabular}{|c|c|c|c|c|}
\hline Assignment $^{\mathrm{a}}$ & 2-CP (2.0 M) & $2-\mathrm{CP} / \mathrm{Ag}^{\circ}{ }_{\mathrm{BH} 4}$ & $2-\mathrm{CP} / \mathrm{Ag}^{\circ}{ }_{\text {cit }}$ & 2-CP/Ag ${ }_{\text {elec }}$ \\
\hline$\beta(\mathrm{CH})$ & - & - & 1031 & 1042 \\
\hline$\beta(\mathrm{CH})$ & 1048 & - & 1051 & 1050 \\
\hline$\beta(\mathrm{CH})$ & 1095 & - & 1091 & 1098 \\
\hline S & - & - & 1110 & - \\
\hline $\mathrm{S}$ & - & 1132 & 1132 & - \\
\hline$\beta(\mathrm{CH})$ & 1161 & - & 1168 & 1157 \\
\hline$\beta(\mathrm{CH})$ & - & - & - & 1179 \\
\hline $\mathrm{C} \equiv \mathrm{N}$ sensitive & 1206 & - & - & 1203 \\
\hline S & 1234 & 1237 & 1231 & - \\
\hline$\alpha(\mathrm{CC})$ & 1258 & - & 1257 & 1254 \\
\hline $\mathrm{S}$ & - & - & 1277 & - \\
\hline$\beta(\mathrm{CH})$ & 1295 & - & 1299 & 1282 \\
\hline$\beta(\mathrm{CH})$ & - & - & - & 1354 \\
\hline$\beta(\mathrm{CH})$ & - & 1395 & 1381 & 1397 \\
\hline $\mathrm{S}$ & - & - & 1403 & - \\
\hline$v(\mathrm{CC}, \mathrm{CN})$ & 1437 & - & 1439 & - \\
\hline$v(\mathrm{CC}, \mathrm{CN})$ & 1469 & - & 1475 & 1475 \\
\hline $\mathrm{S}$ & - & - & 1539 & - \\
\hline$v(C C)$ & 1573 & - & 1574 & 1560 \\
\hline$v(\mathrm{CC})$ & 1587 & - & 1594 & 1595 \\
\hline$v(C C)$ & - & - & - & 1611 \\
\hline$v(C \equiv N)$ & 2243 & - & - & 2255 \\
\hline
\end{tabular}

a. Based on Ref. 4.

b. Based on Ref. 5 . 
comparable surface enhancement to that observed of the adsorption of 4-CP. This would indicate similar interaction between each of these cyanopyridines and the borohydride colloids. This weak surface enhancement suggests that possible interaction between both nitrogens of 2-CP and the metal surface does not generate surface enhancement greater than that observed for 4-CP and 3-CP adsorbed on these silver colloids. Therefore, observation of weak surface enhancement for all three isomers indicates weak interactions between the CP's and the borohydride-based silver colloids.

The SERS of 2-CP on borohydride-based silver colloids exhibits a complete disappearance of the nitrile stretching signal (refer to Figure 6-3 and Table 6-3). The bands at $1237 \mathrm{~cm}^{-1}(\mathrm{C} \equiv \mathrm{N}$ sensitive $), 856 \mathrm{~cm}^{-1}(\mathrm{C} \equiv \mathrm{N}$ sensitive $), 486 \mathrm{~cm}^{-1} \mathrm{C} \equiv \mathrm{N}$ sens., $\left.\delta(\mathrm{C} \equiv \mathrm{N})\right)$ indicate the presence of the nitrile substituent. ${ }^{4}$ The shift to higher frequencies in the SERS indicates adsorption via both the nitrile nitrogen and the pyridine nitrogen, in similar fashion to the adsorption of 2-CP onto a silver electrode in an end-on configuration. ${ }^{5,7,10,11}$

It is interesting to note that the spectral pattern of 2-CP adsorbed on the borohydridebased silver colloids is almost identical to that found of 4-CP adsorbed onto borohydride colloids. This would suggest that the binding and orientation of the two different isomers is identical in nature and results in similar SERS. It is not possible that we are observing an interference or co-adsorption of borohydride on the silver since borohydride would give rise to bands at $610 \mathrm{~cm}^{-1}$ and $920 \mathrm{~cm}^{-1}$ with no observation of SERS. ${ }^{14}$

The adsorption of 2-CP on silver colloids prepared by citrate reduction exhibit SERS with no indication of $v(C \equiv N)$. The bands at $1475 \mathrm{~cm}^{-1}(v(C C, C \equiv N)), 1439 \mathrm{~cm}^{-1}(v(C C$, $\mathrm{C} \equiv N)), 842 \mathrm{~cm}^{-1}(\mathrm{C} \equiv \mathrm{N}$ sensitive $)$, and $381 \mathrm{~cm}^{-1}(\phi(C C), C \equiv N$ sens., $\gamma(C \equiv N))$ signify the 
presence of a nitrile group. ${ }^{4}$ The strongest SERS bands at $1594 \mathrm{~cm}^{-1}(\mathrm{v}(\mathrm{CC})), 1574 \mathrm{~cm}^{-1}$ $(v(\mathrm{CC})), 1439 \mathrm{~cm}^{-1}(v(\mathrm{CC}, \mathrm{C} \equiv \mathrm{N})), 1381 \mathrm{~cm}^{-1}(\beta(\mathrm{CH})), 1168 \mathrm{~cm}^{-1}(\beta(\mathrm{CH})), 1051 \mathrm{~cm}^{-1}$ $(\beta(\mathrm{CH})), 1381 \mathrm{~cm}^{-1}(\beta(\mathrm{CH})), 1012 \mathrm{~cm}^{-1}$ (ring), $842 \mathrm{~cm}^{-1}\left(\mathrm{C} \equiv \mathrm{N}\right.$ sensitive), and $635 \mathrm{~cm}^{-1}$ $(\alpha(\mathrm{CCC}))$ indicate adsorption via both the pyridine and nitrile nitrogens in an end-on configuration. $^{5,7,10,11}$ These frequencies correspond to those of 2-CP adsorbed onto a silver electrode (with the exception of the absence of $v(C \equiv N)$ ) indicating an end-on orientation.

The spectral pattern of 2-CP adsorbed on the citrate-based silver colloids is clearly different than that found of either 3-CP or 4-CP adsorbed on citrate-based silver colloids. This suggests that the binding and the orientation of 2-CP upon adsorption is different from the other isomeric forms of cyanopyridine. The SER spectra of 4-CP and 3-CP support adsorption via the nitrogen on the aromatic ring with a flat-on configuration relative to the metal surface. ${ }^{5,7,10,11}$ The SERS of 2-CP exhibit Raman bands associated with adsorption via both the pyridine and nitrile nitrogens in an end-on fashion..$^{5,7,10,11}$

The similarity in the SERS of 4-CP and 3-CP adsorbed on citrate-based silver colloids could be attributed to an interference or co-adsorption of citrate on the silver surface. ${ }^{12-15}$ The SER scattering by citrate on colloidal silver is shown in Figure 6-4. The Raman frequencies and tentative assignments are presented in Table 6-4. The spectral pattern and the reported frequencies are different than those for the three isomeric forms of cyanopyridine adsorbed onto the citrate-based silver colloids. The bands at $1396 \mathrm{~cm}^{-1}\left(\mathrm{v}_{\mathrm{as}}\left(\mathrm{COO}^{-}\right)\right), 1147 \mathrm{~cm}^{-1}$ $\left(v_{\text {as }}\left(C_{4} \mathrm{O}\right)\right), 1025 \mathrm{~cm}^{-1}\left(\mathrm{v}_{\mathrm{s}}(\mathrm{C}-\mathrm{C})\right), 948 \mathrm{~cm}^{-1}\left(\mathrm{v}_{\mathrm{s}}(\mathrm{C}-\mathrm{C})\right), 835 \mathrm{~cm}^{-1}\left(\mathrm{v}_{\mathrm{as}}\left(\mathrm{C}_{4} \mathrm{O}\right)\right)$, and $799 \mathrm{~cm}^{-1}$ $\left(\mathrm{v}_{\mathrm{s}}\left(\mathrm{C}_{4} \mathrm{O}\right)\right)$ indicate adsorption of the citrate onto the colloidal surface. ${ }^{12,15}$ There appears to be no similarity between these spectral pattern or frequencies 


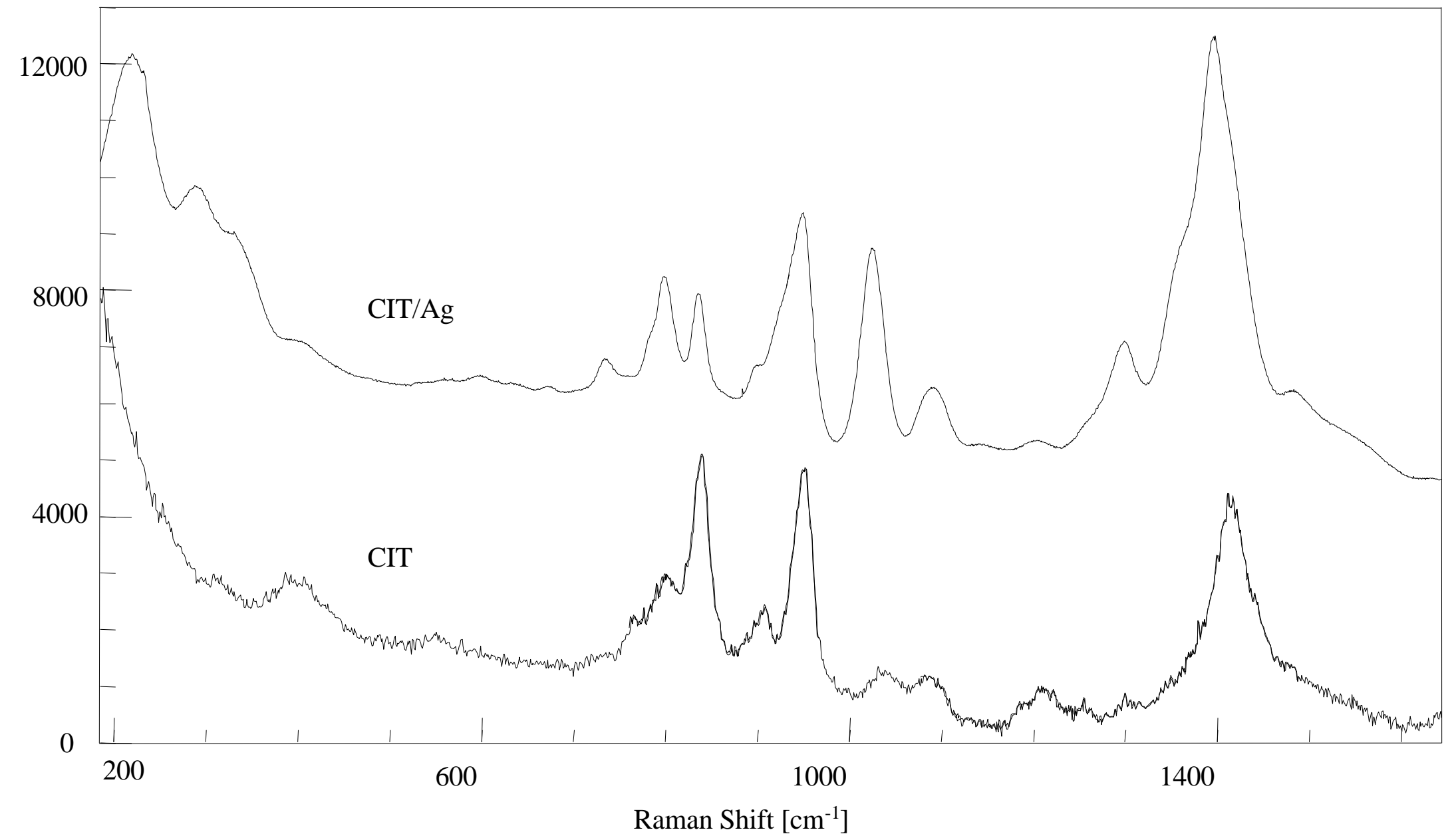

Figure 6-4 SER scattering by trisodium citrate (CIT) in aqueous solution (2.0 M) and adsorbed on colloidal silver surfaces $(/ \mathrm{Ag})$. 
TABLE 6-4: Raman Frequencies $\left(\mathrm{cm}^{-1}\right)$ of Trisodium Citrate (CIT) in Aqueous Solution $(2.0 \mathrm{M})$ and Adsorbed onto Silver Colloids.

\begin{tabular}{|c|c|c|}
\hline Assignment $^{\mathrm{a}}$ & CIT $(2.0 \mathrm{M})$ & CIT/Ag \\
\hline$v(\mathrm{Ag}-\mathrm{O})$ & - & 217 \\
\hline$v(\mathrm{Ag}-\mathrm{O})$ & - & 289 \\
\hline$\rho\left(\mathrm{COO}^{-}\right)$ & 398 & 397 \\
\hline $\mathrm{S}$ & 550 & - \\
\hline$\pi\left(\mathrm{COO}^{-}\right)$ & - & 597 \\
\hline$\delta(\mathrm{COC})$ & - & 674 \\
\hline$v_{s}\left(\mathrm{CCO}^{-}\right)$ & - & 735 \\
\hline $\mathrm{S}$ & 765 & - \\
\hline $\mathrm{v}_{\mathrm{s}}\left(\mathrm{C}_{4} \mathrm{O}\right), \mathrm{v}_{\mathrm{as}}\left(\mathrm{C}_{4} \mathrm{O}\right)$ & 801 & 799 \\
\hline $\mathrm{v}_{\mathrm{s}}\left(\mathrm{C}_{4} \mathrm{O}\right)$ & 839 & 836 \\
\hline $\mathrm{v}_{\mathrm{s}}\left(\mathrm{C}_{4} \mathrm{O}\right)$ & 909 & 902 \\
\hline$v_{s}(C-C)$ & 951 & 950 \\
\hline$v_{s}(C-C)$ & - & 1024 \\
\hline$v_{s}(\mathrm{CCO})$ & 1039 & - \\
\hline$v_{\text {as }}(\mathrm{CCO})$ & 1087 & 1091 \\
\hline $\mathrm{v}_{\mathrm{as}}(\mathrm{CCO})$ & - & 1143 \\
\hline S & 1210 & 1203 \\
\hline $\mathrm{S}$ & 1254 & - \\
\hline $\mathrm{S}$ & 1304 & 1298 \\
\hline$v_{s}\left(\mathrm{CCO}^{-}\right)$ & 1414 & 1396 \\
\hline $\mathrm{S}$ & - & 1483 \\
\hline
\end{tabular}

a. Based on Ref. 12 and 15. 
with those collected for the cyanopyridines. Thus, the observed surface enhancement is not due to an interference or co-adsorption of the citrate ions on the silver surface.

In order to facilitate comparison, the SERS of the three isomers on silver colloids prepared by borohydride and citrate reduction are shown in Figures 6-5 and 6-6. The tabulated Raman frequencies and tentative assignments are shown in Table 6-5. The common characteristic of all the SER spectra is the absence of the $v(C \equiv N)$ stretching signal. The observation of nitrile sensitive Raman signals with shifts in frequency signify the presence of the nitrile substituent. The adsorption of the cyanopyridines on the silver surfaces occur primarily through the nitrogen on the pyridine ring, although the SERS of 2-CP contains Raman bands that indicate an additional interaction between the nitrile nitrogen and the metal surface. The SERS suggests that the molecular orientation of 4-CP and 3-CP are a flat-on configuration, while the 2-CP orients in an end-on fashion. The possibility of interferences or co-adsorption by borohydride or citrate ions are excluded based on the absence of Raman bands indicative of each species in previous reports..$^{13,14}$ The enhanced Raman bands coincide with previous reports of these molecules on silver electrodes. ${ }^{5,7,10,11}$ Thus, the only remaining issue is the absence of the nitrile stretching signal of each isomer.

Based on the disappearance of the nitrile stretching signal in the SERS of the CP's adsorbed on the silver colloids, and the weak display of surface enhancement for the borohydride colloids, it is enigmatic to conclude whether a transition metal-assisted borohydride reduction is occurring. In order to determine if this reaction takes place, the SERS for the potential reduction product, aminomethylpyridine, has been collected. 


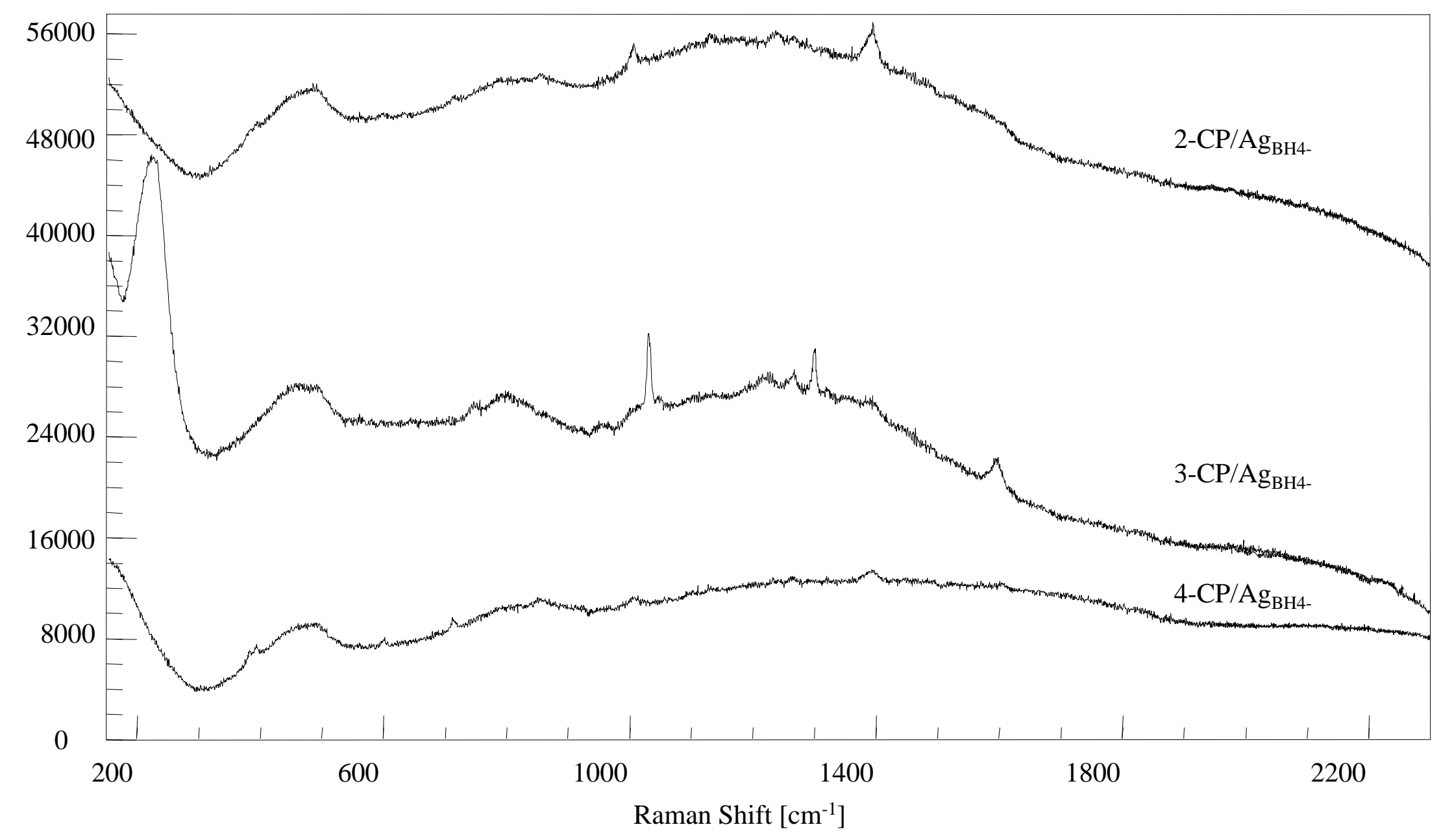

Figure 6-5 SERS of cyanopyridines (4-, 3-, and 2-CP) adsorbed onto silver $\left(/ \mathrm{Ag}_{\mathrm{BH} 4}\right)$ colloids prepared by borohydride reduction. 


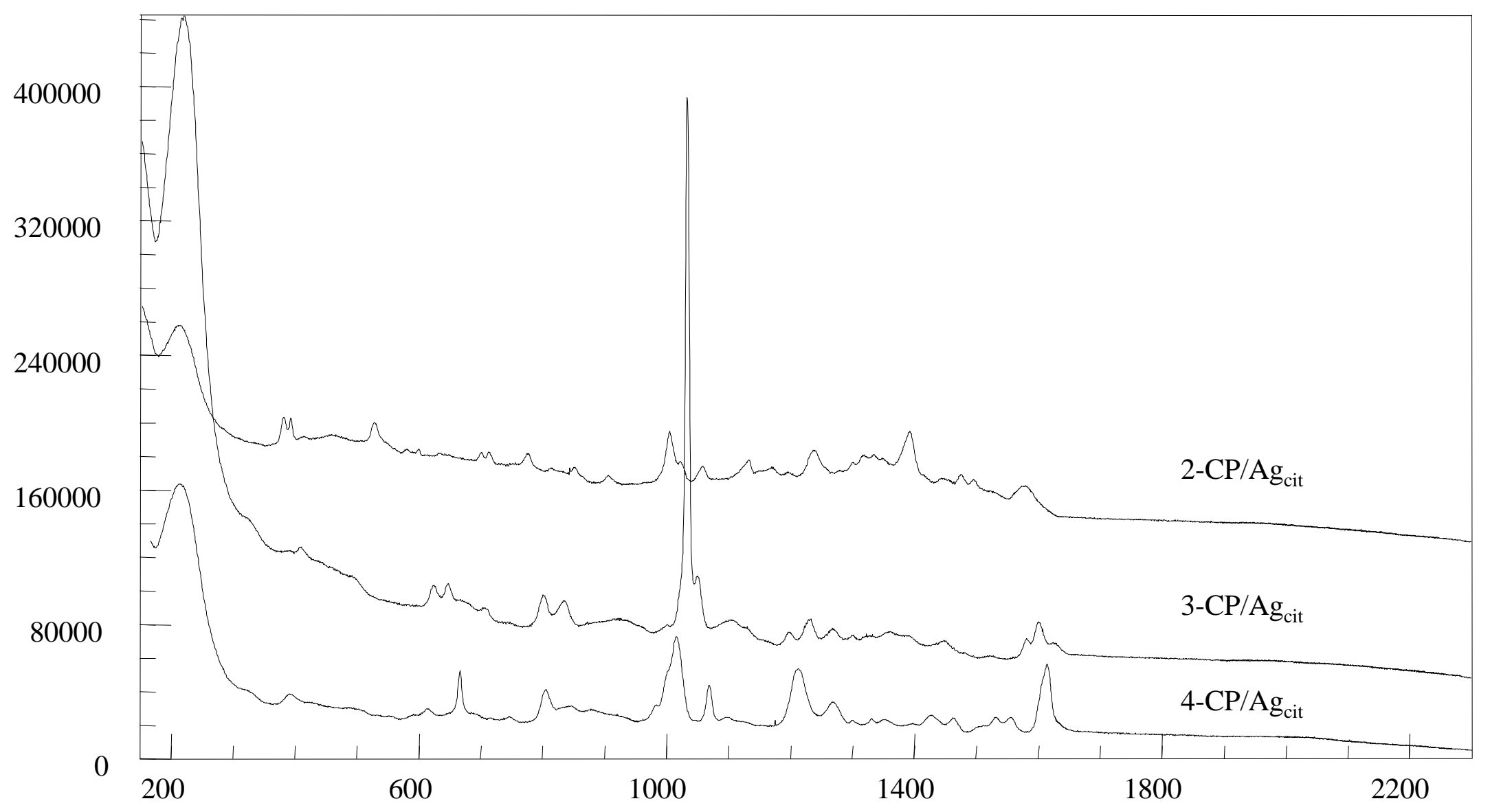

Figure 6-6 SERS of cyanopyridines (4-, 3-, and 2-CP) adsorbed onto silver $\left(/ \mathrm{Ag}_{\mathrm{cit}}\right)$ colloids prepared by citrate reduction. 
TABLE 6-5: Raman Frequencies $\left(\mathrm{cm}^{-1}\right)$ of Cyanopyridines (4-, 3-, and 2-CP) Adsorbed on Silver Colloids Prepared by Borohydride Reduction $\left(/ \mathrm{Ag}^{\circ}{ }_{\mathrm{BH}}{ }_{4}\right)$ and Citrate Reduction $\left(/ \mathrm{Ag}^{\circ}{ }^{\circ}\right)$.

\begin{tabular}{|c|c|c|c|c|c|c|}
\hline Assignment $^{\mathrm{a}}$ & $4-\mathrm{CP} / \mathrm{Ag}^{\circ}{ }_{\mathrm{BH} 4}$ & $3-\mathrm{CP} / \mathrm{Ag}^{\circ}{ }_{\mathrm{BH} 4}$ & $2-\mathrm{CP} / \mathrm{Ag}^{\circ}{ }_{\mathrm{BH} 4}$ & $4-\mathrm{CP} / \mathrm{Ag}^{\circ}{ }_{\text {cit }}$ & $3-\mathrm{CP} / \mathrm{Ag}^{\circ}$ cit & $2-\mathrm{CP} / \mathrm{Ag}^{\circ}{ }_{\text {it }}$ \\
\hline $\mathrm{S}$ & - & 219 & - & 211 & - & 209 \\
\hline $\mathrm{S}$ & - & - & - & - & 313 & - \\
\hline $\mathrm{C} \equiv \mathrm{N}$ sensitive & - & - & - & 383 & 383 & 381 \\
\hline $\mathrm{C} \equiv \mathrm{N}$ sens, $\phi(\mathrm{CC})$ & 390 & - & - & 392 & 392 & 394 \\
\hline $\mathrm{S}$ & - & - & - & - & - & 408 \\
\hline $\mathrm{S}$ & - & - & - & 432 & - & 433 \\
\hline $\mathrm{C} \equiv \mathrm{N}$ sensitive & 483 & 464 & 486 & - & - & - \\
\hline $\mathrm{S}$ & - & - & - & - & 504 & - \\
\hline $\mathrm{S}$ & - & - & - & 520 & 520 & - \\
\hline $\mathrm{S}$ & 601 & - & 600 & 600 & 600 & 600 \\
\hline$\alpha(\mathrm{CCC})$ & - & - & - & - & - & 635 \\
\hline$\phi(\mathrm{CC})$ & - & - & - & - & - & 670 \\
\hline $\mathrm{S}$ & - & - & - & - & - & 704 \\
\hline$\phi(\mathrm{CC})$ & 713 & - & 713 & 714 & 713 & 713 \\
\hline $\mathrm{S}$ & - & - & - & - & - & 752 \\
\hline $\mathrm{C} \equiv \mathrm{N}$ sensitive & - & 787 & - & - & - & - \\
\hline $\mathrm{S}$ & - & - & - & - & - & 825 \\
\hline $\mathrm{C} \equiv \mathrm{N}$ sensitive & 857 & - & 856 & 853 & 853 & 842 \\
\hline $\mathrm{S}$ & - & - & - & 863 & 861 & - \\
\hline $\mathrm{S}$ & - & - & - & - & - & 927 \\
\hline $\mathrm{S}$ & - & - & - & - & - & 978 \\
\hline
\end{tabular}


TABLE 6-5: $\quad$ (Continued)

\begin{tabular}{|c|c|c|c|c|c|c|}
\hline Assignment $^{\mathrm{a}}$ & $4-\mathrm{CP} / \mathrm{Ag}^{\circ}{ }_{\mathrm{BH} 4}$ & $3-\mathrm{CP} / \mathrm{Ag}^{\circ}{ }_{\mathrm{BH} 4}$ & $2-\mathrm{CP} / \mathrm{Ag}^{\circ}{ }_{\mathrm{BH} 4}$ & $4-\mathrm{CP} / \mathrm{Ag}^{\circ}{ }_{\text {cit }}$ & $3-\mathrm{CP} / \mathrm{Ag}^{\circ}{ }_{\text {cit }}$ & $2-\mathrm{CP} / \mathrm{Ag}^{\circ}{ }_{\text {cit }}$ \\
\hline Ring & 1008 & 1006 & 1006 & 1006 & 1007 & 1012 \\
\hline$\beta(\mathrm{CH})$ & - & 1030 & - & 1075 & 1076 & 1031 \\
\hline$\beta(\mathrm{CH})$ & - & - & - & - & - & 1051 \\
\hline$\beta(\mathrm{CH})$ & - & - & - & - & - & 1091 \\
\hline S & 1105 & - & - & - & - & 1110 \\
\hline S & - & - & 1132 & 1133 & 1131 & 1132 \\
\hline$\beta(\mathrm{CH})$ & - & - & - & 1161 & 1158 & 1168 \\
\hline $\mathrm{C} \equiv \mathrm{N}$ sensitive & 1237 & - & 1237 & 1237 & 1239 & 1231 \\
\hline $\mathrm{S}$ & - & - & - & - & - & 1257 \\
\hline$\alpha(\mathrm{CC})$ & 1265 & 1267 & - & 1277 & 1278 & 1277 \\
\hline$\beta(\mathrm{CH})$ & - & 1299 & - & 1301 & 1299 & 1299 \\
\hline S & - & - & - & 1314 & 1315 & - \\
\hline $\mathrm{S}$ & 1391 & 1391 & 1395 & 1391 & 1392 & 1381 \\
\hline S & - & - & - & - & - & 1403 \\
\hline$v(\mathrm{CC}, \mathrm{CN})$ & - & - & - & 1455 & 1455 & 1439 \\
\hline$v(\mathrm{CC}, \mathrm{CN})$ & - & - & - & - & - & 1475 \\
\hline $\mathrm{S}$ & - & - & - & - & - & 1539 \\
\hline$v(C C)$ & - & - & - & 1561 & 1561 & 1574 \\
\hline$v(\mathrm{CC})$ & 1605 & 1594 & - & 1589 & 1590 & 1594 \\
\hline
\end{tabular}

a. Based on Ref. 4. 
SERS for the isomeric forms of aminomethylpyridine (4-AMP, 3-AMP, and 2-AMP) on silver colloids prepared by borohydride and citrate reduction is shown in Figures 6-7 and 6-8. The tabulated Raman frequencies and tentative assignments are shown in Table 6-6. The SERS for the AMP's exhibit different spectral patterns and frequencies than those observed for the CP's on the same types of silver surfaces. This shows conclusively that reduction of the nitrile group in the isomers of $\mathrm{CP}$ is not occurring on the silver colloids.

The SERS of the AMP's on borohydride reduced silver colloids demonstrate an increase in surface enhancement from 4-AMP to 2-AMP. This observation is opposite to that observed for adsorption of these molecules on copper and gold colloids (see Chapters 2 and 3). This would indicate that the interaction between the 2-AMP and the borohydride-based silver colloid is significantly stronger than 4-AMP.

The SERS of AMP's on citrate-based silver colloids display strong surface enhancement. The complexity of the SER spectra increase in the series of 4- to 3- to 2position. This coincides with previously reported SERS for isomeric forms of CP on silver electrodes which display modes associated with the antisymmetric vibrations of the molecule. ${ }^{5,7,10,11}$

It is interesting to note that the SERS for 4-AMP and 3-AMP adsorbed on citratebased silver colloids demonstrate similar spectral patterns. This could be attributed to an interference or co-adsorption of citrate on the silver surface. The SERS bands detected for 4-AMP/3-AMP adsorbed on these silver colloids at $1397 \mathrm{~cm}^{-1} / 1391 \mathrm{~cm}^{-1}, 844 \mathrm{~cm}^{-1} / 835 \mathrm{~cm}^{-1}$, and $804 \mathrm{~cm}^{-1} / 801 \mathrm{~cm}^{-1}(\mathrm{v}(\mathrm{CC}))^{5,16}$ are very similar to the bands that occur in the SERS of 


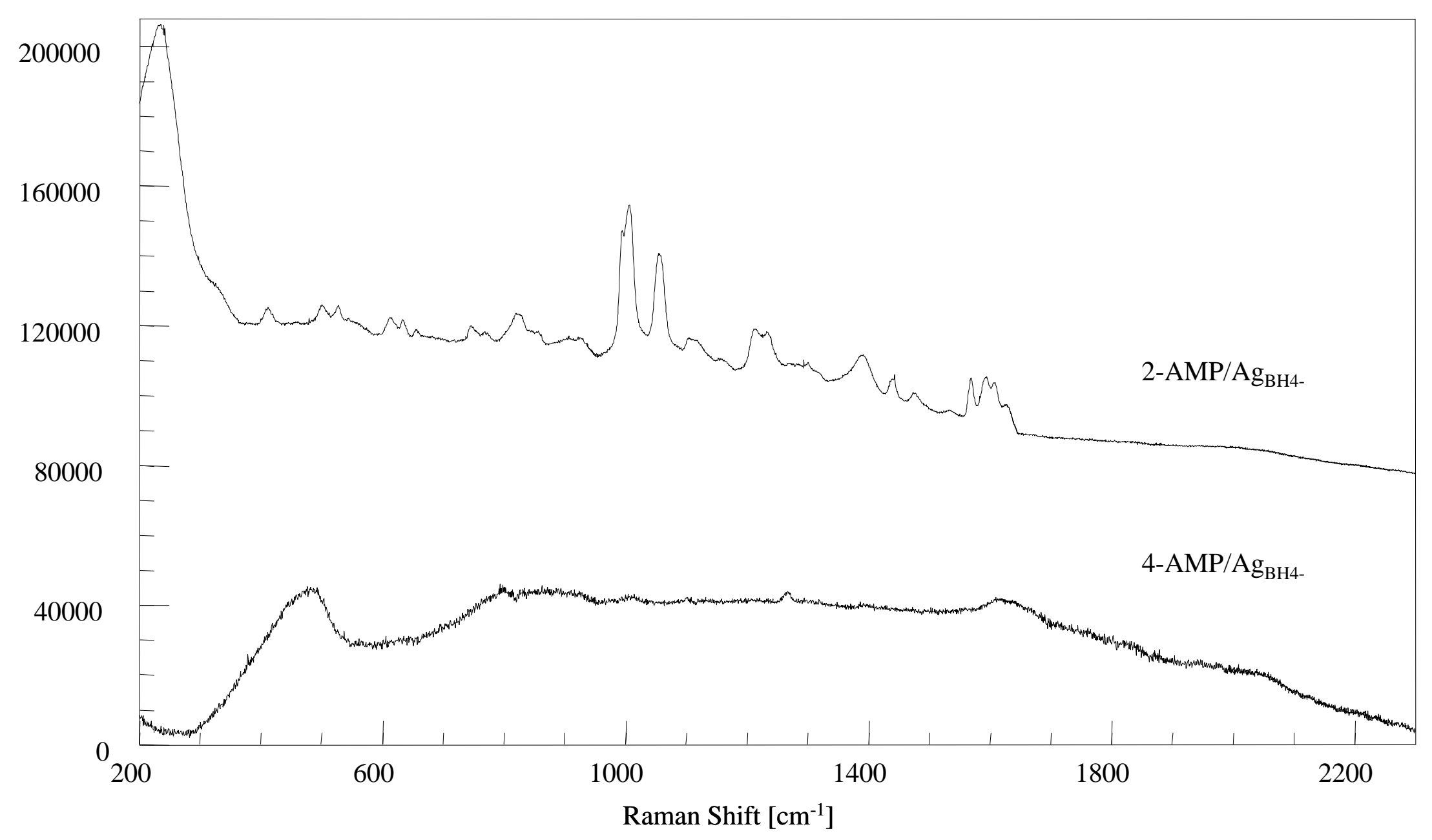

Figure 6-7 SERS of aminomethylpyridines (4-AMP and 2-AMP) adsorbed onto silver $\left(/ \mathrm{Ag}_{\mathrm{BH} 4}\right)$ colloids prepared by borohydride reduction. 


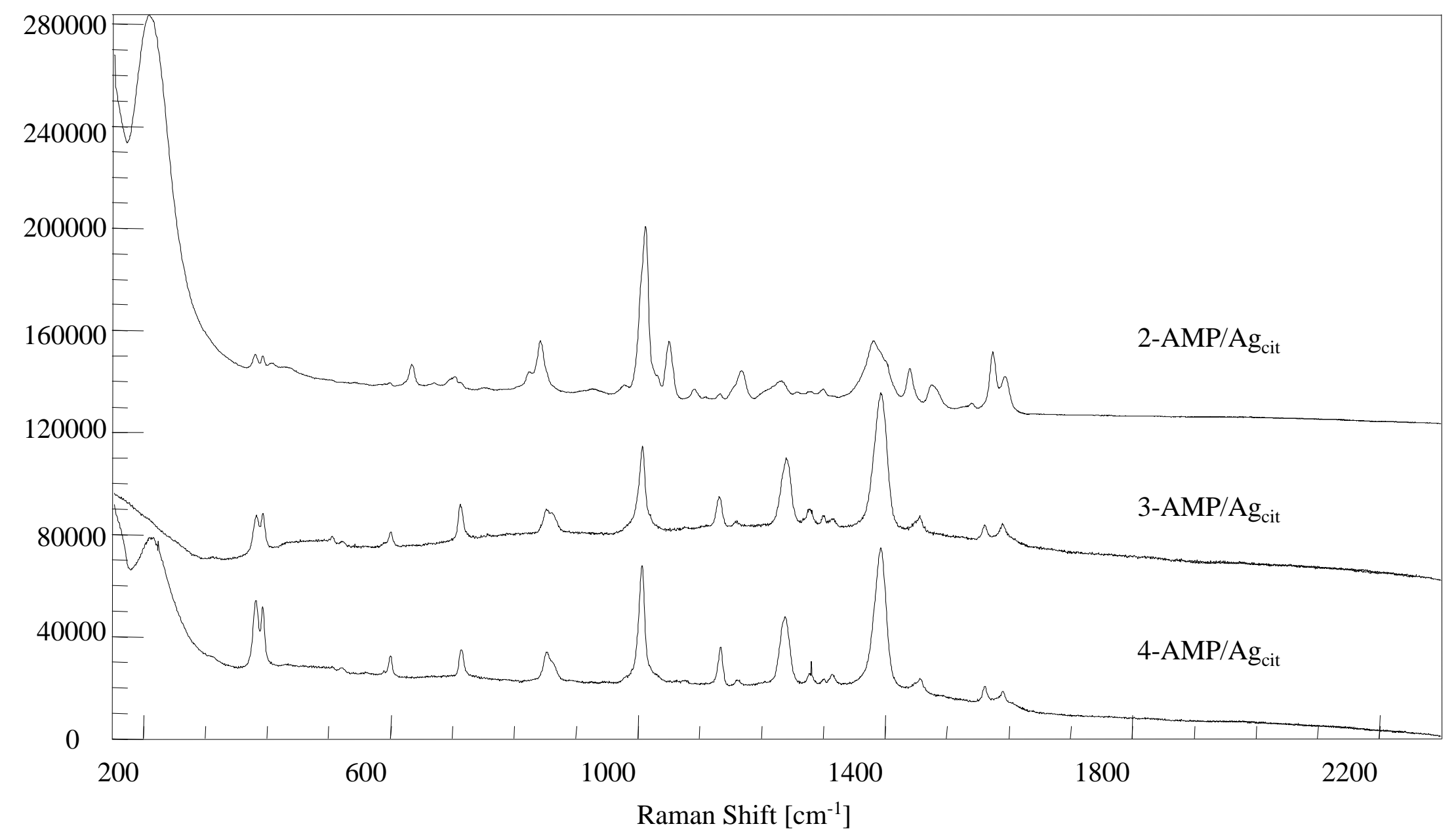

Figure 6-8 SERS of aminomethylpyridines (4-, 3-, and 2-AMP) adsorbed onto silver $\left(/ \mathrm{Ag}_{\text {cit }}\right)$ colloids prepared by citrate reduction. 
TABLE 6-6: Raman Frequencies $\left(\mathrm{cm}^{-1}\right)$ of Aminomethylpyridines (4-, 3-, and 2-AMP) Adsorbed on Silver Colloids Prepared by Borohydride Reduction $\left(/ \mathrm{Ag}^{\circ}{ }_{\mathrm{BH}}{ }_{4}\right)$ and Citrate Reduction $\left(/ \mathrm{Ag}^{\circ}{ }_{\text {cit }}\right)$.

\begin{tabular}{|c|c|c|c|c|c|}
\hline Assignment $^{\mathrm{a}}$ & $4-\mathrm{AMP} / \mathrm{Ag}^{\circ}{ }_{\mathrm{BH} 4}$ & $4-\mathrm{AMP} / \mathrm{Ag}^{\circ}{ }_{\text {cit }}$ & $3-\mathrm{AMP} / \mathrm{Ag}^{\circ}{ }_{\text {cit }}$ & 2-AMP/Ag ${ }_{\mathrm{BH} 4}^{\circ}$ & $2-\mathrm{AMP} / \mathrm{Ag}^{\circ}{ }_{\text {cit }}$ \\
\hline$v(\mathrm{Ag}-\mathrm{N})$ & - & 214 & 221 & 233 & 213 \\
\hline S & - & - & - & - & 381 \\
\hline $\mathrm{S}$ & - & 393 & - & - & 393 \\
\hline $\mathrm{S}$ & - & - & 409 & 411 & 414 \\
\hline $\mathrm{S}$ & - & - & - & - & 460 \\
\hline Ring deformation & 482 & 488 & - & 500 & - \\
\hline S & - & - & - & 527 & 528 \\
\hline $\mathrm{S}$ & - & - & - & - & 580 \\
\hline$\gamma\left(\mathrm{NH}_{2}\right)$ & - & 592 & - & - & 600 \\
\hline$\gamma\left(\mathrm{NH}_{2}\right)$ & - & 615 & - & 613 & - \\
\hline$\alpha(\mathrm{CCC})$ & - & - & 624 & 633 & 632 \\
\hline $\mathrm{S}$ & - & - & - & 655 & - \\
\hline$\hat{\mathrm{S}}$ & - & 666 & - & - & - \\
\hline $\mathrm{S}$ & - & - & 707 & - & 701 \\
\hline $\mathrm{S}$ & - & - & - & - & 713 \\
\hline$v(\mathrm{CH})$ & - & 746 & - & 746 & - \\
\hline $\mathrm{S}$ & - & - & - & 768 & 777 \\
\hline$v(\mathrm{CH})$ & 798 & 804 & 801 & - & 814 \\
\hline $\mathrm{S}$ & 831 & 844 & 834 & 825 & - \\
\hline $\mathrm{S}$ & - & - & - & 855 & 852 \\
\hline$\beta(\mathrm{CH})$ & - & 877 & - & - & - \\
\hline $\mathrm{S}$ & - & - & - & 906 & 906 \\
\hline $\overrightarrow{\mathrm{S}}$ & - & - & - & 929 & - \\
\hline $\bar{S}$ & - & 983 & 1001 & 995 & - \\
\hline Ring breathing & 1007 & 1002 & 1033 & 1006 & 1004 \\
\hline
\end{tabular}


TABLE 6-6: $\quad$ (Continued)

\begin{tabular}{|c|c|c|c|c|c|}
\hline Assignment $^{\mathrm{a}}$ & $4-\mathrm{AMP} / \mathrm{Ag}^{\circ}{ }_{\mathrm{BH} 4}$ & $4-\mathrm{AMP} / \mathrm{Ag}^{\circ}{ }_{\text {cit }}$ & $3-\mathrm{AMP} / \mathrm{Ag}^{\circ}$ cit & $2-\mathrm{AMP} / \mathrm{Ag}^{\circ}{ }_{\mathrm{BH} 4}$ & $2-\mathrm{AMP} / \mathrm{Ag}^{\circ}{ }_{\text {cit }}$ \\
\hline $\mathrm{S}$ & - & 1015 & - & - & 1022 \\
\hline$\beta\left(\mathrm{NH}_{2}\right), \beta(\mathrm{CH})$ & - & 1069 & 1050 & 1056 & 1058 \\
\hline $\mathrm{S}$ & 1100 & 1097 & 1104 & 1106 & - \\
\hline $\mathrm{S}$ & - & - & - & 1115 & - \\
\hline $\bar{S}$ & - & - & - & - & 1133 \\
\hline$\beta(\mathrm{CH})$ & - & - & - & 1157 & - \\
\hline$S$ & - & - & - & - & 1170 \\
\hline$\beta(\mathrm{CH})$ & - & 1212 & 1197 & 1212 & 1196 \\
\hline$\beta\left(\mathrm{NH}_{2}\right), \beta(\mathrm{CH})$ & - & - & 1230 & 1232 & 1239 \\
\hline$\alpha(\mathrm{CC})$ & 1267 & 1269 & 1268 & 1270 & 1279 \\
\hline $\mathrm{S}$ & - & 1310 & - & - & 1317 \\
\hline $\mathrm{S}$ & - & 1331 & - & - & 1334 \\
\hline $\mathrm{S}$ & - & 1352 & 1360 & - & 1349 \\
\hline S & 1393 & 1397 & 1391 & 1390 & 1392 \\
\hline $\mathrm{S}$ & - & 1426 & - & - & - \\
\hline$v(C C)$ & - & - & 1448 & 1440 & 1446 \\
\hline$v(C C)$ & - & 1463 & 1481 & 1476 & 1475 \\
\hline $\mathrm{S}$ & - & - & - & - & 1496 \\
\hline $\mathrm{S}$ & - & 1531 & 1522 & 1533 & - \\
\hline$v(\mathrm{CC})$ & - & 1555 & - & 1569 & 1578 \\
\hline$v(\mathrm{CC})$ & - & - & 1581 & 1594 & - \\
\hline$v(\mathrm{CC})$ & 1612 & 1614 & 1600 & 1607 & - \\
\hline $\mathrm{S}$ & - & - & 1624 & 1626 & - \\
\hline
\end{tabular}


citrate mixed with a silver colloid, namely $1396 \mathrm{~cm}^{-1}\left(\mathrm{v}_{\mathrm{as}}\left(\mathrm{COO}^{-}\right)\right), 835 \mathrm{~cm}^{-1}\left(\mathrm{v}_{\mathrm{as}}\left(\mathrm{C}_{4} \mathrm{O}\right)\right)$, and $799 \mathrm{~cm}^{-1}\left(v_{\mathrm{s}}\left(\mathrm{C}_{4} \mathrm{O}\right)\right) .^{12,15}$ Therefore, SERS collected for the AMP's adsorbed on the citratebased silver colloids show bands that could indicate of co-adsorption of citrate on the silver surface.

The reduction of the nitrile substituent to an amino group upon adsorption of the cyanopyridines onto the silver colloids does not occur. The observation of no nitrile stretching band for the citrate reduced silver colloids indicates that the silver metal is distinct from the copper and gold. The silver colloid experiments complicate the matter and further investigation needs to be performed to elucidate the nature of the cyanopyridine-silver colloid interactions.

\subsection{CONCLUSIONS}

The SERS collected for cyanopyridines (4-CP, 3-CP, and 2-CP) adsorbed onto the surface of silver colloids prepared by borohydride and citrate reduction exhibit a complete disappearance of the nitrile stretching normal mode. The absence of the nitrile stretching signal is not due to a metal-assisted reduction of the nitrile group to an amino group. Adsorption on borohydride-based silver colloids demonstrate weak surface enhancement when compared with SERS of adsorption on citrate-based silver colloid. The observation of no nitrile stretching band for the silver colloids indicates that the silver metal is distinct from the copper and gold. The silver colloids require further investigations in order to elucidate the nature of the SERS collected. 
The SER spectra of each of the three isomeric forms of cyanopyridine adsorbed onto copper, gold and silver colloids are shown in Figures 6-9, 6-10, and 6-11. The gold colloids demonstrate "ideal" behavior with adsorption via the pyridine nitrogen in an end-on configuration. The copper colloids demonstrate a transition metal-assisted borohydride reduction of the nitrile substituent to an amino group with primary interaction occurring through the pyridine nitrogen in a flat-on orientation. The silver colloids demonstrate no reduction of the nitrile substituent to an amino group with no observed $v(C \equiv N)$.

All three metal colloids display SER signals indicative of adsorption primarily through the pyridine nitrogen. Interaction between both the nitrile and pyridine nitrogens with the colloidal surfaces are observed in the SERS for 2-CP. Previous studies would indicate that the degree of surface enhancement would be increasing in the series of copper to gold to silver. ${ }^{17,18}$ Our SERS data concurs with prior results with the exception of borohydride-based silver colloids.

The isomeric effects on enhancement observed for adsorption onto the three metals obey anticipated behavior except in the case of silver. The aggregation of the adsorbates on all three metals increases from 4-CP to $3-\mathrm{CP}$ to $2-\mathrm{CP}$. The loss of molecular symmetry as the substituent is moved from the 4- to 3 - to 2- position also plays a role in the degree of surface enhancement observed. ${ }^{7-9}$ Our data for the CP's mixed with the copper and gold colloids supports the theory that the degree of surface enhancement is lowered by the loss of molecular symmetry. 


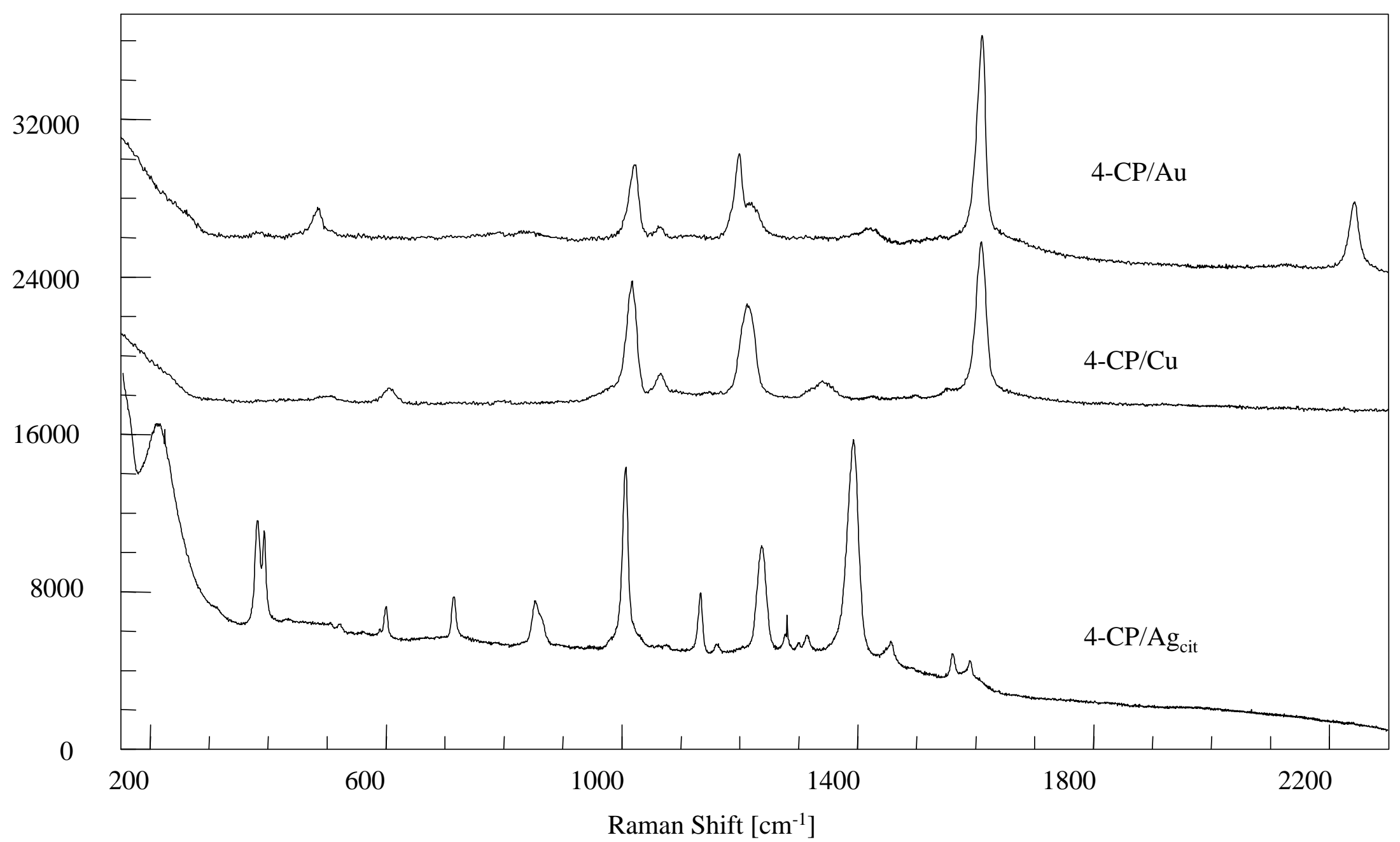

Figure 6-9 SERS of 4-cyanopyridine (4-CP) adsorbed onto silver (/Ag $\mathrm{Agit})$, copper (/Cu), and gold (/Au) colloids. 


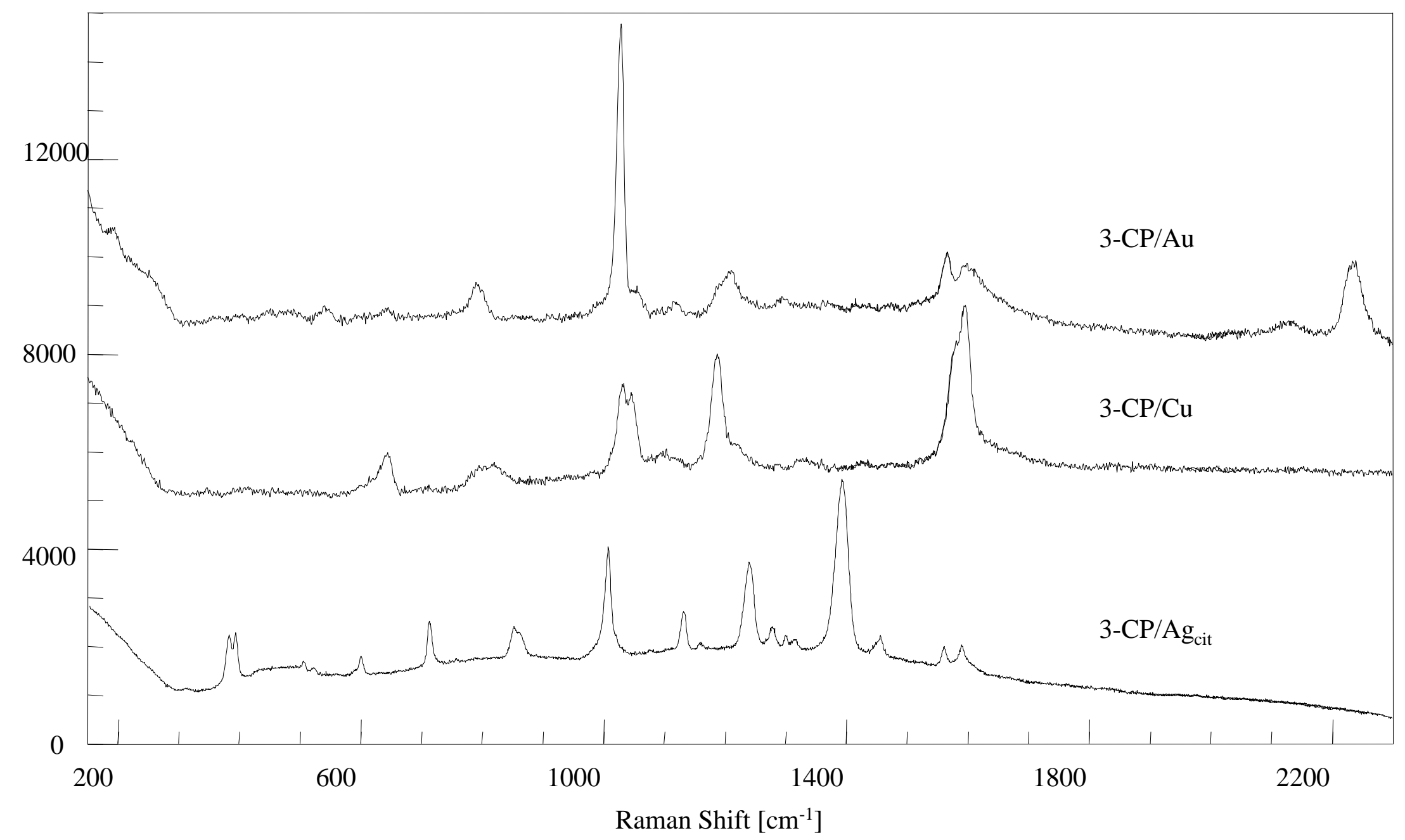

Figure 6-10 SERS of 3-cyanopyridine (3-CP) adsorbed onto silver $\left(/ \mathrm{Ag}_{\mathrm{cit}}\right)$, copper $(/ \mathrm{Cu})$, and gold (/Au) colloids. 


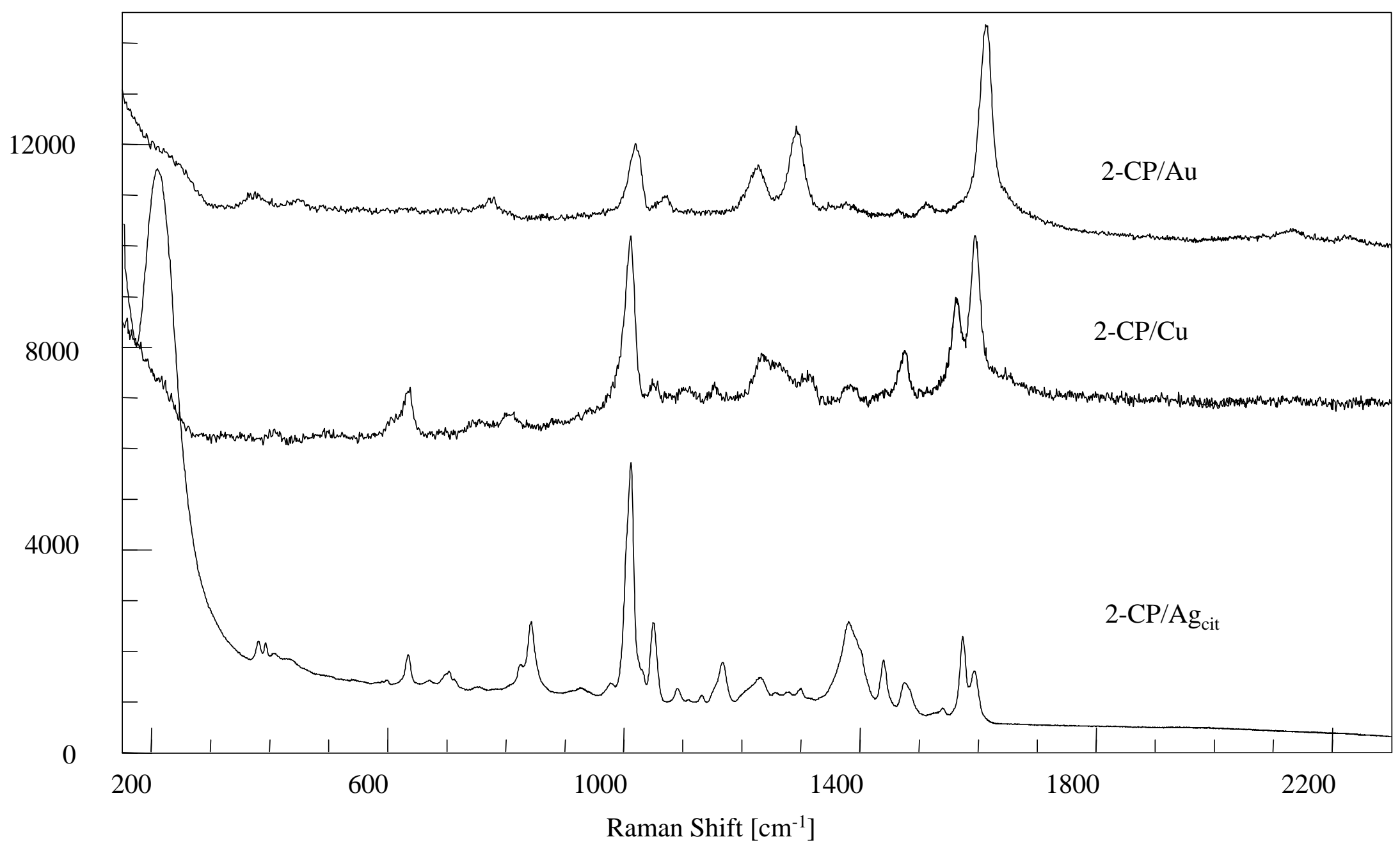

Figure 6-11 SERS of 2-cyanopyridine (2-CP) adsorbed onto silver $\left(/ \mathrm{Ag}_{\mathrm{cit}}\right)$, copper $(/ \mathrm{Cu})$, and gold $(/ \mathrm{Au})$ colloids. 


\section{REFERENCES}

1. A. Otto, Appl. Surface Sci. 6, 309 (1980).

2. D. Meisel and P. C. Lee, J. Phys. Chem. 86, 3391 (1982).

3. J. A. Creighton and D. G. Eadon, J. Chem. Soc., Faraday Trans. 24 87, 3881-3891 (1991).

4. J. H. S. Green and D. J. Harrison, Spectrochim. Acta, Part A 33, 75 (1977).

5. M. L. A. Temperini, J. C. Rubim, O. Sala, A. H. Jubert, M. E. Chacon Vilalba and P. J. Aymonino, J. Raman Spectrosc. 22, 301(1991).

6. K. D. Beer, W. Tanner and R. L. Garrell, J. Electroanal. Chem. 258, 313-325 (1989).

7. C. S. Allen and R. P. Van Duyne, Chem. Phys. Lett. 63, 455 (1979).

8. J. C. Rubim and O. Sala, J. Mol. Spectrosc. 145, 157-172 (1986).

9. J. C. Rubim, J. Electroanal. Chem. 220, 339 (1987).

10. C. S. Allen and R. P. Van Duyne, J. Am. Chem. Soc. 103, 7497-7501 (1981).

11. H. Chang, L. J. Lee and U. H. Sheu, J. Chinese Chem. Soc. 40, 413-418 (1993).

12. O. Siiman, L. A. Bumm, R. Callaghan, C. G. Blatchford and M. Kerker, J. Phys. Chem. 87, 1014 (1983).

13. S. Sanchez-Cortes and J. V. Garcia-Ramos, J. Raman Spectrosc. 29, 365-371 (1998).

14. T. M. Herne and R. L. Garrell, Anal. Chem. 63, 2290-2294 (1991).

15. M. Kerker, O. Siiman, L. A. Bumm and D. S. Wang, Applied Optics 19 19, 3253-3255 (1980).

16. G. Varsanyi, Assignments for Vibrational Spectra of Seven Hundred Benzene Derivatives, pp. 11-35. Wiley, New York (1974).

17. J. A. Creighton, Surface Sci. 158, 211-221 (1985).

18. F. Farha and R. T. Iwamato, Inorg. Chem. 6 4, 844-848 (1965). 


\section{CHAPTER 7}

\section{Conclusions}

Dramatic differences are observed between the SER spectrum of 4-CP mixed with a copper colloid, the spectrum of 4-CP, and the spectrum of 4-CP on a gold colloid. Specifically, $v(C \equiv N)$ is missing in the spectrum involving the copper colloid. $4-\mathrm{CP}-{ }^{15} \mathrm{~N}$ was prepared and the SER spectra collected. Data for that isotopic species indicates that $\mathrm{v}(\mathrm{C} \equiv \mathrm{N})$ is not coupled with the ring modes and hence shifted to lower wavenumbers when 4-CP is mixed with copper colloids. The data are adequately explained by a transition metal assisted borohydride reduction of 4-CP to 4-AMP. SER spectra of these molecules and their reduction products in the presence of copper colloids are identical within experimental error. The $v(C \equiv N)$ signal was observed when a gold colloid was prepared by borohydride reduction, thereby indicating the metal selectivity of the reaction.

SER spectra for two additional isomers of cyanopyridine (3-CP, and 2-CP) adsorbed onto the surface of copper colloids also exhibit a loss of the nitrile stretching band. Based on studies of the corresponding reduced molecules (3-AMP, and 2-AMP) adsorbed onto copper colloids, the SERS verifies the transition metal-assisted reduction of the nitrile group with the subsequent products being adsorbed on the copper surfaces.

The SERS collected for other organonitriles adsorbed onto the surface of a copper colloids exhibit a complete disappearance of the nitrile stretching normal mode in most cases. The absence of the nitrile stretching signal for the organonitriles is due to a metal-assisted 
reduction of the nitrile group to an amino group. Adsorption of alkyl organonitriles onto copper colloids demonstrate weak surface enhancement when compared with SERS of the aromatic organonitriles mixed with a copper colloid. The SERS of the alkyl organonitriles with both copper and gold colloids indicate that the absence of the aromatic ring plays a significant role in the ability of the molecule to sufficiently interact with the metal surface.

The addition of selected salts (sodium chloride, sodium sulfate, sodium sulfide) was used to explore the effect of aggregation, co-adsorption, and desorption of the adsorbates on the observed SERS. This work demonstrates the roles of the chemical and electromagnetic field mechanism in the observation of surface enhancement. For the case of the copper colloids, the use of aggregation and co-adsorption played no significant role in the degree of surface enhancement detected. For the SERS of the cyanopyridines adsorbed onto the gold colloids, the co-adsorption of sodium chloride made a stronger contribution than sodium sulfate. Thus, the role of chemical interaction dominates over the electromagnetic mechanism in the observation of surface enhancement for our systems. The addition of sodium sulfide to both copper and gold colloids successfully desorbs the adsorbates from the metal surfaces indicated by no observable SERS.

The surface potential of the different metals in metal colloids reflect the contributions of the possible mechanisms giving rise to the Raman enhancement. The argument concerning the origin of the surface enhancement mechanism is based on the dominant roles of chemical and electromagnetic field interactions at the metal surface. Our SERS data demonstrate that the increase in surface enhancement is primarily influenced by the chemical interaction between the adsorbate and the metal surface. Although the molecular symmetry of the 
adsorbate, as well as the affects of aggregation, affect the degree of enhancement, the chemical adsorption onto the metal dominates the enhancement mechanism.

The potential use of this reduction reaction can be of utmost significance in the modification of surfaces in the fields of self-assembly and colloidal chemistry. Additionally, the significance of molecule-surface interactions provides insight into energy-related issues, such as field stable chemical probes, deleterious corrosion processes, and catalysis. 


\section{VITA}

Candace Mikki Coyle was born the oldest of three children to USCG Commander Alvin Matthew and JoAnn Nobuyo Coyle on October 31, 1971 in Hawthorne, CA. After attending schools throughout California, Hawaii, Washington, Maryland, and Virginia, she graduated from Western Branch High School in Chesapeake, VA on June 15, 1989. She then enrolled at Virginia Polytechnic Institute and State University (Virginia Tech) in Blacksburg, VA in the spring of 1990. She graduated with a B.S. in Chemistry from Virginia Tech in the spring of 1994 and officially entered the graduate program at West Virginia University in Morgantown, WV in the spring of 1995. Specializing in colloidal and surface chemistry and working under the supervision of Dr. Paul W. Jagodzinski, she is a recipient of the DOE/EPSCoR Traineeship and served a research practicum under the supervision of Dr.

Therese M. Cotton and Dr. George Chumanov at Iowa State University of Science and Technology/Ames National Laboratory in Ames, IA. She is currently a candidate for the degree of Doctor of Philosophy in Physical Chemistry at West Virginia University. 